Cochrane Database of Systematic Reviews

\title{
Treatment options for progression or recurrence of glioblastoma: a network meta-analysis (Review)
}

McBain C, Lawrie TA, Rogozińska E, Kernohan A, Robinson T, Jefferies S

McBain C, Lawrie TA, Rogozińska E, Kernohan A, Robinson T, Jefferies S.

Treatment options for progression or recurrence of glioblastoma: a network meta-analysis.

Cochrane Database of Systematic Reviews 2021, Issue 1. Art. No.: CD013579.

DOI: 10.1002/14651858.CD013579.pub2.

www.cochranelibrary.com 
TABLE OF CONTENTS

HEADER 1

ABSTRACT

PLAIN LANGUAGE SUMMARY

SUMMARY OF FINDINGS

BACKGROUND

OBJECTIVES

METHODS

RESULTS

Figure 1.

Figure 2.

Figure 3.

Figure 4.

Figure 5.

Figure 6.

Figure 7.

Figure 8.

Figure 9.

Figure 10.

Figure 11.

DISCUSSION

AUTHORS' CONCLUSIONS

ACKNOWLEDGEMENTS

REFERENCES

CHARACTERISTICS OF STUDIES

ADDITIONAL TABLES

APPENDICES

HISTORY

CONTRIBUTIONS OF AUTHORS

DECLARATIONS OF INTEREST

SOURCES OF SUPPORT

DIFFERENCES BETWEEN PROTOCOL AND REVIEW 
[Intervention Review]

\section{Treatment options for progression or recurrence of glioblastoma: a network meta-analysis}

Catherine McBain $1 a$, Theresa A Lawrie ${ }^{2 b}$, Ewelina Rogozińska², Ashleigh Kernohan ${ }^{3}$, Tomos Robinson ${ }^{3}$, Sarah Jefferies ${ }^{4}$

1Clinical Oncology, The Christie NHS FT, Manchester, UK. ${ }^{2}$ The Evidence-Based Medicine Consultancy Ltd, Bath, UK. ${ }^{3}$ Population Health Sciences Institute, Newcastle University, Newcastle upon Tyne, UK. ${ }^{4}$ Department of Oncology, Addenbrooke's Hospital, Cambridge, UK

a Joint first author. b Joint first author

Contact address: Theresa A Lawrie, tess@e-bmc.co.uk.

Editorial group: Cochrane Gynaecological, Neuro-oncology and Orphan Cancer Group.

Publication status and date: New, published in Issue 1, 2021.

Citation: McBain C, Lawrie TA, Rogozińska E, Kernohan A, Robinson T, Jefferies S. Treatment options for progression or recurrence of glioblastoma: a network meta-analysis. Cochrane Database of Systematic Reviews 2021, Issue 1. Art. No.: CD013579. DOI: 10.1002/14651858.CD013579.pub2.

Copyright ( 2021 The Cochrane Collaboration. Published by John Wiley \& Sons, Ltd.

\section{A B S T R A C T}

\section{Background}

Glioblastoma (GBM) is a highly malignant brain tumour that almost inevitably progresses or recurs after first line standard of care. There is no consensus regarding the best treatment/s to offer people upon disease progression or recurrence. For the purposes of this review, progression and recurrence are considered as one entity.

\section{Objectives}

To evaluate the effectiveness of further treatment/s for first and subsequent progression or recurrence of glioblastoma (GBM) among people who have received the standard of care (Stupp protocol) for primary treatment of the disease; and to prepare a brief economic commentary on the available evidence.

\section{Search methods}

We searched MEDLINE and Embase electronic databases from 2005 to December 2019 and the Cochrane Central Register of Controlled Trials (CENTRAL, in the Cochrane Library; Issue 12, 2019). Economic searches included the National Health Service Economic Evaluation Database (NHS EED) up to 2015 (database closure) and MEDLINE and Embase from 2015 to December 2019.

\section{Selection criteria}

Randomised controlled trials (RCTs) and comparative non-randomised studies (NRSs) evaluating effectiveness of treatments for progressive/recurrent GBM. Eligible studies included people with progressive or recurrent GBM who had received first line radiotherapy with concomitant and adjuvant temozolomide (TMZ).

\section{Data collection and analysis}

Two review authors independently selected studies and extracted data to a pre-designed data extraction form. We conducted network meta-analyses (NMA) and ranked treatments according to effectiveness for each outcome using the random-effects model and Stata software (version 15). We rated the certainty of evidence using the GRADE approach.

\section{Main results}

We included 42 studies: these comprised 34 randomised controlled trials (RCTs) and 8 non-randomised studies (NRSs) involving 5236 participants. We judged most RCTs to be at a low risk of bias and NRSs at high risk of bias. Interventions included chemotherapy, reoperation, re-irradiation and novel therapies either used alone or in combination. For first recurrence, we included 11 interventions in 
the network meta-analysis (NMA) for overall survival (OS), and eight in the NMA for progression-free survival (PFS). Lomustine (LOM; also known as CCNU) was the most common comparator and was used as the reference treatment. No studies in the NMA evaluated surgery, re-irradiation, PCV (procarbazine, lomustine, vincristine), TMZ re-challenge or best supportive care. We could not perform NMA for second or later recurrence due to insufficient data. Quality-of-life data were sparse.

\section{First recurrence (NMA findings)}

Median OS across included studies in the NMA ranged from 5.5 to 12.6 months and median progression-free survival (PFS) ranged from 1.5 months to 4.2 months. We found no high-certainty evidence that any treatments tested were better than lomustine. These treatments included the following.

Bevacizumab plus lomustine: Evidence suggested probably little or no difference in OS between bevacizumab (BEV) combined with lomustine (LOM) and LOM monotherapy (hazard ratio (HR) 0.91, 0.75 to 1.10; moderate-certainty evidence), although BEV + LOM may improve PFS (HR $0.57,95 \%$ confidence interval $(\mathrm{Cl}) 0.44$ to 0.74 ; low-certainty evidence).

Bevacizumab monotherapy: Low-certainty evidence suggested there may be little or no difference in OS ( $\mathrm{HR} 1.22,95 \% \mathrm{Cl} 0.84$ to 1.76$)$ and PFS (HR 0.90, 95\% Cl 0.58 to 1.38; low-certainty evidence) between BEV and LOM monotherapies; more evidence on BEV is needed.

Regorafenib (REG): REG may improve OS compared with LOM (HR 0.50, 95\% Cl 0.33 to 0.76 ; low-certainty evidence). Evidence on PFS was very low certainty and more evidence on REG is needed.

Temozolomide (TMZ) plus Depatux-M (ABT414): For OS, low-certainty evidence suggested that TMZ plus ABT414 may be more effective than LOM (HR 0.66, $95 \% \mathrm{Cl} 0.47$ to 0.92 ) and may be more effective than BEV (HR 0.54, 95\% $\mathrm{Cl} 0.33$ to 0.89 ; low-certainty evidence). This may be due to the TMZ component only and more evidence is needed.

Fotemustine (FOM): FOM and LOM may have similar effects on OS (HR 0.89, 95\% $\mathrm{Cl} 0.51$ to 1.57, low-certainty evidence).

Bevacizumab and irinotecan (IRI): Evidence on BEV + irinotecan (IRI) versus LOM for both OS and PFS is very uncertain and there is probably little or no difference between BEV + IRI versus BEV monotherapy (OS: HR 0.95, 95\% CI 0.70 to 1.30; moderate-certainty evidence).

When treatments were ranked for OS, FOM ranked first, BEV + LOM second, LOM third, BEV + IRI fourth, and BEV fifth. Ranking does not take into account the certainty of the evidence, which also suggests there may be little or no difference between FOM and LOM.

\section{Other treatments}

Three studies evaluated re-operation versus no re-operation, with or without re-irradiation and chemotherapy, and these suggested possible survival advantages with re-operation within the context of being able to select suitable candidates for re-operation. A cannabinoid treatment in the early stages of evaluation, in combination with TMZ, merits further evaluation.

\section{Second or later recurrence}

Limited evidence from three heterogeneous studies suggested that radiotherapy with or without BEV may have a beneficial effect on survival but more evidence is needed. Evidence was insufficient to draw conclusions about the best radiotherapy dosage. Other evidence suggested that there may be little difference in survival with tumour-treating fields compared with physician's best choice of treatment. We found no reliable evidence on best supportive care.

\section{Severe adverse events (SAEs)}

The BEV+LOM combination was associated with significantly greater risk of SAEs than LOM monotherapy (RR $2.51,95 \% \mathrm{Cl}$ to 3.66 , highcertainty evidence), and ranked joint worst with cediranib + LOM (RR 2.51, 95\% CI 1.29 to 4.90; high-certainty evidence). LOM ranked best and REG ranked second best. Adding novel treatments to BEV was generally associated with a higher risk of severe adverse events compared with BEV alone.

\section{Authors' conclusions}

For treatment of first recurrence of GBM, among people previously treated with surgery and standard chemoradiotherapy, the combination treatments evaluated did not improve overall survival compared with LOM monotherapy and were often associated with a higher risk of severe adverse events. Limited evidence suggested that re-operation with or without re-irradiation and chemotherapy may be suitable for selected candidates. Evidence on second recurrence is sparse. Re-irradiation with or without bevacizumab may be of value in selected individuals, but more evidence is needed.

\section{PLAIN LANGUAGE SUMMARY}

\section{Treatment options for people with recurrent and progressive glioblastoma}

\section{Why this is important}

Treatment options for progression or recurrence of glioblastoma: a network meta-analysis (Review)

Copyright (c) 2021 The Cochrane Collaboration. Published by John Wiley \& Sons, Ltd. 
Glioblastoma multiforme (GBM) is a very aggressive type of brain tumour. Even after treatment involving surgery, radiotherapy and chemotherapy the tumour may continue growing (progress) and almost always comes back (recurs). In this review, we consider progression and recurrence as one entity. A number of different treatments have been tested, but there has been no agreement about the best treatment/s to offer when someone's tumour progresses or recurs.

\section{Objectives}

To evaluate which are the most effective treatments for people with progressive or recurrent GBM who have already received surgery, radiotherapy and chemotherapy. We looked at effectiveness in terms of length of overall survival (OS), survival without disease progression (progression free survival, PFS), serious side effects, and whether treatments affected quality of life. We looked at treatments given when the disease first progressed or recurred (first recurrence) and when it came back again after that (second or subsequent recurrences).

\section{Methods}

We searched for relevant research studies comparing the effectiveness of different treatments for recurrent GBM. We used network metaanalysis (NMA) to compare different treatments. NMA is a statistical method that allows different treatments to be looked at together to decide which is best. This method allows different treatments to be ranked according to their effectiveness, even if treatments have not been directly compared with each other in research studies.

\section{Main results}

We included 42 studies (34 randomised controlled trials (RCTs) and 8 non-randomised studies) involving 5236 people. Interventions included chemotherapy, re-operation, re-irradiation and newly developed treatments either used alone or in combination. NMA could not be performed for second or later recurrence due to insufficient data.

Survival outcomes for people with a first recurrence

We found no good evidence that any of the treatments tested were better than lomustine (also known as CCNU). Adding bevacizumab to lomustine (BEV + LOM) did not improve overall survival compared with lomustine alone. Other chemotherapy and novel agents either did not work, or the evidence on them was uncertain. Unfortunately, we did not find any studies on several commonly used treatments, such as PCV (procarbazine, CCNU, vincristine) and TMZ re-challenge, to include.

Limited evidence suggested that a second operation with or without other treatments may have survival advantages for some individuals with a first recurrence. A small study of a cannabinoid treatment suggests this merits further investigation.

\section{Survival outcomes for people with a second or later recurrence}

For second or later recurrence, insufficient evidence meant that we were not able to carry out statistical analysis. Findings suggested that radiotherapy with or without BEV may have some survival advantages but this evidence is uncertain. We found no reliable evidence on best supportive care.

\section{Serious adverse events (SAES) from treatment}

Most treatments caused some serious side effects (SAEs). The BEV + LOM combination was associated with a significantly greater risk of SAEs than lomustine alone. In general, adding treatments to bevacizumab was associated with more SAEs compared with BEV alone.

\section{Authors' conclusions}

For treatment of first recurrence of GBM, lomustine appears the most effective chemotherapy treatment and other combination therapies tested had a higher risk of serious side effects. A second operation or radiotherapy, or both, may be of value in selected individuals. For second recurrence, radiotherapy with or without bevacizumab may have a role but more evidence is needed. Several commonly used treatments were not evaluated, such as PCV (lomustine plus procarbazine and vincristine) and temozolomide re-challenge. More research is needed. 


\section{SUMMARY OF FINDINGS}

\section{Summary of findings 1 . Summary of overall survival findings}

Estimates of effects, certainty assessment and rankings of different treatment options compared with lomustine on overall survival in people with first recurrence of glioblastoma

Patient or population: people with first recurrence of glioblastoma

Interventions: bevacizumab (BEV), BEV + lomustine (LOM), regorafenib (REG), fotemustine (FOM), ABT414 + temozolomide (TMZ); $\mathrm{BEV}$ + irinotecan (IRI), BEV + onartuzumab (ONA), cediranib (CED), CED + LOM

Comparison: lomustine

Outcome: overall survival

\begin{tabular}{|c|c|c|c|}
\hline All intervention options & $\begin{array}{l}\text { Relative effect and } 95 \% \mathrm{Cl} \\
\text { (network estimate) } \star \star\end{array}$ & $\begin{array}{l}\text { Certainty of the } \\
\text { evidence (GRADE) }\end{array}$ & Ranking* \\
\hline \multicolumn{4}{|c|}{ (9 RCTs; 1734 participants in total)* } \\
\hline $\begin{array}{l}\text { LOM } \\
\text { (5 RCTs; } 403 \text { participants) }\end{array}$ & Reference comparator & $\begin{array}{l}\text { Reference com- } \\
\text { parator }\end{array}$ & 5.9 \\
\hline $\begin{array}{l}\text { REG } \\
\text { (1 RCT; } 59 \text { participants) }\end{array}$ & HR 0.50 (0.33 to 0.76$)$ & $\begin{array}{l}\oplus \oplus \odot \odot \\
\text { low } \mathbf{1}\end{array}$ & 1.3 \\
\hline $\begin{array}{l}\text { Depatux-M (ABT414) + TMZ } \\
\text { (1 RCT; } 88 \text { participants) }\end{array}$ & HR 0.66 (0.47 to 0.92$)$ & $\begin{array}{l}\oplus \oplus \oplus \odot \\
\text { moderate }^{2}\end{array}$ & 2.1 \\
\hline $\begin{array}{l}\text { BEV + LOM } \\
\text { (3 RCTs, } 401 \text { participants) }\end{array}$ & HR 0.91 (0.75 to 1.10$)$ & $\begin{array}{l}\oplus \oplus \oplus \Theta \\
\text { moderate }^{4}\end{array}$ & 4.4 \\
\hline $\begin{array}{l}\text { FOM } \\
\text { (1 RCT; } 32 \text { participants) }\end{array}$ & HR 0.89 (0.51 to 1.57 ) & $\begin{array}{l}\oplus \oplus \odot \ominus \\
\text { low }^{3}\end{array}$ & 4.6 \\
\hline $\begin{array}{l}\text { ABT414(Depatux-M) } \\
\text { (1 RCT; } 86 \text { participants) }\end{array}$ & HR 0.96 (0.69 to 1.34$)$ & $\begin{array}{l}\oplus \oplus \oplus \odot \\
\text { low } \mathbf{4 , 6}\end{array}$ & 5.4 \\
\hline $\begin{array}{l}\text { CED + LOM } \\
\text { (1 RCT, } 129 \text { participants) }\end{array}$ & HR 1.15 (0.76 to 1.74$)$ & $\begin{array}{l}\oplus \oplus \oplus \odot \\
\text { moderate } 4\end{array}$ & 7.2 \\
\hline $\begin{array}{l}\text { BEV + IRI } \\
\text { (1 RCT; } 82 \text { participants) }\end{array}$ & HR 1.16 (0.71 to 1.88$)$ & $\begin{array}{l}\oplus \odot \ominus \ominus \\
\text { very low } \mathbf{4 , 5}\end{array}$ & 7.4 \\
\hline $\begin{array}{l}\text { BEV } \\
\text { (4 RCTs; } 259 \text { participants) }\end{array}$ & HR 1.22 (0.84 to 1.76$)$ & $\begin{array}{l}\oplus \oplus \oplus \odot \\
\text { low4,6 }\end{array}$ & 8.1 \\
\hline $\begin{array}{l}\text { CED } \\
\text { (1 RCT } 131 \text { participants) }\end{array}$ & HR 1.43 (0.97 to 2.12 ) & $\begin{array}{l}\oplus \oplus \oplus \odot \\
\text { moderate }^{4}\end{array}$ & 9.5 \\
\hline BEV + ONA & HR 1.76 (0.94 to 3.30$)$ & $\oplus \odot \odot \odot$ & 10.3 \\
\hline
\end{tabular}

Treatment options for progression or recurrence of glioblastoma: a network meta-analysis (Review) 
Estimates are reported as HR: Hazard Ratio. Cl: confidence interval.

*This refers to the number of studies in the network evaluating the given intervention and the number of participants involved in these studies.

GRADE Working Group grades of evidence

High quality: further research is very unlikely to change our confidence in the estimate of effect.

Moderate quality: further research is likely to have an important impact on our confidence in the estimate of effect and may change the estimate.

Low quality: further research is very likely to have an important impact on our confidence in the estimate of effect and is likely to change the estimate.

Very low quality: we are very uncertain about the estimate.

*We excluded REG and ABT414 on sensitivity analysis, which ranked FOM first, BEV + LOM second, LOM third, BEV+irinotecan (IRI) fourth, and BEV fifth.

1 Downgraded -2 as sparse data from single small open-label study

2 Downgraded for intransitivity ( 30\% of control arm received TMZ not LOM)

3 Downgraded for imprecision and sparse data from single small study

4 Imprecision

5 No direct evidence and HR for direct effect was estimated from trial report

6 Risk of bias

\section{Summary of findings 2 . Summary of progression-free survival findings}

\section{Estimates of effects, certainty assessment and rankings of different treatment options compared with lomustine on overall survival in people with first recurrence of glioblastoma}

Patient or population: people with first recurrence of glioblastoma

Interventions: bevacizumab (BEV), BEV + lomustine (LOM), regorafenib (REG), BEV + irinotecan (IRI), BEV + onartuzumab (ONA), cediranib (CED), CED+LOM

\section{Comparison: lomustine}

Outcome: Progression-free survival

\begin{tabular}{|c|c|c|c|}
\hline All intervention options & $\begin{array}{l}\text { Relative effect and } 95 \% \mathrm{Cl} \text { (net- } \\
\text { work estimate) ** }\end{array}$ & $\begin{array}{l}\text { Certainty of the evi- } \\
\text { dence (GRADE) }\end{array}$ & Ranking* \\
\hline \multicolumn{4}{|c|}{ (7 RCTs; 1383 participants in total)* } \\
\hline $\begin{array}{l}\text { LOM } \\
\text { (4 RCTs; } 317 \text { participants) }\end{array}$ & Reference comparator & Reference comparator & 6.2 \\
\hline $\begin{array}{l}\text { BEV+LOM } \\
\text { (3 RCTs, } 401 \text { participants) }\end{array}$ & HR $0.57(0.44$ to 0.74$)$ & $\begin{array}{l}\oplus \ominus \ominus \ominus \\
\text { low1,4 }\end{array}$ & 1.6 \\
\hline $\begin{array}{l}\text { REG } \\
\text { (1 RCT; } 59 \text { participants) }\end{array}$ & HR 0.65 (0.42 to 1.01$)$ & $\begin{array}{l}\oplus \ominus \ominus \ominus \\
\text { very low } \mathbf{1 , 2}\end{array}$ & 2.7 \\
\hline $\begin{array}{l}\text { CED + LOM } \\
\text { (1 RCT, } 129 \text { participants) }\end{array}$ & HR 0.76 (0.50 to 1.18$)$ & $\begin{array}{l}\oplus \oplus \oplus \ominus \\
\text { moderate }\end{array}$ & 3.8 \\
\hline$B E V+\mid R I$ & HR 0.80 (0.44 to 1.45$)$ & $\oplus \oplus \Theta \Theta$ & 4.2 \\
\hline
\end{tabular}

Treatment options for progression or recurrence of glioblastoma: a network meta-analysis (Review) 


\begin{tabular}{|c|c|c|c|}
\hline (1 RCT; 82 participants) & & very low 1,3 & \\
\hline $\begin{array}{l}\text { BEV } \\
\text { (4 RCTs; } 200 \text { participants) }\end{array}$ & HR 0.90 (0.58 to 1.38$)$ & $\begin{array}{l}\oplus \ominus \ominus \ominus \\
\text { low } 2,4\end{array}$ & 5.2 \\
\hline $\begin{array}{l}\text { BEV + ONA } \\
\text { (1 RCT, } 64 \text { participants) }\end{array}$ & HR 0.98 (0.51 to 1.87$)$ & $\begin{array}{l}\oplus \oplus \ominus \ominus \\
\text { very low } \mathbf{1 , 4}\end{array}$ & 5.8 \\
\hline $\begin{array}{l}\text { CED } \\
\text { (1 RCT } 131 \text { participants) }\end{array}$ & HR 1.05 (0.68 to 1.62$)$ & $\begin{array}{l}\oplus \oplus \oplus \ominus \\
\text { moderate }^{2}\end{array}$ & 6.4 \\
\hline
\end{tabular}

Estimates are reported as HR: Hazard Ratio. Cl: confidence interval.

*This refers to the number of studies in the network evaluating the given intervention and the number of participants involved in these studies.

GRADE Working Group grades of evidence

High quality: further research is very unlikely to change our confidence in the estimate of effect.

Moderate quality: further research is likely to have an important impact on our confidence in the estimate of effect and may change the estimate.

Low quality: further research is very likely to have an important impact on our confidence in the estimate of effect and is likely to change the estimate.

Very low quality: we are very uncertain about the estimate.

*We excluded REG on sensitivity analysis, which ranked FOM first, BEV + LOM second, LOM third, BEV+irinotecan (IRI) fourth, and BEV fifth.

1 Sparse data from single small open-label study

2 Imprecision

3 HRs for direct effect estimated from trial report

4 Risk of bias

\section{Summary of findings 3. Summary of findings for severe adverse events - 1}

\section{Estimates of effects, certainty assessment and rankings of different treatment options compared with lomustine for severe adverse events in people with any recurrence of glioblastoma}

Patient or population: people with any recurrence of glioblastoma

Interventions: bevacizumab (BEV) + lomustine (LOM), regorafenib (REG), cediranib (CED), CED + LOM, CED + gefitinib (GET)

Comparison: lomustine

Outcome: severe adverse events

\begin{tabular}{|c|c|c|c|c|}
\hline \multirow[t]{2}{*}{$\begin{array}{l}\text { Outcomes } \\
\text { (5 RCTs, } 1024 \text { participants) }\end{array}$} & $\begin{array}{l}\text { Illustrative comparative } \\
\text { risks }^{\star}(95 \% \mathrm{Cl})^{\star \star}\end{array}$ & \multirow[t]{2}{*}{$\begin{array}{l}\text { Relative effect } \\
(95 \% \mathrm{Cl})\end{array}$} & \multirow[t]{2}{*}{$\begin{array}{l}\text { Quality of the } \\
\text { evidence } \\
\text { (GRADE) }\end{array}$} & \multirow[t]{2}{*}{ Ranking } \\
\hline & Corresponding risk & & & \\
\hline $\begin{array}{l}\text { LOM } \\
\text { (5 RCTs; } 330 \text { participants) }\end{array}$ & $39 \operatorname{per} 100^{*}$ & Reference comparator & $\mathrm{N} / \mathrm{A}$ & 1.7 \\
\hline $\begin{array}{l}\text { CED } \\
\text { (2 RCTs; } 147 \text { participants) }\end{array}$ & 39 per 100 ( 21 to 72 ) & RR 1.00 (0.54 to 1.85 ) & $\begin{array}{l}\oplus \oplus \odot \ominus \\
\text { moderate }^{\mathbf{1}}\end{array}$ & 1.7 \\
\hline
\end{tabular}

Treatment options for progression or recurrence of glioblastoma: a network meta-analysis (Review) Copyright $\odot 2021$ The Cochrane Collaboration. Published by John Wiley \& Sons, Ltd. 


\begin{tabular}{|c|c|c|c|c|}
\hline $\begin{array}{l}\text { REG } \\
\text { (1 RCT; } 59 \text { participants) }\end{array}$ & 74 per 100 (36 to 100$)$ & RR 1.90 (0.92 to 3.95$)$ & $\begin{array}{l}\oplus \oplus \odot \ominus \\
\text { low } \mathbf{1 , 2}\end{array}$ & 3.8 \\
\hline $\begin{array}{l}\text { CED + GET } \\
\text { (1 RCT; } 19 \text { participants) }\end{array}$ & 96 per 100 (18 to 100$)$ & RR 2.46 (0.46 to 13.26$)$ & $\begin{array}{l}\oplus \odot \Theta \odot \\
\text { very lo }\end{array}$ & 4.3 \\
\hline $\begin{array}{l}\text { BEV+ LOM } \\
\text { (2 RCTs, } 346 \text { participants) }\end{array}$ & 98 per 100 (67 to 100$)$ & RR 2.51 (1.72 to 3.66 ) & $\begin{array}{l}\oplus \oplus \oplus \oplus \\
\text { high }\end{array}$ & 4.7 \\
\hline $\begin{array}{l}\text { CED + LOM } \\
(1 \mathrm{RCT}, 123 \text { participants) }\end{array}$ & 98 per 100 (50 to 100$)$ & RR 2.51 (1.29 to 4.90$)$ & $\begin{array}{l}\oplus \oplus \oplus \oplus \\
\text { high }\end{array}$ & 4.7 \\
\hline \multicolumn{5}{|c|}{$\begin{array}{l}\text { *The basis for thisrisk is the mean risk of SAEs with lomustine across the } 5 \text { studies that evaluated lomustine. The corresponding risk } \\
\text { (and its } 95 \% \text { confidence interval) is based on this risk in the comparison group and the relative effect of the intervention (and its } \\
95 \% \mathrm{Cl} \text { ). }\end{array}$} \\
\hline
\end{tabular}

GRADE Working Group grades of evidence

High quality: further research is very unlikely to change our confidence in the estimate of effect.

Moderate quality: further research is likely to have an important impact on our confidence in the estimate of effect and may change the estimate.

Low quality: further research is very likely to have an important impact on our confidence in the estimate of effect and is likely to change the estimate.

Very low quality: we are very uncertain about the estimate.

1 Downgraded -1 for imprecision

2 Sparse data from single small open label trial

3 Downgraded -2 for imprecision

\section{Summary of findings 4 . Summary of findings for severe adverse events - 2}

\section{Patient or population: people with any recurrence of glioblastoma}

Interventions: bevacizumab (BEV)

Comparison: bevacizumab 9BEV), BEV+carboplatin (CAB), BEV+dasatinib (DAS), BEV+irinotecan (IRI), BEV+onartuzumab (ONA), BEV $+\mathrm{TRC105}, \mathrm{BEV}+\mathrm{VB111}$, Fotemustine (FOM), BEV+HSPPC96 vaccine

Outcome: severe adverse events

\begin{tabular}{|c|c|c|c|c|}
\hline \multirow[t]{2}{*}{$\begin{array}{l}\text { Outcomes } \\
\text { (5 RCTs, } 1024 \text { participants) }\end{array}$} & $\begin{array}{l}\text { Illustrative compara- } \\
\text { tive risks* }(95 \% \mathrm{CI})^{\star \star}\end{array}$ & \multirow[t]{2}{*}{$\begin{array}{l}\text { Relative effect } \\
(95 \% \mathrm{Cl})\end{array}$} & \multirow[t]{2}{*}{$\begin{array}{l}\text { Quality of the } \\
\text { evidence } \\
\text { (GRADE) }\end{array}$} & \multirow[t]{2}{*}{ Ranking } \\
\hline & Corresponding risk & & & \\
\hline $\begin{array}{l}\text { BEV } \\
\text { (8 RCTs; } 498 \text { participants) }\end{array}$ & $36 \operatorname{per} 100^{\star}$ & Reference comparator & $\mathrm{N} / \mathrm{A}$ & 3.1 \\
\hline $\begin{array}{l}\text { FOM } \\
\text { (1 RCT, } 32 \text { participants) }\end{array}$ & 16 per 100 ( 4 to 62 ) & RR 0.44 (0.11 to 1.72 ) & ??? (missing) & 1.6 \\
\hline
\end{tabular}




\section{BEV+HSPPC96}

$$
36 \text { per } 100 \text { (12 to } 100) \quad \text { RR } 1.01 \text { (0.33 to } 3.10)
$$

1 RCTs; 53 participants)

\begin{tabular}{|c|c|c|c|c|}
\hline $\begin{array}{l}\text { BEV+ONA } \\
\text { (1 RCT; } 64 \text { participants) }\end{array}$ & 42 per 100 ( 21 to 86$)$ & RR 1.17 (0.57 to 2.39 ) & $\begin{array}{l}\oplus \oplus \odot \odot \\
\text { low } \mathbf{1}\end{array}$ & 4.0 \\
\hline $\begin{array}{l}\text { BEV+CAB } \\
\text { (1 RCT; } 58 \text { participants) }\end{array}$ & 46 per 100 ( 22 to 96$)$ & RR 1.27 (0.61 to 2.66 ) & $\begin{array}{l}\oplus \oplus \odot \ominus \\
\text { low } \mathbf{1}\end{array}$ & 4.4 \\
\hline $\begin{array}{l}\text { BEV+DAS } \\
\text { (2 RCTs, } 83 \text { participants) }\end{array}$ & 19 per 100 ( 25 to 100$)$ & RR 0.52 (0.69 to 3.34 ) & $\begin{array}{l}\oplus \oplus \oplus \oplus \\
\text { high }\end{array}$ & 5.1 \\
\hline $\begin{array}{l}\text { BEV+IRI } \\
\text { (1 RCT, } 79 \text { participants) }\end{array}$ & 80 per 100 (43 to 100$)$ & RR 2.22 (1.19 to 4.18 ) & $\begin{array}{l}\oplus \oplus \oplus \oplus \\
\text { high }\end{array}$ & 6.5 \\
\hline $\begin{array}{l}\text { BEV+VB111 } \\
\text { (1 RCT, } 128 \text { participants) }\end{array}$ & $>100$ (92 to 100$)$ & RR 3.77 ( 2.25 to 6.33 ) & $\begin{array}{l}\oplus \oplus \oplus \oplus \\
\text { high }\end{array}$ & 8.0 \\
\hline $\begin{array}{l}\text { BEV+TRC } 105 \\
\text { (1 RCT, } 49 \text { participants) }\end{array}$ & $>100$ (92 to 100$)$ & RR 6.86 (2.55 to 18.41$)$ & $\begin{array}{l}\oplus \oplus \oplus \oplus \\
\text { high }\end{array}$ & 8.8 \\
\hline
\end{tabular}

*The basis for thisrisk is the mean risk of SAEs with lomustine across the 5 studies that evaluated lomustine. The corresponding risk (and its $95 \% \mathrm{Cl}$ ) is based on this risk in the comparison group and the relative effect of the intervention (and its $95 \% \mathrm{Cl}$ ).

** Where the corresponding risk value and, or $\mathrm{Cl}$ exceeded 100 values were truncated (at 100)

Cl: Confidence interval; RR: Risk Ratio

GRADE Working Group grades of evidence

High quality: further research is very unlikely to change our confidence in the estimate of effect.

Moderate quality: further research is likely to have an important impact on our confidence in the estimate of effect and may change the estimate.

Low quality: further research is very likely to have an important impact on our confidence in the estimate of effect and is likely to change the estimate.

Very low quality: we are very uncertain about the estimate. 


\section{B A C K G R O U N D}

\section{Description of the condition}

Gliomas are brain tumours that develop from supporting tissue of the brain known as glial cells. The most common and most malignant type of glioma is glioblastoma (GBM). The standard of care (Stupp protocol) for treating GBM in the first instance is surgery (maximal safe resection, which could be biopsy, debulking or resection depending on the tumour's anatomical location) to remove as much of the tumour as possible, followed by radiotherapy ( 60 Gy in 30 fractions) and chemotherapy (concurrent and adjuvant temozolomide) (NCCN 2018). This initial treatment takes approximately nine months to complete. Chemoradiotherapy has been associated with a median progression-free survival of 6.5 months and a median overall survival of 14.6 months among reasonably fit people less than 70 years old (Stupp 2005). Approximately $25 \%$ of people receiving chemoradiotherapy are likely to be alive two years after diagnosis compared with approximately $10 \%$ who receive radiotherapy alone (Stupp 2005). With little improvement in five-year survival rates over the last 40 years, approximately $12 \%$ of people are alive five years after diagnosis (CRUK 2020).

Younger people respond better to first-line treatment than older people, and those with $0^{6}$-methylguanine-DNA methyltransferase (MGMT) gene promoter methylation respond better to temozolomide than those with MGMT-unmethylated status (Malmstrom 2012; Wick 2012). Amongst fitter elderly patients treated with chemoradiotherapy (using a shorter, 3-week RT regime), MGMT-methylated status confers a survival advantage, with a median survival of 13.5 months reported for this subgroup in a recent trial (Perry 2017). When GBM is diagnosed among patients who have had lower-grade gliomas initially treated with radiotherapy only, they are generally treated with temozolomide after surgical confirmation of recurrence as GBM. Not all people receive radiotherapy or chemotherapy (or both) after surgery, however, and best supportive care (palliative care) may be the preferred option, particularly for elderly people and those with poor performance status (NCCN 2018).

After the initial treatment phase, guidelines issued by the National Institute for Health and Care Excellence (NICE) suggest that routine follow-up by magnetic resonance imaging (MRI) be performed at three- to six-month intervals for the first two years, six- to 12 monthly until five years, and then annually thereafter (NICE 2018). Some tumours that are GBM to start with, after an initial response to treatment or stability in growth, can recur and grow. In some cases of GBM, there is no period of response or stability and they continue to grow. Lower-grade tumours (e.g. WHO Grade II or Grade III) can progress to GBM after many years of stability. In all cases, the continued growth is considered 'tumour progression'. Continued GBM growth or recurrence may be detected by these regular surveillance scans or identified upon the development of new symptoms (Thompson 2019). Making a diagnosis of GBM progression or recurrence can, however, be complicated in the first few months after initial treatment by the fact that its appearance on MRI may be indistinguishable from pseudoprogression (NCCN 2018).

As treatment of GBM is not curative, most people who respond to radiotherapy and temozolomide chemotherapy, in combination or sequentially, will experience a recurrence of the disease at some point thereafter, which is usually in the form of local tumour progression (Thon 2013). Following recurrence after chemoradiotherapy, a proportion of people will go on to receive further treatment; however, elderly and frail people are likely to receive best supportive care only.

\section{Description of the intervention}

Treatment options for recurrent GBM include the following.

\section{Chemotherapy}

This is the most common approach to treating recurrent disease (Thon 2013). The most commonly used chemotherapy regimes are either lomustine (CCNU) given as a single agent or given in combination with procarbazine and vincristine in the regime known as PCV or re-challenge with temozolomide (NICE 2018; Niyazi 2011). In a chemotherapy-naive population (i.e. populations that have not received the Stupp protocol) with a first recurrence, single-agent temozolomide and PCV has been shown to have a similar effect on survival, with a median post-recurrence survival of approximately seven months (Brada 2010; Parasramka 2017).

\section{Re-operation}

A second surgical resection at recurrence may be possible in up to a quarter of people with recurrent disease depending on the infiltrative nature of the recurrence (Mandl 2008; Niyazi 2011). This also gives the opportunity for molecular analysis, which is helpful in guiding further treatment.

\section{Re-irradiation}

Re-irradiation in the context of recurrent GBM is usually given as hypofractionated radiotherapy, where the required dose is divided into a number of fractions for larger tumour volumes, with or without chemotherapy (concurrently or adjuvantly, or both), but may also be given as a single high-fraction dose for small tumour volumes (stereotactic radiosurgery (SRS); Chapman 2019; Niyazi 2011).

\section{Novel agents}

There are several novel treatments for GBM recurrence that have been evaluated or are undergoing evaluation in clinical trials but none have been introduced into routine clinical practice. These include anti-angiogenic therapy, local drug delivery, targeted molecular therapy, vaccines, and electric field therapy (tumourtreating fields). The most intensively investigated of these alternatives is the anti-angiogenic agent, bevacizumab. While this agent is currently licensed for use in the USA for treatment of recurrent GBM (Thon 2013), a 2018 review of anti-angiogenic agents for GBM concluded that there was insufficient evidence to support the use of bevacizumab in recurrent disease (Ameratunga 2018).

\section{Best supportive care}

Best supportive (palliative) care only is considered a valid alternative to active treatment of recurrent GBM (Easaw 2011; NICE 2018). The Multinational Association for Supportive Care in Cancer defines supportive care as "the prevention and management of the adverse effects of cancer and its treatment. This includes management of physical and psychological symptoms and side effects across the continuum of the cancer experience, from diagnosis through anti-cancer treatment to post-treatment care. Enhancing rehabilitation, secondary cancer prevention, 
survivorship and end of life care are integral to supportive care" (MASCC 2019). People with GBM experience deteriorating neurological function as well as cancer effects; therefore supportive (palliative) care to improve quality of life and mitigate these effects has an important role to play in the management of this disease from an early stage (EANO 2017).

\section{How the intervention might work}

The mechanism of action of the alkylating chemotherapy agents (e.g. temozolomide, nitrosoureas, procarbazine, carboplatin) is to interfere with DNA synthesis by causing cross-linkage between the strands and DNA breakage, thereby preventing tumour cell division (Drugs.com). Repeated surgical resection aims to reduce the tumour bulk and may only be effective if followed by chemotherapy or radiotherapy (Mandl 2008). Local re-irradiation aims to deliver targeted radiotherapy to the tumour whilst sparing the surrounding normal tissue (Kim 2019; Niyazi 2011). Bevacizumab, the most common targeted therapy, is a monoclonal antibody that binds to and inhibits vascular endothelial growth factor, interfering with tumour blood supply and inhibiting vessel proliferation (Niyazi 2011). Supportive care in the context of GBM commonly includes the treatment of seizures, steroids (e.g. dexamethasone) to control brain oedema, neurocognitive dysfunction, nausea, and venous thromboembolism (Batchelor 2006).

\section{Why it is important to do this review}

There is a general acceptance that the two most effective treatment modalities in GBM are radiotherapy and temozolomide. However, there is no consensus on how to use these and other modalities after initial, first line GBM treatment. The 2015 James Lind Alliance research prioritisation-setting process highlighted the need for more research guidance on GBM treatment after second recurrence (JLA 2015). In particular, a better understanding of the balance between desirable and undesirable effects associated with active treatment of recurrent GBM is necessary.

There are also significant resource implications associated with the management of GBM. A review by Messali 2014 found that the reported costs of managing GBM ranged from USD 4755 to USD 195,773 across five cost-of-illness studies (US dollar (USD) 2013). A greater understanding of the optimum management strategies for GBM will aid in the allocation of future healthcare resources in the most efficient way to maximise patient health. The aim of this review is therefore to identify and evaluate the best evidence on first and subsequent treatment options for when GBM recurs. This should inform conversations between people affected and health professionals, and the effective use of healthcare resources.

\section{O B JE C T IVES}

To evaluate the effectiveness of further treatment/s for first and subsequent progression or recurrence of glioblastoma (GBM) among people who have received the standard of care (Stupp protocol) for primary treatment of the disease; and to prepare a brief economic commentary on the available evidence.

\section{METHODS}

\section{Criteria for considering studies for this review}

\section{Types of studies}

Randomised controlled trials (RCTs), quasi-randomised trials, nonrandomised studies, and controlled before-and-after studies that included relevant concurrent comparison groups. We did not expect to find cluster-randomised trials. In view of the non-stable nature of the conditions under review we did not include studies using cross-over designs, nor did we include case-control studies, or studies without a control group. As many novel interventions evaluated in this field are abandoned after early phase $\mathrm{l} / \mathrm{Il}$ studies due to futility, studies had to include a minimum of 20 participants. We excluded dose-finding studies.

\section{Types of participants}

People aged 16 years of age and older diagnosed with recurrent or progressive disease following primary treatment (surgery and chemoradiotherapy) for glioblastoma (GBM). This included participants whose GBM continued to grow despite standard therapy and those whose disease was initially controlled by standard therapy but which subsequently recurred. Clinical trials included participants with either/both progressive or recurrent disease; definitions were determined by study investigators. For the purposes of this review, these are therefore considered as one entity. Where studies included mixed primary treatments, they were included if at least $80 \%$ of participants had received chemoradiotherapy using the standard 6-week 'Stupp protocol'. Participants with first and subsequent recurrences were included. Where studies included participants with grades 3 and 4 gliomas, we included them if data were reported separately for the GBM subgroup or if at least $80 \%$ of the sample had grade 4 gliomas.

\section{Types of interventions}

Any active treatment (chemotherapy, radiotherapy, surgery or another experimental treatment) or treatment combination compared with another active treatment, best supportive (palliative) care or no active treatment.

\section{Types of outcome measures}

\section{Primary outcomes}

- Overall survival: survival from study entry until death from all causes, or as reported by investigators

- Health-related quality of life (QoL): as measured using a standardised questionnaire, e.g. the European Organisation for Research and Treatment of Cancer (EORTC) QLQ-C30 or QLQBN20 (specific for brain cancer), or the Functional Assessment of Cancer Therapy scale (FACT-G (general) or FACT-Br (specific for brain cancer))

\section{Secondary outcomes}

- Progression-free survival (survival from study entry to disease relapse, or as defined by investigators)

- Severe adverse events (grade 3 or higher according to a standardised measurement tool, such as the Common Terminology Criteria for Adverse Events (CTCAE)) 


\section{Search methods for identification of studies}

\section{Electronic searches}

For evidence on the effectiveness of interventions, we prepared the search strategies and conducted the searches of the following databases from January 2005 (the threshold for the start of the current standard of care, namely maximal surgical resection followed by chemoradiotherapy) onwards (Appendix 1;Appendix 2; Appendix 3).

- Cochrane Central Register of Controlled Trials (CENTRAL; 2019, Issue 12), in the Cochrane Library

- MEDLINE via Ovid (2005 to December week 12019$)$

- Embase via Ovid (2005 to 2019 week 50)

For economic evidence, we searched the NHS EED database from January 2005 up to the end of December 2014 (when the last records were added to that database); and MEDLINE and Embase from 1 January 2015 to 16 December 2019, as NHS EED already included comprehensive searches of these databases prior to 2015. We also considered relevant grey literature - such as health technology assessments, reports and working papers - for inclusion.

We did not apply language restrictions to any of the searches.

\section{Searching other resources}

Study authors searched the following for ongoing trials.

- ClinicalTrials.gov

- International Clinical Trials Registry Platform (ICTRP) (apps.who.int/trialsearch)

We handsearched the reference lists of included studies to identify newly published articles and additional studies of relevance. We searched neuro-oncology conference abstracts from 2014 onwards.

\section{Data collection and analysis}

\section{Selection of studies}

The Information Specialist at the Gynaecological, Neuro-oncology and Orphan Cancer Group (GNOC) downloaded all titles and abstracts retrieved by electronic searching to EndNote ${ }^{\circledR}$ and removed duplicates and those studies that clearly did not meet the inclusion criteria. A minimum of two reviewers (TL, ER, IL) independently screened the search results, rejecting all clearly irrelevant records and categorising the remaining articles into included studies, excluded studies, ongoing studies and studies awaiting classification. We recorded reasons for exclusion and identified any articles that related to the same study and grouped them. We obtained the full text of potentially eligible articles. We resolved any disagreements about eligibility by discussion with the other review authors.

\section{Data extraction and management}

Two reviewers (TL, ER, IL) independently extracted data, including the following items, from eligible studies using a piloted data extraction form.

- Author contact details

- Country
- Setting

- Dates of participant accrual

- Trial registration number/identification

- Funding source

- Declarations of interest

- Participant inclusion and exclusion criteria

- Study design and methodology

- Study population and baseline characteristics

* Number of participants enrolled/analysed

* Age

* Gender

* Performance status

* MGMT-methylation status

* Type of primary surgery (biopsy or resection)

* Details of initial treatment

* Details of treatment of first recurrence

* Time from initial diagnosis

- Intervention details

* Description of intervention

* Description of comparator

- Primary outcome/s of the study

- Risk of study bias (see below)

- Review outcomes

* For time-to-event data (survival and disease progression), we extracted the log of the hazard ratio $(\log (\mathrm{HR}))$ and its standard error from trial reports. Where they were not explicitly reported, we estimated them from Kaplan-Meier plots where possible.

* For dichotomous outcomes, we recorded the number of participants in each treatment arm who experienced the outcome of interest and the number of participants assessed.

* For continuous outcomes, we recorded the value and standard deviation of the outcome of interest and the number of participants assessed at the relevant time point in each group. We also recorded change-from-baseline score data where reported and noted the type of scale used.

We extracted both unadjusted and adjusted statistics where reported. Where possible, we extracted data to allow an intentionto-treat analysis, in which we analysed participants in the groups to which they were assigned. We resolved any differences between reviewers by discussion or by appeal to the other review authors.

\section{Assessment of risk of bias in included studies}

For randomised trials, we assessed risk of bias using Cochrane's tool and the criteria specified in the Cochrane Handbook for Systematic Reviews of Interventions (Higgins 2019). This included assessment of:

- random sequence generation;

- allocation concealment;

- blinding of participants and healthcare providers;

- blinding of outcome assessors;

- incomplete outcome data (we considered more than $20 \%$ missing data to be high risk);

- selective reporting of outcomes; 
- other possible sources of bias, e.g. lack of a power calculation, baseline differences in group characteristics.

For non-randomised studies we used the ROBINS-I tool for assessing risk of bias (Sterne 2016). This included assessment of:

- bias due to confounding (e.g. baseline differences in prognostic factors, or post-baseline prognostic factor differences, or switching interventions);

- bias due to participant selection (both intervention and comparison groups should comprise the same representative group);

- bias in classification of interventions (e.g. differential misclassification of intervention status that is related to the outcome or the risk of the outcome);

- bias due to deviations from intended interventions;

- bias due to missing data (e.g. differential loss to follow-up that is affected by prognostic factors);

- bias due to outcome measures (e.g. outcome assessors were aware of intervention status, different methods were used to assess the outcome, or measurement errors were related to intervention status or effects);

- bias in selection of the reported result.

Two review authors (TL, TD, ER) assessed risk of bias independently and resolved differences by discussion. We summarised judgements in 'Risk of bias' tables along with the characteristics of the included studies. We include both a risk of bias graph and a risk of bias summary. We considered the 'Risk of bias' assessment in our interpretation of the evidence.

\section{Measures of treatment effect}

We used the following measures to evaluate treatment effect.

- For time-to-event data (e.g. death or disease progression) we used the hazard ratio (HR) with 95\% confidence intervals (Cls).

- For dichotomous outcomes, we calculated the effect size as a risk ratio (RR) with its $95 \% \mathrm{Cls}$.

- For continuous outcomes measured using the same scale, we reported the mean difference (MD) between treatment groups with $95 \%$ Cls. For continuous outcomes (e.g. QoL scores) in which different measurement scales had been used, or if studies report change-from-baseline instead of final values, we combined these data using the (unstandardised) mean difference method in Review Manager 5 (RevMan 5) (Review Manager 2014).

\section{Network structure}

Where possible, we aimed to compare and rank the following types of interventions.

- Different chemotherapy agents and regimens (temozolomide, PCV, lomustine/CCNU, etc.)

- Targeted antiangiogenic agents (e.g. bevacizumab) and other anti-growth-factor agents

- Other immunotherapy, e.g. tumour-derived vaccines, viral therapy

- Re-operation

- Re-irradiation

- Tumour-treating fields

\section{- Supportive care}

\section{Unit of analysis issues}

Two review authors (TL and ER) reviewed any unit-of-analysis issues according to Higgins 2019 for each included study and we resolved any differences through discussion. We considered issues such as where there are multiple observations for the same outcome, e.g. repeated measurements with different scales, or outcomes measured at different time points to those stipulated in the review protocol.

\section{Multi-arm trials}

For multi-arm trials, we treated the multiple comparisons as independent in pairwise meta-analyses. In the network metaanalysis, we accounted for the correlation between the effect sizes derived from the same study.

\section{Dealing with missing data}

We did not impute missing data. Where missing data were substantial, we took this into consideration in our grading of the evidence.

\section{Assessment of heterogeneity}

\section{Assessment of clinical and methodological heterogeneity}

We assessed clinical heterogeneity between studies by comparing the studies' characteristics of included participants, and interventions in each meta-analysis of each comparison; by visual inspection of forest plots; by estimation of the percentage heterogeneity between trials which cannot be ascribed to sampling variation (Higgins 2003); and by a formal statistical test of the significance of the heterogeneity (Deeks 2001). If there was evidence of substantial heterogeneity, we investigated it and reported the possible reasons for it.

\section{Assessment of consistency across treatment comparisons}

We examined the assumption of consistency by assessing the distribution of potential effect modifiers across the pair-wise comparisons. The assumption held if the following were true.

- The common treatment used to compare different interventions indirectly is similar when it appears in different trials.

- All pairwise comparisons do not differ with respect to the distribution of effect modifiers.

The potential treatment modifiers are as follows.

- Re-operation

- MGMT-methylation status

- First or subsequent recurrence

- Time from primary diagnosis

\section{Assessment of statistical heterogeneity and inconsistency}

Assumptions when estimating the heterogeneity

We estimated heterogeneity indicators for each pairwise comparison. In network meta-analysis, we assumed a common estimate for the heterogeneity variance across the different comparisons.

Copyright (c 2021 The Cochrane Collaboration. Published by John Wiley \& Sons, Ltd. 


\section{Measures and tests for heterogeneity}

We assessed the presence of statistical heterogeneity within the pairwise comparisons using the $\mathrm{I}^{2}$ statistic, which is the percentage of variability that cannot be attributed to random error. We based the assessment of statistical heterogeneity in the network on the magnitude of the heterogeneity variance parameter $\left(\mathrm{Tau}^{2}\right)$ estimated from the network meta-analysis models.

\section{Assessment of statistical inconsistency}

We evaluated the statistical agreement between the various sources of evidence in a network of interventions (consistency) by global and local to complement the evaluation of consistency (Efthimiou 2016).

\section{Assessment of reporting biases}

We assessed each paper for the extent and transparency of reporting and for suggestion of reporting bias. We did not find sufficient studies of similar interventions to assess publication bias using funnel plots.

\section{Data synthesis}

\section{For effectiveness studies}

\section{Methods for direct treatment comparisons}

We carried out meta-analyses in Stata software (version 15), pooling data from studies measuring the same outcomes in similar populations (first recurrence and any recurrence, including mixed populations). Assuming that we found at least two included studies that were sufficiently similar for the findings to be clinically meaningful, we used the random-effects models with inverse variance weighting for all meta-analyses. If any studies contributing to a meta-analysis had multiple intervention groups, we divided the 'shared' comparison group into the number of treatment groups and comparisons between each treatment group and treated the split comparison group as independent comparisons. If metaanalysis was not possible due to the timing of assessment or the type of outcome measure used, we described these data narratively.

\section{Methods for indirect and mixed comparisons}

We conducted network meta-analyses providing that populations of included studies were sufficiently similar to satisfy the assumption of joint randomisation and that the interventions connected, creating a network. This led to two separate networks, one for studies evaluating populations experiencing first recurrence and one for those experiencing any, first and second and subsequent recurrences. The latter populations would be expected to have a worse prognosis than the first recurrence group. We used the random-effects model in Stata software (version 15) fitting a multivariate network meta-analysis (White 2015). In 'Summary of findings' tables, we report the value of mean rank for included treatments (Chaimani 2015).

For data where meta-analysis was not possible, we attempted narrative synthesis but did not grade the evidence. In general, we interpreted the quality of the evidence based on the Cochrane Effective Practice and Organisation of Care (EPOC) Group's guidance (EPOC 2015).

\section{'Summary of findings' table and results reporting}

Based on the methods described in Chapter 11 of the Cochrane Handbook for Systematic Reviews of Interventions (Higgins 2019), we prepared a 'Summary of findings' table to present the results of the following outcomes, namely:

- overall survival;

- progression free survival; and

- severe adverse events.

There were insufficient data to present QoL findings. We used the GRADE system to rank the quality of the evidence (Schünemann 2019). Two review authors (TL and ER) independently graded the evidence and resolved any differences by discussion or, if necessary, by involving a third review author. We interpreted the results of the graded evidence based on Cochrane Effective Practice and Organisation of Care guidance (EPOC 2015).

\section{Brief economic commentary}

We included a brief economic commentary that summarises the availability and principal findings of the economic evaluations relevant to this review. This includes evaluations alongside trials and model-based evaluations. The work was performed in line with current guidelines, including a supplementary search to identify economic studies (Shemilt 2019).

\section{Subgroup analysis and investigation of heterogeneity}

We analysed data according to studies of populations experiencing a first recurrence and studies with other populations experiencing any (mixed group) or second or subsequent recurrences. We did not conduct subgroup analyses and investigate heterogeneity according to second or subsequent recurrence, MGMT promoter methylation status, and time from primary diagnosis, as data were insufficient for this purpose. We did not find studies specifically of transformed GBM and therefore did not conduct separate analysis of these data.

\section{Sensitivity analysis}

In the network meta-analyses, we explored how the following factors affect the ranking of interventions.

- Study quality, by excluding studies at high risk of bias to investigate how study quality affected the evidence on effects and the certainty of findings.

- If the effects from a multi-arm trial created a single loop in the network (no other loops available), we explored how exclusion of one of the arms affected the NMA findings.

\section{RE S U L T S}

\section{Description of studies}

\section{Results of the search}

The original search conducted by the CGNOC Information Specialist on 16 December 2019 identified the following records.

\section{Searches for studies of effectiveness}

- CENTRAL Issue 122019 - 524 references

- MEDLINE: 2005 to December week 12019 - 1632 references

- Embase: 2005 to 2019 week 50 - 956 references 
- Preliminary de-duplication combined total $n=2738$ references

\section{Economic searches}

- NHS EED - 9 refs

- MEDLINE: 2015 to December week 12019 - 23 references

- Embase: 2015 to 2019 week 50 - 58 references

- Preliminary de-duplication combined total $n=88$ references

For studies of effectiveness, we shortlisted 182 records and obtained the full text of these papers where applicable (several were conference abstracts). Where clinical trial registrations were identified, we visited ClinicalTrials.gov for further trial details. These records were classified as follows.

- Included: 42 studies with 85 related records (including 35 conference abstracts and 6 clinical trial registrations)

- Excluded: 57 studies with 69 related records

- Ongoing: 20 studies with 28 related records

See Figure 1. 
Figure 1. Flow diagram of searches for studies of effectiveness conducted on 16/12/2019

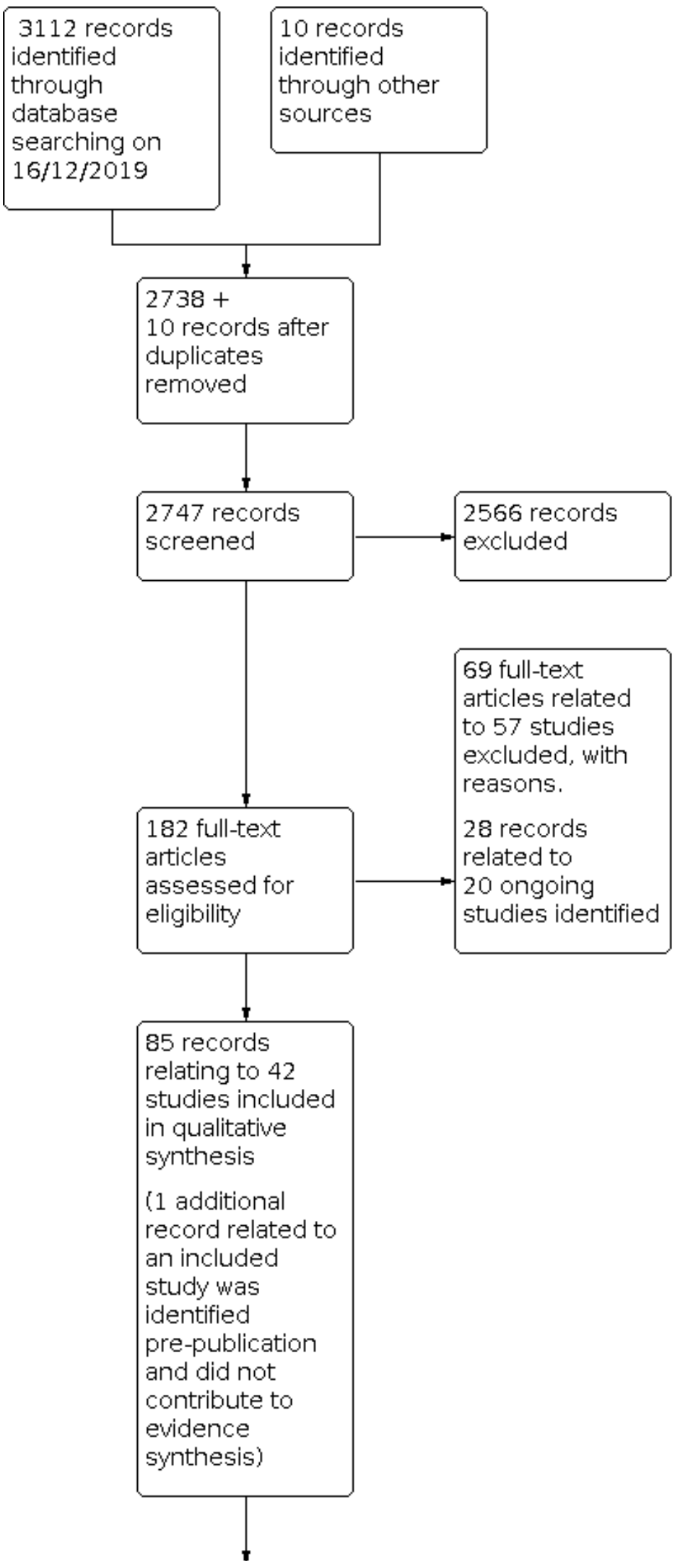


Figure 1. (Continued)

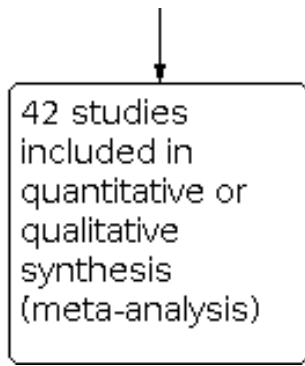

We identified one new (May 2020) trial report related to an already included study after the review was completed (van den Bent 2018).

\section{Included studies}

We included 34 RCTs and 8 non-RCTs. Most RCTs were conducted in multiple centres across several countries with accrual occurring between 2004 and 2018. All participants had recurrent GBM and the vast majority had received chemoradiotherapy as first line treatment. The treatment of first recurrence was most commonly evaluated (20 studies; Azoulay 2017; Batchelor 2013; Brandes 2016a; Brandes 2016b; Brandes 2018; Brown 2016; Cloughesy 2017; Dresemann 2010; Kunwar 2010; Lombardi 2019; Narita 2019; Omuro 2018; Puduvalli 2018; Reardon 2015b; Scorsetti 2015; Suchorska 2016; Taal 2014; Twelves 2017; van den Bent 2018; Wick 2017). Treatment of first and second recurrences were evaluated in six studies (Friedman 2009; Reardon 2018a; Reardon 2018b; Reardon 2020; Wick 2010; Wick 2014); first, second and third recurrence in one study (Weathers 2016); any recurrence in seven studies (Duerinck 2018; Field 2015; Galanis 2017; Gilbert 2017; Modh 2018; Reardon 2011; Stupp 2012); and in the remainder the number of recurrences was not clear. Data were rarely reported separately for first and subsequent recurrences where populations were mixed.

Nine of the RCTs were phase 3 studies (Batchelor 2013; Cloughesy 2017; Cloughesy 2018; Dresemann 2010; Kunwar 2010; Narita 2019; Stupp 2012; Wick 2010; Wick 2017); the rest were phase 2. Most RCTs recruited patients from Europe and America in multicentre study designs; two RCTs were conducted in Japan (Narita 2019; Omuro 2018).

Sample sizes ranged from 20 to 437 participants, with the total number of participants enrolled to the RCTs numbering 4607 (2573 with first recurrence and 2016 with mixed populations). Participants studied in non-randomised studies numbered 629 , bringing the total number taking part in included studies to 5236 people.

\section{Interventions evaluated in the RCTs}

Most interventions were evaluated in single studies leading to 33 different comparisons evaluated in the RCTs alone. (Underlined studies reported hazard ratios (HRs) for survival outcomes; studies that did not report HRs usually reported survival outcomes as median survival). Included RCTs were:

1. cediranib (CED) + lomustine (LOM) vs lomustine (LOM) (Batchelor 2013);

2. HSPPC-96 vaccine + bevacizumab (BEV) vs BEV; (Bloch 2017);

3. galunisertib (GAL) + LOM vs LOM(Brandes 2016a);
4. BEV vs fotemustine (FOT) (Brandes 2016b);

5. BEV + LOM vs LOM(Brandes 2018; Wick 2017);

6. CED + gefitinib (GET) vs CED (Brown 2016);

7. onartuzumab (ONA) + BEV vs BEV(Cloughesy 2017);

8. VB-111 + BEV vs BEV (Cloughesy 2018);

9. Imatinib + hydroxyurea (HU) vs HU (Dresemann 2010);

10. axitinib (AXI) + LOM vs AXI (Duerinck 2018);

11. BEV + carboplatin (CAB) vs BEV (Field 2015);

12. BEV + irinotecan (IRI) vs BEV (Friedman 2009);

13.BEV vs BEV + TRC105 (Galanis 2017);

14. desatinib + BEV vs BEV (Galanis 2019);

15.BEV + IRI vs BEV + TMZ (Gilbert 2017);

16.convection enhanced cintredekin besudotox vs gliadel wafers (Kunwar 2010);

17.regorafenib (REG) vs LOM (Lombardi 2019);

18. fractionated stereotactic radiosurgery with BEV vs BEV with chemotherapy (Modh 2018);

19.personalized peptide vaccination (PPV) vs placebo + best supportive care (Narita 2019);

20.nivolumab (NIV) vs nivolumab (NIV) + ipilimumab (IPI) (Omuro 2018);

21.BEV vs BEV + vorinostat (Puduvalli 2018);

22. metronomic etoposide $+\mathrm{BEV}$ vs temozolomide $+\mathrm{BEV}$ (Reardon 2011);

23.afatinib (AFA) vs TMZ vs AFA + TMZ (Reardon 2015b);

24. rindopepimut vaccine + BEV vs placebo + BEV (Reardon 2020);

25. pembrolizumab vs PEM + BEV (Reardon 2018b);

26.tumour-treating fields (TTF) vs chemotherapy (various)(Stupp 2012);

27.BEV + LOM vs BEV or LOM (Taal 2014);

28. hypofractionated radiotherapy + BEV vs BEV (Tsien 2019);

29.cannabidiol:delta-9-tetrahydrocannabinol (CBD:THC) vs placebo (Twelves 2017);

30.Depatux-m (ABT414) vs depatux-m + TMZ vs TMZ or LOM (van den Bent 2018);

31.BEV vs low dose BEV + LOM (Weathers 2016);

32.enzastaurin (ENZ) vs LOM (Wick 2010);

33. asunercept (APG110) + radiotherapy vs radiotherapy (Wick 2014).

Underlined studies reported hazard ratios (HRs) for survival outcomes; studies that did not report HRs, usually reported survival outcomes as median survival. Bloch 2017, Galanis 2017, Modh 2018, Puduvalli 2018, Reardon 2018b,and Tsien 2019 were published 
as conference abstracts that contained little data. The studies of novel agents imatinib (Dresemann 2010), cediranib (Batchelor 2013), PPV (Narita 2019); nivolumab \pm ipilimumab (Omuro 2018), pembrolizumab (Reardon 2018b), enzastaurin (Wick 2010), and afatinib (Reardon 2015b) did not show clinically meaningful survival benefits. Similarly, no survival benefits were noted when onartuzumab (Cloughesy 2017), HSPPC-96 vaccine (Bloch 2017), carboplatin (Field 2015), irinotecan (Friedman 2009), TRC105 (Galanis 2017), desatinib (Galanis 2019), vorinostat (Puduvalli 2018), or metronomic etoposide or TMZ (Reardon 2011 ) were added to BEV.

Interventions evaluated in the seven non-RCTs were the following.

1. Re-operation vs no re-operation (Azoulay 2017; retrospective)

2. Re-operation vs no re-operation (Suchorska 2016; prospective)

3. BEV vs best supportive care (Cuncannon 2019; prospective);

4. Gamma Knife surgery (GKS) vs TMZ vs GKS + TMZ, vs reoperation vs other (Kim 2015; retrospective);

5. Re-operation \pm radiotherapy + chemotherapy vs chemotherapy (fotemustine + re-challenge TMZ) (Scorsetti 2015; retrospective)

6. Trebananib (TNB) vs TNB + BEV (Reardon 2018a)
7. BEV+CCNU (LOM) vs BEV (Heiland 2016; retrospective study)

8. Intranasal perillyl alcohol (IPA) + ketogenic diet vs IPA + standard $\operatorname{diet}$ (Santos 2018)

For details of individual studies please see Characteristics of included studies.

\section{Excluded studies}

Excluded studies numbered 57 and reasons for exclusion and reasons for exclusion of individual studies can be found in the Characteristics of excluded studies section. WE also identified 20 ongoing studies, and details of these can be found in the Characteristics of ongoing studies section.

\section{Risk of bias in included studies}

We summarise risk of bias in included studies in Figure 2 and Figure 3. In general, we judged RCTs to be at low or unclear risk of bias, and judged non-RCTs to be at high risk of bias. We generally judged studies reported as conference abstracts only as being at unclear risk of bias as they contained insufficient information to make judgements (Bloch 2017; Galanis 2017; Modh 2018; Puduvalli 2018; Reardon 2018b; Tsien 2019; Twelves 2017). 
Figure 2. Risk of bias of included studies

Azoulay 2017

Batchelor 2013

Bloch 2017

Brandes 2016a

Brandes 2016b

Brandes 2018

Brown 2016

Cloughesy 2017

Cloughesy 2018

Cuncannon 2019

Dresemann 2010

Duerinck 2018

Field 2015

Friedman 2009

Galanis 2017

Galanis 2019

Gilbert 2017

Heiland 2016

Kim 2015

Kunwar 2010

Lombardi 2019

Modh 2018

Narita 2019
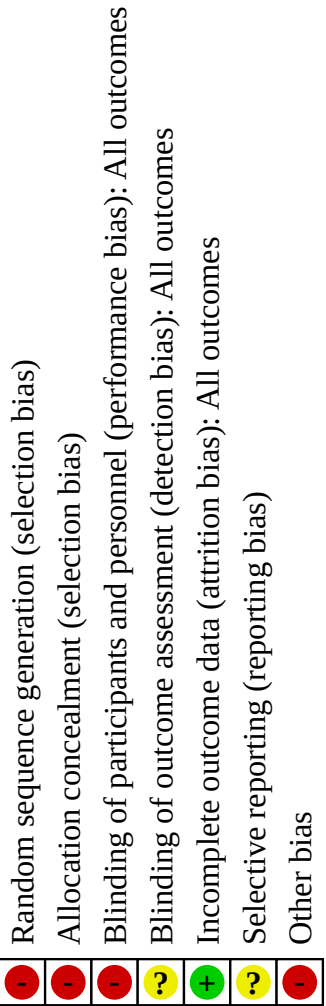

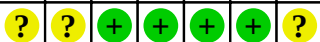

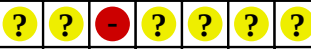

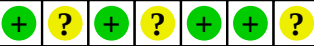
\begin{tabular}{lllllllll}
\hline$?$ & $?$ & - & $?$ & + & + & $?$
\end{tabular}

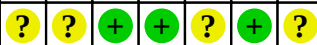

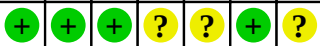
$\begin{array}{llllllll}+ & + & + & + & + & \text { ? }\end{array}$

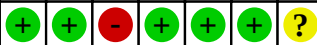
\begin{tabular}{lllllll}
\hline & - & $?$ & + & + & - \\
\hline
\end{tabular} \begin{tabular}{llllllll}
\hline$?$ & $?$ & - & + & + & + & $?$
\end{tabular} \begin{tabular}{|l|l|l|l|l|l|l|}
\hline ? & $?$ & $?$ & + & $?$ & $?$ & $?$ \\
\hline
\end{tabular} \begin{tabular}{llllllll}
\hline$?$ & $?$ & - & + & + & + & ?
\end{tabular} \begin{tabular}{|l|lllllll}
\hline$?$ & $?$ & - & + & + & ? & ? \\
\hline
\end{tabular} \begin{tabular}{lllllllll}
\hline$?$ & $?$ & - & $?$ & $?$ & $?$ & $?$
\end{tabular} \begin{tabular}{llllllll}
\hline$?$ & $?$ & + & + & + & + & $?$
\end{tabular} \begin{tabular}{ll|lllllll}
\hline$?$ & $?$ & $?$ & $?$ & + & + & ?
\end{tabular} $\begin{array}{llllllll}- & - & ? & ? & ? & ? & ?\end{array}$ \begin{tabular}{lllllllll}
\hline & $?$ & $?$ & $?$ & $?$ & + & - \\
\hline
\end{tabular} \begin{tabular}{lll|l|l|l|l|}
\hline$?$ & $?$ & $?$ & + & + & + & + \\
\hline
\end{tabular} + ? $-\odot+\odot$ ? \begin{tabular}{|l|l|l|l|l|l|l|}
\hline ? & $?$ & $?$ & $?$ & $?$ & $?$ & $?$ \\
\hline
\end{tabular} \begin{tabular}{|l|l|l|l|l|l|l|}
\hline & $?$ & $?$ & $?$ & $?$ & $?$ & $?$ \\
\hline+ & $?$ & + & + & + & + & $?$ \\
\hline
\end{tabular} 
Figure 2. (Continued)

\begin{tabular}{|c|c|c|c|c|c|c|}
\hline odh & & & & & & \\
\hline Narita 2019 & + & ? & $+{ }_{-1}$ & +5. & +4 & $?$ \\
\hline Omuro 2018 & $?$ & $?$ & $\begin{array}{ll}? \\
?\end{array}$ & $?$ & ++ & \\
\hline Puduvalli 2018 & $?$ & $?$ & $\begin{array}{l}? \\
?\end{array}$ & $?$ & \begin{tabular}{l|l}
$?$ & $?$ \\
\end{tabular} & $?$ \\
\hline Reardon 2011 & $?$ & $?$ & O? & ? & + ? & \\
\hline Reardon 2015b & ? & $?$ & ? & + & +4 & $?$ \\
\hline Reardon 2018a & - & $?$ & -6 & -5 & + & \\
\hline Reardon 2018b & $?$ & $?$ & $?$ & $?$ & $\begin{array}{l}? \\
\end{array}$ & ? \\
\hline Reardon 2020 & + & $?$ & + & +5 & +4 & ? \\
\hline Santos 2018 & - & $?$ & - & ? & ? & + \\
\hline Scorsetti 2015 & - & - & OT? & ? & \begin{tabular}{l|l}
$?$ & $?$ \\
\end{tabular} & ? \\
\hline Stupp 2012 & + & $?$ & E & ? & $?+$ & ? \\
\hline Suchorska 2016 & - & & & + & +4 & \\
\hline Taal 2014 & + & ? & & - & +5 & \\
\hline Tsien 2019 & $?$ & ? & ? & ? & ? ? & ] \\
\hline Twelves 2017 & $?$ & $?$ & $+?$ & $\begin{array}{l}?^{2} \\
\end{array}$ & $\begin{array}{ll}? & \text { ? }\end{array}$ & ? \\
\hline den Bent 2018 & + & + & - T- & + & ++ & T \\
\hline Weathers 2016 & $?$ & $?$ & $?$ & + & $+?$ & 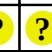 \\
\hline Wick 2010 & $?$ & $?$ & 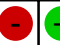 & + & +4 & \\
\hline Wick 2014 & + & ? & O? & $?$ & ++ & \\
\hline Wick 2017 & & \begin{tabular}{|l|}
$?$ \\
\end{tabular} & & & & \\
\hline
\end{tabular}

Figure 3.

Random sequence generation (selection bias)

Allocation concealment (selection bias)

Blinding of participants and personnel (performance bias): All outcomes

Blinding of outcome assessment (detection bias): All outcomes Incomplete outcome data (attrition bias): All outcomes

Selective reporting (reporting bias)

Other bias

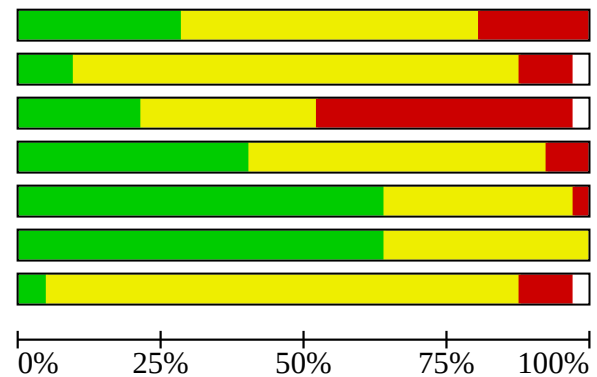

Low risk of bias

Unclear risk of bias

High risk of bias

\section{Allocation}

Most randomised studies were at an unclear risk of selection bias as the randomisation and treatment allocation process was seldom clearly reported. All non-randomised studies were at a high risk of selection bias, as patients in Azoulay 2017, Heiland 2016, Kim 2015, Santos 2018, Scorsetti 2015 and Suchorska 2016 were most likely selected for different study treatments based on clinical factors. Cuncannon 2019 selected patients according to willingness to pay for treatment with bevacizumab, which may have been influenced by patient prognosis. Reardon 2018a was a non-randomised study with little information on how patients were allocated to the different treatment arms.

\section{Blinding}

Most studies were open label studies. Less than 25\% had blinding of participants and personnel and less than $40 \%$ applied assessor blinding to assessments. In grading the findings, however, we assumed a low risk of bias for this criterion with respect to overall survival, which is an objective outcome.

\section{Incomplete outcome data}

Most studies were judged to be at low $(\sim 60 \%)$ or unclear risk ( $35 \%$ ) of attrition bias. We judged one non-randomised study to be at high risk of attrition bias because less than half the participants completed the study (Santos 2018). 


\section{Selective reporting}

The majority of studies ( 70\%) reported overall survival, progression free survival and toxicity outcomes and we judged them to be at low risk of bias for this criterion; the remainder we judged as having an unclear risk of bias.

\section{Other potential sources of bias}

RCTs were usually sponsored by the intervention's manufacturer and affiliated pharmaceutical companies and most had authors with declared interests. The risk of bias implications of these potential sources of bias was judged as unclear in all instances.

\section{Effects of interventions}

See: Summary of findings 1 Summary of overall survival findings; Summary of findings 2 Summary of progression-free survival findings; Summary of findings 3 Summary of findings for severe adverse events - 1; Summary of findings 4 Summary of findings for severe adverse events - 2

\section{Figure 4. Network for Overall Survival (first recurrence)}

We found median survival data for most included studies and these are presented in Table 1, grouped according to the level of recurrence. NMAs for survival outcomes were performed for studies evaluating treatments for first recurrence only. Where studies evaluated further recurrence or mixed recurrence, we did not perform NMA as networks connecting these mainly single phase 2 studies of novel interventions among mixed populations that were mostly shown not to warrant further investigation would produce very low certainty results. Several of the studies in the latter network did not report hazard ratios and were not powered to test efficacy, and most reported no clinically meaningful survival effects or were terminated early for futility.

\section{Overall survival (first recurrence)}

\section{The NMA findings}

Nine RCTs involving the following 11 treatments contributed to this network (Figure 4). Median overall survival estimates across this group of studies ranged from 5.5 months (LOM arm of Brandes 2018) to 12.6 months (BEV arm of Cloughesy 2017) (Table 1).

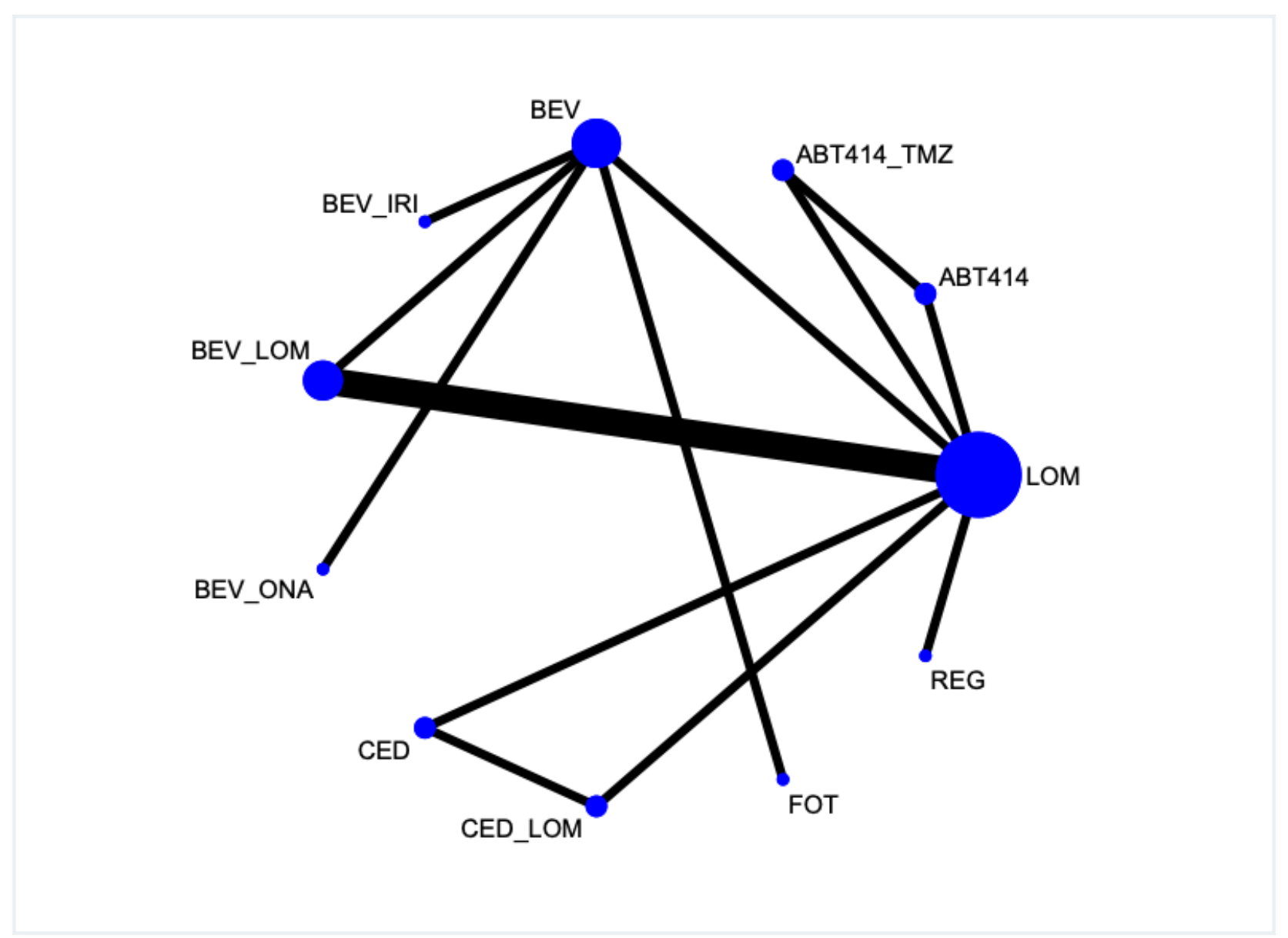

- Five trials (403 participants) involving lomustine (LOM) (Brandes 2018; Lombardi 2019; Taal 2014; van den Bent 2018; Wick 2017)

- Four trials (259 participants) involving bevacizumab (BEV) (Brandes 2016b; Cloughesy 2017; Friedman 2009; Taal 2014)
- Three trials (401 participants) involving BEV + LOM (Brandes 2018; Taal 2014; Wick 2017)

- One trial (64 participants) involving BEV + ONA (Cloughesy 2017)

- One trial (88 participants) involving ABT414 (Depatux-M) +TMZ (van den Bent 2018) 
- One trial (86 participants) involving ABT414 (van den Bent 2018)

- One trial (82 participants) involving BEV + irinotecan (IRI) (Friedman 2009)

- One trial (32 participants) involving fotemustine (FOM) (Brandes 2016b)

- One trial (59 participants) involving regorafenib (REG) (Lombardi 2019)

- One trial (131 participants) involving cediranib (CED) (Batchelor 2013)
- One trial (129 participants) involving CED + LOM (Batchelor 2013)

Results for this network can be found in the forest plot (Figure 5) and also in the league table showing HRs and $95 \% \mathrm{Cl}$ estimates for all intervention comparisons (Table 2). The global test for inconsistency was not statistically significant $(P=0.15)$. We found no high-certainty evidence that any of the treatments evaluated were superior to lomustine monotherapy. Graded pooled network estimates for overall survival of treatments compared with lomustine monotherapy suggest the following.

\section{Figure 5. Forest plot of effects on overall survival of different treatments compared with lomustine}

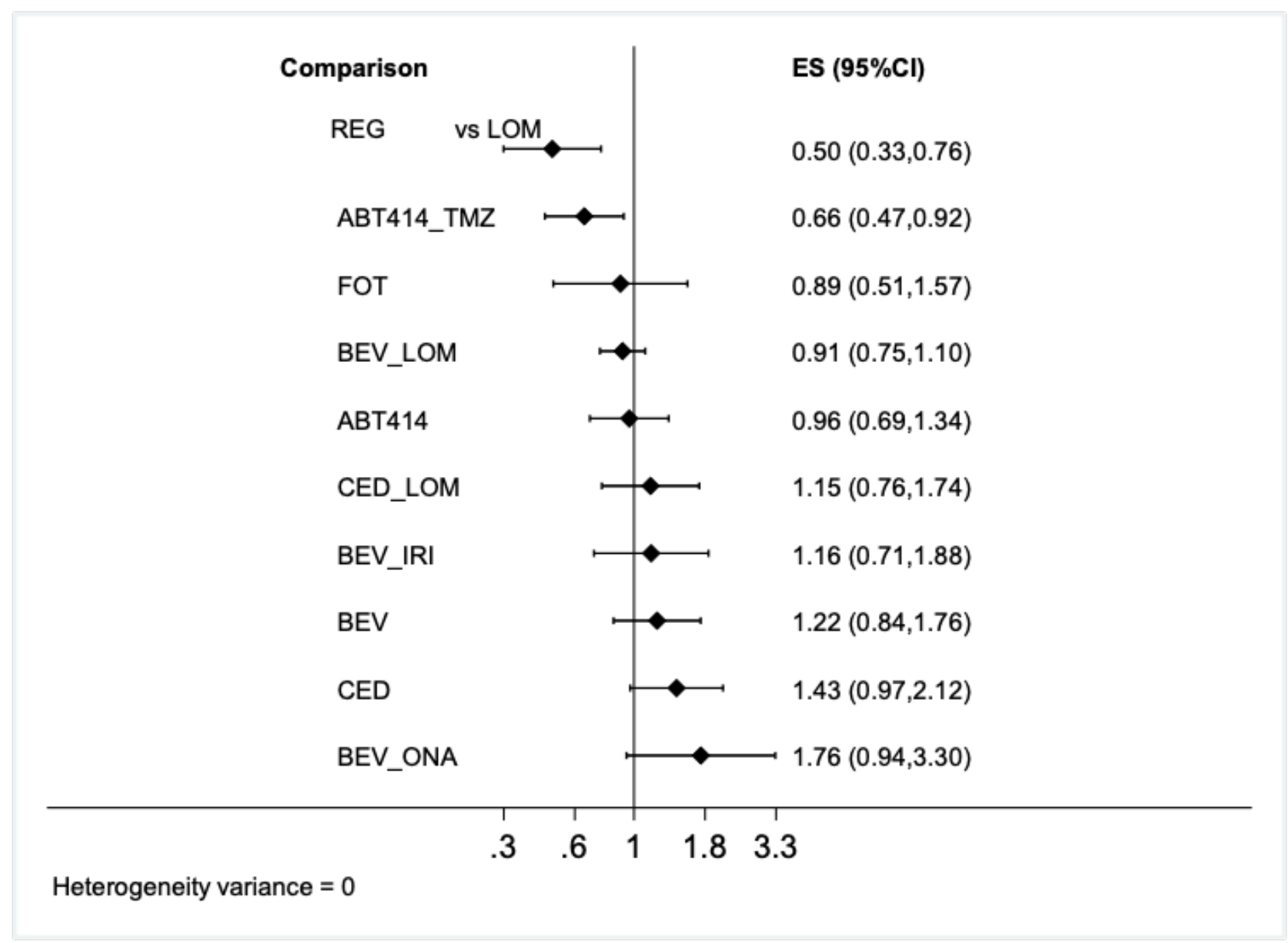

- There is probably little or no difference between BEV + LOM and LOM only (HR $0.91,95 \% \mathrm{Cl} 0.75$ to 1.10 ; moderate-certainty evidence).

- There may be little or no difference between FOM and LOM (HR $0.89,95 \% \mathrm{Cl} 0.51$ to 1.57 ; low-certainty evidence)

- There is probably little or no difference between BEV and LOM (HR 1.22, $95 \% \mathrm{Cl} 0.84$ to 1.76 ; low-certainty evidence)

- REG may be more effective than LOM (HR $0.50,95 \% \mathrm{Cl} 0.33$ to 0.76; low-certainty evidence)

- ABT414 + TMZ may be more effective than LOM (HR 0.66, 95\% Cl 0.47 to 0.92 ; low-certainty evidence)

- CED is probably less effective than LOM (HR 1.43, 95\% Cl 0.97 to 2.12; moderate-certainty evidence)
- There is probably little or no difference between CED + LOM and LOM (HR 1.15, 95\% Cl 0.76 to 1.74; moderate-certainty evidence)

- Evidence on BEV + ONA versus LOM (HR 1.76, 95\% 0.94 to 3.30) and BEV + IRI versus LOM (HR $1.16,95 \% \mathrm{Cl} 0.71$ to 1.88 ) was very low certainty.

When treatments other than LOM were compared with BEV monotherapy, there was no clear difference in effect between any of the treatments and BEV for this outcome, except for ABT414 + TMZ, which the evidence suggested may be more effective than BEV (HR $0.54,95 \% \mathrm{Cl} 0.33$ to 0.89 ; low-certainty evidence). The evidence also suggested that there is probably little or no difference between BEV + IRI compared with BEV monotherapy (HR 0.95, 95\% CI 0.70 to 1.30 ; moderate-certainty evidence). 
On sensitivity analysis, when we excluded Lombardi 2019 (a small study of REG) and van den Bent 2018 (a study of ABT414; 73\% of control participants received LOM, the others received TMZ), FOT ranked first, $\mathrm{BEV}+\mathrm{LOM}$ ranked second, and LOM ranked third, $\mathrm{BEV}$ $+\mid \mathrm{RI}$ ranked fourth, and BEV ranked fifth. Ranking does not take into account the certainty of the evidence, which indicated that there was little or no difference between BEV + LOM and LOM, probably little or no difference between FOT and LOM, and probably little or no difference between BEV + IRI and BEV. ABT414, CED and ONA were not associated with clinical benefits. See Summary of findings 1.

Other studies conducted among patients with first recurrence that could not be included in the NMA due to insufficient data did not report encouraging results and were considered not to warrant further investigation in the context of recurrent GBM. We found no studies assessing TMZ re-challenge (without ABT414) in this context.

\section{Progression-free survival (first recurrence)}

Median PFS across all RCTs reporting this outcome ranged from 1.5 months (LOM arm of Wick 2014) to 4.2 months (BEV + LOM arm of Wick 2017).

\section{The NMA findings}

Seven RCTs involving the following eight treatments contributed data to this NMA (Figure 6).

\section{Figure 6. Network for progression free survival (first recurrence)}

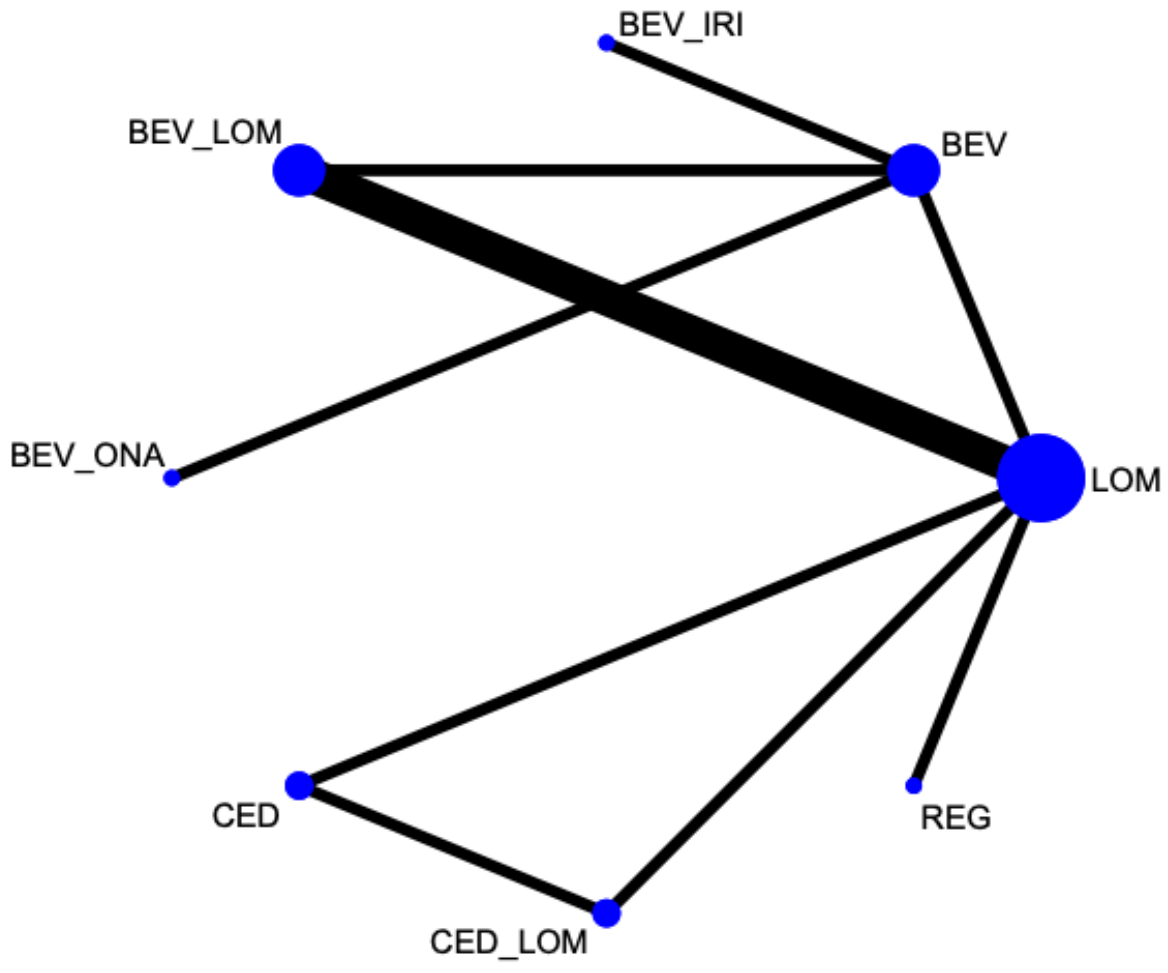

- Four trials (317 participants) involving lomustine (LOM) (Brandes 2018; Lombardi 2019; Taal 2014; Wick 2017)

- Three trials (401 participants) involving bevacizumab (BEV) + LOM (Brandes 2018; Taal 2014; Wick 2017)

- Three trials (200 participants) involving BEV (Cloughesy 2017; Friedman 2009; Taal 2014)

- One trial (64 participants) involving BEV + onartuzumab (ONA) (Cloughesy 2017)

- One trial (82 participants) involving BEV + irinotecan (Friedman 2009)
- One trial (59 participants) involving regorafenib (REG) (Lombardi 2019

- One trial (131 participants) involving cediranib (CED) (Batchelor 2013)

- One trial (129 participants) involving CED + LOM (Batchelor 2013)

Effect estimates for this network can be found in the forest plot (Figure 7) and also in the league table showing HRs and $95 \% \mathrm{Cl}$ estimates for all intervention comparisons (Table 3). The global test for inconsistency was not statistically significant $(P=$ 0.80 ). Again, we found no high-certainty evidence that any of the 
treatments evaluated were superior to lomustine monotherapy. Graded pooled network estimates for progression-free survival of treatment compared with lomustine monotherapy suggest the following.

\section{Figure 7. Forest plot of PFS for different treatments compared with lomustine (first recurrence)}

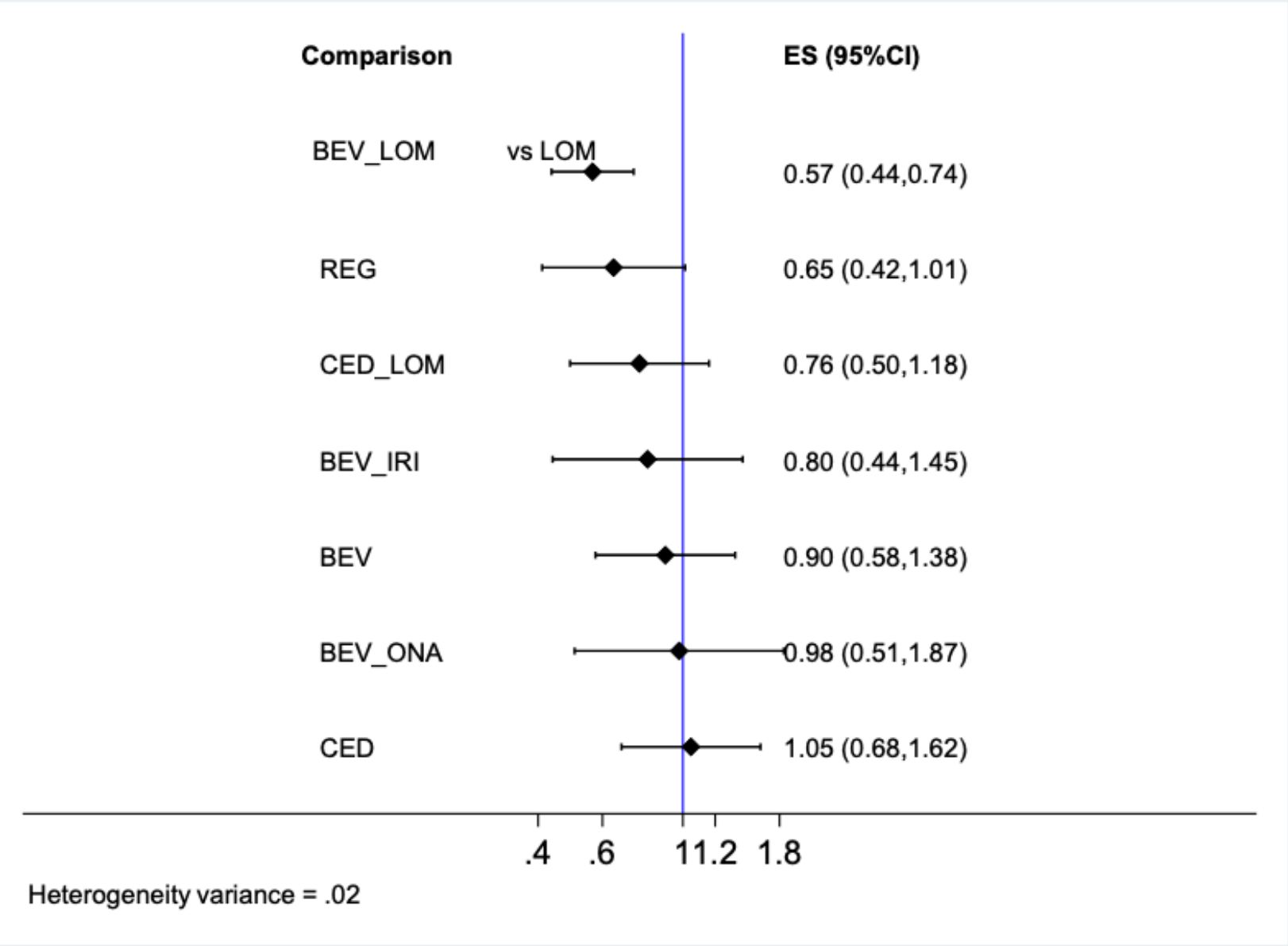

- BEV + LOM may be more effective than LOM only (HR 0.57, 95\% $\mathrm{Cl} 0.44$ to 0.74 ; low-certainty evidence);

- There may be little or no difference between BEV and LOM (HR $0.90,95 \% \mathrm{Cl} 0.58$ to 1.38 ; low-certainty evidence);

- There is probably little or no difference between CED + LOM and LOM (HR 0.76, 95\% Cl 0.50 to 1.18; moderate-certainty evidence);

- There is probably little or no difference between CED and LOM (HR 1.05; 95\% Cl 0.68 to 1.62; moderate-certainty evidence);

- Evidence on BEV + ONA versus LOM (HR 0.98, 95\% $\mathrm{Cl} 0.51$ to 1.87 ) and BEV + IRI versus LOM (HR 0.80, 95\% CI 0.44 to 1.45 ) and REG versus $\mathrm{LOM}$ ( $\mathrm{HR} 0.65,95 \% \mathrm{Cl} 0.42$ to 1.01 ) was very low certainty.

When treatments other than LOM were compared with BEV monotherapy there were no clear differences, with the exception of $\mathrm{BEV}+\mathrm{LOM}$, the evidence for which suggested that BEV + LOM may be more effective than BEV monotherapy $(0.64,95 \% \mathrm{Cl} 0.41$ to 0.99 ; high-certainty evidence). For BEV + IRI versus BEV, the evidence suggested that there may be little or no difference $(0.90,95 \% \mathrm{Cl} 0.60$ to 1.34 ; low-certainty evidence).

In terms of ranking, BEV + LOM ranked first, REG ranked second, BEV + IRI ranked third, BEV ranked fourth, LOM ranked fifth and BEV +
ONA ranked last. See Summary of findings 2 . Ranking does not take into account the certainty of the evidence above.

\section{Other study findings evaluating interventions at first recurrence}

The studies of novel agents imatinib (Dresemann 2010), axitinib (Duerinck 2018), personalised peptide vaccination (PPV; Narita 2019), nivolumab with or without ipilimumab (Omuro 2018), pembrolizumab (Reardon 2018b), enzastaurin (Wick 2010), and afatinib (Reardon 2015b) could not be included in the NMA, either due to insufficient data (no HRs reported) or due to no common nodes; however they did not show clinically meaningful survival benefits. Similarly, we could not include studies of HSPPC-96 vaccine (Bloch 2017), VB111 (Cloughesy 2018), carboplatin (Field 2015), TRC105 (Galanis 2017), desatinib (Galanis 2019), vorinostat (Puduvalli 2018), or metronomic etoposide or TMZ (Reardon 2011) added to BEV in the NMA due to insufficient data or no common nodes; however, we noted no survival benefits with these combinations and published findings suggest that they do not warrant further investigation in the context of recurrent GBM.

One randomised study evaluated the novel intervention cintredekin besudotox compared with gliadel wafers in patients with a first recurrence and no survival differences (median OS $\sim 9$ 
months) (Kunwar 2010); however, the risk of pulmonary embolism was increased with cintredekin besudotox $(P=0.014)$.

A small pilot study evaluated a cannabidiol:delta-9tetrahydrocannabinol (CBD:THC) oro-mucosal spray among 12 people with recurrent GBM randomised to the intervention and 9 randomised to placebo (Twelves 2017). All participants also received dose-intense TMZ. The median survival in the CBD:THC group was better than the placebo group ( 18.3 months vs $\sim 12.3$ months, respectively). One-year survival was $83 \%$ and $56 \%$ in the CBD:THC and placebo groups, respectively.

\section{Re-operation and re-irradiation}

Three non-randomised studies evaluated re-operation among people with first recurrence (Table 1) (Azoulay 2017; Scorsetti 2015; Suchorska 2016). These non-randomised studies are at a high risk of selection bias and this evidence was not graded. Azoulay 2017 retrospectively compared re-operation (with or without salvage chemoradiotherapy) with salvage chemoradiotherapy or best supportive care at first recurrence (median time from diagnosis 7.43 months). Sixty-nine people had repeat surgery and 111 did not: the decision on treatment was made by a multi-disciplinary team and was based on prognostic factors such as tumour extent and location. The median survival after repeat surgery was 9.8 months compared to 5.0 months for those receiving other treatment $(\mathrm{P}<$ 0.0001 ) (study authors acknowledge a "lack of consistent selection criteria for each treatment modality" as a study limitation).

Scorsetti 2015 retrospectively evaluated overall survival and progression-free survival in a retrospective study including 21 people receiving re-resection and/or re-irradiation plus chemotherapy (combined treatment) and 22 receiving chemotherapy alone. People selected for the different treatment groups had different clinical characteristics at the time of relapse. The median interval from initial diagnosis with glioblastoma was 13 months (6 to 78 months). Median overall and progression-free survival in the combined treatment group were reported to be 17 and 15 months versus 6 and 5 months in the group receiving chemotherapy alone.

Suchorska 2016 prospectively evaluated re-operation versus no re-operation in an exploratory sub-study of the DIRECTOR trial, which compared different dose-intense TMZ regimens among 105 people with recurrent GBM. Seventy-one participants in the cohort underwent re-operation. There was no significant difference in PFS (2.0 months vs 1.9 months, respectively) or post-recurrence survival (11.4 months versus 9.8 months, respectively) between those who had surgery and those who did not. However, complete resection was associated with better survival than incomplete resection (9.8 months versus 6.5 months, respectively).

In a retrospective study involving 144 patients at first progression of GBM, Kim 2015 and colleagues evaluated five different treatment options: Gamma Knife (stereotactic) radiosurgery (GKS) $(n=29)$; temozolomide: either $50 \mathrm{mg} / \mathrm{m}^{2}$ daily (metronomic dose) or 150 to $200 \mathrm{mg} / \mathrm{m}^{2}$ for 5 days per 4 weeks $(\mathrm{n}=31)$; Gamma Knife radiosurgery + temozolomide: $67.9 \%$ received metronomic TMZ chemotherapy $(n=28)$; re-operation $(n=38)$; or 'other treatment': ( $n$ $=18$ ). We have set out results for each arm in the Characteristics of included studies table. The authors concluded that GKS with TMZ was associated with improved overall survival. However, as with the other retrospective studies, it was not clear how patients were selected for the different treatment options (in this study average tumour volume differed across treatment arms).

\section{Evidence on survival outcomes for treatment of second and/or subsequent recurrence}

As described above, we could not perform NMAs of second and subsequent recurrence due to insufficient data. Twenty studies evaluated different interventions in mixed populations with first, second and/or subsequent recurrences. Ten of these studies were phase 2 studies that did not show meaningful clinical benefits. Wick 2014 was a phase 2 study of the novel intervention APG101, which the investigators considered to have potential for further development, but only $29 \%$ of these participants had second or subsequent recurrence, the majority had first recurrence. Similarly, a phase 2 study of BEV + dose dense TMZ versus BEV + irinotecan reported that both treatment arms passed pre-specified efficacy thresholds (Gilbert 2017); the proportion of second and subsequent recurrences in this study was unclear.

A few studies have evaluated mainly second or later recurrences. These included Cuncannon 2019, Galanis 2017 (terminated early for futility), Heiland 2016, Modh 2018 and Stupp 2012. Tsien 2019 is also discussed below, although the proportion of second and later recurrences in this study is unclear. Four studies evaluated reirradiation but with diversity of line of treatment, fractionation and accompanying systemic therapy. Three studies evaluated BEV with or without radiotherapy.

- Cuncannon 2019 prospectively evaluated BEV compared with supportive care for chemo-refractory disease following treatment of relapsed GBM among 48 patients. BEV was offered to the 48 patients at a maximum cost of EUR 12,000; 15 refused for financial reasons and 28 accepted. Most patients were experiencing a second or third relapse and the median survival of patients accepting BEV was 6 months versus 1 month with supportive care only $(P<0.01)$. Patients in the BEV arm $(n=$ 16) were more likely to receive radiotherapy (35 to $40 \mathrm{~Gy}$ in 15 fractions over 3 weeks) than those in the supportive care only $\operatorname{arm}(n=0)$, which authors suggested may have been facilitated by BEV. These findings are at high risk of bias.

- Modh 2018 compared BEV + fractionated stereotactic radiotherapy (8 Gy $\times 4$ fractions over 2 weeks) with BEV + chemotherapy in an RCT involving 34 heavily pre-treated participants (median recurrence was 3 ). The BEV + radiotherapy arm experienced longer progression-free survival (5.3 months vs 1.8 months) and better local control. Overall survival was 7.1 months vs 4.8 months, respectively. This was reported in a conference abstract only and details were sparse.

- Tsien 2019, also reported as a conference abstract, was a phase 2 RCT of 170 participants comparing hypofractionated radiotherapy (35 Gy in 10 fractions) plus BEV versus BEV only. The proportion of participants with second or subsequent recurrence among this study sample is not clear as findings are available in a conference abstract only; however, the duration of overall survival ( 10 months) suggests that the majority of participants had a first recurrence. Investigators reported no significant difference in overall survival; however, significantly more participants were progression-free at 6 months in the BEV + radiotherapy arm than the BEV arm ( $54 \%$ vs $29 \%)$. Authors conclude that the "role of BEV + RT should be limited to small volume recurrences, especially in previously non-irradiated 
treatment areas at least 6 months following completion of previous RT." Evidence from these studies is difficult to interpret but suggest that BEV + radiotherapy may have a role in delaying disease progression in second and subsequent recurrence of GBM.

Twenty-nine per cent of participants in Wick 2014 were experiencing second or third recurrences. This phase 2 RCT evaluated radiotherapy (36 Gy, 2 Gy fractions $\times 5$ per week) plus APG101 (a CD95 inhibitor) compared with radiotherapy alone. Median PFS was 2.5 months $(95 \% \mathrm{Cl} 2.30$ to 3.80$)$ months for radiotherapy and $4.5(95 \% \mathrm{Cl} 3.70$ to 5.40$)$ months for radiotherapy + APG101 with a hazard ratio (HR) of $0.49(95 \% \mathrm{Cl} 0.27$ to 0.88 $P=0.0162$ ) adjusted for tumour size in favour of radiotherapy plus APG101, with no clear difference in overall survival. Authors reported that the novel agent APG101 warrants further clinical development.

Heiland 2016 retrospectively evaluated "last-line" therapy in 43 patients at third recurrence. In this study, BEV monotherapy ( $\mathrm{n}=$ 17) was compared with combined BEV + LOM therapy $(n=18)$. It was not clear how patients were selected for the two treatment options. Median overall survival after BEV monotherapy was 4.07 months $(95 \% \mathrm{Cl} 3.02$ to 12.98$)$ while in the combined therapy group median overall survival was 6.59 months $(95 \% \mathrm{Cl} 5.51$ to 16.30$)$. Median progression-free survival was 2.3 months $(95 \% \mathrm{Cl} 1.87$ to 4.39 months) compared with 6.11 months $(95 \% \mathrm{Cl} 3.41$ to 12.98 months) in the combined BEV + LOM group. We considered this study to be at a high risk of bias.

Stupp 2012 was a phase 3 RCT in which more than $80 \%$ of 237 participants had failed two or more prior lines of chemotherapy (second recurrence) and 20\% of the patients had failed bevacizumab prior to enrolment. Participants were randomised to receive tumour-treating fields (TTF) or physicians best choice of treatment - most received single agent or a combination chemotherapy regimen containing bevacizumab $(31 \%)$, or irinotecan $(31 \%)$, followed by nitrosoureas $(25 \%)$, carboplatin $(13 \%)$, temozolomide $(11 \%)$ or various other agents $(5 \%)$. Interpretation of findings is difficult because the survival effects of TTF were similar to the control but it is unclear how effective the control arm treatments are, if at all.

\section{Quality of life}

Seven studies reported findings on health-related quality of life (HRQoL) using the European Organisation for Research and Treatment of Cancer (EORTC) core questionnaire (QLQ-C30) (Brandes 2016a; Brown 2016; Field 2015; Galanis 2017; Stupp 2012; Suchorska 2016; Taal 2014). All but one of these studies (Taal 2014) also used the EORTC questionnaire relating to brain cancer (BN-20). In addition, Galanis 2017 used the shorter EORTC QLQ-C15-PAL along with the BN-20 questionnaire.

A multi-centre trial in the Netherlands (Taal 2014) recruited patients at first recurrence and included three arms: bevacizumab alone $(n=46)$, lomustine alone $(n=45)$, or combined treatment ( $n=47)$. At baseline, QoL scores were similar in the three groups and, compared with the general population, these patients had impaired scores. Following treatment there were no clear differences between arms for any of the five sub-scales assessed.
Brandes 2016a also examined bevacizumab for patients with recurrent disease. In this study participants were randomised in a $2: 1$ ratio to receive bevacizumab $(n=59)$ or fotemustine $(n=32)$. QoL was assessed at approximately eight weeks after study drug administration or at disease progression. Follow-up questionnaires were only completed by $15(13.56 \%)$ in the bevacizumab group and eight $(25 \%)$ in the fotemustine group. Authors reported an improvement in physical functioning from baseline; although there was no significant difference between groups and there appeared to be variability within groups (SDs were large). For other QLQ C-30 dimensions the authors reported deteriorations in scores for fatigue, nausea, insomnia and appetite loss for patients in the fotemustine group and in emotional functioning in the bevacizumab group. However, scores for these items were not reported for both groups, and it was not clear whether or not there were any significant differences between the two arms for any of these dimensions of QoL.

In another study (Stupp 2012), patients with recurrent glioblastoma were randomised to TTF $(n=120)$ versus chemotherapy ("best available" according to physician choice) ( $n=117$ ). At three months, post-treatment QoL scores were available for $27 \%$ ( $n=$ 63) of patients randomised. Results were set out in graphs and authors report "no meaningful differences" between arms for global health and social functioning. For other QoL dimensions, symptoms appeared to be related to treatment-associated toxicity in the chemotherapy arm (loss of appetite, diarrhoea, constipation, nausea and vomiting). Authors also reported increased pain and fatigue in the chemotherapy arm. It was not clear whether apparent differences between groups for these symptoms were statistically significant.

A multi-centre RCT comparing cediranib plus gefitinib with cediranib plus placebo including patients at first progression was terminated early after recruitment of 38 patients (19 in each arm) (Brown 2016). Twenty-six patients completed questionnaires at six weeks and there were no clear differences between arms for global health status or for any of the sub-scales. The authors concluded that there was no evidence that the addition of gefitinib resulted in poorer QoL; but the study was most likely underpowered to detect possible differences between groups.

A trial including 122 patients with recurrent GMB compared bevacizumab alone with bevacizumab plus carboplatin (Field 2015). Authors reported change from baseline and there was no significant differences in overall scores detected between groups.

The study by Galanis 2017 compared bevacizumab plus TRC105 with bevacizumab alone. Of 101 patients recruited 65 were included in the main QoL analysis. In terms of overall scores on the EORTC QLQ-C15-PAL questionnaire, there was no clear difference between groups $(P=0.19)$. For the $B N 20$ items, there were no significant differences between groups for any of the dimensions. At four weeks patients were asked whether they thought it had been worthwhile participating in the study and similar proportions in both arms said yes (BEV plus TRC105, 69.4\% (25/36), BEV alone $71.9 \%(23 / 32)$.

Suchorska 2016, a non-randomised study, evaluated QoL among 71 people who underwent re-operation and 34 who did not at the 8-week follow-up visit as part of the DIRECTOR trial. Surgery was associated with better cognitive functioning $(P=0.46)$. Constipation occurred more commonly in this group $(P=0.039)$. Complete 
resection was associated with better global health status compared with incomplete resection $(P=0.008)$.

Finally, Lombardi 2019 randomised patients with relapsed GMB and compared regorafenib with lomustine. One hundred and fourteen patients completed baseline QoL questionnaires but only 37 were available for follow-up (24 in the regorafenib group and 13 in the lomustine group). There were no significant differences on any dimensions of either the general or brain tumour questionnaires, other than for appetite loss which was worse in those patients treated with regorafenib: 9 out of 24 receiving regorafenib and none of 13 receiving lomustine had what was described as clinically meaningful worsening appetite $(P=0.0146)$.

\section{Severe adverse events}

Two disconnected networks were constructed from the available data, one around lomustine and the other around bevacizumab.

\section{Network 1: treatments versus lomustine}

Five RCTs contributed to the lomustine-based network involving six different treatments, including:

\section{Figure 8. Severe adverse events - network 1}

- four trials (330 participants) involving lomustine (LOM) (Batchelor 2013; Brandes 2018; Lombardi 2019; Wick 2017);

- two trials (346 participants) involving BEV + LOM (Brandes 2018; Wick 2017);

- two trials (147 participants) involving cediranib (CED) (Batchelor 2013; Brown 2016);

- one trial (123 participants) involving CED + LOM (Batchelor 2013);

- one trial (19 participants) involving CED + gefitinib (GET) (Brown 2016); and

- one trial (59 participants) involving regorafenib (REG) (Lombardi 2019).

The network diagram is presented in Figure 8 , the league table showing $\mathrm{HRs}$ and $95 \% \mathrm{Cl}$ estimates for all intervention comparisons in Table 4 and the forest plot in Figure 9. We interpreted the evidence as follows.

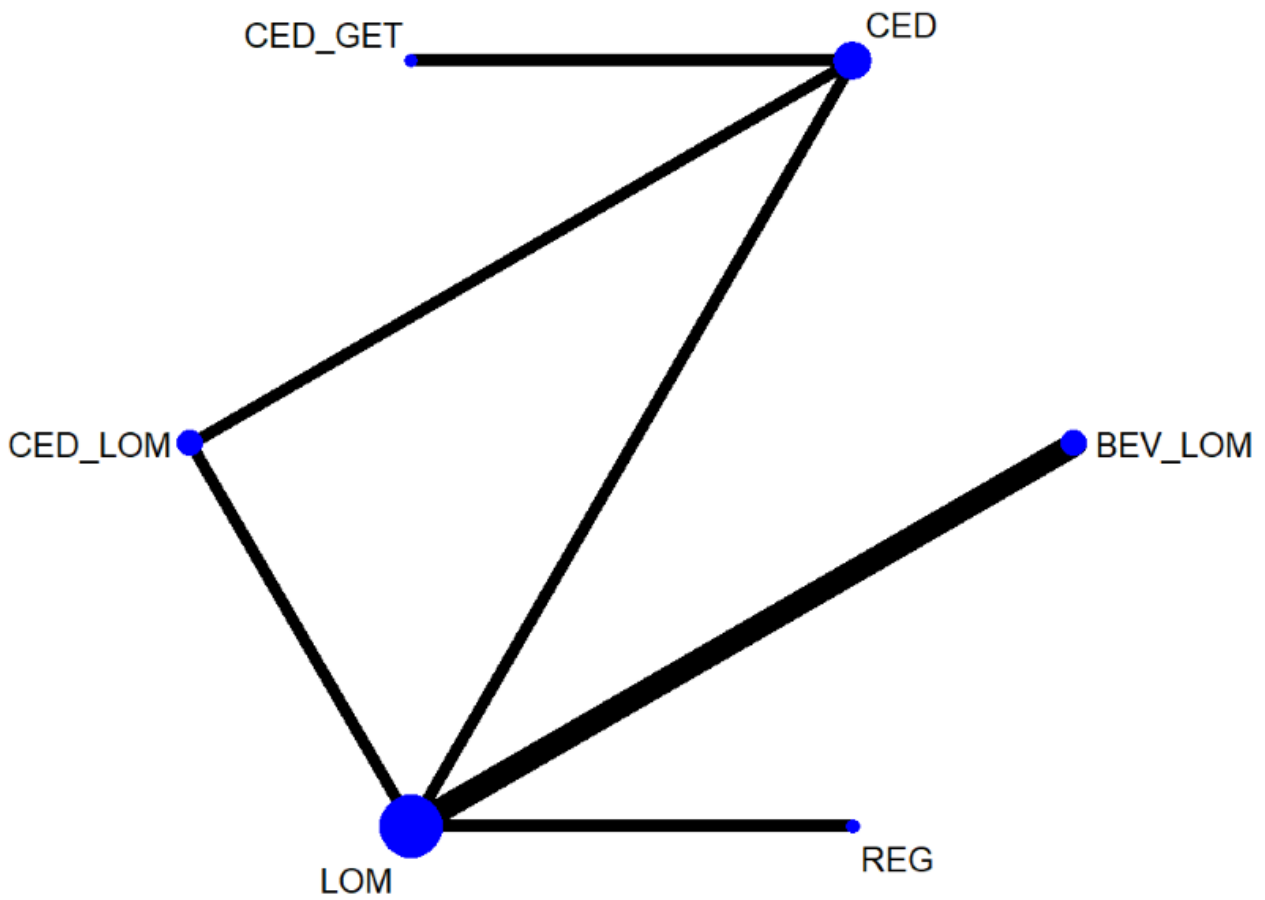

Treatment options for progression or recurrence of glioblastoma: a network meta-analysis (Review) 


\section{Figure 9. Severe adverse events forest plot for network 1 (treatments vs lomustine)}

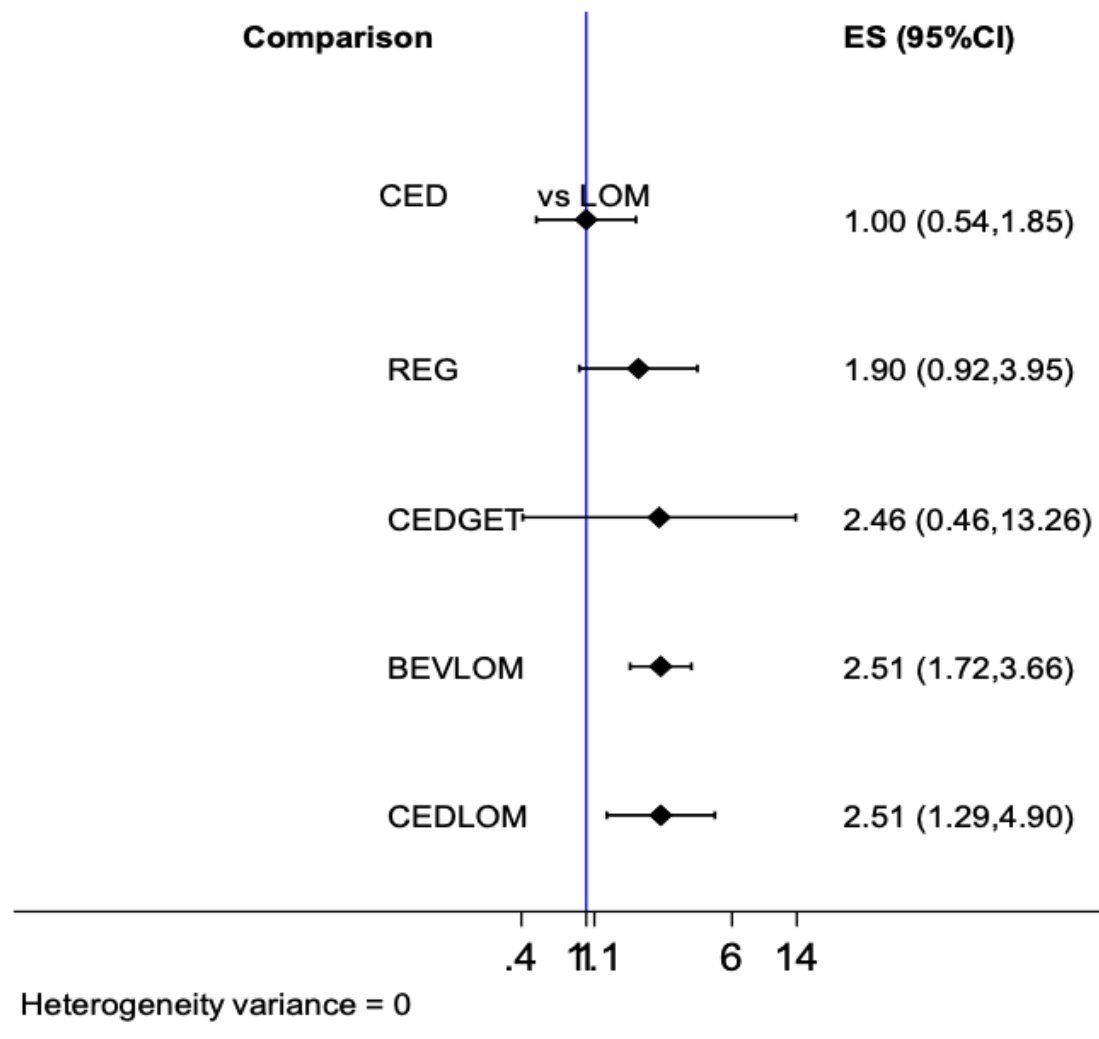

- BEV + LOM is associated with significantly more severe adverse events than LOM (RR $2.51,95 \% \mathrm{Cl} 1.72$ to 3.66 ; high-certainty evidence)

- There may be little difference in the risk of severe adverse events between REG and LOM, but the point estimate favours LOM (RR $1.90,95 \% \mathrm{Cl} 0.92$ to 3.95 ; low-certainty evidence)

- There may be little difference in risk of severe adverse events between CED and LOM (RR 1.00, 95\% Cl 0.54 to 1.85; lowcertainty evidence)

- CED + LOM is associated with significantly more severe adverse events than LOM (RR 2.51, 95\% Cl 1.29 to 4.90; high-certainty evidence)

- The evidence on CED + GET versus LOM is very low certainty.

In terms of ranking, lomustine and cediranib single therapies ranked best with the fewest severe adverse events. REG ranked second although the point estimate of REG suggesting more severe adverse events than lomustine was almost statistically significant. Bevacizumab plus lomustine ranked joint worst with CED + LOM (Figure 9). Ranking does not take into account the certainty of the evidence. See Summary of findings 3.

\section{Network 2: treatments versus bevacizumab}

Eight RCTs contributed data to this network involving nine different treatments, including:
- eight trials (498 participants) involving BEV (Bloch 2017; Brandes 2016b; Cloughesy 2017; Cloughesy 2018; Field 2015; Friedman 2009; Galanis 2017; Galanis 2019);

- one trial (58 participants) involving BEV + carboplatin (CAB) (Field 2015);

- one trial (83 participants) involving BEV + desatinib (DAS) (Galanis 2019);

- one trial (79 participants) involving BEV + irinotecan (IRI) (Friedman 2009);

- one trial (64 participants) involving BEV + onartuzumab (ONA) (Cloughesy 2017);

- one trial (49 participants) involving BEV + TRC105 (Galanis 2017);

- one trial (128 participants) involving BEV + VB111 (Cloughesy 2018);

- one trial (32 participants) involving fotemustine (FOM) (Brandes 2016b);

- one trial (53 participants) involving BEV + HSPPC96 vaccine (Bloch 2017).

The network diagram is presented in Figure 10, the league table showing $\mathrm{HRs}$ and $95 \% \mathrm{Cl}$ estimates for all intervention comparisons in Table 5 and the forest plot in Figure 11. The network comprised mainly novel treatments added to bevacizumab compared with bevacizumab. As expected, pooled network estimates suggested that, compared with bevacizumab, adding treatments to bevacizumab was associated with a higher frequency of severe adverse events. Fotemustine was also compared with 
bevacizumab and there was no clear difference Summary of findings 4 .

Figure 10. Severe adverse events - network 2

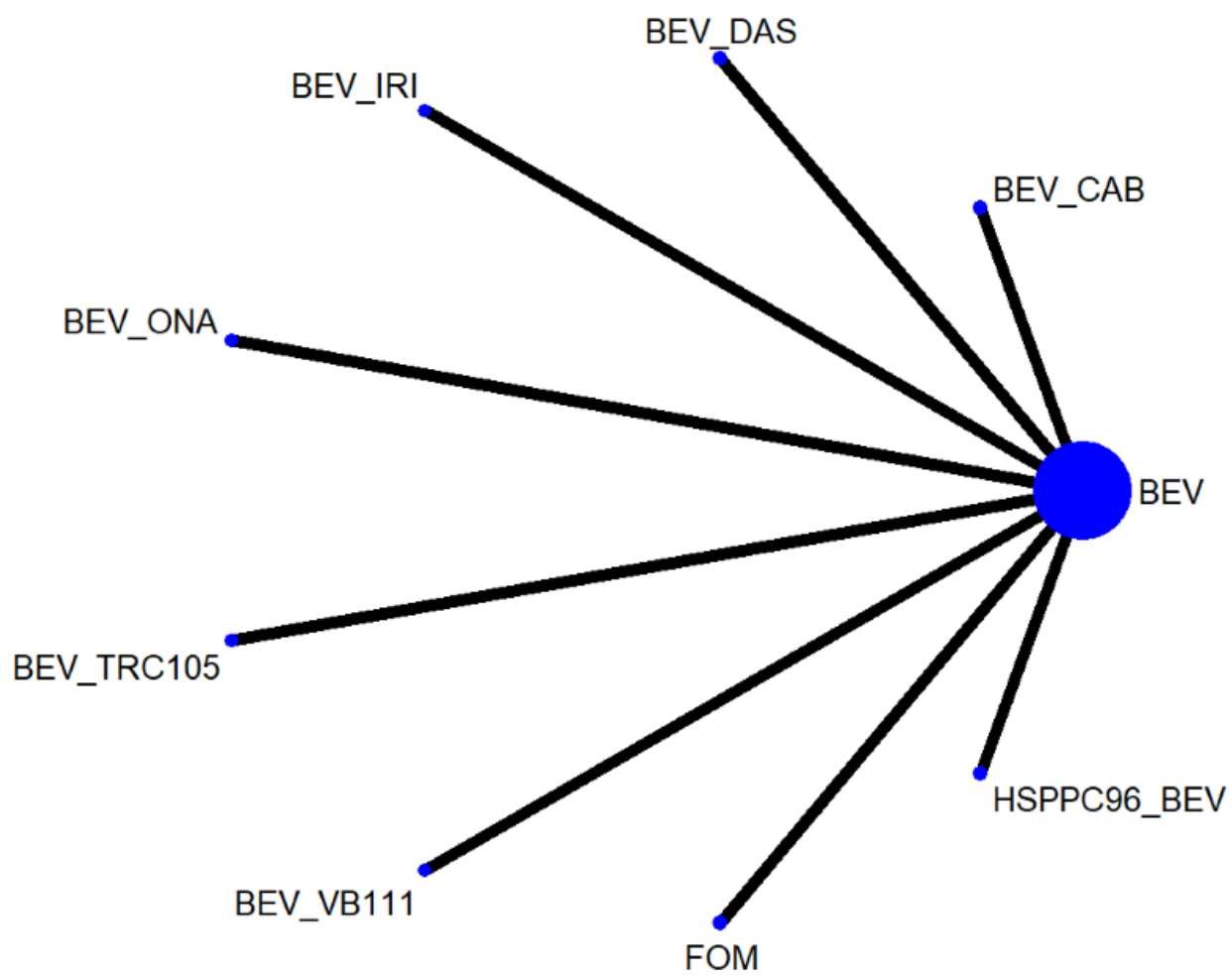


Figure 11. Severe adverse events forest plot for network 2 (treatments vs BEV)

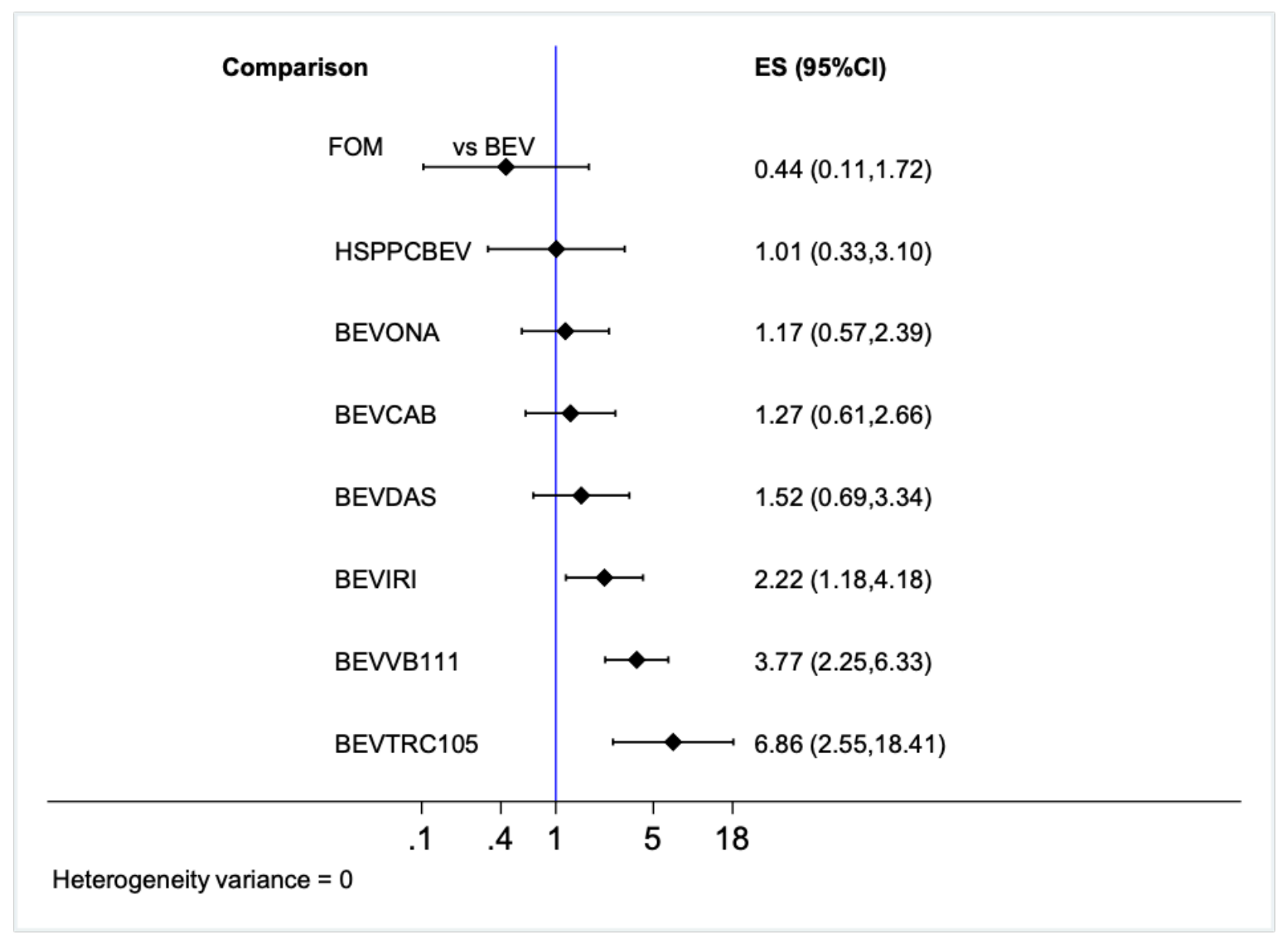

In terms of ranking, fotemustine ranked best with fewest severe adverse events, BEV ranked second, BEV + HSPPV96 vaccine ranked third, BEV + ONA ranked fourth, BEV + CAB ranked fifth, BEV + DAS ranked sixth, $B E V+I R I$ ranked seventh, $B E V+V B 111$ ranked eighth and $\mathrm{BEV}+\mathrm{TRC} 105$ ranked worst.

\section{Brief economic commentary}

For this brief economic commentary, we summarise the results of identified studies based upon what the study authors have said. These studies have not been critically appraised, and the studies may have used methods that are not consistent with accepted practice. For this reason and because the studies are conducted at different times and in different places, we do not attempt to draw any firm or general conclusions regarding the relative costs or efficiency of the different strategies to manage recurrent glioma.

The results of the economic search yielded four economic evaluations that compare the costs and benefits of the management of recurrent glioma. Three of the studies were reported to be cost-effectiveness analyses (Conen 2017; RuizSanchez 2016; Voigt 2016). The other study was reported to be a cost-effectiveness analysis and cost-benefit analysis (Roussakow 2017). The studies were all conducted in different countries. One study was conducted in Switzerland (Conen 2017); one in Spain (Ruiz-Sanchez 2016); one in the USA (Voigt 2016); and one in Germany (Roussakow 2017). Two of the studies assessed the use of bevacizumab (Conen 2017; Ruiz-Sanchez 2016); one study assessed modulated electrohyperthermia concurrent to dosedense temozolomide (Roussakow 2017); and one assessed the value of laser interstitial thermal therapy (LITT) where maximal safe resection may not be feasible (Voigt 2016).

Conen 2017 is a study (reported in a conference abstract) that retrospectively used data from a GBM database over a five-year period to assess the cost-effectiveness of the use of bevacizumab in recurrent GBM. The study used a sample of 82 newly diagnosed GBM patients, of which 75 had a first line treatment, 36 had a second line treatment and 14 had a third line therapy. Forty per cent of patients were treated with bevacizumab at first or second recurrence. The authors conclude that bevacizumab treatment increased the overall treatment costs by 1.7 times. The populationadjusted incremental cost-effectiveness ratio (ICER) was CHF (Swiss francs) 75,669 per life-year gained (the price year was not stated). The authors conclude that patients who received bevacizumab treatment for GMB recurrences had longer overall survival and longer quality-adjusted survival at costs below the accepted threshold of CHF 100,000 per life year gained. The authors state that whether this estimated increase in lifespan is a direct result of bevacizumab treatment or a consequence of a selection bias needs to be addressed prospectively.

Ruiz-Sanchez 2016 carried out a cost-effectiveness analysis on the bevacizumab-irinotecan regimen in GBM recurrences in a 
retrospective cohort study design with a control group. The intervention group included patients diagnosed with primary GBM between January 2001 and December 2011 in the Principality of Asturias (Spain) and treated in the Central University Hospital of Asturias (HUCA; Oviedo, Spain). The control cohort included all patients treated with TMZ between January 2001 and December 2006. There were 151 patients in the non-bevacizumab control cohort and 52 in the bevacizumab-irinotecan cohort. Costs, valued in 2014 EUR, were derived from the study data (including cost of the antineoplastic drug treatment, cost of the antineoplastics, administration and monitoring of administration and premedication). In the cohort with the regimen that included bevacizumab-irinotecan, the final cost for the 36 patients treated stood at EUR 629,278. The cost in the control cohort was EUR 16,771 . In this way, increasing survival by 4.4 months for 36 patients came to EUR 612,506 , meaning an additional cost of EUR 46,402 per person for each year of life gained. The authors conclude that bevacizumab-irinotecan is an effective therapy but it is not cost-effective. As such, they do not recommend adoptions by their specific local public health system.

The analysis by Voigt 2016 carried out a model-based analysis that did not primarily focus on recurrent glioma, but did include a sensitivity analysis focusing on the effects of recurrence, and the subsequent impact of that on patient and cost outcomes. A decision tree was developed to evaluate the cost-effectiveness of using brain laser interstitial thermal therapy (LITT) versus current treatments. The model was purported to adopt the societal perspective; the included costs and benefits are primarily healthcare based, however, and do not include any wider costs. The decision tree evaluated the initial procedure and the resultant outcome (i.e. gross total resection, subtotal resection) using probabilities as identified in the literature. Costs are presented in 2015 US dollars (USD). Patients were followed through the treatment decision tree until they died. The incremental cost per life year gained was USD 48,552 when compared to biopsy. This authors conclude this is higher than is acceptable using an "International Threshold" of USD 32,575/LYG (which is based on Spanish systematic review of Barrios 2012) but acceptable from US threshold of USD 50,000/LYG. A one-way sensitivity analysis was carried out to assess how GBM recurrence affects this incremental cost-effectiveness. The authors report that the higher the occurrence of local GBM recurrence (vs. diffuse recurrence), the more likely brain LITT was to be costeffective. This was based on willingness to pay (WTP) of USD 2714 per month based on the "International Threshold".

Roussakow 2017 assessed the efficacy and cost-effectiveness of modulated electrohyperthermia ( $\mathrm{mEHT}$ ) concurrent to dose-dense temozolomide (ddTMZ) 21/28 days regimen to five pooled ddTMZ 21/28 days cohorts (114 patients) enrolled between 2008 and 2013. A retrospective clinical and economic evaluation was based on the comparison and effect-to-treatment analysis (ETA) of a retrospective, single-arm study performed in two German centres between 2000 and 2005. The results of the regression analysis show the ddTMZ+mEHT cohort did not significantly improve mean survival time (mST) against the pooled ddTMZ 21/28 days cohorts. Using the effect-to-treatment analysis (ETA) suggests that mEHT significantly enhances the efficacy of the ddTMZ 21/28 days regimen, with significantly less toxicity and an estimated maximal attainable median survival time of 10.10 months. The author reported carrying out a cost-effectiveness analysis with results presented as a cost-utility ratio. They also reported carrying out a cost-benefit analysis. Costs were expressed in 2017 US dollars and Euros. Two cost models were used for the cost-effectiveness analysis: conditionally termed 'German' and 'US'. The first, socalled German option, is specific for a high-income country with rigid governmental regulation of the medical market, which leads to relatively low prices for pharmaceuticals with low variance. The second, so-called US option, is specific for a high-income country with lower governmental regulation, which leads to relatively high prices for pharmaceuticals with higher variance. The cost-utility ratio presented found that the ddTMZ+mEHT regimen, both in the German (EUR 19,871 per QALY $(95 \% \mathrm{Cl} 17,719$ to 22,024$)$ and the US (USD 32,704/QALY (95\% Cl 27,215 to 38,193) models were less than that of the comparator. The sources of the utility values and how these QALY values are derived are not reported. The purported costeffectiveness analysis and cost-benefit analysis only consider costs, not natural units or a monetary valuation of benefits and, thus, are in fact cost analysis, meaning that these elements of the study are only partial economic evaluations.

In summary, the economic evidence identified in this review found conflicting evidence on the use of bevacizumab in recurrent GBM. Of the two studies which evaluated its use, Conen 2017 reported it to be a cost-effective intervention, whereas RuizSanchez 2016 did not. Voigt 2016 estimated the cost effectiveness of the use of brain LITT versus current treatments and concluded that it improves survival at a cost which appears to be of good value to society according to US thresholds for good value. Roussakow 2017 reported evidence on the cost-effectiveness of modulated electrohyperthermia ( $\mathrm{mEHT}$ ) concurrent to dose-dense temozolomide (ddTMZ) and concluded that ddTMZ+mEHT is costeffective, budget-saving and profitable, although methods used are not consistent with definitions of the different types of economic evaluation. Economic studies of most treatments evaluated in this review are lacking.

\section{DISCUSSION}

\section{Summary of main results}

We included 34 RCTs and 8 non-RCTs involving 5236 patients with progressive/recurrent GBM; 20 studies involved patients with first recurrences and the remainder involved patients with subsequent recurrence or the study sample comprised patients with mixed recurrences (e.g. first, second and/or third recurrences). Several studies lacked suitable data and we could not connect them in the network meta-analyses (NMA), hence we did not grade evidence from these single studies and nonrandomised studies. We judged most RCTs to be at a low risk of bias and NRSs at high risk of bias. Most interventions were evaluated in single studies and included trials of systemic chemotherapy agents, re-operation, re-irradiation, anti-angiogenic agents, antibody therapies, tumour-treating fields, and vaccines alone or in combination. For first recurrence, 11 interventions (involving 9 RCTs and 1931 participants) were connected in the network for overall survival (OS), and eight (involving 7 RCTs and 1500 participants) in the network for progression-free survival (PFS). No studies in the NMA evaluated surgery, re-irradiation, PCV (procarbazine, lomustine, vincristine), TMZ re-challenge or best supportive care. We could not perform NMA for second or later recurrence due to insufficient data. Quality of life data were sparse. Only one NRS evaluated best supportive care. 


\section{First recurrence (NMA findings)}

Median overall survival (OS) across included studies in the NMA ranged from 5.5 to 12.6 months and median PFS across included studies ranged from 1.5 months to 4.2 months. We found no highcertainty evidence that any treatments tested were better than lomustine, including the following.

\section{Bevacizumab plus lomustine}

Evidence suggested that there is probably little or no difference in OS between bevacizumab (BEV) combined with lomustine (LOM) and LOM monotherapy (HR 0.91, 0.75 to 1.10 ; moderate-certainty evidence).

Low-certainty evidence suggested that BEV + LOM may improve PFS compared with LOM monotherapy ( $\mathrm{HR} 0.57,95 \% \mathrm{Cl} 0.44$ to 0.74 ) and more evidence is needed.

\section{Bevacizumab monotherapy}

Low-certainty evidence suggested there may be little or no difference in OS between BEV and LOM monotherapies (HR 1.22, $95 \% \mathrm{Cl} 0.84$ to 1.76 ) and that there may be little or no difference in PFS between BEV and LOM monotherapies ( $\mathrm{HR} 0.90,95 \% \mathrm{Cl} 0.58$ to 1.38; low-certainty evidence); more evidence is needed.

\section{Regorafenib (REG)}

Evidence suggested that REG may improve OS compared with LOM but more evidence is needed ( $\mathrm{HR} 0.50,95 \% \mathrm{Cl} 0.33$ to 0.76 ; lowcertainty evidence). Evidence on PFS was very low certainty.

\section{Temozolomide (TMZ) plus Depatux-M (ABT414)}

With regard to OS, low-certainty evidence suggested that TMZ plus ABT414 may be more effective than LOM (HR $0.66,95 \% \mathrm{Cl} 0.47$ to 0.92 ) and may be more effective than BEV (HR $0.54,95 \% \mathrm{Cl} 0.33$ to 0.89 ; low-certainty evidence) but more evidence is needed.

\section{Fotemustine (FOM)}

Evidence suggests that FOM and LOM may have similar effects on OS (HR $0.89,95 \% \mathrm{Cl} 0.51$ to 1.57 , low-certainty evidence).

\section{Bevacizumab and irinotecan (IRI)}

Evidence on BEV + irinotecan (IRI) versus LOM for both OS and PFS is very uncertain.

Evidence on BEV + IRI versus BEV monotherapy suggested that there is probably little or no difference between these options for OS (HR $0.95,95 \% \mathrm{Cl} 0.70$ to 1.30 ; moderate-certainty evidence) and PFS (HR $0.95,95 \% \mathrm{Cl} 0.70$ to 1.30 ; moderate-certainty evidence).

Treatments were ranked according to effectiveness on OS as follows: FOM ranked first, BEV + LOM ranked second, LOM ranked third, BEV + IRI ranked fourth and BEV ranked fifth. It is important to note that ranking does not take into account the certainty of the evidence, which indicated that there was little or no difference between BEV + LOM and LOM, probably little or no difference between FOT and LOM, and probably little or no difference between $\mathrm{BEV}+\mathrm{IRI}$ and $\mathrm{BEV}$.

\section{Other interventions for first recurrence}

\section{Re-operation with or without re-irradiation and chemotherapy}

Three non-randomised studies evaluated re-operation versus no re-operation with or without re-irradiation and chemotherapy and these suggested possible survival advantages with re-operation within the context of being able to select suitable candidates for reoperation (Azoulay 2017; Scorsetti 2015; Suchorska 2016).

\section{Novel agents}

Findings of a small pilot study that evaluated a cannabidiol:delta-9tetrahydrocannabinol (CBD:THC) oro-mucosal spray compared with placebo suggested that survival may be improved with CBD:THC among people receiving dose-intense TMZ (Twelves 2017).

\section{Second or later recurrence}

Data on second and subsequent recurrence was sparse.

\section{Bevacizumab monotherapy}

One non-randomised study compared BEV with best supportive care for people with chemorefractory disease (second and third recurrence) and showed a survival advantage with BEV; the study was at a high risk of bias, however, as participants selected their treatments and many in the BEV arm also received radiotherapy.

\section{Radiotherapy plus bevacizumab}

Limited evidence from three heterogeneous studies (different control groups and populations with different levels of GBM recurrences) reported findings of improved PFS or OS with this intervention for all or for selected candidates. More evidence on radiotherapy with and without $\mathrm{BEV}$ is needed.

\section{Tumour-treating fields}

Evidence from one RCT suggested that there may be little difference in effects on PFS or OS of tumour-treating fields (TTF) compared with physician's choice of treatment in this context.

\section{Severe adverse events (SAEs)}

Two distinct networks were constructed around LOM (5 RCTs, 6 interventions, 1024 participants) and BEV (8 RCTs, 9 interventions, 1044 participants). In the LOM network, LOM ranked best and REG second best. BEV + LOM were associated with significantly greater risk of SAEs than LOM monotherapy (RR $2.51,95 \% \mathrm{Cl} 1.72$ to 3.66 , high-certainty evidence), and ranked joint worst with CED + LOM.

The BEV network comprised mainly novel treatments added to BEV compared with BEV. In general, adding treatments to bevacizumab was associated with a higher frequency of SAEs compared with BEV monotherapy. FOM ranked best, BEV ranked third and BEV + IRI ranked seventh. Other ranked treatments were clinically ineffective. The SAE network connections did not facilitate ranking lomustine and bevacizumab against each other.

\section{Quality of life (QoL)}

Quality of life data reported in seven studies of different interventions were sparse and unreliable, mainly due to high dropout rates. 


\section{Overall completeness and applicability of evidence}

The 2015 JLA priority question was "In second recurrence glioblastoma, what is the effect of further treatment on survival and quality of life, compared with best supportive care?" (JLA 2015). We found little good-quality evidence that addressed this question as the one study that compared bevacizumab with best supportive care was at a high risk of bias (Cuncannon 2019). Evidence on other interventions, such as radiotherapy, systemic anti-cancer agents and best supportive care, was lacking. We found only one small study of cannabinoids, which have shown promising anti-cancer functions in GBM (Dumitru 2018), and the single study evaluating a ketogenic diet was at high risk of bias (Santos 2018); these types of interventions are of interest and high-quality RCTs on their effects in recurrent GBM are needed (Martin-McGill 2018).

Other evidence was very incomplete and the best treatment options compared with each other, even for first recurrence, remain uncertain. We found no RCTs comparing the commonly used regimen of $P C V$ (procarbazine, lomustine and vincristine) and lomustine, or TMZ re-challenge. One trial that employed TMZ rechallenge used it in combination with a novel agent (Depatux-M/ ABT414) and, although patients in this arm experienced improved survival relative to the control group who received LOM (73\% of control participants) or TMZ ( $27 \%$ of control participants), it was not possible to determine whether these effects were due to the TMZ or ABT414 component of the treatment, or both (van den Bent 2018).

With respect to people with second or later recurrence, among included studies the following interventions have shown potential (see Table 1) and, although it was not possible to conduct a NMA for second recurrence, they appear to warrant further investigation, bearing in mind that combination treatments are frequently associated with a higher risk of severe adverse events: radiotherapy; radiotherapy + bevacizumab; radiotherapy + APG101; bevacizumab + temozolomide; and bevacizumab + irinotecan.

\section{Quality of the evidence}

Quality of the evidence on lomustine with or without bevacizumab and bevacizumab monotherapy was generally of a moderate to high quality; these interventions had the most data and trials were at low risk of bias. Quality of evidence on other interventions was often from single studies and, therefore, tended to be of a lower quality due to the sparse data and open-label design of many of the phase 2 trials. Most included studies evaluated novel agents that were compared with or added to lomustine or bevacizumab and many novel agents tested in this patient population have not been investigated further in phase 3 trials because the early phase studies failed. A recent exception is regorafenib, which showed potential survival benefits compared with lomustine in a phase 2 trial. This evidence was of a generally low quality due to sparse data from a single, open-label study. A phase 3 trial of this intervention among patients with first recurrence of GBM is ongoing (NCT03970447 2019b). Another intervention for which the evidence was generally graded low-certainty is ABT414 (Depatux-M) + TMZ, and more evidence on these novel interventions is needed.

We did not grade the evidence on second recurrence because either the novel interventions did not show a clinical benefit, e.g. TRC105 + BEV (Galanis 2017), or narrative findings were based mainly on conference abstracts at unclear risk of bias and/or non-randomised studies that were at high risk of bias, for example radiotherapy and bevacizumab (Cuncannon 2019; Modh 2018; Tsien 2019).

\section{Potential biases in the review process}

We aimed to provide a balanced independent evaluation on this topic across a large number and wide range of interventions assessed since 2005, when the Stupp regimen became the standard of care for treatment of newly diagnosed GBM. We are mindful that the review process itself may introduce bias. We took steps to minimise the potential for such bias by ensuring that at least two members of the review team, working independently, screened titles identified by the search strategy, assessed full texts of reports for potentially eligible studies, extracted data and assessed risk of bias. Where we had any doubt, or where there was discrepancy between reviewers, we consulted the wider review team.

We acknowledge that a potential bias may have been introduced by including the TMZ/LOM arm of van den Bent 2018 in the LOM treatment node of our NMAs. This three-arm trial evaluated ABT414 (Depatux-M) versus ABT414 + TMZ versus TMZ or LOM. At the time of the analysis it was unclear what proportion of the participants in the TMZ/LOM arm had received LOM as limited findings were reported in conference abstracts. To investigate the effects of including this trial, we performed a sensitivity analysis by excluding this trial from analyses. This did not change the treatment rankings of LOM or the other treatments, and we concluded that it was unlikely that bias was introduced by including this trial in the NMA. Full details of this trial have since been published showing that 21 out of 77 participants received TMZ and the rest, 56 out of 77 or $73 \%$, received LOM (van den Bent 2020).

\section{Agreements and disagreements with other studies or reviews}

A study of patients from eight consecutive phase 2 clinical trials conducted in the USA between 1986 and 1995 showed that the median progression-free survival time for recurrent GBM was 9 weeks (95\% Cl 8 to 10 weeks) and the median OS time was 25 weeks (95\% 21 to 28 weeks) (Wong 1999). With reference to Table 1 , the review findings suggest that median survival for people with recurrent GBM in clinical trials in the post-Stupp era may not have improved substantially. For people with a first recurrence, median PFS ranged from 1.5 to 4.2 months (6.5 to 18.3 weeks) across included study arms; and median OS ranged from 5.5 months to 12.6 months ( 23.9 months to 54.8 months).

\section{Bevacizumab}

With regard to bevacizumab, our findings are in agreement with other reviews, which have concluded that bevacizumab has little or no effect on overall survival in patients with recurrent GBM (Ameratunga 2018; Lombardi 2017). We found that bevacizumab improved progression-free survival but not overall survival compared with lomustine monotherapy. Progression-free survival is a less reliable outcome in this context compared with overall survival because pseudo-response can occur in which contrast-enhancing disease may seem improved or stable with bevacizumab when it is not. When bevacizumab was combined with lomustine, we also found an increased risk of severe adverse events; thus our findings suggest that the net clinical effect of bevacizumab added to lomustine may not necessarily be one of overall benefit and such combinations need to be carefully considered. We found no evidence of benefit with the bevacizumab- 
irinotecan combination in recurrent GBM and agree with the AbdelRahman 2015 review, that this regimen should be limited to a clinical trial setting until better evidence is available. Evidence on the effectiveness of BEV combined with re-irradiation is uncertain and needs further study.

\section{TMZ re-challenge}

We included two RCTs that evaluated TMZ in recurrent GBM: one in combination with ABT414 (van den Bent 2018); and the other in combination with bevacizumab (Gilbert 2017). These data were insufficient to draw conclusions on the effectiveness of TMZ rechallenge, which may be more effective for MGMT methylated tumours compared with other options.

An excluded study, Sun 2013, was an RCT conducted in patients with recurrent GBM or anaplastic astrocytoma comparing TMZ with semustine (Me-CCNU). Results were not reported separately for the GBM subgroup. Six-month PFS for the mixed population was $78.9 \%$ in the TMZ group compared with $55.9 \%$ in the Me-CCNU group ( $P$ $<0.05$ ) and study authors concluded that TMZ was better than MeCCNU with mostly mild adverse events.

Weller 2015 was a TMZ re-challenge study that compared two maintenance TMZ cycles in an RCT of 105 patients with recurrent GBM. It was not suitable for inclusion in this review because it was a dose-finding study (both arms received TMZ; one week on, one week off, versus three weeks on, one week off). Median time to treatment failure was longer among patients with MGMTmethylated tumours compared to those with MGMT-unmethylated tumours (3.2 months vs 1.8 months) but not significantly different between the treatment arms (median of $\sim 2$ months). Investigators concluded that TMZ re-challenge should no longer be used in patients with recurrence of MGMT-unmethylated tumours but that it may be appropriate for those with MGMT-unmethylated tumours at first recurrence.

\section{Re-operation and/or re-irradiation}

We found little evidence on the effectiveness of re-operation and re-irradiation. Similarly, other reviews have highlighted the need for high-quality RCTs of re-irradiation for recurrent GBM to be conducted (Kim 2019; Kazmi 2019). Evaluating limited evidence from 50 non-comparative studies, Kazmi 2019 found that re-irradiation may improve survival with relatively low toxicity. However, the best salvage radiotherapy regimen in this context remains to be defined. Kim 2019 highlights that narrow margins should be observed to limit irradiation of normal brain tissue. In addition, it has been suggested that prognostic scoring that makes use of MGMT methylation, age, tumour volume at recurrence and other predictive biomarkers could be used to facilitate selection of patients to different treatment options (Chapman 2019; Kim 2019).

\section{Immunotherapies}

Findings from this review show that none of the treatments that have been developed to harness the immune system to target cancer have had demonstrable clinical success in recurrent GBM. Arguably, bevacizumab is the only agent to date that may have an effect equivalent to established systemic chemotherapeutic agents, such as lomustine. It has been suggested that surgical debulking and localised delivery may enhance the effect of immunotherapies in recurrent GBM and more research in this area is anticipated (Brown 2018).

\section{AUTHORS' CONCLUSIONS}

\section{Implications for practice}

Based on the available evidence for people with a first recurrence of GBM previously treated with surgery and chemoradiotherapy (Stupp protocol), lomustine (LOM) monotherapy appears to be the best chemotherapy option. Findings suggested that adding bevacizumab to lomustine therapy probably does not improve overall survival and is associated with a significantly greater risk of severe adverse events. We found no evidence on TMZ re-challenge or PCV, two commonly used salvage regimens, in this context. Reoperation with or without re-irradiation and chemotherapy may be suitable for selected candidates.

In the course of conducting the review, we had hoped to answer the JLA question on best treatments for second recurrence; however, although several studies included people with a second recurrence, data were usually not separately analysed and reported for this subgroup. We found little reliable evidence on re-irradiation with or without bevacizumab and on best supportive care. The role of tumour-treating fields is also uncertain.

While there is an acceptance of the need to develop and test new agents, combination treatments for recurrent GBM are likely to be associated with a higher risk of severe adverse events than monotherapy and people should be informed of this when deciding whether or not to participate in such clinical trials.

The cost-effectiveness of different treatment options for recurrent GBM remains unclear as economic studies in this field are lacking.

\section{Implications for research}

Findings of this review have highlighted the following research questions in this field. Trial participant randomisation and reporting of findings should be stratified by first and second recurrence. Prognostic scoring to select participants to different trials may be worthwhile.

- For patients with first or second recurrence, what are the effects of PCV versus lomustine, or lomustine or PCV versus TMZ rechallenge?

- For patients with first or second recurrence, what are the effects of radiotherapy or bevacizumab + radiotherapy compared with lomustine?

- Does delaying BEV to chemorefractory disease extend survival and improve quality of life beyond best supportive care alone?

- For patients with resectable tumours, what are the effects of reoperation?

- What are patients' and health care professionals' experiences and views on treatment of recurrent GBM at first and subsequent recurrences?

We identified several ongoing trials. These include a trial of bevacizumab + dose-dense TMZ versus bevacizumab alone (JCOG1308C 2019); surgery followed by second-line therapy versus second-line therapy alone (NCT02394626 2015); and a phase 3 trial of regorafenib versus lomustine (NCT03970447 2019b). Another ongoing trial is evaluating the effects of early palliative care (STEP care) among patients with various cancers including glioblastoma (ACTRN12617000534381 2017). 
Early studies of some oncolytic virus treatments and vaccines have shown promise (e.g. see Ji 2016; Lang 2018; Reardon 2020) and further clinical trials of these therapies are anticipated. Alternative interventions, such as cannabinoid treatments and dietary measures, also need further study. Studies should evaluate economic outcomes.

\section{A C K N OWLEDGEMENTS}

We thank Robin Grant, Co-ordinating Editor, and Gail Quinn and Clare Jess, Managing Editors from Gynaecological, Neuro-oncology and Orphan Cancers (GNOC), for their advice and support in the preparation of this review. We also thank the Information Specialist, Jo Platt, for designing the search strategy; Imogen
Lawrie for assisting with study selection and data extraction; Therese Dowswell for providing author support; and Andy Bryant for conducting the network meta-analysis.

This project is supported by the National Institute for Health Research (NIHR), via Cochrane Programme Grant funding - 16/144 to Cochrane Gynaecological, Neuro-oncology and Orphan Cancers. The views and opinions expressed herein are those of the review authors and do not necessarily reflect those of the Systematic Reviews Programme, NIHR, National Health Service, or the Department of Health.

The authors and GNOC team are grateful to the following peer reviewers for their time and comments: Helen Bulbeck, Michael Hart and Fiona McKevitt. 


\section{R E F E R E N C E S}

\section{References to studies included in this review}

Azoulay 2017 \{published data only\}

* Azoulay M, Santos F, Shenouda G, Petrecca K, Oweida A, Guiot MC, et al. Benefit of re-operation and salvage therapies for recurrent glioblastoma multiforme: results from a single institution. Journal of Neuro-oncology 2017;132(3):419-26.

\section{Batchelor 2013 \{published data only\}}

* Batchelor TT, Mulholland P, Neyns B, Nabors LB, Campone M, Wick $A$, et al. Phase III randomized trial comparing the efficacy of cediranib as monotherapy, and in combination with lomustine, versus lomustine alone in patients with recurrent glioblastoma. Journal of Clinical Oncology 2013;31(26):3212-8.

\section{Bloch 2017 \{published data only\}}

* Bloch O, Shi Q, Anderson SK, Knopp M, Raizer J, Clarke J, et al. Alliance a071101: a phase II randomized trial comparing the efficacy of heat shock protein peptide complex-96 (HSPPC-96) vaccine given with bevacizumab versus bevacizumab alone in the treatment of surgically resectable recurrent glioblastoma. Neuro-oncology 2017;19(suppl 6):vi29. [DOI: 10.1093/neuonc/ nox168.110]

\section{Brandes 2016a \{published data only\}}

Brandes AA, Carpentier AF, Kesari S, Sepulveda J, Wheeler H, Chinot OL, et al. A phase II study of galunisertib monotherapy or galunisertib plus lomustine compared to lomustine monotherapy in recurrent glioblastoma. Journal of Clinical Oncology 2015;33(15):SUPPL. 1.

* Brandes AA, Carpentier AF, Kesari S, Sepulveda-Sanchez JM, Wheeler HR, Chinot O, et al. A Phase II randomized study of galunisertib monotherapy or galunisertib plus lomustine compared with lomustine monotherapy in patients with recurrent glioblastoma. Neuro-oncology 2016;18(8):1146-56.

\section{Brandes 2016b \{published data only\}}

* Brandes AA, Finocchiaro G, Zagonel V, Reni M, Caserta C, Fabi A, et al. AVAREG: a phase II, randomized, noncomparative study of fotemustine or bevacizumab for patients with recurrent glioblastoma. Neuro-oncology 2016;18(9):1304-12.

\section{Brandes 2018 \{published data only\}}

* Brandes AA, Gil-Gil M, Saran F, Carpentier AF, Nowak AK, Mason W, et al. A randomized Phase II Trial (TAMIGA) evaluating the efficacy and safety of continuous bevacizumab through multiple lines of treatment for recurrent glioblastoma. Oncologist 2018;24(4):521-8.

\section{Brown 2016 \{published data only\}}

* Brown N, McBain C, Nash S, Hopkins K, Sanghera P, Saran F, et al. Multi-center randomized phase ii study comparing cediranib plus gefitinib with cediranib plus placebo in subjects with recurrent/progressive glioblastoma. PLoS One 2016;11(5):e0156369.

\section{Cloughesy 2017 \{published data only\}}

* Cloughesy T, Finocchiaro G, Belda-Iniesta C, Recht L, Brandes AA, Pineda E, et al. Randomized, double-blind, placebo-controlled, multicenter phase II study of onartuzumab plus bevacizumab versus placebo plus bevacizumab in patients with recurrent glioblastoma: efficacy, safety, and hepatocyte growth factor and 06-methylguanine-DNA methyltransferase biomarker analyses. Journal of Clinical Oncology 2017;35(3):343-51.

\section{Cloughesy 2018 \{published data only\}}

Cloughesy T, Brenner AJ, Butowski N, Cohen YC, LowentonSpier N, Wen P. Results of the globe study: a phase 3, randomized, controlled, double-arm, open label, multi-center study of VB-111 combined with bevacizumab vs. bevacizumab monotherapy in patients with recurrent glioblastoma. Neurooncology 2018;20(suppl_6):vi4-5.

* Cloughesy TF, Brenner A, de Groot JF, Butowski NA, Zach L, Campian Jl, et al. A randomized controlled phase III study of VB-111 combined with bevacizumab vs. bevacizumab monotherapy in patients with recurrent glioblastoma (GLOBE). Neuro-oncology 2020;22(5):705-17. [DOI: 10.1093/neuonc/ noz232]

NCT02511405. A phase 3, pivotal trial of VB-111 plus bevacizumab vs. bevacizumab in patients with recurrent glioblastoma (GLOBE) [A phase 3, randomized, controlled, double-arm, open-label, multi-center study of VB-111 combined with bevacizumab vs. bevacizumab monotherapy in patients with recurrent glioblastoma]. www.clinicaltrials.gov/ct2/show/ NCT02511405 (first received 30 July 2015).

\section{Cuncannon 2019 \{published data only\}}

* Cuncannon M, Wong M, Jayamanne D, Guo L, Cove N, Wheeler $\mathrm{H}$, et al. Role of delayed salvage bevacizumab at symptomatic progression of chemorefractory glioblastoma. BMC Cancer 2019;19(1):445. [DOI: 10.1186/s12885-019-5678-1]

\section{Dresemann 2010 \{published data only\}}

Dresemann G, Weller M, Rosenthal MA, Wedding U, Wagner W, Engel $\mathrm{E}$, et al. Imatinib in combination with hydroxyurea versus hydroxyurea alone as oral therapy in patients with progressive pretreated glioblastoma resistant to standard dose temozolomide. Journal of Neuro-oncology 2010;96(3):393-402.

\section{Duerinck 2018 \{published data only\}}

* Duerinck J, Du Four S, Bouttens F, Andre C, Verschaeve V, Van Fraeyenhove F, et al. Randomized phase II trial comparing axitinib with the combination of axitinib and lomustine in patients with recurrent glioblastoma. Journal of Neuro-oncology 2018;136(1):115-25.

Duerinck J, Du Four S, Bouttens F, Verschaeve V, Andre C, Van Fraeyenhove $F$, et al. Axitinib for the treatment of patients with recurrent glioblastoma, final results from a randomized phase II clinical trial. Neuro-oncology 2017;18(suppl_4):iv41-42. [DOI: 10.1093/neuronc/now188.142] [PMID: PMC5782638] 
Duerinck J, Du Four S, Bouttens F, Verschaeve V, Andre C, Van Fraeyenhove F, et al. Randomized phase II study of axitinib alone or combined with lomustine in patients with recurrent glioblastoma. Journal of Clinical Oncology 2016;34(15 suppl):2038.

Duerinck J, Du Four S, Vandervorst F, D'Haene N, Mercier M, Michotte A, et al. Randomized phase II study of axitinib versus physicians best alternative choice of therapy in patients with recurrent glioblastoma. Journal of Neuro-oncology 2016;128:147-55.

\section{Field 2015 \{published data only\}}

Field KM, King MT, Simes J, Espinoza D, Barnes EH, Sawkins K, et al. Health-related quality of life outcomes from CABARET: a randomized phase 2 trial of carboplatin and bevacizumab in recurrent glioblastoma. Journal of Neuro-oncology 2017;133(3):623-31.

* Field KM, Simes J, Nowak AK, Cher L, Wheeler H, Hovey EJ, et al. Randomized phase 2 study of carboplatin and bevacizumab in recurrent glioblastoma. Journal of Neuro-oncology 2015;17(11):1504-13.

Hovey EJ, Field KM, Rosenthal M, Nowak AK, Cher L, Wheeler $\mathrm{H}$, et al. Continuing or ceasing bevacizumab at disease progression: results from the CABARET study, a prospective randomized phase II trial in patients with recurrent glioblastoma. Journal of Clinical Oncology 2015;33(15_suppl):2003. [DOI: 10.1200/ jco.2015.33.15_suppl.2003]

Hovey EJ, Field KM, Rosenthal MA, Barnes EH, Nowak AK, Phal P, et al. Continuing or ceasing bevacizumab beyond progression in recurrent glioblastoma: an exploratory randomized phase II trial. Neuro-oncology Practice 2017;4(3):171-81.

\section{Friedman 2009 \{published data only\}}

Anonymous. Erratum: a phase II, randomized, non-comparative clinical trial of the effect of bevacizumab (BV) alone or in combination with irinotecan (CPT) on 6-month progression free survival (PFS6) in recurrent, treatment-refractory glioblastoma (GBM) (Journal of Clinical Oncology (2008) 26 (15S)). Journal of Clinical Oncology 2011;29(10):1394.

* Friedman HS, Prados MD, Wen PY, Mikkelsen T, Schiff D, Abrey LE, et al. Bevacizumab alone and in combination with irinotecan in recurrent glioblastoma. Journal of Clinical Oncology 2009;27(28):4733-40.

\section{Galanis 2017 \{published data only\}}

* Galanis E, Anderson SK, Butowski NA, Hormigo A, Schiff D, Tran DD, et al. NCCTG N1174: phase I/comparative randomized phase $(\mathrm{Ph})$ II trial of TRC105 plus bevacizumab versus bevacizumab in recurrent glioblastoma (GBM) (Alliance). In: Journal of Clinical Oncology. Vol. 35. 2017:2023.

NCT01648348. Bevacizumab with or without anti-endoglin monoclonal antibody TRC105 in treating patients with recurrent glioblastoma multiforme. clinicaltrials.gov/ct2/show/results/ NCT01648348 (first received 20 July 2012).

\section{Galanis 2019 \{published data only\}}

Galanis E, Anderson SK, Anastasiadis P, Tran DD, Jeyapalan SA, Anderson DM, et al. NCCTG N0872 (Alliance): a randomized placebo-controlled phase II trial of bevacizumab plus dasatinib in patients with recurrent glioblastoma (GBM). Journal of Clinical Oncology 2015;33(15_suppl 1):2004. [DOI: 10.1200/ jco.2015.33.15_suppl.2004]

* Galanis E, Anderson SK, Twohy EL, Carrero XW, Dixon JG, Tran DD, et al. A phase 1 and randomized, placebo-controlled phase 2 trial of bevacizumab plus dasatinib in patients with recurrent glioblastoma: Alliance/North Central Cancer Treatment Group N0872. Cancer 2019;125(21):3790-800.

\section{Gilbert 2017 \{published data only\}}

* Gilbert MR, Pugh SL, Aldape K, Sorensen AG, Mikkelsen T, Penas-Prado M, et al. NRG oncology RTOG 0625: a randomized phase II trial of bevacizumab with either irinotecan or dosedense temozolomide in recurrent glioblastoma. Journal of Neuro-oncology 2017;131(1):193-9.

\section{Heiland 2016 \{published data only\}}

Heiland DH, Masalha W, Franco P, Machein MR, Weyerbrock A. Progression-free and overall survival in patients with recurrent glioblastoma multiforme treated with last-line bevacizumab versus bevacizumab/lomustine. Journal of Neuro-oncology 2016;126(3):567-75.

\section{Kim 2015 \{published data only\}}

* Kim HR, Kim KH, Kong DS, Seol HJ, Nam DH, Lim DH, et al. Outcome of salvage treatment for recurrent glioblastoma. Journal of Clinical Neuroscience 2015;22(3):468-73.

\section{Kunwar 2010 \{published data only\}}

Kunwar S, Chang S, Westphal M, Vogelbaum M, Sampson J, Barnett $\mathrm{G}$, et al. Phase III randomized trial of CED of IL13PE38QQR vs Gliadel wafers for recurrent glioblastoma. Neurooncology 2010;12(8):871-81.

\section{Lombardi 2019 \{published data only\}}

EUCTR2014-003722-41-IT. Clinical trial to evaluate the regorafenib therapy in patients with brain tumor progression after standard therapy (Radiotherapy and Temozolomide) with or without bevacizumab. www.clinicaltrialsregister.eu/ctrsearch/trial/2014-003722-41/IT (first received 29 January 2015).

Lombardi G, Del Bianco P, Brandes AA, Eoli M, Ruda R, Ibrahim T, et al. Health-related quality of life (HRQoL) evaluation in the REGOMA trial: a randomized, phase II clinical trial analyzing regorafenib activity in relapsed glioblastoma patients. Journal of Clinical Oncology 2019;37(15 suppl):2045.

Lombardi G, De Salvo G, Ruda R, Franceschi E, Eoli M, Faedi M, et al. Updated results of REGOMA: a randomized, multicenter, controlled open-label Phase II clinical trial evaluating regorafenib in relapsed glioblastoma patients. Journal of Clinical Oncology 2018;36(15_suppl):2047.

Lombardi G, De Salvo GL, Brandes AA, Eoli M, Ruda R, Faedi M, et al. REGOMA: a randomized, multicenter, controlled open-label phase II clinical trial evaluating regorafenib activity in relapsed glioblastoma patients. Journal of 
Clinical Oncology 2017;15_suppl:v610. [DOI: 10.1200/ JCO.2017.35.15_suppl.TPS2085]

* Lombardi G, De Salvo GL, Brandes AA, Eoli M, Ruda R, Faedi M, et al. Regorafenib compared with lomustine in patients with relapsed glioblastoma (REGOMA): a multicentre, openlabel, randomised, controlled, phase 2 trial. Lancet Oncology 2019;20(1):110-9.

Lombardi G, De Salvo GL, Ruda R, Franceschi E, Eoli M, Faedi M, et al. Updated results of REGOMA: A randomized, multicenter, controlled open-label phase II clinical trial evaluating regorafenib in relapsed glioblastoma (GBM) patients (PTS). Journal of Clinical Oncology 2018;36(15_suppl):2047. [DOI: 10.1200/JCO.2018.36.15_suppl.2047]

NCT02926222. Regorafenib in relapsed glioblastoma (REGOMA) [Regorafenib in relapsed glioblastoma REGOMA study randomized, controlled open-label phase ii clinical trial]. clinicaltrials.gov/ct2/show/NCT02926222 (first received 6 October 2016).

\section{Modh 2018 \{published data only\}}

Modh A, Bergman D, Hanna R, Schultz L, Snyder J, Mikkelsen $T$, et al. Randomized prospective trial of stereotactic radiosurgery versus chemotherapy for recurrent malignant glioma after second-line chemotherapy. Neuro-oncology 2019; Conference: ARS 101st Annual Meeting. United States.103(5 Supplement):E17-8.

Modh A, Bergman D, Schultz L, Snyder J, Mikkelsen T, Ryu S, et al. Randomized prospective trial of stereotactic radiosurgery versus chemotherapy for recurrent malignant glioma after second-line chemotherapy. Neuro-oncology. Conference abstract. 23rd Annual Scientific Meeting and Education Day of the Society for Neuro-Oncology 2018;20(Supplement 6):vi226.

Walbert T, Modh A, Bergman D, Schultz L, Snyder J, Mikkelsen T, et al. Randomized prospective trial of stereotactic radiosurgery versus chemotherapy for recurrent malignant glioma after second-line chemotherapy. Neuro-oncology 2019; Conference: 71st Annual Meeting of the American Academy of Neurology, AAN 2019. United States. 92(15 Supplement 1).

\section{Narita 2019 \{published data only\}}

Arakawa Y, Nagane M, Hirose Y, Sasada T, Yamada A, Itoh K, et al. Randomized, double-blind, phase III trial of a personalized peptide vaccination for recurrent glioblastoma patients. Cancer Science 2018;109:1126.

Fujimaki T, Itoh K, Terasaki M, Narita Y, Arakawa Y, Sugiyama K, et al. Trials of a personalized peptide vaccine (ITK-1) for patients with recurrent or progressive glioblastoma (GBM). In: Neurooncology. Vol. 19. 2017:iii52.

Narita Y, Arakawa Y, Yamasaki F, Nishikawa R, Aoki T, Kanamori M, et al. A randomized, double-blind, phase III trial of personalized peptide vaccination for recurrent glioblastoma. Neuro-oncology 2019;21(3):348-59.

\section{Omuro 2018 \{published data only\}}

* Omuro A, Vlahovic G, Lim M, Sahebjam S, Baehring J, Cloughesy T, et al. Nivolumab with or without ipilimumab in patients with recurrent glioblastoma: results from exploratory phase I cohorts of CheckMate 143. Neuro-oncology 2018;20(5):674-86.

Reardon DA, Omuro A, Brandes AA, Rieger J, Wick A, Sepulveda J, et al. Randomized phase 3 study evaluating the efficacy and safety of nivolumab vs bevacizumab in patients with recurrent glioblastoma: CheckMate 143. In: Neurooncology. Conference: 5th Quadrennial Meeting of the World Federation of Neuro-oncology Societies, WFNOS. Switzerland. Vol. 19. 2017:iii21.

Sampson JH, Vlahovic G, Sahebjam S, Omuro AMP, Baehring JM, Hafler DA, et al. Preliminary safety and activity of nivolumab and its combination with ipilimumab in recurrent glioblastoma (GBM): CheckMate 143. In: Journal of Clinical Oncology. Conference abstract. Vol. 33. 2015:3010.

\section{Puduvalli 2018 \{published data only\}}

* Phase I/II adaptive randomized trial of bevacizumab versus bevacizumab plus vorinostat in adults with recurrent glioblastoma. ClinicalTrials.gov 2018:https://clinicaltrials.gov/ ct2/show/results/NCT01266031.

Puduvalli V, Yuan Y, Armstrong T, Wu J, Giglio P, Xu J, et al. A bayesian adaptive randomized phase ii trial of bevacizumab versus bevacizumab plus vorinostat in adults with recurrent glioblastoma final results, Conference Abstract: 23rd Annual Scientific Meeting and Education Day of the Society for Neurooncology. United States. In: Neuro-oncology. Vol. 20. 2018:vi13.

Puduvalli VK, Wu J, Yuan Y, Armstrong TS, Groves MD, Raizer JJ, et al. Brain tumor trials collaborative bayesian adaptive randomized phase II trial of bevacizumab plus vorinostat versus bevacizumab alone in adults with recurrent glioblastoma (BTTC-1102). In: Journal of Clinical Oncology. Vol. 33. 2015.

\section{Reardon 2011 \{published data only\}}

Reardon DA, Desjardins A, Peters K, Gururangan S, Sampson J, Rich JN, et al. Phase II study of metronomic chemotherapy with bevacizumab for recurrent glioblastoma after progression on bevacizumab therapy. Journal of Neuro-oncology 2011;103(2):371-9.

\section{Reardon 2015b \{published data only\}}

Reardon DA, Nabors LB, Mason WP, Perry JR, Shapiro W, Kavan $P$, et al. Phase $1 /$ randomized phase II study of afatinib, an irreversible ErbB family blocker, with or without protracted temozolomide in adults with recurrent glioblastoma. Neurooncology 2015;17(3):430-9.

\section{Reardon 2018a \{published data only\}}

* Reardon DA, Lassman AB, Schiff D, Yunus SA, Gerstner ER, Cloughesy TF, et al. Phase 2 and biomarker study of trebananib, an angiopoietin-blocking peptibody, with and without bevacizumab for patients with recurrent glioblastoma. Cancer 2018;124(11):1438-48

Reardon 2018b \{published data only\} NCT02337491. Pembrolizumab +/- Bevacizumab for Recurrent GBM. ClinicalTrials.gov 2015. 
* Reardon DA, Nayak L, Peters KB, Clarke JL, Jordan JT, De Groot JF, et al. Phase II study of pembrolizumab or pembrolizumab plus bevacizumab for recurrent glioblastoma (rGBM) patients. In: Journal of Clinical Oncology. Conference abstract. Vol. 36. 2018:2006.

\section{Reardon 2020 \{published data only\}}

Reardon DA, Desjardins A, Vredenburgh JJ, O'Rouke DM, Tran DD, Fink KL. Rindopepimut with bevacizumab for patients with relapsed EGFRvIII-expressing glioblastoma (ReACT): results of a double-blind randomized phase II trial. Clinical Cancer Research 2020;26:1586-94.

Reardon DA, Schuster J, Tran DD, Fink KL, Nabors LB, Li G, et al. ReACT: overall survival from a randomized phase II study of rindopepimut (CDX-110) plus bevacizumab in relapsed glioblastoma. Journal of Clinical Oncology 2015;33(15):SUPPL. 1.

Reardon DA, Schuster JM, Tran DD, Fink KL, Nabors LB, Li G, et al. React: overall survival from a randomized phase II study of rindopepimut (CDX-110) plus bevacizumab in relapsed glioblastoma. In: Clinical Neurosurgery. Vol. 62. 2015:198-9.

Sampson JH, Desjardins A, Schuster J, Tran D, Fink K, Nabors L, et al. ReACT: a randomized phase II study of rindopepimut (CDX-110) plus bevacizumab in relapsed glioblastoma national brain tumor society mahaley award. In: Journal of Neurosurgery. Vol. 124. 2016:A1152.

\section{Santos 2018 \{published data only\}}

RBR-3byz2c. Evaluation of inflammatory substances in the blood of patients with recurrent glioblastoma in treatment with inhalation of perillyl alcohol associated with reduced carbohydrate diet and supplementation with omega 3. ICTRP Search Portal. World Health Organization 2018:RBR-3byz2c.

RBR-8x8fd9. Low sugar diet combined with nasal administration of perillyl alcohol: strategy therapy for resistant glioblastoma multiforme to chemotherapy and radiotherapy. ICTRP Search Portal. World Health Organization 2016.

* Santos JG, Souza da Cruz WM, Schonthal AH, D'Alincourt Salazar, Fontes CAP, Quirico-Santos T, et al. Efficacy of a ketogenic diet with concomitant intranasal perillyl alcohol as a novel strategy for the therapy of recurrent glioblastoma. Oncology Letters 2018;15:1263-1270.

\section{Scorsetti 2015 \{published data only\}}

Scorsetti M, Navarria P, Pessina F, Ascolese AM, D'Agostino G, Tomatis S, et al. Multimodality therapy approaches, local and systemic treatment, compared with chemotherapy alone in recurrent glioblastoma. BMC Cancer 2015;15:486.

\section{Stupp 2012 \{published data only\}}

Stupp R, Wong ET, Kanner AA, Steinberg D, Engelhard H, Heidecke V, et al. NovoTTF-100A versus physician's choice chemotherapy in recurrent glioblastoma: a randomised phase III trial of a novel treatment modality. European Journal of Cancer 2012;48(14):2192-202.

\section{Suchorska 2016 \{published data only\}}

Wirsching HG, Tonn JC, Tabatabai G, Senft C, Hau P, Sabel MC, et al. Complete resection of contrast enhancing tumor volume is associated with improved survival in recurrent glioblastomaresults from the DIRECTOR trial. European Journal of Neurology 2016;23:921-2.

\section{Taal 2014 \{published data only\}}

Beije N, Kraan J, Taal W, van der Holt B, Oosterkamp HM, Walenkamp AM, et al. Prognostic value and kinetics of circulating endothelial cells in patients with recurrent glioblastoma randomised to bevacizumab plus lomustine, bevacizumab single agent or lomustine single agent. A report from the Dutch Neuro-oncology Group BELOB trial. British Journal of Cancer 2015;113(2):226-31.

Dirven $\mathrm{L}$, van den Bent MJ, Bottomley A, van der Meer N, van der Holt $B$, Vos MJ, et al. The impact of bevacizumab on health-related quality of life in patients treated for recurrent glioblastoma: results of the randomised controlled phase 2 BELOB trial. European Journal of Cancer 2015;51(10):1321-30.

* Taal W, Oosterkamp HM, Walenkamp AM, Dubbink HJ, Beerepoot LV, Hanse MC, et al. Single-agent bevacizumab or lomustine versus a combination of bevacizumab plus lomustine in patients with recurrent glioblastoma (BELOB trial): a randomised controlled phase 2 trial. The Lancet 2014;15(9):943-53.

\section{Tsien 2019 \{published data only\}}

Tsien C, Pugh S, Dicker AP, Raizer JJ, Matuszak MM, Lallana E, et al. Randomized phase II trial of re-irradiation and concurrent bevacizumab versus bevacizumab alone as treatment for recurrent glioblastoma (NRG Oncology/RTOG 1205): initial outcomes and RT plan quality report. In: International Journal of Radiation Oncology, Biology, Physics. Conference abstract. Vol. 105. Suppl 1. 2019:S78.

\section{Twelves 2017 \{published data only\}}

Twelves C, Short S, Wright S. A two-part safety and exploratory efficacy randomized double-blind, placebo-controlled study of a 1: 1 ratio of the cannabinoids cannabidiol and delta-9-tetrahydrocannabinol (CBD: tHC) plus dose-intense temozolomide in patients with recurrent glioblastoma multiforme (GBM). Journal of Clinical Oncology 2017;35(15):2046.

\section{van den Bent 2018 \{published data only\}}

Clement P, Van Den Bent M, Eoli M, Sepulveda JM, Walenkamp AME, Frenel JS, et al. Health related quality of life and neurological deterioration free survival in intellance 2/ EORTC trial 1410, a randomized phase ii study on ABT414 in recurrent EGFR amplified glioblastoma. In: Neuro-oncology. Vol. Conference: 22nd Annual Scientific Meeting and Education Day of the Society for Neuro-oncology. United States.19. 2017:vi211.

EUCTR2014-004438-24-GB. ABT-414 alone or ABT-414 plus temozolomide versus temozolomide or lomustine alone in subjects with recurrent glioblastoma. 2015. EU Clinical Trial Register. 
Van Den Bent M, Eoli M, Sepulveda JM, Smits M, Walenkamp AME, Frenel JS, et al. First results of the randomized phase ii study on depatux-m alone, depatux-m in combination with temozolomide and either temozolomide or lomustine in recurrent EGFR amplified glioblastoma: first report from intellance 2/eortc trial 1410. Neuro-oncology 2017; Conference: 22nd Annual Scientific Meeting and Education Day of the Society for Neuro-Oncology. United States.19(Supplement 6):vi316.

van den Bent M, Eoli M, Sepulveda JM, Smits M, Walenkamp AME, Frenel JS, et al. INTELLANCE 2/EORTC 1410 randomised phase II study of depatux-m alone and with temozolomide vs tmeozolomide or lomustine in recurrent EGFR amplified glioblastoma. Neuro-oncology 2020;22(5):684-93.

Van Den Bent M, French P, Eoli M, Sepulvado J, Walenkamp AME, Weller M, et al. Updated results of the intellance 2/EORTC trial 1410 randomized phase II study on depatux-m alone, depatux$m$ in combination with temozolomide (TMZ) and either TMZ or lomustine (LOM) in recurrent egfr amplified glioblastoma (NCT02343406). Neuro-oncology 2018;20:iii240-1.

Van Den Bent M, French P, Eoli M, Sepulveda J, Walenkamp AME, Frenel JS, et al. Two-year results of the intellance 2/eortc trial 1410 randomized phase ii study on depatux-m alone, depatux-m combined with temozolomide (TMZ) and either tmz or lomustine in recurrent EGFR amplified glioblastoma (NCT02343406). Neuro-oncology 2018;Conference: 23rd Annual Scientific Meeting and Education Day of the Society for Neuro-Oncology. United States. 20(Supplement 6):vi20.

* Van Den Bent MJ, French P, Eoli M, Sepulveda JM, Walenkamp AME, Frenel JS, et al. Updated results of the INTELLANCE 2/EORTC trial 1410 randomized phase II study on depatux-m alone, depatux-m in combination with temozolomide (TMZ) and either TMZ or lomustine (LOM) in recurrent EGFR amplified glioblastoma (NCT02343406). Neurooncology 2018;36(15).

\section{Weathers 2016 \{published data only\}}

Weathers SP, Han X, Liu DD, Conrad CA, Gilbert MR, Loghin ME, et al. A randomized phase II trial of standard dose bevacizumab versus low dose bevacizumab plus lomustine (CCNU) in adults with recurrent glioblastoma. In: Journal of Clinical Oncology. Conference abstract. Vol. 33. 15 SUPPL. 1. 2015:2005.

* Weathers SP, Han X, Lui DD, Conrad CA, Gilbert MR, Loghin ME, et al. A randomized phase II trial of standard dose bevacizumab versus low dose bevacizumab plus lomustine (NCCNU) in adults with recurrent glioblastoma. Journal of Neuro-oncology 2016;129(3):487-94.

\section{Wick 2010 \{published data only\}}

Wick W, Puduvalli VK, Chamberlain MC, van den Bent MJ, Carpentier AF, Cher LM, et al. Phase III study of enzastaurin compared with lomustine in the treatment of recurrent intracranial glioblastoma. Journal of Clinical Oncology 2010;28(7):1168-74.

\section{Wick 2014 \{published data only\}}

Ficke H, Hanke N, Kunz C, Wick W, Lehr T. Aunercept plus radiotherapy in relapsed glioblastoma. Update on five years overall survival of study NCT01071837 and development of a population PK - tumour growth inhibition - survival model. In: Neuro-oncology. 2018:vi3.

* Wick W, Fricke H, Junge K, Kobyakov G, Martens T, Heese O, et al. A phase II randomized study of weekly APG101+reirradiation versus reirradiation in progressive glioblastoma. Clinical Cancer Research 2014;20(24):6304-13.

Wick W, Krendyukov A, Junge K, Hbger T, Kunz C, Fricke H. Longitudinal analysis of quality of life following treatment with asunercept plus reirradiation versus reirradiation in progressive glioblastoma patients. In: Journal of Clinical Oncology. Vol. 37. 2019:Suppl 15.

Wick W, Krendyukov A, Junge K, Hbger T, Kunz C, Fricke H. Longitudinal analysis of quality of life following treatment with asunercept plus reirradiation versus reirradiation in progressive glioblastoma patients. Journal of Neuro-oncology 2019;145:531-40.

\section{Wick 2017 \{published data only\}}

Taphoorn M, Bottomley A, Coens C, Reijneveld J, Gorlia T, Brandes AA, et al. Health-related quality of life (HRQoL) in patients with progressive glioblastoma treated with combined bevacizumab and lomustine versus lomustine only (randomized phase iii EORTC study 26101). In: Neuro-oncology. Conference abstract. Vol. 18. 2016:vi157.

Taphoorn MJB, Bottomley A, Coens C, Reijneveld JC, Gorlia T, Brandes AA, et al. Health-related quality of life (HRQOL) in patients with progressive glioblastoma treated with combined bevacizumab and lomustine versus lomustine only (randomized phase III eortc study 26101). In: Neuro-oncology. Vol. 18. 2017:iv11-2.

* Wick W, Gorlia T, Bendszus M, Taphoorn M, Sahm F, Harting I, et al. Lomustine and bevacizumab in progressive glioblastoma. New England Journal of Medicine 2017;377(20):1954-1963.

Wick W, Stupp R, Gorlla T, Bendszus M, Sahm F, Bromberg JE, et al. Phase II part of EORTC study 26101: the sequence of bevacizumab and lomustine in patients with first recurrence of a glioblastoma. In: Journal of Clinical Oncology. Vol. 34. 2016:Suppl 15.

\section{References to studies excluded from this review}

Abacioglu 2011 \{published data only\}

Abacioglu U, Caglar HB, Yumuk PF, Akgun Z, Atasoy BM, Sengoz M. Efficacy of protracted dose-dense temozolomide in patients with recurrent high-grade glioma. Journal of Neurooncology 2011;103(3):585-93.

\section{Abdel-Rahman 2015 \{published data only\}}

Abdel-Rahman O, Fouad M. Irinotecan-based regimens for recurrent glioblastoma multiforme: [corrected] a systematic review. Expert Review of Neurotherapeutics 2015;15(11):1255-70.

\section{ACTRN12615001072505 2015 \{published data only\}}

ACTRN12615001072505. A phase II randomised placebocontrolled, double blind, multisite study of acetazolamide 
versus placebo for management of cerebral oedema in recurrent and/or progressive high grade glioma requiring treatment with dexamethasone - The ACED trial. www.anzctr.org.au/Trial/Registration/TrialReview.aspx? id=368253 (first received 19 August 2015).

\section{Ahluwalia 2018 \{published data only\}}

Ahluwalia M, Peereboom D, Schilero C, Forst D, Wong E, Wen P, et al. Randomized phase 2 open label study of nivolumab plus standard dose bevacizumab versus nivolumab plus low dose bevacizumab in recurrent glioblastoma. Neuro-oncology 2018;20((suppl_6)):vi234.

NCT03452579. Nivolumab plus standard dose bevacizumab versus nivolumab plus low dose bevacizumab in GBM. clinicaltrials.gov/ct2/show/NCT03452579 (first received 2 March 2018).

\section{Aoki 2016 \{published data only\}}

Aoki T, Arakawa Y, Ueba T, Oda M, Nishida N, Akiyama Y, et al. Phase I/II study of temozolomide plus nimustine chemotherapy for recurrent malignant gliomas: Kyoto neuro-oncology group. Neuro-oncology 2016;18((suppl_6)):vi2.

Aoki T, Arakawa Y, Ueba T, Oda M, Nishida N, Akiyama Y, et al. Phase I/II study of temozolomide plus nimustine chemotherapy for recurrent malignant gliomas. Neuro-oncology 2017;57(1):17-27.

\section{Bartsch 2005 \{published data only\}}

Bartsch R, Weitmann HD, Pennwieser W, Wenzel C, Muschitz S, Baldass $\mathrm{M}$, et al. Retrospective analysis of re-irradiation in malignant glioma: a single-center experience. Wiener klinische Wochenschrift 2005;117(23-4):821-6.

\section{Bogdahn 2011 \{published data only\}}

Bogdahn U, Hau P, Stockhammer G, Venkataramana NK, Mahapatra AK, Suri A, et al. Targeted therapy for high-grade glioma with the TGF- $\beta 2$ inhibitor trabedersen: results of a randomized and controlled phase llb study. Neuro-oncology 2011;13(1):132-42.

\section{Boiardi 2008 \{published data only\}}

Boiardi A, Silvani A, Eoli M, Lamperti E, Salmaggi A, Gaviani P, et al. Treatment of recurrent glioblastoma: can local delivery of mitoxantrone improve survival? Journal of Neuro-oncology 2008;88(1):105-13.

\section{Brada 2010 \{published data only\}}

Brada M, Stenning S, Gabe R, Thompson LC, Levy D, Rampling R, et al. Temozolomide versus procarbazine, lomustine, and vincristine in recurrent high grade glioma. Journal of Clinical Oncology 2010;28(30):4601-8.

\section{Brandes 2009 \{published data only\}}

Brandes AA, Tosoni A, Franceschi E, Blatt V, Santoro A, Faedi M, et al. Fotemustine as second-line treatment for recurrent or progressive glioblastoma after concomitant and/or adjuvant temozolomide: a phase II trial of Gruppo Italiano Cooperativo di Neuro-Oncologia (GICNO). Cancer chemotherapy and pharmacology 2009;64(4):769-75.

\section{Chen 2015 \{published data only\}}

* Chen C, Ravelo A, Yu E, Dhanda R, Schnadig I. Clinical outcomes with bevacizumab-containing and non-bevacizumabcontaining regimens in patients with recurrent glioblastoma from US community practices. Journal of Neuro-oncology 2015;122(3):595-605.

\section{Cher 2017 \{published data only\}}

Cher L, Nowak AK, latropoulos G, Lee WS, Lee SY, Shim SR, et al. A multicenter, 3-arm, open-label, phase Ila clinical trial to evaluate the safety and efficacy of tanibirumab (VEGFR2 $\mathrm{mAb}$ ), in patients with recurrent glioblastoma (GBM). Journal of Clinical Oncology 2017;35:15 Supplement 1 (no pagination).

\section{CTRI/2018/01/011542 \{published data only\}}

CTRI/2018/01/011542. Mebendazole in brain tumor. ClinicalTrials.gov 2018.

\section{Dixit 2015 \{published data only\}}

Dixit S, Hingorani M. Comparative efficacy of bevacizumab and PCV chemotherapy in recurrent glioblastoma. Clinical Oncology 2015;27(4):246-7.

\section{Duque 2017 \{published data only\}}

Duque AED, De Feyter H, Kemble G, McCulloch W, Brenner AJ. A phase 2 study to determine the efficacy and safety of TVB-2640 in combination with bevacizumab in patients with first relapse of high grade astrocytoma. Journal of Clinical Oncology 2017;35:15.

\section{Ellingson 2019 \{published data only\}}

Ellingson BM, Raymond C, Yao J, Chakhoyan A, Turley D, Tsung J, et al. Quantitative radiographic analysis of phase II and III trials in recurrent glioblastoma treated with VB111 with or without bevacizumab or bevacizumab monotherapy. Journal of Clinical Oncology 2019;37:No pagination.

\section{Fogh 2010 \{published data only\}}

Fogh SE, Andrews DW, Glass J, Curran W, Glass C, Champ C, et al. Hypofractionated stereotactic radiation therapy: an effective therapy for recurrent high grade gliomas. Journal of Clinical Oncology 2010;28(18):3048-53.

\section{Gan 2015 \{published data only\}}

* Gan HK, Papadopoulos KP, Fichtel L, Lassman AB, Merrell R, Van Den Bent MJ, et al. Phase I study of ABT-414 mono-or combination therapy with temozolomide (TMZ) in recurrent glioblastoma (GBM). Journal of Clinical Oncology 2015;33(15 Supp. 1):2016.

\section{Gatson 2015 \{published data only\}}

Erratum: reACT Phase II trial: a critical evaluation of the use of rindopepimut plus bevacizumab to treat EGFRvIlI-positive recurrent glioblastoma (CNS Oncology (2016) 5: 1 (11-26)). CNS Oncology 2016.

\section{Haslund 2016 \{published data only\}}

Haslund C, Muhic A, Lukacova S, Lund B, Lassen-Ramshad Y, Meyer M, et al. An open-labelled, randomized phase II study in patients with recurrent glioblastoma multiforme comparing progression free survival of alecsat (autologous 
lymphoid effector cells specific against tumour-cells) versus bevacizumab/irinotecan. In: Neuro-oncology. Vol. 18. 2016:iv6.

\section{Hong 2013 \{published data only\}}

Hong B, Wiese B, Bremer M, Heissler HE, Heidenreich F, Krauss JK, et al. Multiple microsurgical resections for repeated recurrence of glioblastoma multiforme. American Journal of Clinical Oncology 2013;36(3):261-8.

\section{Idbaih 2016 \{published data only\}}

Idbaih A, Clement PM, Vos FYF, Platten M, Mulholland P, Taphoorn MJB, et al. First results of the randomized phase II tavarec trial on temozolomide with or without bevacizumab in 1P/19Q intact 1st recurrence grade II and III glioma. In: Neurooncology. Vol. 18. 2016:iv13. [DOI: 10.1093/neuonc/now188.041]

\section{Immonen 2004 \{published data only\}}

Immonen A, Vapalahti M, Tyynela K, Hurskainen H, Sandmair A, Vanninen R, et al. AdvHSV-tk gene therapy with intravenous ganciclovir improves survival in human malignant glioma: a randomised, controlled study. Molecular Therapy 2004;10(5):967-72.

\section{Ji 2016 \{published data only\}}

* Ji N, Weng D, Liu C, Gu Z, Chen S, Guo Y, et al. Adenovirusmediated delivery of herpes simplex virus thymidine kinase administration improves outcome of recurrent highgrade glioma. Oncotarget 2016;7(4):4369-78. [10.18632/ oncotarget.6737]

\section{Kaloshi 2015 \{published data only\}}

Kaloshi G, Diamandi P, Cakani B, Brace G, Rroji A, Petrela M. The added value of bevacizumab concomitantly administered with carboplatin versus carboplatin alone in patients with recurrent glioblastomas. Tumori 2015;101(1):41-5.

\section{Kesari 2017 \{published data only\}}

* Kesari S, Ram Z. Tumor-treating fields plus chemotherapy versus chemotherapy alone for glioblastoma at first recurrence: a post hoc analysis of the EF-14 trial. Journal of Clinical Neurooncology 2017;6(3):185-93.

Kesari S, Tran D, Read W, Ahluwalia M, Villano J, Toms S, et al. Tumor treating fields with second line treatment compared to second line treatment alone in patients at first recurrence of glioblastoma-a post hoc analysis of the EF-14 phase 3 clinical trial. Conference abstract. Conference: 22nd Annual Scientific Meeting and Education Day of the Society for Neuro-Oncology. United States 2017;19(Supplement 6):vi13.

\section{Kinzel 2018 \{published data only\}}

Kinzel A, Lavy-Shahaf G, Kirson E. Tumor treating fields (TTfields) in combination with lomustine (CCNU) in the EF-14 phase 3 clinical study-a safety analysis. In: Neuro-oncology. Vol. 20. 2018:vi23.

\section{Komotar 2010 \{published data only\}}

Komotar RJ, Starke RM, Connolly ES, Sisti MB. Evaluating the benefit of repeat surgery for recurrent glioblastoma multiforme. Neurosurgery 2010;67(6):N16-7.

\section{Konkel 2018 \{published data only\}}

Konkel B, Caflisch L, Duque AED, Brenner AJ. Updated results from a prospective, randomized phase 2 study in patients with first relapse of high-grade astrocytoma using TVB-2640 in combination with avastin versus avastin alone. Neurooncology. Conference abstract of the Society for Neuro-Oncology 2018;20:vi16.

Konkel B, Caflisch LD, Duque AED, Michalek J, Liu Q, Brenner AJ. Prospective phase II trial in patients with first relapse of high-grade astrocytoma using TVB-2640 in combination with bevacizumab versus bevacizumab alone. Journal of Clinical Oncology 2019;37(15 suppl 1):2064.

NCT03032484. TVB- 2640 in combination with bevacizumab in patients with first relapse of high grade astrocytoma. ClinicalTrials.gov 2017.

\section{Lang 2018 \{published data only\}}

* Lang FF, Conrad C, Gomez-Manzano C, Yung WKA, Sawaya R, Weinberg JS, et al. Phase I study of DNX-2401 (Delta-24-RGD) oncolytic adenovirus: replication and immunotherapeutic effects in recurren malignant glioma. Journal of Clinical Oncology 2018;36(14):1419-27.

Lang FF, Tran ND, Puduvalli VK, Elder JB, Fink KL, Conrad CA, et al. Phase $1 \mathrm{~b}$ open-label randomized study of the oncolytic adenovirus DNX-2401 administered with or without interferon gamma for recurrent glioblastoma. Journal of Clinical Oncology 2017;35(15 suppl):2002.

Tufaro F, Peterkin J, Gammon K, Salvosa M, Mitchell E, Ewald B, et al. Phase 1B open-label randomized study of the oncolytic virus DNX-2401 administered with or without interferon gamma for recurrent glioblastoma. In: Neuro-oncology. Conference abstract. Vol. 18. 2016:vi24.

\section{Levin 2017 \{published data only\}}

Levin VA, Cruickshank S. STELLAR: a phase 3, randomized, open-label study of eflornithine with lomustine vs lomustine for patients with first recurrence of anaplastic astrocytoma after RT and adjuvant temozolomide. Journal of Clinical Oncology. ASCO conference abstract. 2017;35(15 suppl):10.1200/ JCO.2017.35.15_suppl.TPS2081.

NCT02796261. Study to evaluate eflornithine and lomustine vs lomustine in recurrent anaplastic astrocytoma (AA) patients. ClinicalTrials.gov 2016.

\section{Mau-Sorensen 2016 \{published data only\}}

Karyopharm Therapeutics Inc. A phase 2 study evaluating the efficacy and safety of selinexor (KPT-330) in patients with recurrent gliomas. ClinicalTrials.gov/ct2/show/NCT01986348 2013.

Lassen UN, Mau-Soerensen M, Kung AL, Wen PY, Lee EQ, Plotkin SR, et al. A phase 2 study on efficacy, safety and intratumoral pharmacokinetics of oral selinexor (KPT-330) in patients with recurrent glioblastoma (GBM). Journal of Clinical Oncology 2015;33(15):SUPPL. 1.

Mau-Sorensen M, Plotkin SR, Wen PY, Kung AL, Lassen UN, Saint-Martin JR, et al. A phase 2 study on efficacy, safety and 
intratumoral pharmacokinetics of oral selinexor (KPT-330) in patients with recurrent glioblastoma (GBM). In: Journal of Clinical Oncology. Conference abstract. Vol. 34. 2016:2077.

\section{Minniti 2015 \{published data only\}}

* Minniti G, Agolli L, Falco T, Scaringi C, Lanzetta G, Caporello P, et al. Hypofractionated stereotactic radiotherapy in combination with bevacizumab or fotemustine for patients with progressive malignant gliomas. Journal of Neuro-oncology 2015;122(3):559-66.

\section{Muhic 2013 \{published data only\}}

Muhic A, Poulsen HS, Sorensen M, Grunnet K, Lassen U. Phase II open-label study of nintedanib in patients with recurrent glioblastoma multiforme. Journal of Neuro-oncology 2013;111(2):205-12.

\section{NCT02529072 2015 \{published data only\}}

NCT02529072. Nivolumab with DC vaccines for recurrent brain tumors. ClinicalTrials.gov 2015.

\section{NCT02852655 2016 \{published data only\}}

NCT02852655. A pilot surgical trial to evaluate early immunologic pharmacodynamic parameters for the PD-1 checkpoint inhibitor, pembrolizumab (MK-3475), in patients with surgically accessible recurrent/progressive glioblastoma. ClinicalTrials.gov 2016.

Prins R, Mochizuki A, Orpilla J, Lee A, Davidson T, Gaffey S, et al. Neoadjuvant anti-PD-1 immunotherapy promotes intratumoral and systemic immune responses in recurrent glioblastoma: an ivy consortium trial. In: Neuro-oncology. Vol. Conference: 23rd Annual Scientific Meeting and Education Day of the Society for Neuro-oncology. United States. 20. 2018:vi3.

\section{NCT02866747 2016 \{published data only\}}

NCT02866747. A study evaluating the association of hypofractionated stereotactic radiation therapy and durvalumab for patients with recurrent glioblastoma. ClinicalTrials.gov 2016.

\section{NCT03014804 2016 \{published data only\}}

NCT03014804. Autologous dendritic cells pulsed with tumor lysate antigen vaccine and nivolumab in treating patients with recurrent glioblastoma. ClinicalTrials.gov 2016.

\section{NCT03149575 2017 \{published data only\}}

* NCT03149575. VAL-083 Phase 3 Study in TemozolomideAvastin (Bevacizumab) Recurrent GBM. ClinicalTrials.gov 2017.

\section{Penas-Prado 2015 \{published data only\}}

Penas-Prado M, Hess KR, Levin VA, De Groot JF, Colman H, Groves MD, et al. Phase I study of vorinostat combined with isotretinoin and temozolomide in adults with recurrent malignant gliomas. Journal of Clinical Oncology 2015;33(15):SUPPL. 1.

\section{Rahman 2014 \{published data only\}}

Rahman R, Hempfling K, Norden AD, Reardon DA, Nayak L, Rinne ML, et al. Retrospective study of carmustine or lomustine with bevacizumab in recurrent glioblastoma patients who have failed prior bevacizumab. Neuro-oncology 2014;16(11):1523-9.

Reardon 2008 \{published data only\}

Reardon DA, Fink KL, Mikkelsen T, Cloughesy TF, O'Neill A, Plotkin S, et al. Randomized phase II study of cilengitide, an integrin-targeting arginine-glycine-aspartic acid peptide, in recurrent glioblastoma multiforme. Journal of Clinical Oncology 2008;26(34):5610-7.

\section{Ruiz-Sanchez 2012 \{published data only\}}

Ruiz-Sanchez D, Calero MA, Sastre-Heres AJ, Garcia MTI, Hernandez MAC, Martinez FM, et al. Effectiveness of the bevacizumab-irinotecan regimen in the treatment of recurrent glioblastoma multiforme: comparison with other secondline treatments without this regimen. Oncology Letters 2012;4(5):1114-8.

\section{Schmidt 2006 \{published data only\}}

Schmidt F, Fischer J, Herrlinger U, Dietz K, Dichgans J, Weller M PCV chemotherapy for recurrent glioblastoma. PCV chemotherapy for recurrent glioblastoma. Neuro-oncology 2006;66(4):587-9.

\section{Seystahl 2013 \{published data only\}}

Seystahl K, Wiestler B, Hundsberger T, Happold C, Wick W, Weller M, et al. Bevacizumab alone or in combination with irinotecan in recurrent WHO Grade II and Grade III gliomas. European Neurology 2013;69(2):95-101.

\section{Short 2017 \{published data only\}}

Short SC, Little C. A 2-part safety and exploratory efficacy randomised double-blind, placebo-controlled study of a 1:1 ratio of cannabidiol and delta-9-tetrahydrocannabinol (CBD: $\mathrm{tHC}$ ) plus dose intense temozolomide in patients with recurrent glioblastoma multiforme (GBM). Neuro-oncology 2017;Conference: 22nd Annual Scientific Meeting and Education Day of the Society for Neuro-oncology. United States. 19:vi13.

\section{Socha 2016 \{published data only\}}

Socha J, Kepka L, Ghosh S, Roa W, Kumar N, Sinaika V, et al. Outcome of treatment of recurrent glioblastoma multiforme in elderly and/or frail patients. Journal of Neuro-oncology 2016;126(3):493-8.

\section{Sun 2013 \{published data only\}}

Sun J, Yang XJ, Yang SY. Multicenter randomized controlled study of temozolomide versus semustine in the treatment of recurrent malignant glioma]. [Chinese CNO - CN-00908562. Zhonghua yi xue za zhi 2013;93(3):165-8.

\section{Taylor 2018 \{published data only\}}

Taylor JW, Parikh M, Phillips JJ, James CD, Molinaro AM, Butowski NA, et al. Phase-2 trial of palbociclib in adult patients with recurrent RB1-positive glioblastoma. Neuro-oncology 2018;140(2):477-83.

Taylor JW. Phase 2 trial of palbociclib in adult patients with recurrent rb positive glioblastoma. Neuro-oncology 2017; Conference: 5th Quadrennial Meeting of the 
World Federation of Neuro-oncology Societies, WFNOS. Switzerland.19(Supplement 3):iii83.

Van den Bent 2009 \{published data only\}

van den Bent MJ, Brandes AA, Rampling R, Kouwenhoven MC, Kros JM, Carpentier AF, et al. Randomized phase II trial of erlotinib versus temozolomide or carmustine in recurrent glioblastoma: EORTC brain tumor group study 26034. Journal of Clinical Oncology 2013;27 XST - M XAOC - TRT(8):1268-74.

van den Bent 2016 \{published data only\}

* NCT03149003. A study of DSP-7888 dosing emulsion in combination with bevacizumab in patients with recurrent or progressive glioblastoma following initial therapy.

ClinicalTrials.gov 2017.

van den Bent M, Clement P, Vos F, Platten M, Mulholland P, Taphoorn M, et al. Clinical results of the eortc randomized phase ii tavarec trial on temozolomide with or without bevacizumab in 1st recurrence of grade ii or III glioma without 1P/19Q co-deletion. Neuro-oncology 2016;Conference: 21st Annual Scientific Meeting and Education Day of the Society for Neuro-oncology. United States 18:vi3.

Vauleon 2012 \{published data only\}

Vauleon E, Mesbah H, Gedouin D, Lecouillard I, Louvel G, Hamlat $A$, et al. Retrospective analysis of 24 recurrent glioblastoma after chemoradiation and treated with nitrosoureas or irinotecan and bevacizumab. Bulletin du Cancer 2012;99(2):121-6.

\section{Weller 2015 \{published data only\}}

Weller M, Tabatabai G, Kastner B, Felsberg J, Steinbach JP, Wick A, et al. MGMT promoter methylation is a strong prognostic biomarker for benefit from dose-intensified temozolomide rechallenge in progressive glioblastoma: the DIRECTOR Trial. Clinical Cancer Research 2015;21(9):2057-64.

\section{Yasuda 2018 \{published data only\}}

Yasuda T, Muragaki Y, Nitta M, Miyamoto K, Oura Y, Henmi T, et al. Effectiveness of stereotactic radiotherapy and bevacizumab for recurrent high-grade gliomas: A potential therapy for isocitrate dehydrogenase wild-type recurrent high-grade gliomas. World Neurosurgery 2018;epub. doi 10.1016/ j.wneu.2018.03.161:e1138.

\section{Yung 2000 \{published data only\}}

Yung W K A, Albright R E, Olson J, Fredericks R, Fink K, Prados $M D$, et al. A phase II study of temozolemide vs. procarbazine in patients with glioblastoma multiforme at first relapse. British Journal of Cancer 2000;83:588-93.

\section{Zadeh 2018 \{published data only\}}

NCT02414165. The toca 5 trial: toca 511 \& toca FC versus standard of care in patients with recurrent high grade glioma. NCT02414165 2015

* Zadeh G, Walbert T, Perry J, Zhu J, Salacz M, Bota D, et al. Toca 5: toca 511 combined with Toca FC versus standard of care in patients undergoing planned resection for recurrent glioblastoma or anaplastic astrocytoma. In: Canadian Journal of Neurosciences. Vol. 45. 2018:S2.
Zakharia 2017 \{published data only\}

Zakharia Y, Munn D, Link C, Vahanian N, Kennedy E. Interim analysis of phase $1 \mathrm{~B} / 2$ combination study of the IDO pathway inhibitor indoximod with temozolomide for adult patients with temozolomide-refractory primary malignant brain tumors. Neuro-oncology 2017;18:vi13-4.

\section{References to ongoing studies}

\section{ACTRN12617000534381 2017 \{published data only\}}

ACTRN12617000534381. A randomised phase II trial to examine feasibility of standardised, early palliative (STEP) care for patients with advanced cancer and their families. Australian Clinical Trials Register 2017.

\section{ChiCTR1900020646 2019 \{published data only\}}

ChiCTR1900020646. A multicenter open-label randomized controlled trial for apatinib combined with temozolomide in adult primary glioblastoma at first recurrence. ChiCTR1900020646 2019.

\section{Combs 2010 \{published data only\}}

Combs SE, Burkholder I, Edler L, Rieken S, Habermehl D, Jakel O, et al. Randomised phase I/II study to evaluate carbon ion radiotherapy versus fractionated stereotactic radiotherapy in patients with recurrent or progressive gliomas: the CINDERELLA trial. BMC Cancer 2010;10:533. [https:// doi.org/10.1186/1471-2407-10-533]

\section{JCOG1308C 2019 \{published data only\}}

jRCTs031180083. JCOG1308C: a multicenter randomized phase III study for recurrent glioblastoma. jRCTs031180083 2019.

KCT0002632 2018 \{published data only\}

KCT0002632. Phase 2 clinical trial for the efficacy and safety of low dose Temozolomide plus metformin as combination chemotherapy compared with low dose Temozolomide plus placebo in patient with recurrent or refractory Glioblastoma. CRIS_Clinical Search Information Service 2018.

\section{NCT01252459 2016 \{published data only\}}

Oehlke O, Mix M, Graf E, Schimek-Jasch T, Nestle U, Gotz I, et al. Amino-acid PET versus MRI guided re-irradiation in patients with recurrent glioblastoma multiforme (GLIAA) protocol of a randomized phase II trial (NOA 10/ARO 2013-1). ClinicalTrials.gov 2016;16(1):769.

\section{NCT01903330 2018 \{published data only\}}

Bota D, Carrillo J, Kong XT, Fu D, Chung J, Pretto C, et al. A randomized, double-blinded, placebocontrolled phase 2 study of the ERC-1671 (Gliovac) vaccine in combination with bevacizumab (BEV) in recurrent GBM patients: safety leadin analysis. Neuro-oncology 2016;Conference: 21st Annual Scientific Meeting and Education Day of the Society for Neuro-Oncology. United States.18:vi22.

Bota D, Chung J, Carrillo J, Kong XT, Fu B, Pretto C, et al. A preliminary data report on a phase 2 study of ERC1671 in recurrent glioblastoma. Neuro-oncology. Conference abstract of Society for Neuro-oncology 2017;19(Suppl 6):vi109. [DOI: $10.1093 /$ neuonc/nox168.448] 
* Bota DA, Chung J, Dandekar M, Carrillo JA, Kong XT, Fu BD, et al. Phase II study of ERC1671 plus bevacizumab versus bevacizumab plus placebo in recurrent glioblastoma: interim results and correlations with CD4+ T-lymphocyte counts. CNS Oncology 2018;7(3):CNS22. [DOI: 10.2217/cns-2018-0009]

Bota DA, Chung J, Dandekar M, Carrillo JA, Kong XT, Fu DB, et al. Phase 2 study of erc1671 plus bevacizumab vs bevacizumab plus placebo in recurrent GBM interim results and correlations with CD4+ T lymphocyte counts. Neuro-oncology. Conference abstract of Society for Neuro-oncology 2018;20:vi7.

NCT02394626 2015 \{published data only\}

NCT02394626. Surgery for Recurrent Glioblastoma. ClinicalTrials.gov 2015.

\section{NCT02678975 2016 \{published data only\}}

Jakola AS, Werlenius K, Mudaisi M, Hylin S, Kinhult S, Bartek $\mathrm{J} J \mathrm{~J}$, et al. Disulfiram repurposing combined with nutritional copper supplement as add-on to chemotherapy in recurrent glioblastoma (Direct): study protocol for a randomized controlled trial. PMID: 30647912 2018;7:1797.

NCT02678975. Disulfiram in Recurrent Glioblastoma. ClinicalTrials.gov 2016.

\section{NCT02715297 2018 \{published data only\}}

NCT02715297. Adjuvant stereotactic fractionated radiotherapy to the resection cavity in recurrent glioblastoma. ClinicalTrials.gov 2016.

Straube C, Scherb H, Gempt J, Kirschke J, Zimmer C, SchmidtGraf F, et al. Adjuvant stereotactic fractionated radiotherapy to the resection cavity in recurrent glioblastoma - the GlioCave study (NOA 17 - ARO 2016/3 - DKTK ROG trial). BMC Cancer 2018;18(1):15.

\section{NCT02761070 2016 \{published data only\}}

NCT02761070. Bevacizumab alone versus dose-dense temozolomide followed by bevacizumab for recurrent glioblastoma, phase III. ClinicalTrials.gov 2016.

\section{NCT02794883 2016 \{published data only\}}

NCT02794883. Tremelimumab and durvalumab in combination or alone in treating patients with recurrent malignant glioma. ClinicalTrials.gov 2016.

\section{NCT02942264 2016 \{published data only\}}

NCT02942264. TG02 plus dose-dense or metronomic temozolomide followed by randomized phase II trial of TG02 plus temozolomide versus temozolomide alone in adults with recurrent anaplastic astrocytoma and glioblastoma. ClinicalTrials.gov 2016.

\section{NCT02974621 2016 \{published data only\}}

NCT02974621. Cediranib maleate and olaparib compared to bevacizumab in treating patients with recurrent glioblastoma. ClinicalTrials.gov 2016.

\section{NCT03025893 2019 \{published data only\}}

Brahm CG, Van Linde ME, Labots M, Kouwenhoven MC, Aliaga ES, Enting RH, et al. A phase II/III trial of high-dose, intermittent sunitinib in patients with recurrent glioblastoma: the STELLAR study. In: Cancer Research. Vol. 79. 2019.

EUCTR2016-001797-15-NL. A trial testing an alternative highdose, intermittend scheduling for sunitinib in patients with recurrent brain cancer. European Clinical Trials Register 2016.

NCT03025893. A phase II/III study of high-dose, intermittent sunitinib in patients with recurrent glioblastoma multiforme. ClinicalTrials.gov 2017.

NCTR6308. A phase II/III study of high-dose, intermittent sunitinib in patients with recurrent glioblastoma multiforme: the STELLAR study. ClinicalTrials.gov 2016.

\section{NCT03149003 2018 \{published data only\}}

De Groot JF, Cloughesy TF, Pitz MW, Narita Y, Nonomura T. A randomized, multicenter phase 2 study of DSP-7888 dosing emulsion in combination with bevacizumab (Bev) versus Bev alone in patients with recurrent or progressive glioblastoma. ClinicalTrials.gov 2018;36(15).

\section{NCT03632135 2018 \{published data only\}}

NCT03632135. Standard chemotherapy vs. chemotherapy guided by cancer stem cell test in recurrent glioblastoma. ClinicalTrials.gov 2018.

\section{NCT03746288 2018 \{published data only\}}

NCT03746288. To evaluate the efficacy and safety of CAN008 combined with re-irradiation ( $\mathrm{rRT}$ ) for treating patients with recurrent glioblastoma (GBM). ClinicalTrials.gov 2018.

\section{NCT03970447 2019b \{published data only\}}

NCT03970447. A trial to evaluate multiple regimens in newly diagnosed and recurrent glioblastoma. ClinicalTrials.gov 2019.

\section{NCT04003649 2019 \{published data only\}}

NCT04003649. IL13Ralpha2-targeted chimeric antigen receptor (CAR) T cells with or without nivolumab and ipilimumab in treating patients with recurrent or refractory glioblastoma. ClinicalTrials.gov 2019.

\section{Additional references}

\section{Ameratunga 2018}

Ameratunga M, Pavlakis N, Wheeler H, Grant R, Simes J, Khasraw M. Anti-angiogenic therapy for high-grade glioma. Cochrane Database of Systematic Reviews 2018, Issue 11. Art. No: CD008218. [DOI: 10.1002/14651858.CD008218.pub4]

\section{Barrios 2012}

Barrios JMR, Alcántara FP, Palomo CC, García PG, De Las Heras AE, Riestra BM. The use of cost per life year gained as a measurement of cost-effectiveness in Spain: a systematic review of recent publications. European Journal of Health Economics 2012;13(6):723-40.

\section{Batchelor 2006}

Batchelor TT, Byrne TN. Supportive care of brain tumor patients. Hematology/oncology Clinics of North America 2006;20(6):1337-61. 


\section{Brown 2018}

Brown NF, Carter TJ, Ottaviani D, Mulholland P. Harnessing the immune system in glioblastoma. British Journal of Cancer 2018;119(10):1171-81.

\section{Chaimani 2015}

Chaimani A, Salanti G. Visualizing assumptions and results in network meta-analysis: the network graphs package. Stata Journal 2015;15(4):905-50.

\section{Chapman 2019}

Chapman CH, Hara JH, Molinaro AM, Clarke JL, Oberheim Bush NA, Taylor JW, et al. Reirradiation of recurrent high-grade glioma and development of prognostic scores for progression and survival. Neuro-oncology Practice 2019;6(5):364-74.

\section{Conen 2017}

Conen KL, Matter-Walstra K, Schadelin S, Mariani L, Hess V. Benefits and costs of bevacizumab in recurrent glioblastoma: a quality adjusted survival and cost analysis (EVALUATE). In: Journal of Clinical Oncology, Conference: 2017 Annual Meeting of the American Society of Clinical Oncology, ASCO. United States. 35. Vol. 35. 2017.

\section{CRUK 2020}

https://www.cancerresearchuk.org/health-professional/ cancer-statistics/statistics-by-cancer-type/brain-other-cns-andintracranial-tumours. Web page 2020.

\section{Deeks 2001}

Deeks JJ, Altman DG, Bradburn MJ. Chapter 15: Statistical methods for examining heterogeneity and combining results from several studies in meta-analysis. In: Systematic Reviews in Health Care: Meta-Analysis in Context. 2nd edition. London: BMJ Publication Group, 2001.

\section{Drugs.com}

Drugscom. Alkylating agents. www.drugs.com/drug-class/ alkylating-agents.html (accessed 9 December 2019).

\section{Dumitru 2018}

Dumitru CA, Sandalcioglu IE, Karsak M. Cannabinoids in glioblastoma therapy: new applications for old drugs. Frontiers of Molecular Neuroscience 2018;11:159.

\section{EANO 2017}

Pace A, Dirven L, Koekkoek JAF, Golla H, Fleming J, Ruda R. European association for Neuro-oncology (EANO) guidelines for palliative care in adults with glioma. Lancet Oncology 2017;18(6):e330-40.

\section{Easaw 2011}

Easaw JC, Mason WMP, Perry J, Laperrière N, Eisenstat DD, Del Maestro R, et al. Canadian recommendations for the treatment of recurrentor progressive glioblastoma multiforme. Current Oncology (Toronto, Ont.) 2011;18(3):126-36.

\section{Efthimiou 2016}

Efthimiou O, Debray TP, van Valkenhoef G, Trelle S, Panayidou K, Moons KG, et al. GetReal in network meta-analysis: a review of the methodology. Research Synthesis Methods 2016;7(3):236-63.

\section{EPOC 2015}

Cochrane Effective Practice and Organisation of Care (EPOC). EPOC resources for review authors. 2015. epoc.cochrane.org/ epoc-specific-resources-review-authors (accessed 6 July 2016).

\section{Higgins 2003}

Higgins JP, Thompson SG, Deeks JJ, Altman DG. Measuring inconsistency in meta-analyses. BMJ 2003;327(7414):557-60.

\section{Higgins 2019}

Higgins JPT, Thomas J, Chandler J, Cumpston M, Li T, Page MJ, Welch VA (editors). Cochrane Handbook for Systematic Reviews of Interventions Version 6.0 [updated July 2019]. Cochrane, 2019. Available from www.training.cochrane.org/handbook.

\section{JLA 2015}

MacDonald L, on behalf of the Neuro-oncology Group. Top 10 priorities for clinical research in primary brain and spinal cord tumours. www.jla.nihr.ac.uk/priority-setting-partnerships/ neuro-oncology/downloads/Neuro-Oncology-Group-FinalReport-June-2015.pdf (accessed 1 March 2018).

\section{Kazmi 2019}

Kazmi F, Soon YY, Leong YH, Koh WY, Vellayappan B. Reirradiation for recurrent glioblastoma (GBM): a systematic review and meta-analysis. Journal of Neuro-oncology 2019;142:79-90.

\section{Kim 2019}

Kim IH. Appraisal of re-irradiation for the recurrent glioblastoma in the era of MGMT promotor methylation. Radiation Oncology Journal 2019;37(1):1-12.

\section{Lombardi 2017}

Lombardi G, Pambuku A, Bellu L, Farina M, Della Puppa A, Denaro $L$, et al. Effectiveness of antiangiogenic drugs in glioblastoma patients: A systematic review and meta-analysis of randomised clinical trials. Critical Reviews in Oncology/ hematology 2017;111:94-102.

\section{Malmstrom 2012}

Malmstrom A, Grønberg BH, Marosi C, Stupp R, Frappaz D, Schultz $\mathrm{H}$, et al. Temozolomide versus standard 6-week radiotherapy versus hypofractionated radiotherapy in patients older than 60 years with glioblastoma: the Nordic randomised, phase 3 trial. Lancet Oncology 2012;13(9):916-26.

\section{Mandl 2008}

Mandl ES, Dirven CM, Buis DR, Postma TJ, Vandertop WP. Repeated surgery for glioblastoma multiforme: only in combination with other salvage therapy. Surgical Neurology 2008;69(5):506-9.

\section{Martin-McGill 2018}

Martin-McGill KJ, Srikandarajah N, Marson AG, Tudur Smith C, Jenkinson MD. The role of ketogenic diets in the therapeutic management of adult and paediatric gliomas: a systematic review. CNS Oncology 2018;10.2217/cns-2017-0030:Epub. 


\section{MASCC 2019}

Multinational Association of Supportive Care in Cancer. What is supportive care. www.mascc.org/about-mascc (accessed 8 October 2019).

\section{Messali 2014}

Messali A, Villacorta R, Hay JW. A review of the economic burden of glioblastoma and the cost effectiveness of pharmacologic treatments. PharmacoEconomics 2014;32:1201-12.

\section{NCCN 2018}

National Comprehensive Cancer Network. NCCN Guidelines version 1. 2018. Central Nervous System Cancers. www.optune.com/Content/pdfs/CNS_FlashCard_4Page.pdf (accessed 5 April 2020).

\section{NICE 2018}

National Institute for Health and Care Excellence. Brain tumours (primary) and brain metastases in adults. Available at www.nice.org.uk/guidance/ng99.

\section{Niyazi 2011}

Niyazi M, Siefert A, Schwarz SB, Ganswindt U, Kreth FW, Tonn JC, et al. Therapeutic options for recurrent malignant glioma. Radiotherapy and Oncology 2011;98(1):1-14.

\section{Parasramka 2017}

Parasramka S, Talari G, Rosenfeld M, Guo J, Villano JL. Procarbazine, lomustine and vincristine for recurrent high-grade glioma. Cochrane Database of Systematic Reviews 2017, Issue 7. Art. No: CD011773. [DOI: 10.1002/14651858.CD011773.pub2]

\section{Perry 2017}

Perry JR, Laperriere N, O'Callaghan CJ, Brandes AA, Menten J, Phillips $\mathrm{C}$, et al. Short-course radiation plus temozolomide in elderly patients with glioblastoma CNO - CN-01366980. New England Journal of Medicine 2017;376(11):1027-37.

\section{Review Manager 2014 [Computer program]}

Nordic Cochrane Centre, The Cochrane Collaboration Review Manager 5 (RevMan 5). Version 5.3. Copenhagen: Nordic Cochrane Centre, The Cochrane Collaboration, 2014.

\section{Roussakow 2017}

Roussakow SV. Clinical and economic evaluation of modulated electrohyperthermia concurrent to dose-dense temozolomide $21 / 28$ days regimen in the treatment of recurrent glioblastoma: a retrospective analysis of a two-centre German cohort trial with systematic comparison and effect-to-treatment analysis. BMJ Open 2017;7:e017387.

\section{Ruiz-Sanchez 2016}

Ruiz-Sanchez D, Peinado II, Alaguero-Calero M, SastreHeres AJ, Diez BG, Pena-Diaz J. Cost-effectiveness analysis of the bevacizumab-irinotecan regimen in the treatment of primary glioblastoma multiforme recurrences. Oncology Letters 2016;12(3):1935-40.

\section{Schünemann 2019}

Schünemann HJ, Vist GE, Higgins JP, Santesso N, Deeks JJ, Glasziou P, et al. Chapter 15: Interpreting results and drawing conclusions. In: Higgins JPT, Thomas J, Chandler J, Cumpston M, Li T, Page MJ, Welch VA (editors), editors(s). Cochrane Handbook for Systematic Reviews of Interventions version 6.0 (updated July 2019). Wiley, 2019:Available from training.cochrane.org/handbook/current/chapter-15 (Accessed 5 April 2020).

\section{Shemilt 2019}

Shemilt I, Aluko P, Graybill E, Craig D, Henderson C, Drummond $\mathrm{M}$, et al, on behalf of the Campbell and Cochrane Economics Methods Group. Chapter 20: Economic evidence. In: Higgins JPT, Thomas J, Chandler J, Cumpston M, Li T, Page MJ, Welch VA (editors). Cochrane Handbook for Systematic Reviews of Interventions version 6.0 (updated July 2019). Cochrane, 2019. Available from www.training.cochrane.org/handbook.

\section{Sterne 2016}

Sterne JA, Hernán MA, Reeves BS, Savovíc J, Berkman ND, Viswanathan V, et al. ROBINS-I: a tool for assessing risk of bias in non-randomised studies of interventions. BMJ 2016;355:i4919.

\section{Stupp 2005}

Stupp R, Mason WP, van den Bent MJ, Weller M, Fisher B, Taphoorn MJ, et al. Radiotherapy plus concomitant and adjuvant temozolomide for glioblastoma. New England Journal of Medicine 2005;352(10):987-96.

\section{Thompson 2019}

Thompson G, Lawrie TA, Kernohan A, Jenkinson MD. Interval brain imaging for adults with cerebral glioma. Cochrane Database of Systematic Reviews 2019, Issue 12. Art. No: CD013137. [DOI: 10.1002/14651858.CD013137.pub2]

\section{Thon 2013}

Thon N, Kreth S, Kreth FW. Personalized treatment strategies in glioblastoma: MGMT promoter methylation status. OncoTargets and Therapy 2013;6:1363-72.

\section{Voigt 2016}

Voigt JD, Barnett G. The value of using a brain laser interstitial thermal therapy (LITT) system in patients presenting with high grade gliomas where maximal safe resection may not be feasible. Cost Effectiveness and Resource Allocation 2016;14:6.

\section{White 2015}

White IR. Network meta-analysis. Stata Journal 2015;15(4):951-85.

\section{Wick 2012}

Wick W, Platten M, Meisner C, Felsberg J, Tabatabai G, Simon M, et al. Temozolomide chemotherapy alone versus radiotherapy alone for malignant astrocytoma in the elderly: the NOA-08 randomised, phase 3 trial. Lancet Oncology 2012;13(7):707-15.

\section{Wong 1999}

Wong ET, Hess KR, Gleason MJ, Jaeckle KA, Kyritsis AP, Prados MD, et al. Outcomes and prognostic factors in recurrent 
glioma patients enrolled onto phase II clinical trials. Journal of Clinical Oncology 1999;17(8):2572-8.

\section{CHARACTERISTICS OF STUDIES}

Characteristics of included studies [ordered by study ID]

Azoulay 2017

\section{Study characteristics}

Methods
Country: Canada
Accrual dates: patients receiving initial treatment between Jan 2005 and Dec 2012, this study was car-
ried out at first progression (dates not clear)
Trial registration: not trial
Funding: not clear
DOI: not clear

* Indicates the major publication for the study

\section{Participants No. analysed: 183 (3 lost to follow-up) \\ Inclusion/exclusion criteria: patients receiving initial treatment for GBM between January 2005 and De- cember 2012 that had received standard treatment (maximal safe resection, concurrent chemoradi- ation with RT dose of $60 \mathrm{~Gy}$ (in 20 or 30 fractions) followed by adjuvant temozolomide chemotherapy (TMZ)}

Age: adults, median age 58

Gender: $71 \mathrm{~F}(39.4 \%) 109 \mathrm{M}(60.6 \%)$

Performance status:

MGMT status: 70 unmethylated (50.4\%) 69 methylated (49.6\%),

Initial treatment details: (at least 80\% must have had chemoradiotherapy) All had standard treatment which included chemoradiation.

Sort of recurrence: first progression

Time from initial diagnosis: time to tumour progression from diagnosis was median 7.43 months.

Interventions Arm 1: re-operation with or without salvage chemoradiotherapy (69)

Arm 2: salvage chemoradiotherapy or best supportive care depending on MDT decision (111)

The decision re treatment group was based on an MDT meeting decision taking into account prognostic factors such as tumour location and extent and patient characteristics. Patients who were re-operated on were "matched" to patients who were not operated on in further analysis.

Outcomes Survival from time of first progression.

\section{Notes}

\section{Risk of bias}

Bias Authors' judgement Support for judgement


Azoulay 2017 (Continued)

Random sequence genera- High risk Not RCT. This study is at high risk of selection bias. It included a cohort of pation (selection bias)

tients with the decision whether or not to re-operate based on MDT meeting taking into account prognostic factors, tumour extent and location.

\begin{tabular}{|c|c|c|}
\hline $\begin{array}{l}\text { Allocation concealment } \\
\text { (selection bias) }\end{array}$ & High risk & High risk of selection bias. Treatment modalities decided by MDT decision. \\
\hline $\begin{array}{l}\text { Blinding of participants } \\
\text { and personnel (perfor- } \\
\text { mance bias) } \\
\text { All outcomes }\end{array}$ & High risk & No blinding of patients or staff. \\
\hline $\begin{array}{l}\text { Blinding of outcome as- } \\
\text { sessment (detection bias) } \\
\text { All outcomes }\end{array}$ & Unclear risk & $\begin{array}{l}\text { No blinding of outcome assessment but survival outcomes may be less sus- } \\
\text { ceptible to bias. }\end{array}$ \\
\hline $\begin{array}{l}\text { Incomplete outcome data } \\
\text { (attrition bias) } \\
\text { All outcomes }\end{array}$ & Low risk & Most patients were followed up. \\
\hline $\begin{array}{l}\text { Selective reporting (re- } \\
\text { porting bias) }\end{array}$ & Unclear risk & $\begin{array}{l}\text { Not apparent. Although as the decision re treatment allocation was based on } \\
\text { prognostic factors and outcome was progression/survival results are likely to } \\
\text { be confounded. }\end{array}$ \\
\hline Other bias & High risk & $\begin{array}{l}\text { Authors state limitation: lack of consistent selection criteria for each treatment } \\
\text { modality. }\end{array}$ \\
\hline
\end{tabular}

\section{Batchelor 2013}

\section{Study characteristics}

Methods

A phase 3, 3-arm, multicentre RCT with partial blinding; ratio 2:2:1

Country: Canada, Germany, France, the Netherlands, UK, USA

Accrual dates: Oct 2008 to Sept 2009

Trial reg: NCT00777153, REGAL

Funding: AstraZeneca

DOI: several authors declared stock interests and pharmaceutical funding
Participants
No. randomised: 325
No. analysed: 323
Inclusion criteria: People with recurrent GBM after TMZ + RT (first recurrence); Karnofsky PS > $70 \%$; MMSE > 15; life expectancy of $>12$ weeks
Exclusions: prior anti-VEGF therapy or cranial radiation within 3 months of study entry
Age: median age $=54$ years
Gender: NR
KPS PS: 70 to $80=50 \%$ group $1,48 \%$ group 2 and $36.2 \%$ group $3 ; 80$ to $100=50 \%$ group $1,51.2 \%$ group $2 ; 62.5 \%$ group 3 
Batchelor 2013 (Continued)

Resection for recurrent disease: group $1=38.2 \%$, group $2=38 \%$, group $3=36.9 \%$

MGMT: NR

Initial treatment: TMZ + RT

Interventions

Arm 1: cediranib monotherapy (30 mg daily po)

Arm 2: cediranib (20 mg daily po) + lomustine (110 mg po every 6 weeks)

Arm 3: lomustine (110 mg po every 6 weeks) + placebo (once daily)

\begin{tabular}{ll}
\hline Outcomes & PFS, OS, SAES, TTD \\
\hline Notes & Group 3 had better PS than the other groups.
\end{tabular}

\section{Risk of bias}

\begin{tabular}{|c|c|c|}
\hline Bias & Authors' judgement & Support for judgement \\
\hline $\begin{array}{l}\text { Random sequence genera- } \\
\text { tion (selection bias) }\end{array}$ & Unclear risk & $\begin{array}{l}\text { "Patients randomly assigned, stratified by age and resection status". Not } \\
\text { specifically stated. }\end{array}$ \\
\hline $\begin{array}{l}\text { Allocation concealment } \\
\text { (selection bias) }\end{array}$ & Unclear risk & Not reported. \\
\hline $\begin{array}{l}\text { Blinding of participants } \\
\text { and personnel (perfor- } \\
\text { mance bias) } \\
\text { All outcomes }\end{array}$ & Low risk & Placebo was identical to the cediranib. \\
\hline $\begin{array}{l}\text { Blinding of outcome as- } \\
\text { sessment (detection bias) } \\
\text { All outcomes }\end{array}$ & Low risk & "independent, centralized, treatment-arm blinded radiographic review" \\
\hline $\begin{array}{l}\text { Incomplete outcome data } \\
\text { (attrition bias) } \\
\text { All outcomes }\end{array}$ & Low risk & 2 patients excluded from analysis \\
\hline $\begin{array}{l}\text { Selective reporting (re- } \\
\text { porting bias) }\end{array}$ & Low risk & Expected outcomes reported. \\
\hline Other bias & Unclear risk & Funding and author interests noted. \\
\hline
\end{tabular}

Bloch 2017

\section{Study characteristics}

Methods

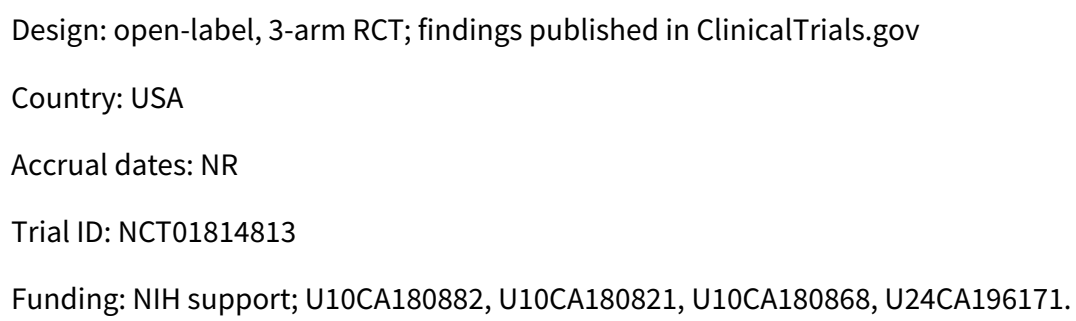


Bloch 2017 (Continued)

Declaration of interests: NR

Randomised: 90
Inclusion/exclusion: Patients with 1st/2nd recurrence of resectable GBM; must have received prior RT +
TMZ; no prior treatment with anti-angiogenic agent targeting the VEGF pathway; no RT within 90 days;
no gliadel wafers; Karnofsky functional status rating $\geq 70$
Gender: $27.8 \% \mathrm{~F}: 72.2 \% \mathrm{M}$

Performance status: KPS $\geq 70$

MGMT status: NR

Re-operation: all patients underwent re-operation

Time from diagnosis: NR

Interventions

Patients were randomized (1:1:1) to receive:

Arm 1: HSPPC-96 vaccine followed by bevacizumab at subsequent progression

Arm 2: concurrent HSPPC-96 vaccine and bevacizumab

Arm 3: bevacizumab alone

\begin{tabular}{ll}
\hline Outcomes & OS, PFS, toxicity (CTCAE v5) \\
\hline Notes & $\begin{array}{l}\text { Authors concluded that "The study failed to demonstrate a survival benefit for patients treated with } \\
\text { HSPPC-96 alone or in combination with bevacizumab compared to bevacizumab alone" on pre- } \\
\text { planned interim analysis. }\end{array}$ \\
\hline
\end{tabular}

\section{Risk of bias}

\begin{tabular}{|c|c|c|}
\hline Bias & Authors' judgement & Support for judgement \\
\hline $\begin{array}{l}\text { Random sequence genera- } \\
\text { tion (selection bias) }\end{array}$ & Unclear risk & Insufficient information to make a judgement \\
\hline $\begin{array}{l}\text { Allocation concealment } \\
\text { (selection bias) }\end{array}$ & Unclear risk & Insufficient information to make a judgement \\
\hline $\begin{array}{l}\text { Blinding of participants } \\
\text { and personnel (perfor- } \\
\text { mance bias) } \\
\text { All outcomes }\end{array}$ & High risk & Open label \\
\hline $\begin{array}{l}\text { Blinding of outcome as- } \\
\text { sessment (detection bias) } \\
\text { All outcomes }\end{array}$ & Unclear risk & Insufficient information to make a judgement \\
\hline $\begin{array}{l}\text { Incomplete outcome data } \\
\text { (attrition bias) } \\
\text { All outcomes }\end{array}$ & Unclear risk & Insufficient information to make a judgement \\
\hline $\begin{array}{l}\text { Selective reporting (re- } \\
\text { porting bias) }\end{array}$ & Unclear risk & Insufficient information to make a judgement \\
\hline Other bias & Unclear risk & $\begin{array}{l}\text { All Principal Investigators are employed by the organization sponsoring the } \\
\text { study }\end{array}$ \\
\hline
\end{tabular}


Brandes 2016a

\section{Study characteristics}

Methods

Design: 3-arm, randomized Bayesian augmented control Phase II

Country: multicounty (34 centres in 10 countries)

Accrual dates: May 2012 and July 2014

Trial reg: NCT01582269

Funding: Eli Lilly and Company (Indianapolis Indiana).

Declaration of interests: Dr. Brandes has received traveling grants for ASCO, SNO, and ESMO meetings from Eli Lilly and Company, Roche, and Pfizer. Dr. Wick has received research grants from Apogenix, Boehringer Ingelheim, Eli Lilly and Company, Immatics, MSD, and Roche as well as honoraria for lectures or advisory board participation from MSD and Roche. He is or has been the coordinating investigator for sponsored clinical trials evaluating APG101 (Apogenix), bevacizumab (Roche), galunisertib (Eli Lilly and Company), temozolomide (MSD), and temsirolimus (Pfizer). Dr. Steinbach has received a grant from Merck as well as honoraria for lectures, travel, or advisory board participation from Roche, Medac, and Mundipharma. Dr. Carpentier has served as a consultant for Roche. Drs. Capper, Cher, Chinot, Kesari, Rodon, Sepu' Iveda-Sanchez, Specenier, and Wheeler have no financial disclosures. Drs. Gueorguieva, Desaiah, and Guba and Ms. Cleverly, Ms. Smith, and Mr. Miles are employees of Eli Lilly and Company (Indianapolis, Indiana) and may hold company stock. Dr. Lahn. is a former employee of Eli Lilly and Company and holds company stock.

Participants

No. randomised: 158 (180 patients entered)

No. analysed: 158

Inclusion criteria

1. Patients must have had evidence of tumour progression as determined by Response Assessment in Neuro Oncology (RANO) criteria following at least 12 weeks after the end of standard chemoradiotherapy

2. Patients must have completed 1 prior regimen (all patients were considered at first relapse)

3. Patients were required to have adequate haematologic, hepatic, and renal function

4. Patients had discontinued all previous therapies including chemotherapy (excluding palliative care for cancer) at least 4 weeks prior to study enrollment

\section{Exclusion criteria}

1. Medically uncontrolled cardiovascular illness, medically significant electrocardiogram abnormalities, and serious pre-existing medical conditions

2. If person was enrolled in a clinical trial investigating galunisertib and/or vascular endothelial growth factor receptor (VEGFR) inhibitors

3. If person had prior treatment for glioblastoma with nitrosourea (lomustine) and/or bevacizumab

Median age: 58 years

Gender: Male $64.6 \%$ \& Female $35.4 \%$

Performance status: $63.3 \%$ had ECOG PS $\leq 1$

MGMT: NR

Resection/biopsy:

Initial treatment details: standard chemoradiotherapy

Details of treatment of first occurrence (2nd line?): not given 
Brandes 2016a (Continued)

Time from initial diagnosis: not given

\begin{tabular}{ll} 
Interventions & Arm 1: galunisertib monotherapy \\
& Arm 2: galunisertib plus lomustine \\
& Arm 3: lomustine monotherapy \\
& Oral galunisertib was given in a dose $300 \mathrm{mg} /$ day ( $150 \mathrm{mg}$ tablets twice a day, morning and evening) for \\
14 days followed by 14 days off in a 28 -day cycle & \\
& $\begin{array}{l}\text { The first dose of lomustine was given as } 100 \mathrm{mg} / \mathrm{m}^{2} \text { after } 7 \text { days of galunisertib treatment and there- } \\
\text { after (at the discretion of the investigator) was given orally once every } 6 \text { weeks at } 100 \text { to } 130 \mathrm{mg} / \mathrm{m}^{2}\end{array}$ \\
\hline Outcomes & OS, AEs, HRQOL and neurocognitive outcomes, response \\
\hline Notes & Authors concluded that "Galunisertib + lomustine failed to demonstrate improved OS relative to place- \\
\hline
\end{tabular}

\section{Risk of bias}

\begin{tabular}{lll}
\hline Bias & Authors' judgement & Support for judgement \\
\hline $\begin{array}{l}\text { Random sequence genera- } \\
\text { tion (selection bias) }\end{array}$ & Low risk & $\begin{array}{l}\text { "Participants were randomized with a 2:1:1 allocation ratio; randomization } \\
\text { used a dynamic allocation method to minimize imbalance according to the fol- } \\
\text { lowing factors:.." }\end{array}$ \\
\hline $\begin{array}{l}\text { Allocation concealment } \\
\text { (selection bias) }\end{array}$ & Unclear risk & Not described in the study report. \\
\hline $\begin{array}{l}\text { Blinding of participants } \\
\begin{array}{l}\text { and personnel (perfor- } \\
\text { mance bias) } \\
\text { All outcomes }\end{array}\end{array}$ & Low risk & \\
\hline
\end{tabular}

Blinding of outcome as- Unclear risk Not described in the study report.

sessment (detection bias)

All outcomes

\begin{tabular}{lll}
\hline $\begin{array}{l}\text { Incomplete outcome data } \\
\text { (attrition bias) } \\
\text { All outcomes }\end{array}$ & Low risk & All patients were analysed. \\
\hline $\begin{array}{l}\text { Selective reporting (re- } \\
\text { porting bias) }\end{array}$ & Low risk & Expected outcomes were reported. \\
\hline Other bias & Unclear risk & $\begin{array}{l}\text { Slight imbalance between arms in \% of men, and type of diagnosis at study en- } \\
\text { try. Funding and author interests noted. }\end{array}$ \\
\hline
\end{tabular}

Brandes 2016b

\section{Study characteristics}

Design: Phase 2 open-label, non-comparative, multicentre RCT
Country: Italy
Accrual dates: November 2011 and September 2012

Treatment options for progression or recurrence of glioblastoma: a network meta-analysis (Review) 
Brandes 2016b (Continued)

Trial reg: EudraCT: 2011-001363-46; NCT01474239 (AVAREG)

Funding: F. Hoffmann-La Roche Ltd.

Declaration of interests: A.A. Brandes: travel grants from Merck Serono Ltd and Pfizer Ltd; E. Franceschi: travel grant from F. Hoffmann-La Roche Ltd; E. Proietti: employee of Roche S.p.A. Italy as Medical Manager. All other authors have no conflicts of interest to declare.

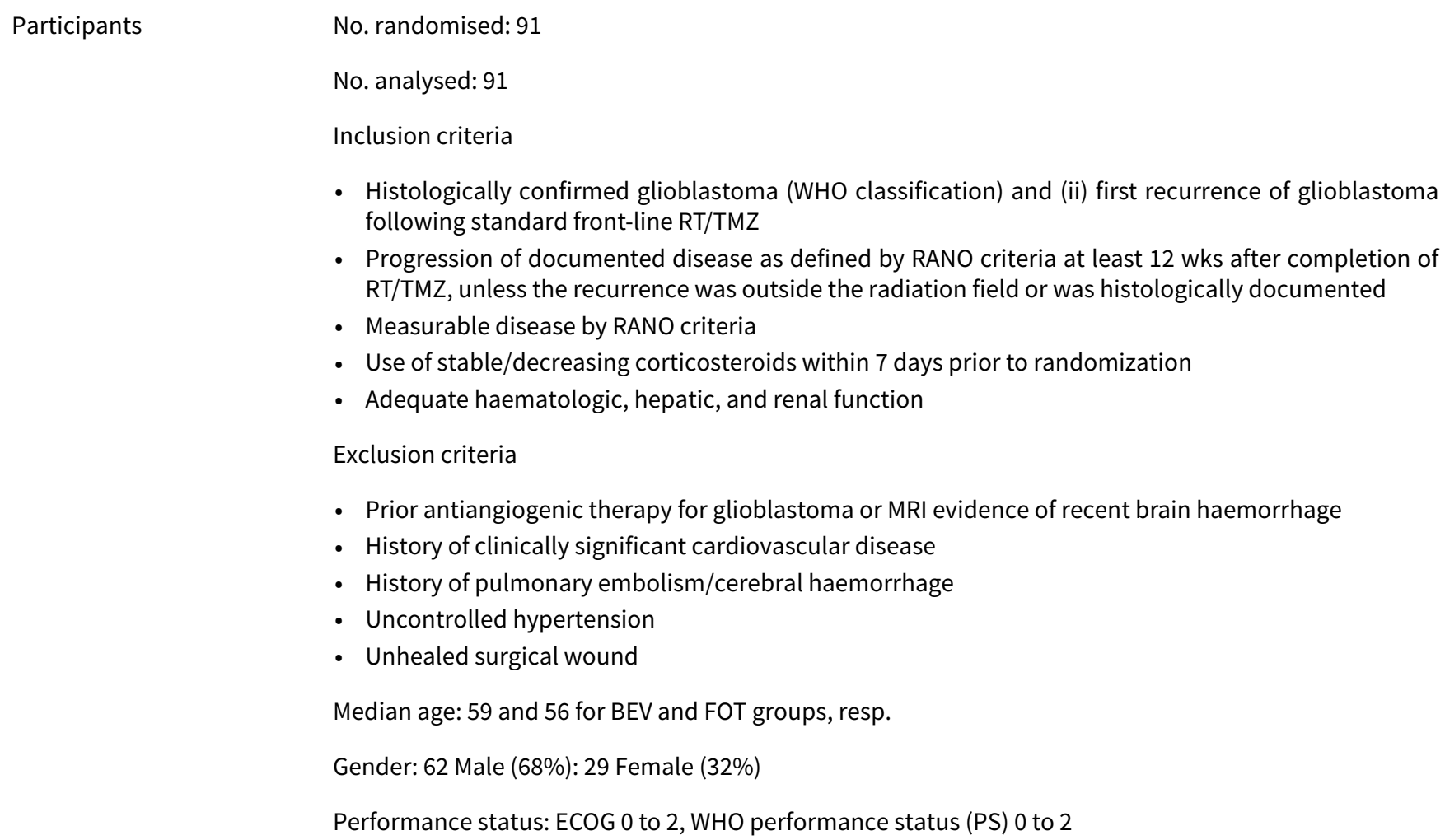

- Histologically confirmed glioblastoma (WHO classification) and (ii) first recurrence of glioblastoma following standard front-line RT/TMZ

- Progression of documented disease as defined by RANO criteria at least 12 wks after completion of RT/TMZ, unless the recurrence was outside the radiation field or was histologically documented

- Measurable disease by RANO criteria

- Use of stable/decreasing corticosteroids within 7 days prior to randomization

- Adequate haematologic, hepatic, and renal function

Exclusion criteria

- Prior antiangiogenic therapy for glioblastoma or MRI evidence of recent brain haemorrhage

- History of clinically significant cardiovascular disease

- History of pulmonary embolism/cerebral haemorrhage

- Uncontrolled hypertension

- Unhealed surgical wound

Median age: 59 and 56 for BEV and FOT groups, resp.

Gender: 62 Male (68\%): 29 Female (32\%)

Performance status: ECOG 0 to 2, WHO performance status (PS) 0 to 2

MGMT: data available from 73 participants of which 45 had MGMT+ $(62 \%$ overall; $58 \%$ and $68 \%$ of patients treated with bevacizumab and fotemustine, respectively)

Re-operation: 21 patients underwent surgical resection before study inclusion, 13 (22\%) in the bevacizumab arm and $8(25 \%)$ in the fotemustine arm.

Initial treatment details: RT + TMZ

Time from initial diagnosis: median from diagnosis to MRI at screening in days (range): BEV 331 (163 to 2271), FOT 462 (162 to 1383)

Arm 2 (32 pts): fotemustine $75 \mathrm{mg} / \mathrm{m}^{2}$ i.v. was administered on days 1,8 , and 15 (induction phase); after a 35-day break, patients received fotemustine $100 \mathrm{mg} / \mathrm{m}^{2}$ i.v. every 3 weeks (maintenance phase).

\begin{tabular}{ll}
\hline Outcomes & OS, PFS, QOL and AEs \\
\hline Notes & $\begin{array}{l}\text { Since fotemustine was only a balancing arm, no formal efficacy comparison was made between the } \\
\text { treatment arms. }\end{array}$ \\
\hline Risk of bias & Authors' judgement Support for judgement \\
\hline Bias &
\end{tabular}


Brandes 2016b (Continued)

Random sequence genera- Unclear risk Not described in the report. tion (selection bias)

\begin{tabular}{lll}
\hline $\begin{array}{l}\text { Allocation concealment } \\
\text { (selection bias) }\end{array}$ & Unclear risk described in the report.
\end{tabular}

Blinding of participants High risk Open label study

and personnel (perfor-

mance bias)

All outcomes

Blinding of outcome as-
sessment (detection bias) $\quad$ Unclear risk Not reported, but could be assumed "low" for primary outcome (OS)

All outcomes

Incomplete outcome data Low risk $\quad$ All patients were analysed.
(attrition bias)

All outcomes

\begin{tabular}{lll}
\hline $\begin{array}{l}\text { Selective reporting (re- } \\
\text { porting bias) }\end{array}$ & Low risk & Expected outcomes were reported. \\
\hline Other bias & Unclear risk & Funding and author interests noted. \\
\hline
\end{tabular}

Brandes 2018

\section{Study characteristics}

Design: Phase 2 randomized, double-blind, placebo-controlled, multicentre (51 sites); ratio 1:1
Country: Australia, Austria, Canada, Italy, Spain, Switzerland
Accrual dates: August 2013 to December 2014
Trial reg: NCT01860638 (TAMIGA)
Funding: Not clear. F. Hoffmann-La Roche Ltd.
Declaration of interests: Miguel Gil-Gil: F. Hoffmann-La Roche Ltd. (H, SAB); Frank Saran: F. Hoffmann-La
Roche Ltd., Bristol-Myers Squibb (C/A); Antoine F. Carpentier: F. Hoffmann-La Roche Ltd. (C/A, H); An-
na Nowak: F. Hoffmann-La Roche Ltd. (SAB); Warren Mason: F. Hoffmann-La Roche Ltd. (C/A); Gaetano
Finocchiaro: Bristol-Meyers Squibb (C/A); George Fountzilas: Pfizer, Sanofi, Roche (SAB), AstraZeneca
(H); Dana Michaela Cernea: F. Hoffmann-La Roche Ltd. (H); Oliver Chinot: F. Hoffmann-La Roche Ltd.,
Ipsen, AbbVie (C/A), Bristol-Myers Squibb, Celldex Therapeutics, Immatics, Servier Laboratories (H);
Martina Makrutzki: F. Hoffmann-La Roche Ltd. (E); Chiedzo Mpofu: F. Hoffmann-La Roche Ltd. (E, OI);
Hans-Joerg Urban: F. Hoffmann-La Roche Ltd. (E); Josef Pichler: F. Hoffmann-La Roche Ltd. (H). The
other authors declared no conflicts of interest

Participants No. randomised: 123

No. analysed: 123

Inclusion/exclusion criteria following progressive disease after treatment with chemoradiotherapy and surgical resection: documented progression according to RANO criteria; eligibility for second-line treatment with lomustine and bevacizumab; ECOG PS 0-2; bevacizumab well tolerated and not interrupted for longer than 60 days during first-line treatment; tissue submission among participants for whom operation/re-operation is indicated before second-line treatment starts; operation/re-operation performed 28 days or more after last bevacizumab administration and second-line treatment initiated at 
least 28 days after surgical wound healed; randomization within 28 days after progression among participants for whom operation/re-operation was not necessary

Exclusion: any other prior chemotherapy or RT for progression; prior or current anti-angiogenic treatment; treatment with any other investigational drug within 28 days or 2 investigational agent half-lives (whichever is longer) prior to study treatment; inadequate haematological, renal, or liver function; inadequately controlled hypertension; prior history of gastrointestinal perforation or abscess; clinically significant cardiovascular disease; history or evidence of central nervous system disease unrelated to cancer unless adequately treated with standard medical therapy; history or evidence of inherited bleeding diathesis or significant coagulopathy at risk of bleeding; serious non-healing wound, active ulcer, or untreated bone fracture; known hypersensitivity to any component of bevacizumab/placebo or any of the study drugs; active infection requiring IV antibiotics at start of study treatment; other malignancy within 5 years prior to study enrolment, except for carcinoma in situ of the cervix, basal or squamous cell skin cancer, localized prostate cancer, or ductal carcinoma in situ treated with curative intent; pregnant or lactating women; participation in any other study

Median age: 56 years (range 30 to 74 )

Gender: Male $\mathrm{n}=89(72 \%)$ Female $\mathrm{n}=34(28 \%)$

Performance status: ECOG $0=41 \%$, ECOG $1=41 \%$ and ECOG $2=19 \%$

MGMT: unmethylated: Arm $1=25$, Arm $2=26$. Methylated: Arm $1=12$, Arm $2=11$. Not all randomized patients had a valid MGMT status result.

Resection/biopsy: 8 underwent re-operation (7\%), the remainder did not.

Initial treatment details: first-line treatment included RT plus TMZ and BEV, followed by maintenance treatment with 6 cycles of TMZ plus BEV, then BEV monotherapy until first disease progression (PD1).

\begin{tabular}{|c|c|}
\hline \multirow[t]{4}{*}{ Interventions } & Arm 1 (61 pts): CCNU + BEV \\
\hline & Arm 2 (62 pts): CCNU + placebo \\
\hline & $\begin{array}{l}\text { The CCNU dose was } 90 \mathrm{mg} / \mathrm{m}^{2} \text { (maximum of } 160 \mathrm{mg} \text { ) every } 6 \text { weeks, increasing to } 110 \mathrm{mg} / \mathrm{m}^{2} \text { (maxi- } \\
\text { mum of } 200 \mathrm{mg} \text { ) in the absence of haematologic toxicity grade > } 1 \text { during the first cycle. }\end{array}$ \\
\hline & $\begin{array}{l}\text { The BEV dose was } 10 \mathrm{mg} / \mathrm{kg} \text { every } 2 \text { weeks (intravenous). At PD2, patients continued to receive BEV or } \\
\text { placebo (according to randomization at PD1) in addition to chemotherapy of investigator's choice. }\end{array}$ \\
\hline Outcomes & OS, SAE, HRQOL \\
\hline \multirow[t]{2}{*}{ Notes } & Participants in this study received BEV in addition to the Stupp protocol for primary treatment of GBM. \\
\hline & $\begin{array}{l}\text { This study was terminated prematurely because of a high drop-out rate and was underpowered to ad- } \\
\text { dress the primary objective. "No survival benefit was observed with the use of BEV through multiple } \\
\text { lines in patients with glioblastoma who had progressed after first-line treatment (radiotherapy + temo- } \\
\text { zolomide + BEV). No new safety concerns arose from the use of BEV through multiple lines of thera- } \\
\text { py." No P values are reported and only } 95 \% \text { confidence intervals (CIs) are shown. }\end{array}$ \\
\hline
\end{tabular}

\section{Risk of bias}

\section{Bias \\ Authors' judgement Support for judgement}

Random sequence genera- Unclear risk tion (selection bias)

The sequence generation was not clearly described in study report.

Allocation concealment $\quad$ Unclear risk
(selection bias)


Brandes 2018 (Continued)

Blinding of participants Low risk "Investigators and patients were blinded to this treatment". and personnel (performance bias)

All outcomes

\begin{tabular}{lll}
\hline $\begin{array}{l}\text { Blinding of outcome as- } \\
\text { sessment (detection bias) } \\
\text { All outcomes }\end{array}$ & Low risk & "Investigators and patients were blinded to this treatment". \\
\hline $\begin{array}{l}\text { Incomplete outcome data } \\
\text { (attrition bias) }\end{array}$ & Unclear risk & $\begin{array}{l}\text { "The study was terminated prematurely because of a high drop-out rate dur- } \\
\text { ing first-line treatment, implying underpowered (i.e. } 60 \%) \text { inferential testing; } \\
\text { only } 98 \text { of the targeted } 130 \text { OS events for the primary endpoint were reached in } \\
\text { the } 123 \text { randomized patients." }\end{array}$ \\
\hline
\end{tabular}

Selective reporting (re- Low risk Expected outcomes reported.

porting bias)

Other bias Unclear risk Funding and author interests noted.

Brown 2016

\section{Study characteristics}

Methods Design: multi-centre, 2-armed, double-blinded phase II RCT; ratio 1:1

Country: UK

Accrual dates: May 2011 and August 2012

Trial reg: NCT01310855

Funding: AstraZeneca, Cancer Research UK E/10/044, the National Institute of Health Research/Wellcome University College Hospital (NIHR/UCH) Clinical Research Facility, the University College Hospital/University College London (UCH/UCL) Biomedical Research Centre and UCL Experimental Cancer Medicine Centre, and the National Brain Appeal.

Declaration of interests: none of the authors declared any competing interests with respect to AstraZeneca.

Participants

No. randomised: 38

No. analysed: 38

Inclusion/exclusion criteria: life expectancy of 12 weeks; KPS > 70. MMSE $\geq 15$; presence of measurable tumour 7 days prior to enrolment; stable dose of steroids ( $8 \mathrm{mg} /$ day) for at least 5 days prior to baseline MRI; adequate bone marrow reserve (absolute neutrophil count $>1.5 \times 109 / \mathrm{L}$ ); serum bilirubin $<1.5$ $\times$ ULRR; ALT and AST< $5 \times$ ULRR. Excluded if enzyme-inducing anti-epileptic drugs used within 2 weeks prior to enrolment, pregnancy or breast-feeding, and infection with HIV or hepatitis B or C.

Median age: 57 (range 30 to 71 )

Gender: Female $11(29 \%)$, Male 27 (71\%)

Performance status: KPS $>80=68.4 \%$; KPS 70 to $80=31.6 \%$

MGMT: NR

Resection for recurrence: 6 patients (4 CED vs 2 GEF)

Details of initial treatment: surgery + RT + TMZ 
Brown 2016 (Continued)

Follow-up: at the time of the analysis, all patients had died, with a maximum follow-up time of 16.7 months.

\begin{tabular}{ll}
\hline Interventions & Arm 1 (19 pts): 30 mg CED plus 500 mg Gefitinib (both orally) \\
& Arm 2 (19 pts): 30 mg CED plus placebo (both orally) \\
\hline Outcomes & PFS, OS, HRQOL, SAEs \\
& HRQOL was assessed using the EORTC QLQ-C30 and the EORTC brain tumour module BN-20. Patients \\
& were invited to complete forms at baseline, at 6-weekly intervals, and at discontinuation of treatment. \\
\hline Notes & $\begin{array}{l}\text { Authors concluded that there was a trend towards increased survival with CED + GEF compared with } \\
\text { CED. Median OS was } 7.2 \text { months with CED + GEF and } 5.5 \text { months with CED + placebo. "Further studies of } \\
\text { the combination... are warranted." }\end{array}$
\end{tabular}

\section{Risk of bias}

\begin{tabular}{|c|c|c|}
\hline Bias & Authors' judgement & Support for judgement \\
\hline $\begin{array}{l}\text { Random sequence genera- } \\
\text { tion (selection bias) }\end{array}$ & Low risk & $\begin{array}{l}\text { "Online randomization system to produce/contain the numbers..." "Random- } \\
\text { ization was performed in the ratio } 1: 1 \text { using an algorithm stratified by dichoto- } \\
\text { mous factors of age...". }\end{array}$ \\
\hline $\begin{array}{l}\text { Allocation concealment } \\
\text { (selection bias) }\end{array}$ & Low risk & $\begin{array}{l}\text { "Upon receipt of registration...trial staff would use an online randomization } \\
\text { system to produce container numbers for the assigned treatment." }\end{array}$ \\
\hline $\begin{array}{l}\text { Blinding of participants } \\
\text { and personnel (perfor- } \\
\text { mance bias) } \\
\text { All outcomes }\end{array}$ & Low risk & $\begin{array}{l}\text { "The contents of the bottles were concealed from site staff, patients and trial } \\
\text { management" }\end{array}$ \\
\hline $\begin{array}{l}\text { Blinding of outcome as- } \\
\text { sessment (detection bias) } \\
\text { All outcomes }\end{array}$ & Unclear risk & Assessor blinding was not described. \\
\hline $\begin{array}{l}\text { Incomplete outcome data } \\
\text { (attrition bias) } \\
\text { All outcomes }\end{array}$ & Unclear risk & $\begin{array}{l}\text { "One patient on the cediranib plus gefitinib arm did not complete their med- } \\
\text { ication diary so is excluded from the results." }\end{array}$ \\
\hline $\begin{array}{l}\text { Selective reporting (re- } \\
\text { porting bias) }\end{array}$ & Low risk & Expected outcomes were reported. \\
\hline Other bias & Unclear risk & Funding and author interests noted. \\
\hline
\end{tabular}

Cloughesy 2017

\section{Study characteristics}

Design: randomized, double-blind, placebo-controlled, multicentre Phase II study
Country: 42 centres across 8 countries (USA, Italy, Spain, France, UK, Canada, Germany, Switzerland).
Accrual dates: June 2012 to January 2016
Trial reg: NCT01632228 (GO27819)
Funding: F. Hoffmann-La Roche.


Declaration of interests: Timothy Cloughesy Consulting or Advisory Role: Genentech, Celgene, Tocagen, VBLTherapeutics, NewGen Therapeutics, Novartis, Upsher-Smith, Proximagen, Lpath, StemCycle, Amgen, INSYS Therapeutics Expert Testimony:Roche Gaetano Finocchiaro Travel, Accommodations, Expenses: Roche for 19th Annual Scientific Meeting and Education Day of the Society for Neuro-Oncology (2014).Cristobal Belda-IniestáEmployment: HM Hospitales, Merck Serono Honoraria: Roche, AbbVie, Merck Serono Consulting or Advisory Role: Roche, AbbVi. among others.

\begin{tabular}{|c|c|}
\hline \multirow[t]{10}{*}{ Participants } & No. randomised: 129 \\
\hline & No. analysed: 129 \\
\hline & $\begin{array}{l}\text { Inclusion/exclusion criteria: prior treatment with chemoradiotherapy, no more than } 1 \text { prior line of } \\
\text { chemotherapy, no prior treatment with bevacizumab, no sensitivity to bevacizumab or onartuzum- } \\
\text { ab; Karnofsky performance status greater than or equal to }(\geq) 70 \%\end{array}$ \\
\hline & Median age: 57 years in ONA + BEV group and 55 years in BEV group \\
\hline & Gender: 83 Male (64\%), 46 Female (36\%) \\
\hline & Performance status: all KPS $\geq 70 \%$. \\
\hline & $\begin{array}{l}\text { MGMT: } 110 \text { patients }(O N A+B E V, n=56 ; \text { Pla }+B E V, n=54) \text { were analyzed for MGMT methylation status. } \\
47 \text { patients had methylated MGMT, } 57 \text { had unmethylated MGMT, and } 6 \text { patients had unconfirmed MGMT } \\
\text { status. }\end{array}$ \\
\hline & Resection/biopsy: complete resection (70), partial resection (49) and biopsy(7) \\
\hline & Initial treatment details: chemoradiotherapy (RT plus TMZ) \\
\hline & Time from initial diagnosis: NR \\
\hline \multirow[t]{2}{*}{ Interventions } & $\begin{array}{l}\text { Arm } 1 \text { ( } 64 \text { patients): onartuzumab intravenous (IV) infusion followed by bevacizumab IV infusion every } 3 \\
\text { weeks. }\end{array}$ \\
\hline & $\begin{array}{l}\text { Arm } 2 \text { ( } 65 \text { patients): placebo matched with onartuzumab followed by bevacizumab IV infusion every } 3 \\
\text { weeks. }\end{array}$ \\
\hline Outcomes & OS, PFS, SAES \\
\hline Notes & $\begin{array}{l}\text { "Median PFS and OS were longer with ONA + BEV }(\mathrm{n}=32) \text { compared with } \mathrm{Pla}+\mathrm{BEV}(\mathrm{n}=25) \text { in patients } \\
\text { with unmethylated MGMT; the median PFS was } 4.2 \mathrm{v} 2.8 \text { months, respectively }(\mathrm{HR}, 0.46 ; 95 \% \mathrm{Cl}, 0.25 \\
\text { to } 0.84 ; \mathrm{P}=.0108) \text { and the median OS was } 10.9 \mathrm{v} 7.5 \text { months, respectively }(\mathrm{HR}, 0.53 ; 95 \% \mathrm{Cl}, 0.26 \text { to } 1.10 \text {; } \\
\mathrm{P}=.0836) \text {." Authors concluded that there was "no evidence of further clinical benefit with the addition } \\
\text { of ONA to BEV compared with BEV plus placebo in unselected patients with glioblastoma in this study. } \\
\text { However, further investigation into biomarker subgroups is warranted." }\end{array}$ \\
\hline
\end{tabular}

\section{Risk of bias}

\begin{tabular}{lll}
\hline Bias & Authors' judgement & Support for judgement \\
\hline $\begin{array}{l}\text { Random sequence genera- } \\
\text { tion (selection bias) }\end{array}$ & Low risk & "randomly assigned 1:1 by interactive voice/Web response system..." \\
\hline $\begin{array}{l}\text { Allocation concealment } \\
\text { (selection bias) }\end{array}$ & Low risk & "randomly assigned 1:1 by interactive voice/Web response system..." \\
\hline $\begin{array}{l}\text { Blinding of participants } \\
\begin{array}{l}\text { and personnel (perfor- } \\
\text { mance bias) } \\
\text { All outcomes }\end{array}\end{array}$ & Low risk & "double blinded" \\
\hline
\end{tabular}


Cloughesy 2017 (Continued)

Blinding of outcome as- Unclear risk Not reported in the paper. sessment (detection bias)

All outcomes

Incomplete outcome data Low risk All patients accounted for.
(attrition bias)
All outcomes

Selective reporting (re- Low risk Expected outcomes reported.
porting bias)

Other bias Unclear risk funding and author interests noted.

\section{Cloughesy 2018}

\section{Study characteristics}

Design: Phase 3 multi-site, international, randomized, open-label, controlled trial
Country: Canada, Israel, USA
Accrual dates: August 2015 and January 2017
Trial reg: NCT02511405 (GLOBE)
Funding: VBL Therapeutics
Declaration of interests: YC, TRM, SFS, and NL-S are employees of VBL Therapeutics. LSF is a statistical
consultant to VBL Therapeutics and his institute (Gertner Institute for Epidemiology and Health Policy
Research) received payment for the statistical advice and analysis provided, among others.

\section{Participants}

\section{No. randomised: 256 \\ No. analysed: 256}

Inclusion/exclusion criteria: adults aged $>18$ years with first or second progression of histologically confirmed recurrent GBM, who had received previous treatment with standard of care radiotherapy and temozolomide. Additional key inclusion criteria included KPS of at least $70 \%$, life expectancy of at least 3 months, an interval of at least 12 weeks since the cessation of radiotherapy, and measurable disease by RANO criteria at time of progression. Patients treated with steroids had to be on a stable or decreasing dose. Exclusion criteria included prior anti-angiogenic therapy, history of recent grade 2 or higher CNS haemorrhage, gastrointestinal bleeding or pulmonary haemorrhage/haemoptysis, inherited bleeding diathesis or significant coagulopathy at risk of bleeding, surgical treatment or significant trauma within 4 weeks, active vascular disease, proliferative and/or vascular retinopathy, inadequately controlled hypertension, history of gastrointestinal perforation or abscess.

Age: mean age of patients was 55 years, all patients were $18+$.

Gender: 171 Male (67\%), 85 Female (33\%)

Performance status: PS of at least 70\%; 21\% had a KPS lower than 80

MGMT: $18 \%$ methylated, $40 \%$ unmethylated, $42 \%$ unknown $/$ missing

Resection/biopsy: NA

Initial treatment details: RT + TMZ

Details of treatment of first recurrence: 
Time from initial diagnosis: median time since initial diagnosis was 11.5 months.

Recurrence: approximately $74 \%$ had a first recurrence and $26 \%$ had a second recurrence

\begin{tabular}{ll}
\hline Interventions & Arm 1 (128 pts): VB-111 + bevacizumab \\
& Arm 2 (128 pts): bevacizumab \\
\hline
\end{tabular}

\begin{tabular}{ll}
\hline Outcomes & OS, PFS and SAES \\
\hline Notes & $\begin{array}{l}\text { Authors concluded that "concomitant VB111+bEV failed to improve outcomes in rGBM. Change of } \\
\text { treatment regimen with lack of VB111 monotherapy priming may explain the differences from the } \\
\text { favourable phase } 2 \text { results." }\end{array}$ \\
\hline
\end{tabular}

\title{
Risk of bias
}

\begin{tabular}{|c|c|c|}
\hline Bias & Authors' judgement & Support for judgement \\
\hline $\begin{array}{l}\text { Random sequence genera- } \\
\text { tion (selection bias) }\end{array}$ & Low risk & "treatment assignment was determined by central randomisation" \\
\hline $\begin{array}{l}\text { Allocation concealment } \\
\text { (selection bias) }\end{array}$ & Low risk & "treatment assignment was determined by central randomisation" \\
\hline $\begin{array}{l}\text { Blinding of participants } \\
\text { and personnel (perfor- } \\
\text { mance bias) } \\
\text { All outcomes }\end{array}$ & High risk & An open-label trial \\
\hline $\begin{array}{l}\text { Blinding of outcome as- } \\
\text { sessment (detection bias) } \\
\text { All outcomes }\end{array}$ & Low risk & "Assessed both locally and by a central blinded independent radiology review" \\
\hline $\begin{array}{l}\text { Incomplete outcome data } \\
\text { (attrition bias) } \\
\text { All outcomes }\end{array}$ & Low risk & "All 256 patients...were included in the efficacy analysis" \\
\hline $\begin{array}{l}\text { Selective reporting (re- } \\
\text { porting bias) }\end{array}$ & Low risk & Expected outcomes reported. \\
\hline Other bias & Unclear risk & Funding and author interests noted. \\
\hline
\end{tabular}

Cuncannon 2019

\section{Study characteristics}

Methods

\author{
Design: prospective, 2-arm \\ Country: Australia \\ Accrual dates: March 2013 to December 2016 \\ Trial reg: not found \\ Funding: no funding was received. BEV required patient funding under a pharmaceutical access \\ scheme involving a patient co-payment to a maximum of approximately EUR 12,000.
}


Inclusion/exclusion criteria: consecutive patients managed at a regional cancer centre, with adjuvant chemo-radiation therapy as per the EORTC-NCIC Protocol for newly diagnosed GBM from March 2013 to December 2016 were entered into a prospective database, approved by an Institutional Ethics Review Board. Elderly patients managed with hypofractionated RT were not included in the analysis. No patients were enrolled onto an intercurrent clinical trial during this study period. (Not very clear on other criteria).

Age: 18 to $70.43 / 55$ were $<50$ years

Gender: 24 females (44\%), 31 Male (56\%)

Performance status: median Karnofsky Performance Status score was 80 (range, 50 to 100).

MGMT: MGMT methylation status was only available on $51 \%$ of patients, and of these $43 \%$ had methylated tumours.

Resection/biopsy: 9 biopsys, 46 resections in total

Re-operation: NR

Initial treatment details: patients managed with adjuvant long course chemo-radiation therapy for GBM were entered into a prospective database. At chemorefractory symptomatic progression, patients were offered BEV or best supportive care. Re-irradiation (ReRT) was used with BEV in selected patients.

Elderly patients managed with hypo-fractionated RT were not included in the analysis.

Details of treatment of first occurrence:

Time from initial diagnosis:

Arm 2: Supportive care $(\mathrm{N}=15)$

Only 1 patient had a GBM with IDH mutation; remaining progression-free at 15 months and thus not included in the relapse analysis. 28 patients (51\%) had a near-total resection and $43(78 \%)$ had ECOG 0/1 status at start of RT.

MGMT methylation status was only available on $51 \%$ of patients, and of these $43 \%$ had methylated tumours. 45 patients have died with a median follow-up of 17.5 months in 10 remaining survivors at data censure. 1 patient death was unrelated to disease progression and was removed from analysis regarding BEV decision. Median OS from date of initial diagnosis was 17.0 months ( $95 \% \mathrm{Cl} 14.8$ to 19.2 ).

\section{Notes}

\section{Risk of bias}

\begin{tabular}{lll}
\hline Bias & Authors' judgement & Support for judgement \\
\hline $\begin{array}{ll}\text { Random sequence genera- } \\
\text { tion (selection bias) }\end{array}$ & High risk & $\begin{array}{l}\text { This prospective non-randomised study has an inherent risk of patient selec- } \\
\text { tion bias because patients chose whether to receive BEV or not and the cost of } \\
\text { BEV was usually the reason that patients chose not to participate (patients had } \\
\text { to bear up to EUR } 12,000 \text { of the cost). Patients choosing not to bear the cost } \\
\text { may have had a worse prognosis than those choosing to bear the cost. }\end{array}$
\end{tabular}


Cuncannon 2019 (Continued)

\begin{tabular}{lll}
$\begin{array}{l}\text { Allocation concealment } \\
\text { (selection bias) }\end{array}$ & High risk & See above. \\
\hline $\begin{array}{l}\text { Blinding of participants } \\
\text { and personnel (perfor- } \\
\text { mance bias) }\end{array}$ & Unclear risk & Not applicable. \\
All outcomes & &
\end{tabular}

\begin{tabular}{|c|c|c|}
\hline $\begin{array}{l}\text { Blinding of outcome as- } \\
\text { sessment (detection bias) } \\
\text { All outcomes }\end{array}$ & Unclear risk & Not applicable. \\
\hline $\begin{array}{l}\text { Incomplete outcome data } \\
\text { (attrition bias) } \\
\text { All outcomes }\end{array}$ & Low risk & All patients accounted for. \\
\hline $\begin{array}{l}\text { Selective reporting (re- } \\
\text { porting bias) }\end{array}$ & Low risk & No suspicion of selective reporting. \\
\hline Other bias & High risk & $\begin{array}{l}16 \text { patients in the BEV group also received } \mathrm{RT} \text { compared with none in the con- } \\
\text { trol group. This may represent a high risk of bias due to deviation from intend- } \\
\text { ed intervention. }\end{array}$ \\
\hline
\end{tabular}

\section{Dresemann 2010}

\section{Study characteristics}

Design: A randomized, multi-centre, open-label, phase 3 study; ratio 1:1.
Country: Multi-centre (Germany, Australia, Denmark, Norway)
Accrual dates: October 2004 and July 2006
Trial reg: NR
Funding: NR
Declaration of interests: NR

Participants
No. randomised: 240
No. analysed: 240
Inclusion/exclusion criteria: adult patients with a histologically confirmed GBM, measurable disease, and an Eastern Cooperative Oncology Group (ECOG) performance score $\leq 2$ who had previously under- gone surgery and received radiotherapy and prior chemotherapy were eligible for randomization. Pa- tients on steroids were required to have been on a stable dose for $\geq 5$ days. Patients at excessive risk of intracranial haemorrhagic events (evidence of intracranial haemorrhage in initial magnetic reso- nance imaging (MRI) scan or in MRI at less than 4 weeks after surgery) or with evidence of intratumoural haemorrhage at baseline scan, were not eligible.

Age: median age was 51, range 19 to 73

Gender: 152 Male (63\%), 88 Female (37\%)

Performance status: median KPS score was 80 (range, 50 to 100).

MGMT: NR 
Dresemann 2010 (Continued)

Initial treatment details: surgery $+\mathrm{RT}+\mathrm{TMZ}$

Re-operation: NR

Time from initial diagnosis: mean 18 months, SD 23, range 0 to 230

\begin{tabular}{ll}
\hline Interventions & Arm 1: HU alone $(\mathrm{n}=120)$ \\
& Arm 2: HU plus imatinib $(\mathrm{n}=120)$ \\
& Imatinib is an inhibitor of platelet derived growth factor receptor (PDGFR) and c-KIT receptors. \\
& Upon progression, patients with good performance status who were receiving HU alone were permit- \\
ted to switch to the combination arm. Only the first progression on treatment was evaluated for the pri- \\
mary end point.
\end{tabular}

\section{Risk of bias}

\section{Bias}

Random sequence generation (selection bias)

\section{Authors' judgement Support for judgement}

Unclear risk

Not specified in the report.

\begin{tabular}{|c|c|c|}
\hline $\begin{array}{l}\text { Allocation concealment } \\
\text { (selection bias) }\end{array}$ & Unclear risk & Not specified in the report. \\
\hline $\begin{array}{l}\text { Blinding of participants } \\
\text { and personnel (perfor- } \\
\text { mance bias) } \\
\text { All outcomes }\end{array}$ & High risk & Open-label \\
\hline $\begin{array}{l}\text { Blinding of outcome as- } \\
\text { sessment (detection bias) } \\
\text { All outcomes }\end{array}$ & Low risk & $\begin{array}{l}\text { "Blinded CIR data were used for the primary analyses on an intent to treat ba- } \\
\text { sis" and "all MRI scans and neurologic and steroid information were evaluated } \\
\text { at the local (investigator) study sites in addition to a review by a blinded cen- } \\
\text { tral independent reviewer" }\end{array}$ \\
\hline
\end{tabular}

Incomplete outcome data Low risk Expected outcomes were reported.

(attrition bias)

All outcomes

Selective reporting (re- Low risk None noted.
porting bias)

Other bias Unclear risk Investigator interests and funding not declared.

Duerinck 2018

\section{Study characteristics}

Mesign: multicentre, randomised, non-comparative 2-arm phase II clinical trial
Country: Belgium


Duerinck 2018 (Continued)

Accrual dates: August 2011 and July 2015

Trial reg: EudraCT: 2011-000900-16 / NCT01562197 part of study before amendment

Funding: Pfizer Belgium provided the study with medication and a research grant.

Declaration of interests: NR.

No. randomised: 101
No. analysed: 79
Inclusion/exclusion criteria: aged $\geq 18$ years or older and have tumour recurrence or progression follow-
ing prior treatment with surgery, radiation therapy and temozolomide. A measurable tumour lesion on
gadolinium-enhanced T1-MRI of the brain was required. An interval of at least 3 months was needed af-
ter ending prior radiotherapy as well as an interval of at least 4 weeks after the last administration of a
cytotoxic treatment or any other type of anti-glioblastoma treatment. No previous treatment with axi-
tinib or other VEGF-targeted drugs (including bevacizumab).

Age: $\geq 18$ yrs; median age 56 (range 27 to 79 )

Gender: 51 males and 28 females

Performance status: WHO PS $24 \%$ grade $0,34 \%$ grade $1,27 \%$ grade $2,15 \%$ grade 3 or 4

MGMT: methylated 19 unmethylated 43, unknown or missing 17

Resection/biopsy: resection $80 \%$, biopsy $20 \%$

Initial treatment details: surgery $+\mathrm{RT}+\mathrm{TMZ}$

Time from initial diagnosis: NR

\begin{tabular}{|c|c|}
\hline Interventions & $\begin{array}{l}\text { Arm } 1 \text { ( } 22 \text { pts): Control arm - physicians' best alternative therapy } \\
\text { Arm } 2 \text { ( } 50 \text { pts): Axitinib monotherapy (AXI) } \\
\text { Arm } 3 \text { ( } 31 \text { pts): axtinib + lomustine (AXI + LOM) }\end{array}$ \\
\hline Outcomes & PFS, OS and safety outcomes \\
\hline Notes & $\begin{array}{l}\text { PFS and OS were significantly longer in patients with MGMT-promoter hypermethylation (log-rank P= } \\
0.014 \text { and } 0.018 \text {, respectively) and in patients who were not on steroid treatment at baseline (log-rank } \\
\mathrm{P}=0.009 \text { and } 0.006 \text {, respectively). Authors concluded that "This trial provides clinical evidence that axi- } \\
\text { tinib as a monotherapy has anti-tumour activity in patients with recurrent GBM and that treatment can } \\
\text { be administered with an acceptable safety profile. There is no indication that upfront combination of } \\
\text { axitinib with lomustine improves the tumour response rate or survival and the risk for haematological } \\
\text { toxicity is increased." }\end{array}$ \\
\hline
\end{tabular}

\section{Risk of bias}

Bias Authors' judgement Support for judgement

Random sequence genera- Unclear risk No details on how random sequence was generated. tion (selection bias)

Allocation concealment $\quad$ Unclear risk No details on whether the allocation concealment was implemented.
(selection bias)

Blinding of participants Unclear risk This was not reported.
and personnel (perfor-
mance bias)


Duerinck 2018 (Continued)

All outcomes

Blinding of outcome as-
sessment (detection bias) $\quad$ Low risk $\quad$ Dropout rate was minimal.

sessment (detection bias)

All outcomes

Incomplete outcome data Unclear risk Primary outcomes were reported.
(attrition bias)

All outcomes

Selective reporting (re- Unclear risk $\quad$ HRs not reported.
porting bias)

porting bias)

Other bias Unclear risk 19/50 patients were allowed to cross over to AXI + LOM on progression.

The non-comparative findings are difficult to interpret in the absence of a concurrent non-AXI control group.

\section{Study characteristics}

Methods

Design: multicenter, sequential, stratified, non-blinded, randomized phase 2 study

Country: Australia

Accrual dates: November 2010 and March 2012

Trial reg: ACTRN12610000915055.

Funding: Roche Products Australia Pty Ltd

Declaration of interests: KF has received conference travel grants and honoraria from Roche for speaking invitations. EH has been a member of a Roche Advisory Board $2009-2013$. AN has been a member of a Roche Advisory board 2013 and received honoraria from Roche for speaking invitations. MR has been a member of a Roche Advisory Board. JS has received research funding from Roche. HW has received research funding from Roche and has been a member of a Roche Advisory board. EB, GF, PP, KS, $\mathrm{CB}, \mathrm{AL}$, and $\mathrm{LC}$ declare no conflict of interest. There is no stated conflict of interest for RF.

Inclusion/exclusion criteria: a histological diagnosis of GBM (WHO grade IV glioma) following resection or biopsy; patients had received treatment with both radiotherapy and temozolomide (concurrently and/or sequentially). Patients with first or subsequent recurrences were eligible to participate, provided that prior therapy had only included radiotherapy and temozolomide. Exclusion criteria included prior chemotherapy other than temozolomide, prior bevacizumab or other investigational agent for the treatment of glioma, surgery within 4 weeks before treatment commencement, evidence of recent haemorrhage on MRI with the exception of asymptomatic punctate haemorrhage or resolving postsurgical change, inability to undergo MRI, inadequately controlled hypertension, clinically significant cardiovascular disease, history of coagulation disorder, prior or concurrent malignancy (except non melanomatous skin cancer or malignancy treated and disease-free for 5 years), pregnancy or lactation, or other concurrent physical, psychological, or sociological condition that could jeopardize patient safety or compliance.

Age: 25 to 82

Gender: 55 females (45\%), 67 Males (55\%) 
Field 2015 (Continued)

Performance status: ECOG performance status $\leq 2$

MGMT: NR

Resection/biopsy: 15 biopsies, 70 resections

Details of treatment of first occurrence: all received radiotherapy and temozolomide.

Time from initial diagnosis: months from initial glioblastoma surgery to randomisation was median 11 months

\begin{tabular}{ll}
\hline Interventions & Arm 1: 10 mg bevacizumab monotherapy $(\mathrm{N}=62)$ \\
& Arm 2: $10 \mathrm{mg}$ bevacizumab + 5 AUC carboplatin $(\mathrm{N}=60)$ \\
\hline Outcomes & QOL, adverse events, PFS and OS. \\
\hline Notes & $\begin{array}{l}\text { Authors concluded that "Adding carboplatin resulted in more toxicity without additional clinical bene- } \\
\text { fit." }\end{array}$
\end{tabular}

Risk of bias

\begin{tabular}{|c|c|c|}
\hline Bias & Authors' judgement & Support for judgement \\
\hline $\begin{array}{l}\text { Random sequence genera- } \\
\text { tion (selection bias) }\end{array}$ & Unclear risk & Insufficient details to make a judgement \\
\hline $\begin{array}{l}\text { Allocation concealment } \\
\text { (selection bias) }\end{array}$ & Unclear risk & Not reported. \\
\hline $\begin{array}{l}\text { Blinding of participants } \\
\text { and personnel (perfor- } \\
\text { mance bias) } \\
\text { All outcomes }\end{array}$ & High risk & Not blinded. \\
\hline $\begin{array}{l}\text { Blinding of outcome as- } \\
\text { sessment (detection bias) } \\
\text { All outcomes }\end{array}$ & Low risk & $\begin{array}{l}\text { The primary endpoint, as well as the secondary and exploratory radiological } \\
\text { endpoints, were assessed by blinded central radiology review. }\end{array}$ \\
\hline $\begin{array}{l}\text { Incomplete outcome data } \\
\text { (attrition bias) } \\
\text { All outcomes }\end{array}$ & Low risk & Low attrition and intention-to-treat analysis used. \\
\hline $\begin{array}{l}\text { Selective reporting (re- } \\
\text { porting bias) }\end{array}$ & Low risk & Expected outcomes were reported. \\
\hline Other bias & Unclear risk & Funding and author interests noted. \\
\hline
\end{tabular}

Friedman 2009

\section{Study characteristics}

Methods Design: phase II, multicenter, open-label, non-comparative trial.

Country: USA

Accrual dates: June 2006 to February 2007 
Friedman 2009 (Continued)

\author{
Trial reg: NCT00345163.
}

Funding: Genentech

Declaration of interests: Numerous interests declared. Employment or leadership position: Jane Huang, Grenentech (c) Maoxia Zheng, Genentech, Consultant or Advisory Role:Henry S.Friedman, Genentech; Michael D. Prados, Genentech; Patrick Y.Wen, Genentech, Schering-Plough; Tom Mikkelsen,Schering-Plough; David Schiff, Genentech; Lauren E. Abrey,Genentech; W.K. Alfred Yung, Schering-Plough, Novartis;James Vredenburgh, Genentech; Martin K. Nicholas, Genentech. Honoraria:Henry S. Friedman, Genentech;Tom Mikkelsen, Genentech, Schering-Plough; Lauren E. Abrey, Genentech; W.K. Alfred Yung, Schering-Plough, Novartis; Timothy Cloughesy, Genentech Research Funding:Henry S. Friedman, Genentech; Michael D. Prados, Genentech; Patrick Y. Wen, Genentech;Tom Mikkelsen, Genentech; Lauren E. Abrey, Genentech, Pfizer; W.K. Alfred Yung, Genentech; Nina Paleologos, Genentech; Martin K.Nicholas, Genentech; James Vredenburgh, Genentech; Timothy Cloughesy, Genentech Expert Testimony: Michael D. Prados; Timothy Cloughesy

Participants

No. randomised: 167

No. analysed: 167

Inclusion/exclusion criteria

- Confirmed GBM in 1st or 2nd relapse and had disease progression confirmed by MRI $=<14$ days before the 1st study treatment

- Patients had been treated with standard RT + TMZ

- Life expectancy > 12 weeks

- Adequate haematologic (i.e. platelet count $\geq 100,000 / \mu \mathrm{L}$, absolute neutrophil count $\geq 1500 / \mu \mathrm{L}$ ), hepatic, and renal function.

- Patients taking corticosteroids were required to be on a stable or decreasing dose for 5 or fewer days before baseline MRI.

- Therapeutic systemic anticoagulation with low molecular weight heparin or warfarin was allowed.

Excluded if:

- previous treatment with prolifeprospan 20 with carmustine wafer, CPT-11, or anti-VEGF agents;

- MRI evidence of recent intracranial haemorrhage;

- history of bleeding diathesis or coagulopathy;

- clinically significant cardiovascular disease;

- arterial thromboembolism less than 6 months before the first study treatment;

- uncontrolled hypertension.

Age: range 23 to $79 \mathrm{yrs}$

Gender: male \& female

Performance status: KPS $\geq 70 \%$

MGMT: not reported

Resection/biopsy: not specified in inclusion criteria; partial resection 49.4\% BEV 53.7\% BEV + CPT-11; complete resection 42.4\% BEV 37.8\% BEV + CPT-11; only biospy $8.2 \%$ BEV 8.5\% BEV + CPT-11

Initial treatment details: RT + TMZ

Details of treatment of first occurrence (2nd line?):

Time from initial diagnosis: "The median time from initial diagnosis to study random assignment was 8.6 months for the BV group and 9.8 months for the BV + CPT-11 group." (pg 4735) 
Friedman 2009 (Continued)

Arm 2: bevacizumab + carboplatin $(N=79)$

\begin{tabular}{ll}
\hline Outcomes & Adverse events, PFS and OS and objective response \\
\hline Notes & "The randomized design of the trial was intended only to prevent bias in treatment assignment, and \\
there was no formal plan to compare outcomes in the two treatment groups." (pg. 4739)
\end{tabular}

\section{Risk of bias}

\begin{tabular}{|c|c|c|}
\hline Bias & Authors' judgement & Support for judgement \\
\hline $\begin{array}{l}\text { Random sequence genera- } \\
\text { tion (selection bias) }\end{array}$ & Unclear risk & Not described in the report. \\
\hline $\begin{array}{l}\text { Allocation concealment } \\
\text { (selection bias) }\end{array}$ & Unclear risk & Not described in the report. \\
\hline $\begin{array}{l}\text { Blinding of participants } \\
\text { and personnel (perfor- } \\
\text { mance bias) } \\
\text { All outcomes }\end{array}$ & High risk & Open-label study. \\
\hline $\begin{array}{l}\text { Blinding of outcome as- } \\
\text { sessment (detection bias) } \\
\text { All outcomes }\end{array}$ & Low risk & $\begin{array}{l}\text { "Progression and objective response were assessed by a blinded, independent } \\
\text { radiology facility according to WHO Response Evaluation Criteria, and corti- } \\
\text { costeroid dose was taken into account." }\end{array}$ \\
\hline $\begin{array}{l}\text { Incomplete outcome data } \\
\text { (attrition bias) } \\
\text { All outcomes }\end{array}$ & Low risk & Low attrition and most patients accounted for in analyses. \\
\hline $\begin{array}{l}\text { Selective reporting (re- } \\
\text { porting bias) }\end{array}$ & Unclear risk & All expected outcomes reported, except no HRs \\
\hline Other bias & Unclear risk & $\begin{array}{l}\text { "The randomized design of the trial was intended only to prevent bias in treat- } \\
\text { ment assignment, and there was no formal plan to compare outcomes in the } \\
\text { two treatment groups." } \\
\text { Numerous investigator interests declared. }\end{array}$ \\
\hline
\end{tabular}

Galanis 2017

\section{Study characteristics}

\begin{tabular}{ll}
\hline Methods & Design: randomised phase 2 study; open-label; ratio 1:1 \\
\hline Participants & No. randomised: 101 \\
No. analysed: 101 \\
Inclusion criteria: histological confirmation of glioblastoma multiforme; evidence of tumour progres- \\
sion following most recent anti-tumour therapy; measurable disease; ECOG 0-2; life expectancy $\geq 12$ \\
weeks \\
Age: Mean 55.8 (10.8) \\
Gender:72 males and 29 females \\
MGMT status: NR
\end{tabular}

Treatment options for progression or recurrence of glioblastoma: a network meta-analysis (Review) 
Galanis 2017 (Continued)

Performance status: ECOG 0-2

Initial treatment: NR

Time from diagnosis: NR

\begin{tabular}{ll}
\hline Interventions & Arm 1: bevacizumab and TRC105 \\
& Arm 2: BEV \\
\hline Outcomes & PFS, SAEs, OS, QOL \\
\hline Notes & Results data were obtained on the ClinicalTrials.gov website.
\end{tabular}

\section{Risk of bias}

\begin{tabular}{|c|c|c|}
\hline Bias & Authors' judgement & Support for judgement \\
\hline $\begin{array}{l}\text { Random sequence genera- } \\
\text { tion (selection bias) }\end{array}$ & Unclear risk & Insufficient details to make a judgement. \\
\hline $\begin{array}{l}\text { Allocation concealment } \\
\text { (selection bias) }\end{array}$ & Unclear risk & Insufficient details to make a judgement. \\
\hline $\begin{array}{l}\text { Blinding of participants } \\
\text { and personnel (perfor- } \\
\text { mance bias) } \\
\text { All outcomes }\end{array}$ & High risk & Open label \\
\hline $\begin{array}{l}\text { Blinding of outcome as- } \\
\text { sessment (detection bias) } \\
\text { All outcomes }\end{array}$ & Unclear risk & Insufficient details to make a judgement. \\
\hline $\begin{array}{l}\text { Incomplete outcome data } \\
\text { (attrition bias) } \\
\text { All outcomes }\end{array}$ & Unclear risk & $\begin{array}{l}\text { All patients were analysed for the primary outcome. High risk for QoL out- } \\
\text { come, as only } 65 \text { patients were evaluated. }\end{array}$ \\
\hline $\begin{array}{l}\text { Selective reporting (re- } \\
\text { porting bias) }\end{array}$ & Unclear risk & This study has not been published in a peer-reviewed journal. \\
\hline Other bias & Unclear risk & $\begin{array}{l}\text { There is an agreement between Principal Investigators and the Sponsor (or its } \\
\text { agents) that restricts the PI's rights to discuss or publish trial results after the } \\
\text { trial is completed. }\end{array}$ \\
\hline
\end{tabular}

Galanis 2019

\section{Study characteristics}

Methods

Design: RCT, Phase 2, double blinded, 2 arms; ratio 2:1

Country: USA

Accrual dates: October 2009 to November 2014

Trial reg: NCT00892177

Funding: supported by the National Cancer Institute of the National Institutes of Health under awards UG1CA189823 (Alliance for Clinical Trials in Oncology National Cancer Institute Community Oncolo- 
Galanis 2019 (Continued)

gy Research Program Grant) U10CA180821, U10CA180882, and U10CA180833. Some funding also from Bristol-Myers Squibb and Genentech.

Declaration of interests: numerous interests declared. Evanthia Galanis - funding from MedImmune Inc, Denovo Biopharma, Tracon, Genentech, and Bristol- Myers Squibb; has acted as a paid member of the advisory board for (compensation to Mayo Clinic) Vyriad, Celgene Corporation, and KIYATEC; has acted as a paid general consultant (compensation to Mayo Clinic) for F. Hoffman La Roche Ltd; and has acted as a paid general consultant for Tactical Therapeutics Inc and Oncorus for work performed outside of the current study.

Participants
No. randomised: 128

No. analysed: 121

Inclusion/exclusion criteria

- Evidence of tumour progression and measurable and evaluable disease by MRI or CT

- Acceptable haematologic, liver, and renal function

- Eastern Cooperative Oncology Group (ECOG) performance status of 0 to 2

- $\geq 12$ weeks from the completion of prior radiotherapy; $\geq 4$ weeks from prior chemotherapy (6 weeks for nitrosourea-based regimens)

- having received up to 2 prior chemotherapy regimens with $\leq 1$ regimen for recurrent disease; and no prior treatment with angiogenesis inhibitors or dasatinib

The main exclusion criteria were inadequately controlled hypertension; comorbid systemic illnesses or other severe concurrent disease; other active malignancy $\leq 3$ years prior to registration, with the exception of non-melanotic skin cancer or carcinoma in situ of the cervix; history of myocardial infarction or unstable angina $\leq 6$ months prior to registration

Age: 115 patients were < 70 (95\%), 6 patients were $>70$ (5\%). Median age was 57, range was 18 to 79 .

Gender: 44 Female (36\%), 77 Male (67\%)

Performance status: $\mathrm{ECOG} \leq 2$

MGMT: NR

Resection/biopsy: NR

Initial treatment details: not clear but likely RT + TMZ.

Details of treatment of first recurrence: varied.

Time from initial diagnosis: 7.3 months and 7.7 months, respectively

Interventions Arm A ( $\mathrm{N}=83$ ): bevacizumab plus dasatinib, $(100 \mathrm{mg}$ twice daily dasatinib orally, $10 \mathrm{mg} / \mathrm{kg}$ of iv bevacizumab (> 90 minutes) on day 1 of each 14-day cycle)

Arm $B(N=38)$ : bevacizumab plus placebo, (placebo from day 1 to day 14 of each 14-day cycle and 10 $\mathrm{mg} / \mathrm{kg}$ of IV bevacizumab (> 90 minutes) on day 1 of each 14-day cycle)

Outcomes QOL, PFS, Objective response, OS, TTD, SAES

Notes

Authors concluded that "...the combination of bevacizumab with dasatinib did not appear to significantly improve the outcomes of patients with recurrent GBM compared with bevacizumab alone."

\section{Risk of bias}


Galanis 2019 (Continued)

Random sequence genera- Unclear risk Not described in the report.
tion (selection bias)

\begin{tabular}{lll}
\hline $\begin{array}{l}\text { Allocation concealment } \\
\text { (selection bias) }\end{array}$ & Unclear risk & Not described in the report. \\
\hline $\begin{array}{l}\text { Blinding of participants } \\
\text { and personnel (perfor- }\end{array}$ & Low risk & Described as "double-blind". \\
$\begin{array}{l}\text { mance bias) } \\
\text { All outcomes }\end{array}$ & &
\end{tabular}

\begin{tabular}{|c|c|c|}
\hline $\begin{array}{l}\text { Blinding of outcome as- } \\
\text { sessment (detection bias) } \\
\text { All outcomes }\end{array}$ & Low risk & Radiographic responses were verified by central review \\
\hline $\begin{array}{l}\text { Incomplete outcome data } \\
\text { (attrition bias) }\end{array}$ & Low risk & All patients were evaluated for the primary end-points. \\
\hline
\end{tabular}

All outcomes

\begin{tabular}{lll}
\hline $\begin{array}{l}\text { Selective reporting (re- } \\
\text { porting bias) }\end{array}$ & Low risk & All expected outcomes reported. \\
\hline Other bias & Unclear risk & Funding and author interests noted. \\
\hline
\end{tabular}

\section{Gilbert 2017}

\section{Study characteristics}

Mesign: randomised, multicentre, phase 2 trial
Country: USA
Accrual dates: 1 March 2007,
Trial reg: RTOG 062
Funding: this project was supported by grants U10CA21661, U10CA180868, U10CA180822, U10CA37422,
and U24CA180803 from the National Cancer Institute (NCI).
Declaration of interests: Dr. Gilbert reports personal fees and non-financial support from Merck, per-
sonal fees from Genentech Roche, personal fees from Abbvie, personal fees from Wellcome Trust, and
personal fees from Foundation Medicine, outside the submitted work. Dr. Sorensen reports employ-
ment by Siemens Healthcare, outside the submitted work. Dr. Mikkelsen has a consulting or advisory
role with Roche Genentech and has received honoraria, travel and research funding from Roche Genen-
tech, outside the submitted work. Dr. Penas-Prado has received research funding from Bayer, Genen-
tech, Glaxo, and Novartis, outside the submitted work. Dr. Mehta has a leadership role with Pharma-
cyclics, stock or ownership interest in Pharmacyclics, consulting or advisory roles with Cavion, Elekta,
Novartis and Novocure, and has received research funding from Novocure and Novellos, outside the
submitted work

Participants

No. randomised: 123

No. analysed: 117

Inclusion/exclusion criteria

\section{Inclusion}

- Recurrent or progressive GBM or gliosarcoma 
- Failed RT + TMZ

- $\mathrm{KPS} \geq 70$

- No limits placed on the number of prior treatment regimens

- Patients with prior treatment with interstitial brachytherapy, stereotactic radiosurgery or Gliadel ${ }^{\circledR}$ wafers (polifeprosan 20 with carmustine implant) were required to have histologic evidence of recurrent tumour

- Measurable tumour was not required if the patient underwent a repeat tumour resection prior to enrolment

- RT completed at least 42 days prior enrolment

- Age $\geq 18$

- Karnofsky Performance status $\geq 70$

- Systolic blood pressure $\leq 160 \mathrm{mg} \mathrm{Hg}$ or diastolic pressure $\leq 90 \mathrm{mg} \mathrm{Hg}$

- Adequate haematologic function (white blood cell count $(\mathrm{WBC}) \geq 3,000 / \mu \mathrm{L}$, absolute neutrophil count $(\mathrm{ANC}) \geq 1,500 / \mu \mathrm{L}$, platelet count $\geq 100,000$ cells $/ \mu \mathrm{L}$, and haemoglobin $\geq 10 \mathrm{gm} / \mu \mathrm{L}$ ) renal and hepatic function

- On a stable or decreasing dose of corticosteroids for the 5 days prior to study enrolment

\section{Exclusion}

- Ongoing treatment with a hepatic-enzyme-inducing anticonvulsant

- Acute intratumoural haemorrhage on MR imaging

- Active comorbid condition including recent (<6 months) myocardial infarction

- Unstable angina

- Uncontrolled hypertension or history of recent (< 6 months) stroke or transient ischemic attack

- Major surgical procedure or history of abdominal abscess or fistula or gastrointestinal perforation within 28 days of study enrollment

Age: median 58 yrs (range 24 to 82) BEV + TMZ, 55 yrs (range 23 to 78) BEV CPT

Gender: male $58 \%$ vs female $42 \%$

Performance status: KPS 70 to 80 52\%, KPS 90 to $10048 \%$

MGMT: not reported

Resection/biopsy: not reported

Initial treatment details: RT + TMZ

Details of treatment of first recurrence: not reported

Time from initial diagnosis: not reported

\begin{tabular}{ll}
\hline Interventions & $\operatorname{Arm} 1(\mathrm{~N}=60): \operatorname{BEV}(10 \mathrm{mg} / \mathrm{kg} \mathrm{q} 2 \mathrm{wk})+\mathrm{IRI}\left(125 \mathrm{mg} / \mathrm{m}^{2} \mathrm{q} 2 \mathrm{wk}\right)$ \\
& $\operatorname{Arm} 2(\mathrm{~N}=60): \operatorname{BEV}(10 \mathrm{mg} / \mathrm{kg} \mathrm{q} 2 \mathrm{wk})+\operatorname{TMZ}\left(75\right.$ to $\left.100 \mathrm{mg} / \mathrm{m}^{2} 21 / 28\right)$
\end{tabular}

Outcomes PFS, SAEs, OS, objective response

Notes

\section{Risk of bias}

Bias Authors' judgement Support for judgement

Random sequence genera- Unclear risk No details reported.


Gilbert 2017 (Continued)

Allocation concealment Unclear risk
(selection bias)

Blinding of participants Unclear risk No information given on blinding.
and personnel (perfor-
mance bias)
All outcomes

\begin{tabular}{lll}
\hline $\begin{array}{l}\text { Blinding of outcome as- } \\
\text { sessment (detection bias) } \\
\text { All outcomes }\end{array}$ & Unclear risk & Not described in report. \\
\hline $\begin{array}{l}\text { Incomplete outcome data } \\
\begin{array}{l}\text { (attrition bias) } \\
\text { All outcomes }\end{array}\end{array}$ & Low risk & Low attrition and all patients accounted for. \\
\hline $\begin{array}{l}\text { Selective reporting (re- } \\
\text { porting bias) }\end{array}$ & Low risk & Expected outcomes were reported. \\
\hline Other bias & Unclear risk & Funding and author interests noted. \\
\hline
\end{tabular}

Heiland 2016

\section{Study characteristics}

Design: retrospective, 2-arm study.
Country: Germany
Accrual dates: 2010 and 2014
Trial reg: NR
Funding: NR
Declaration of interests: author AW has received honorarium from Roche Pharma AG and was a mem-
ber of the scientific advisory board at Roche Pharma AG.

\section{Participants}

No. randomised: 43

No. analysed: 35

Inclusion criteria: age older than 18 years; histopathological confirmation of a glioblastoma multiforme (WHO criteria); recurrent GBM after adjuvant radiochemotherapy with TMZ and following TMZ highdose therapy; repetitive surgery, CCNU monotherapy and/or re-radiotherapy.

Age: mean age in BEV arm 39.5, mean age in BEV/CCNU arm was 50 years.

Gender: 16 Female (43\%), 21 Male (57\%)

Performance status: NR

MGMT: methylated 6 vs 4 in arm 1 and arm 2, respectively; unmethylated 10 vs 13 in arm 1 and arm 2 respectively.

Resection/biopsy: NR

Initial treatment details: all patients with first diagnosis of GBM were treated with a total or near total resection of the brain tumour followed by standard chemoradiation ( $60 \mathrm{~Gy}$, concomitant TMZ $75 \mathrm{mg} / \mathrm{kg}$ BW) followed by adjuvant TMZ (5/23 regimen, 150 to $200 \mathrm{mg} / \mathrm{kg}$ ) 
Heiland 2016 (Continued)

Time from initial diagnosis: NR

\begin{tabular}{ll} 
Outcomes & PFS, OS, Adverse events. \\
\hline Notes & This study evaluated "last line" or third-line therapy. Authors concluded that "Last-line therapy with \\
& BEV/CCNU results in a longer PFS and OS compared to BEV monotherapy and is well-tolerated."
\end{tabular}

\section{Risk of bias}

\begin{tabular}{lll}
\hline Bias & Authors' judgement & Support for judgement \\
\hline $\begin{array}{l}\text { Random sequence genera- } \\
\text { tion (selection bias) }\end{array}$ & High risk & Non-randomised study (retrospective). \\
\hline $\begin{array}{l}\text { Allocation concealment } \\
\text { (selection bias) }\end{array}$ & High risk & $\begin{array}{l}\text { This study is at risk of selection bias as patients would most likely have been } \\
\text { selected for treatments based on clinical factors. Patients had various pre- } \\
\text { treatments and it is not clear why they were selected to receive the treatments } \\
\text { studied. }\end{array}$ \\
\hline
\end{tabular}

Blinding of participants Unclear risk Not applicable.

and personnel (perfor-

Arm 1: BEV monotherapy group were treated with $10 \mathrm{mg} / \mathrm{kg}$ BW every 2 weeks. $(\mathrm{N}=17)$ Arm 2: BEV/CCNU group was treated with CCNU in the dose of $90 \mathrm{mg} / \mathrm{m}^{2}$ every 6 weeks and BEV in the dose of $5 \mathrm{mg} / \mathrm{kg}$ BW every 2 weeks. $(\mathrm{N}=18)$

mance bias)

All outcomes

\begin{tabular}{lll}
\hline $\begin{array}{l}\text { Blinding of outcome as- } \\
\text { sessment (detection bias) } \\
\text { All outcomes }\end{array}$ & Unclear risk & Not described, but the OS outcome can be assumed to be at low risk of bias. \\
\hline $\begin{array}{l}\text { Incomplete outcome data } \\
\text { (attrition bias) } \\
\text { All outcomes }\end{array}$ & Unclear risk & $8(18.6 \%)$ out of 43 were excluded due to missing data. \\
\hline $\begin{array}{l}\text { Selective reporting (re- } \\
\text { porting bias) }\end{array}$ & Unclear risk & None suspected. \\
\hline $\begin{array}{l}\text { Other bias } \\
\text { Unclear risk }\end{array}$ & $\begin{array}{l}\text { Baseline characteristics reported were similar between the 2 groups, except } \\
\text { that the average age of patients in the BEV arm was younger than the BEV + } \\
\text { LOM arm, and there were slightly more IDH-1 wild types (13/17 vs 10/18). }\end{array}$ \\
\hline
\end{tabular}

\section{Kim 2015}

\section{Study characteristics}

Design: retrospective, 5-arm study
Country: Korea
Accrual dates: January 2002 and December 2011
Trial reg: NA
Funding: not stated.


Kim 2015 (Continued)

Declaration of interests: the authors declare that they have no financial or other conflicts of interest in relation to this research and its publication

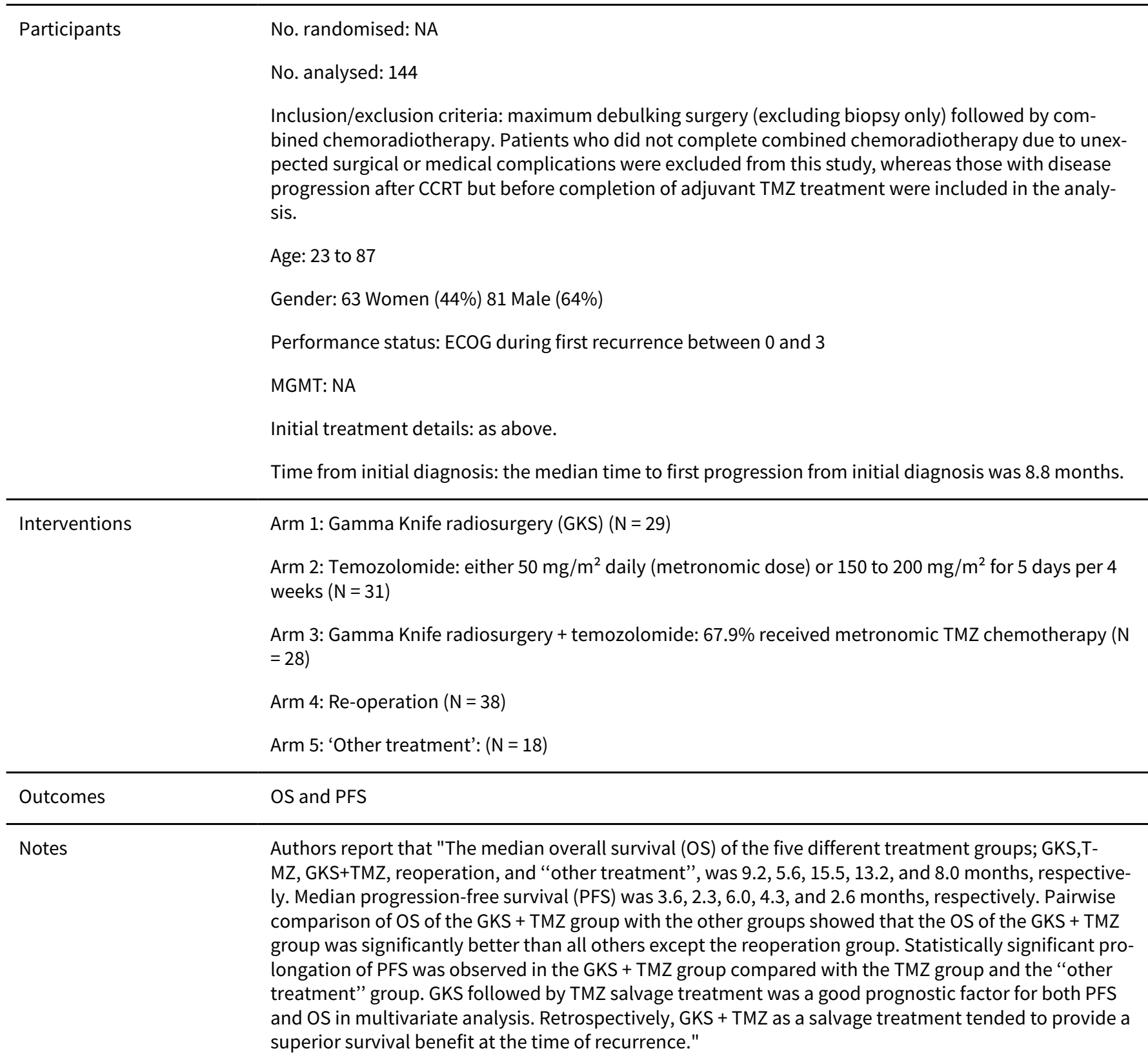

\section{Risk of bias}

\begin{tabular}{lll}
\hline Bias & Authors' judgement & Support for judgement \\
\hline $\begin{array}{l}\text { Random sequence genera- } \\
\text { tion (selection bias) }\end{array}$ & High risk & This is a non-randomised study at high risk of selection bias. \\
\hline $\begin{array}{l}\text { Allocation concealment } \\
\text { (selection bias) }\end{array}$ & Unclear risk & $\begin{array}{l}\text { This non-randomised study is at risk of selection bias because it is not clear } \\
\text { why patients received 1 treatment or another. }\end{array}$ \\
\hline $\begin{array}{l}\text { Blinding of participants } \\
\text { and personnel (perfor- } \\
\text { mance bias) }\end{array}$ & Unclear risk & Not applicable. \\
\hline
\end{tabular}


Kim 2015 (Continued)

All outcomes

Blinding of outcome as-
sessment (detection bias) $\quad$ Unclear risk $\quad$ Not reported.

sessment (detection bias)

All outcomes

Incomplete outcome data Unclear risk

(attrition bias)

222 pts were eligible but 78 were excluded due to inadequate follow up data or

All outcomes because they received no further salvage therapy due to progressive disease.

Selective reporting (re- Low risk Not suspected.
porting bias)

\begin{tabular}{ll}
\hline Other bias & Bagh risk \\
& age, sex, performance status at first progression, the extent of surgery, adju- \\
vant TMZ cycles and the time to first progression in the five groups". However, \\
tumour volume was smaller in those receiving GKS, GKS + TMZ and other treat- \\
ments, and larger amongst those receiving TMZ only and re-operation. These \\
factors are likely to influence the effectiveness of the treatments.
\end{tabular}

\section{Study characteristics}

Randomised phase III multicentre trial; ratio 2:1
Country: 52 medical centres, mainly in USA but also Germany, Israel, the Netherlands, Canada and the
UK
Accrual dates: March 2004 to December 2005
Trial reg: NCT00076986
Funding: Commercial funding. NeoPharm Inc
Declaration of interests: 1 author reports an agreement between the Food and Drug Administration and
NeoPharm Inc with a patent on the therapeutic agent evaluated, along with NIH and Val-Chum. A sec-
ond author serves as a consultant and receives a fee from NeoPharm Inc, Eisai, and Schering-Plough
and lecture fees from Schering-Plough and Genentech.

No. analysed: 276. (269 included in safety evaluation: i.e. received any study drugs)

Inclusion/exclusion criteria: adult patients with first recurrence of GBM. Patients were excluded if they were unable to undergo surgical procedures necessary for the placement of the GW. Patients that had previously received either of the 2 study drugs, had had prior brachytherapy, radiosurgery or other investigational intracerebral agents were also excluded.

Age: $48 \%<55,52 \% \geq 55$. Similar proportions in each treatment group. Mean age CB 54.8 (sd 11.23); GW 54.7 (SD 11.06)

Gender: 90 (33\%) female 62 (34\%) CB; 28 (30\%) GW. 186 (67\%) male 121 (66\%) CB; 65 (70\%) GW.

Performance status: KPS similar proportions in both treatment arms: 70, 13\%; 80, 21\%; 90, 45\%; 100, 20\%. Mean CB: 86.9 (SD 9.46); GW 87.7 (SD 9.22)

MGMT status: not stated

Initial treatment details: surgery plus chemoradiotherapy (> $80 \%$ of cases) 
Time from initial diagnosis: (time from initial diagnosis to study resection) median weeks SB 32.14; GW 30.43 .

Interventions

Arm 1: (192 patients) Convection enhanced delivery (CED) of intraparenchymal cintredekin besudotox (CB) (also known as IL13-PE38QQR). Catheter placement ( 2 to 4 catheters) 2 to 7 days post-operatively after tumour resection in areas at greatest risk of infiltrating disease. A CT scan was used to confirm appropriate catheter placement and infusion started 24 hours later at a concentration of $0.5 \mathrm{mi}-$ $\mathrm{crog} / \mathrm{mL}$ and a total rate of $0.750 \mathrm{~mL} / \mathrm{h}$ for 96 hours. (Neurosurgeons had received training in catheter placement).

Arm 2: (104 patients) Intraparenchymal gliadel wafers (GW). Wafers were placed immediately following resection and MRI performed within 48 hours.

Clinical and radiographic assessment every 8 weeks.
Primary outcome: overall survival (from randomisation)
Secondary outcomes: safety and toxicity. Health related quality of life.
Toxicity was assessed using the Cancer Therapy Evaluation Program Common Terminology Criteria for
Adverse Events, version 3.0.

Adverse Events, version 3.0.

Notes

\section{Risk of bias}

\begin{tabular}{|c|c|c|}
\hline Bias & Authors' judgement & Support for judgement \\
\hline $\begin{array}{l}\text { Random sequence genera- } \\
\text { tion (selection bias) }\end{array}$ & Unclear risk & $\begin{array}{l}\text { Randomisation before gross total resection of their tumour. Methods not de- } \\
\text { scribed in report. }\end{array}$ \\
\hline $\begin{array}{l}\text { Allocation concealment } \\
\text { (selection bias) }\end{array}$ & Unclear risk & Not described. \\
\hline $\begin{array}{l}\text { Blinding of participants } \\
\text { and personnel (perfor- } \\
\text { mance bias) } \\
\text { All outcomes }\end{array}$ & Unclear risk & $\begin{array}{l}\text { Study treatments were not masked. Staff (and probably patients) would be } \\
\text { aware of treatment allocation. OS probably unaffected by lack of blinding but } \\
\text { other outcomes such as QoL may have been affected. }\end{array}$ \\
\hline $\begin{array}{l}\text { Blinding of outcome as- } \\
\text { sessment (detection bias) } \\
\text { All outcomes }\end{array}$ & Low risk & $\begin{array}{l}\text { It was reported that the investigators and sponsor were blind to allocation } \\
\text { and results until after efficacy analysis was performed by an independent data } \\
\text { monitoring committee. A blinded committee assessed compliance with surgi- } \\
\text { cal procedures }\end{array}$ \\
\hline $\begin{array}{l}\text { Incomplete outcome data } \\
\text { (attrition bias) } \\
\text { All outcomes }\end{array}$ & Low risk & $\begin{array}{l}\text { There was some loss to follow-up but it appeared balanced across groups ( } 296 \\
\text { randomised, } 276 \text { underwent treatments, } 269 \text { available for safety analysis) }\end{array}$ \\
\hline $\begin{array}{l}\text { Selective reporting (re- } \\
\text { porting bias) }\end{array}$ & Low risk & $\begin{array}{l}\text { Not apparent, ITT and by protocol analysis (patients that had received } 90 \% \text { of } \\
\text { study drug). Power calculation based on median survival. Interim analysis af- } \\
\text { ter } 160 \text { deaths, and efficacy analysis after } 250 \text { deaths. }\end{array}$ \\
\hline Other bias & Low risk & Patient characteristics were similar in the 2 arms. \\
\hline
\end{tabular}


Lombardi 2019

\section{Study characteristics}

Methods

Design: randomised, multicentre, open-label phase 2 trial done in 10 centres in Italy

Country: Italy

Accrual dates: 27 November 2015, and 23 February 2017

Trial reg: NCT02926222.

Funding: Veneto Institute of Oncology and Bayer Italy.

Declaration of interests: Veneto Institute of Oncology received a grant from Bayer to partially support the study. GL received personal fees from Bayer, outside the submitted work. GL, GLDS, and SI are coinventors in a pending patent application: development of a biomarker predictive of response to regorafenib in glioblastoma patients (number: 102018000003449). BD reports personal fees and non-financial support from Bayer and Bristol-Myers Squibb; personal fees from IPSEN, EISAI, Lilly, MSD and Merck; and non-financial support from Sanofi, outside the submitted work. VZ reports personal fees and an advisory role from Bristol-Myers Squibb; an advisory role and travel and accommodation expenses from Celgene; non-financial support, an advisory role, and travel and accommodation expenses from Merck; personal fees and non-financial support from Bayer and Roche; and personal fees from Pfizer, Janssen, Novartis, Astellas, and Servier, outside the submitted work.

Participants

No. randomised: 119

No. analysed: 119

Inclusion criteria

- Histologically confirmed glioblastoma with first progression after surgery followed by RT + TMZ

- Disease progression on MRI as defined by Response Assessment in Neuro-Oncology (RANO) criteria 26 at least 12 weeks after completion of radiotherapy

- At least 1 target lesion with a diameter of at least $10 \mathrm{~mm}$; on a stable or decreasing dose of steroids for 1 week before the base-line MRI scan

- Adequate bone marrow and liver function

Exclusion criteria

- Previous chemotherapy for recurrent disease

- Previous treatment with regorafenib or any other VEGFR-targeting kinase inhibitor

- Treatment with temozolomide within the previous 4 weeks

- Recurrent disease located outside of the brain

- Uncontrolled hypertension (systolic blood pressure $>140 \mathrm{~mm} \mathrm{Hg}$ or diastolic blood pressure $>90 \mathrm{~mm}$ $\mathrm{Hg}$ ); myocardial infarction less than 6 months before the start of study treatment; arterial thrombotic or embolic events within 6 months before the start of study treatment; active or chronic hepatitis B or $C$ virus infection requiring treatment with antiviral therapy; and use of strong cytochrome P3A4 (CYP3A4) inhibitors or inducers.

Age: $18+$

Gender: 35 women (29\%), 84 men (71\%)

Performance status: Eastern Cooperative Oncology Group (ECOG) performance status score of 1 or lower (or Karnofsky performance score $\geq 70$ ).

MGMT: arm 1 49\% vs arm 2 46\% methylated

Initial treatment details: RT + TMZ

Time from initial diagnosis: median time between diagnosis and first recurrence were 10.7 months vs 9.8 months, respectively. 
Lombardi 2019 (Continued)

Interventions

Arm 1: regorafenib $160 \mathrm{mg}$ (given as $4 \times 40 \mathrm{mg}$ tablets) orally once daily for the first 3 weeks of each 4week cycle $\mathrm{N}=59$

Arm 2: lomustine $110 \mathrm{mg} / \mathrm{m}^{2}$ (in $40 \mathrm{mg}$ capsules, up to a maximum dose of $200 \mathrm{mg}$ ) orally on day 1 of every 6 -week cycle until disease progression $\mathrm{N}=60$

Outcomes $\quad$ OS, HRQOL, PFS, SAEs, objective response

Notes

Authors concluded "REGOMA showed an encouraging overall survival benefit of regorafenib in recurrent glioblastoma. This drug might be a new potential treatment for these patients and should be investigated in an adequately powered phase 3 study."

Also reported in a conference abstract that "HRQOL did not change during REG treatment. Pts treated with REG and LOM reported no significant difference in HRQoL."

\section{Risk of bias}

\begin{tabular}{lll}
\hline Bias & Authors' judgement & Support for judgement \\
\hline $\begin{array}{l}\text { Random sequence genera- } \\
\text { tion (selection bias) }\end{array}$ & Low risk & $\begin{array}{l}\text { "Eligible patients were randomly assigned (1:1) to receive regorafenib or lo- } \\
\text { mustine by a web-based system, stratified in block sizes of four by centre and } \\
\text { surgery at recurrence (yes vs no)" }\end{array}$ \\
\hline $\begin{array}{l}\text { Allocation concealment } \\
\text { (selection bias) }\end{array}$ & Unclear risk & Not clear from the study report. \\
\hline $\begin{array}{l}\text { Blinding of participants } \\
\text { and personnel (perfor- } \\
\text { mance bias) } \\
\text { All outcomes }\end{array}$ & High risk & "Neither investigators nor patients were masked to treatment allocation." \\
\hline
\end{tabular}

$\begin{array}{lll}\begin{array}{l}\text { Blinding of outcome as- } \\ \text { sessment (detection bias) } \\ \text { All outcomes }\end{array} & \text { High risk } & \text { "Neither investigators nor patients were masked to treatment allocation." "Re- } \\ \text { sponse was evaluated by the local investigator based on RANO criteria." }\end{array}$

Incomplete outcome data Low risk All patients accounted for in main paper.

(attrition bias)

All outcomes

Selective reporting (re- Low risk $\quad$ Expected outcomes were reported.
porting bias)

Other bias Unclear risk $\quad$ Funding and author interests noted.

Modh 2018

\section{Study characteristics}

$\begin{array}{ll}\text { Methods } & \text { Design: randomized trial } \\ \text { Country: USA } \\ \text { Accrual dates: February } 2012 \text { to December } 2016 \\ \text { Trial reg: NR } \\ \text { Funding: NR }\end{array}$


Modh 2018 (Continued)

Declaration of interests: NR

\begin{tabular}{|c|c|}
\hline \multirow[t]{11}{*}{ Participants } & No. randomised: 34 \\
\hline & No. analysed: 34 \\
\hline & $\begin{array}{l}\text { Inclusion/exclusion criteria: high-grade glioma patients with tumour progression after } 2 \text { previous treat- } \\
\text { ment regimens were enrolled. }\end{array}$ \\
\hline & Age: $18+$ \\
\hline & Gender: NR \\
\hline & Performance status: NR \\
\hline & MGMT: NR \\
\hline & Resection/biopsy: NR \\
\hline & Initial treatment details: NR \\
\hline & Details of treatment of first recurrence: NR. The median number of prior recurrences was 3. \\
\hline & Time from initial diagnosis: NR \\
\hline \multirow[t]{2}{*}{ Interventions } & $\begin{array}{l}\text { Arm } 1(n=\text { ?): fractionated radiosurgery with bevacizumab (FSRS was delivered as } 32 \text { Gy ( } 8 \text { Gy } \times 4 \text { treat- } \\
\text { ments within } 2 \text { weeks) to the gross target volume (gadolinium enhancing lesion and DWI abnormality), } \\
\text { and } 24 \text { Gy }(6 \text { Gy } \times 4) \text { to the clinical target volume (FLAIR abnormality). }\end{array}$ \\
\hline & $\begin{array}{l}\text { Arm } 2(n=\text { ?): bevacizumab with irinotecan, temozolomide, or carboplatin (discretion of the treating } \\
\text { provider) }\end{array}$ \\
\hline Outcomes & PFS, OS \\
\hline Notes & Trial data were reported as a conference abstract only. \\
\hline
\end{tabular}

\section{Risk of bias}

\begin{tabular}{lll}
\hline Bias & Authors' judgement & Support for judgement \\
\hline $\begin{array}{l}\text { Random sequence genera- } \\
\text { tion (selection bias) }\end{array}$ & Unclear risk & Insufficient information to make a judgement \\
\hline $\begin{array}{l}\text { Allocation concealment } \\
\text { (selection bias) }\end{array}$ & Unclear risk & Insufficient information to make a judgement \\
\hline $\begin{array}{l}\text { Blinding of participants } \\
\text { and personnel (perfor- } \\
\text { mance bias) } \\
\text { All outcomes }\end{array}$ & Unclear risk & Insufficient information to make a judgement \\
\hline $\begin{array}{l}\text { Blinding of outcome as- } \\
\text { sessment (detection bias) } \\
\text { All outcomes }\end{array}$ & Unclear risk & Insufficient information to make a judgement \\
\hline $\begin{array}{l}\text { Incomplete outcome data } \\
\text { (attrition bias) } \\
\text { All outcomes }\end{array}$ & Unclear risk & Insufficient information to make a judgement \\
\hline $\begin{array}{l}\text { Selective reporting (re- } \\
\text { porting bias) }\end{array}$ & Unclear risk & \\
\hline
\end{tabular}


Modh 2018 (Continued)

$\begin{array}{ll}\text { Other bias } \quad \text { Unclear risk } & 7 / 34(20.6 \%) \text { patients had AA and } 27 / 34(79.4 \%) \text { had GBM, therefore borderline } \\ \text { for review participant criteria. }\end{array}$

Narita 2019

\section{Study characteristics}

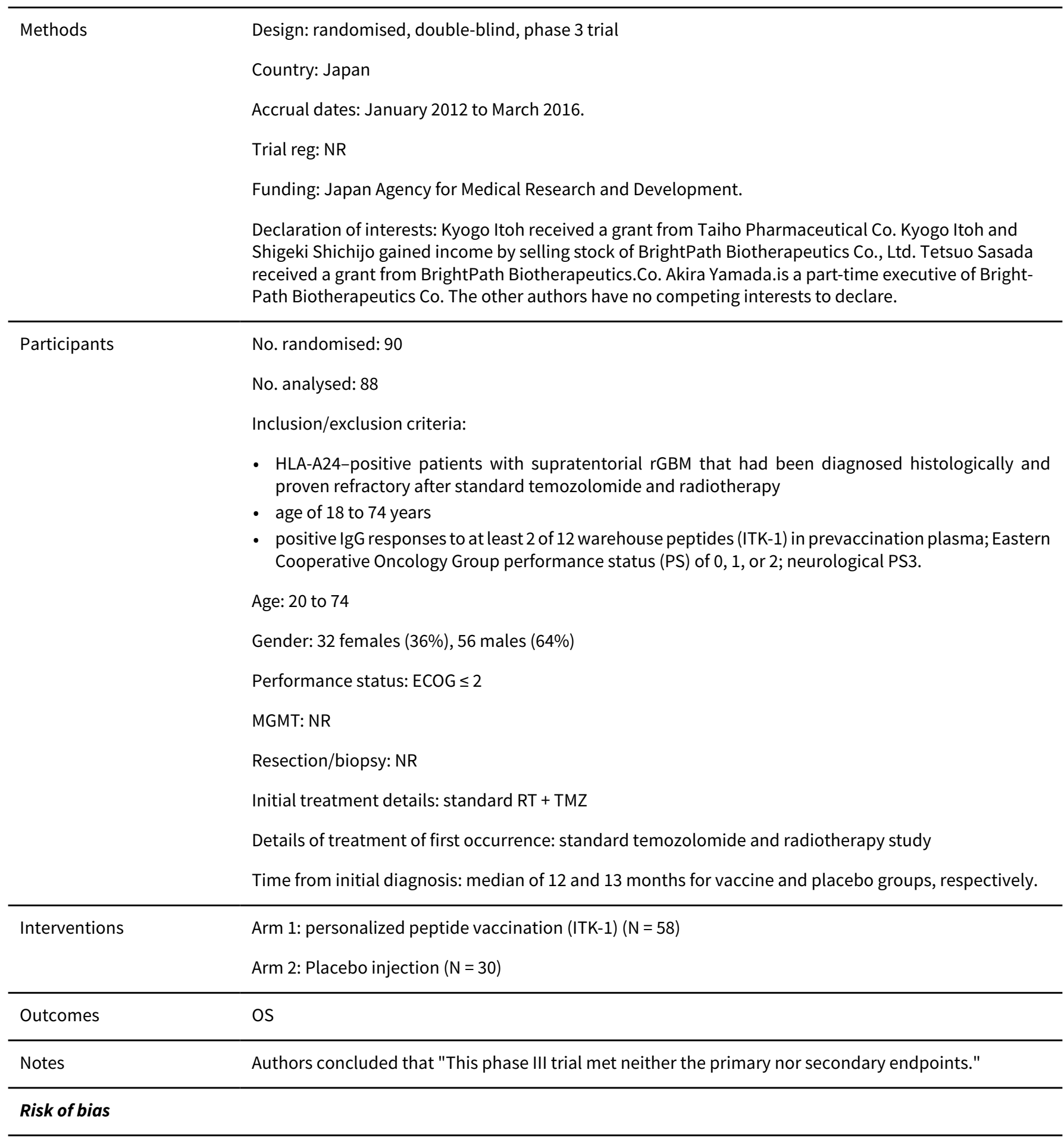


Narita 2019 (Continued)

Bias Authors' judgement Support for judgement

$\begin{aligned} & \text { Random sequence genera- } \\ & \text { tion (selection bias) }\end{aligned} \quad$ Low risk 2:1 allocation was performed by computer-generated block randomization"

tion (selection bias)

Allocation concealment Unclear risk Insufficient detail for judgement.

(selection bias)

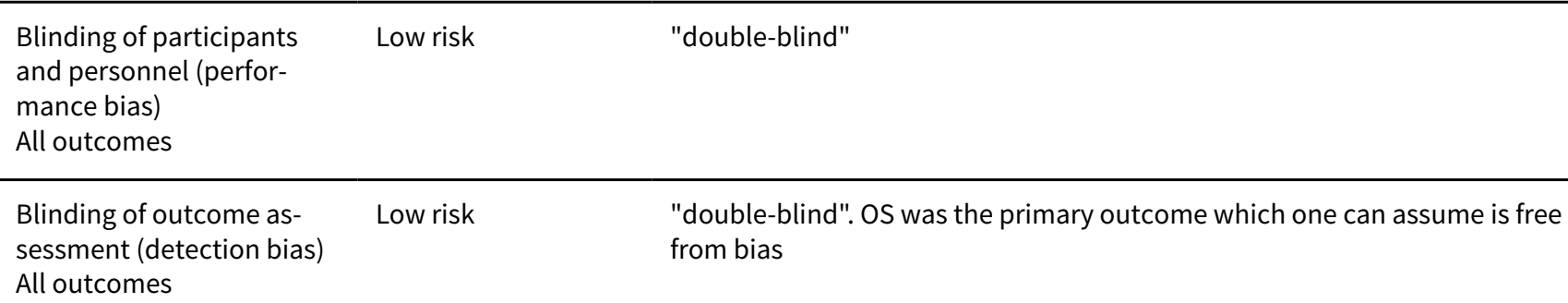

Incomplete outcome data Low risk Minimal attrition - "two dropped out before receiving their first treatment".

(attrition bias)

All outcomes

Selective reporting (re- Low risk $\quad$ None suspected.
porting bias)

\begin{tabular}{ll}
\hline Other bias $\quad$ Unclear risk & Funding and author interests noted. \\
\hline
\end{tabular}

\section{Study characteristics}

\begin{tabular}{ll}
\hline Methods & Design: RCT, multicentre \\
Country: USA \\
Accrual dates: February 2014 and September 2014 \\
Trial reg: NCT02017717 \\
Funding: Bristol-Myers Squibb. \\
Declaration of interests: none stated.
\end{tabular}

Participants

No. randomised: 20

No. analysed: 20

Inclusion criteria

- $\geq 18$ and had a histologically confirmed diagnosis GBM or gliosarcoma

- at least 1 measurable lesion with at least 2 perpendicular enhancing diameters measuring $\geq 10 \mathrm{~mm}$.

Exclusion

- If they had more than 1 recurrence of GBM; diagnosis of secondary GBM; evidence of extracranial metastatic or leptomeningeal disease; active, known, or suspected autoimmune disease; or prior treatment with an anti-PD-1 or anti-CTLA-4 therapy.

Age: NIV median 58.5 (range 42 to 73), NIVO1 + IPI3 median 57 (range 37 to 68), NIVO3 + IPI1 median 60 (range 27 to 73 ) 
Omuro 2018 (Continued)

Gender: male $=25$, female $=15$

Performance status: KPS of $\geq 70 \%$

MGMT: $20 \%$ methylated, 50\% unmethylated

Resection/biopsy/re-operation: NR

Initial treatment details: standard first-line treatment with at least radiotherapy and temozolomide

Time from initial diagnosis: Mths (range) 9.7 (3.7 to 48.9) median 8.4 (5.1 to 23), respectively

\begin{tabular}{ll}
\hline Interventions & Arm 1: nivolumab (NIV) $(\mathrm{n}=10)$ \\
& Arm 2: NIV+ipilimumab (IPI) $(\mathrm{n}=10)$ \\
\hline Outcomes & Safety, tolerability, objective response, PFS \\
& OS was analysed as an exploratory ad hoc objective. \\
\hline Notes & $\begin{array}{l}\text { Authors concluded that "Nivolumab monotherapy was better tolerated than nivolumab + ipilimumab; } \\
\text { the tolerability of the combination was influenced by ipilimumab dose. These safety and exploratory } \\
\text { findings merit further investigation of immunotherapies in glioblastoma." }\end{array}$ \\
\hline
\end{tabular}

\section{Risk of bias}

\begin{tabular}{|c|c|c|}
\hline Bias & Authors' judgement & Support for judgement \\
\hline $\begin{array}{l}\text { Random sequence genera- } \\
\text { tion (selection bias) }\end{array}$ & Unclear risk & Insufficient detail to make a judgement \\
\hline $\begin{array}{l}\text { Allocation concealment } \\
\text { (selection bias) }\end{array}$ & Unclear risk & Insufficient detail to make a judgement \\
\hline $\begin{array}{l}\text { Blinding of participants } \\
\text { and personnel (perfor- } \\
\text { mance bias) } \\
\text { All outcomes }\end{array}$ & Unclear risk & Insufficient detail to make a judgement \\
\hline $\begin{array}{l}\text { Blinding of outcome as- } \\
\text { sessment (detection bias) } \\
\text { All outcomes }\end{array}$ & Unclear risk & Insufficient detail to make a judgement \\
\hline $\begin{array}{l}\text { Incomplete outcome data } \\
\text { (attrition bias) } \\
\text { All outcomes }\end{array}$ & Low risk & All patients accounted for. \\
\hline $\begin{array}{l}\text { Selective reporting (re- } \\
\text { porting bias) }\end{array}$ & Low risk & None suspected. \\
\hline Other bias & Unclear risk & Small sample size. "OS was analysed as an ad hoc exploratory objective" \\
\hline
\end{tabular}

\section{Puduvalli 2018}

\section{Study characteristics}


Puduvalli 2018 (Continued)

Country: USA

Accrual dates: NR

Trial ID: NR

Funding: NR

\begin{tabular}{ll}
\hline Participants & No. randomised: 90 \\
& No. analysed: 74 \\
Included if: adults $(\geq 18$ yrs) with histologically confirmed GBMs recurrent after prior radiation and \\
temozolomide therapy, adequate organ function, KPS $\geq 60$, and no prior bevacizumab/HDAC inhibitors \\
Age: NR \\
Gender: NR \\
Performance status: KPS $\geq 60$ \\
MGMT status: \\
Initial treatment: RT +TMZ \\
Time from diagnosis: NR \\
\hline Arm 1: BEV + vorinostat \\
Arm 2: BEV \\
\hline Interventions \\
\hline PFS, OS, QOL, toxicity \\
\hline Sparse data as conference abstract only.
\end{tabular}

\section{Risk of bias}

\begin{tabular}{|c|c|c|}
\hline Bias & Authors' judgement & Support for judgement \\
\hline $\begin{array}{l}\text { Random sequence genera- } \\
\text { tion (selection bias) }\end{array}$ & Unclear risk & Insufficient details to make a judgement. \\
\hline $\begin{array}{l}\text { Allocation concealment } \\
\text { (selection bias) }\end{array}$ & Unclear risk & Insufficient details to make a judgement. \\
\hline $\begin{array}{l}\text { Blinding of participants } \\
\text { and personnel (perfor- } \\
\text { mance bias) } \\
\text { All outcomes }\end{array}$ & Unclear risk & Insufficient details to make a judgement. \\
\hline $\begin{array}{l}\text { Blinding of outcome as- } \\
\text { sessment (detection bias) } \\
\text { All outcomes }\end{array}$ & Unclear risk & Insufficient details to make a judgement. \\
\hline $\begin{array}{l}\text { Incomplete outcome data } \\
\text { (attrition bias) } \\
\text { All outcomes }\end{array}$ & Unclear risk & Insufficient details to make a judgement. 90 randomised but only 74 analysed. \\
\hline $\begin{array}{l}\text { Selective reporting (re- } \\
\text { porting bias) }\end{array}$ & Unclear risk & $\begin{array}{l}\text { Insufficient details to make a judgement. Not reported in full yet. QoL data not } \\
\text { reported in the conference abstract. }\end{array}$ \\
\hline
\end{tabular}


Puduvalli 2018 (Continued)

Other bias Unclear risk Insufficient details to make a judgement.

Reardon 2011

\section{Study characteristics}

Mesign: 2-arm, open-label, phase II randomised study
Country: USA
Accrual dates: August 2008 and January 2010
Trial reg: NR
Funding: 5 R37 CA11898; NIH Grant MO1 RR 30, GCRCProgram, NCRR; and NCI SPORE 1 P20 CA096890;
and a grant from Genentech Pharmaceuticals.
Declaration of interests: not stated

Participants

No. randomised: 23

No. analysed: 23

Inclusion/exclusion criteria: patients with recurrent GBM including progression on prior bevacizumab-based therapy. Eligible patients were also: on a stable corticosteroid dose for at least 1 week; at least 4 weeks between surgical resection or chemotherapy, and at least 12 weeks between radiotherapy. There were no limits based on either the number of prior episodes of progression or therapeutic regimens received.

Patients were excluded for: grade $\geq 3$ toxicity on prior bevacizumab; progressive disease or grade $\geq 3$ toxicity on any prior protracted temozolomide schedule; progressive disease or grade $\geq 3$ toxicity on prior metronomic etoposide; uncontrolled hypertension; therapeutic anticoagulation use; acute haemorrhage on baseline MRI; urine protein: creatinine ratio > 1; pregnancy or nursing; active infection requiring intravenous antibiotics; and prior stereotactic radiosurgery, radiation implants, or radiolabeled monoclonal antibody therapy unless there was unequivocal disease progression.

Age: $18+$

Gender: 25 Male 100\%

Performance status: had a KPS $\geq 60 \%$

MGMT: NR

Resection/biopsy: NA

Initial treatment details: RT + TMZ + BEV

Time from initial diagnosis: range time from initial diagnosis 39.1 to 217.9 weeks.

Interventions Arm 1: metronomic temozolomide $\left(50 \mathrm{mg} / \mathrm{m}^{2} /\right.$ day orally) plus bevacizumab $(10 \mathrm{mg} / \mathrm{kg}$ intravenously every 14 days) $\mathrm{N}=10$

Arm 2: metronomic etoposide $\left(50 \mathrm{mg} / \mathrm{m}^{2}\right.$ of etoposide daily for 21 consecutive days of each 28 day cycle) plus bevacizumab (10 mg/kg intravenously every 14 days) $\mathrm{N}=13$ 
Reardon 2011 (Continued)

Notes

Heavily pretreated patients with recurrent GBM. Authors concluded that "Metronomic etoposide or temozolomide is ineffective when administered with bevacizumab among recurrent GBM patients who have progressed on prior bevacizumab therapy".

\section{Risk of bias}

\begin{tabular}{|c|c|c|}
\hline Bias & Authors' judgement & Support for judgement \\
\hline $\begin{array}{l}\text { Random sequence genera- } \\
\text { tion (selection bias) }\end{array}$ & Unclear risk & Not described in the report. \\
\hline $\begin{array}{l}\text { Allocation concealment } \\
\text { (selection bias) }\end{array}$ & Unclear risk & Not described in the report. \\
\hline $\begin{array}{l}\text { Blinding of participants } \\
\text { and personnel (perfor- } \\
\text { mance bias) } \\
\text { All outcomes }\end{array}$ & High risk & An open-label study. \\
\hline $\begin{array}{l}\text { Blinding of outcome as- } \\
\text { sessment (detection bias) } \\
\text { All outcomes }\end{array}$ & Unclear risk & Not described in the report. \\
\hline $\begin{array}{l}\text { Incomplete outcome data } \\
\text { (attrition bias) } \\
\text { All outcomes }\end{array}$ & Low risk & Study closed after interim analysis and findings were reported for 23 patients. \\
\hline $\begin{array}{l}\text { Selective reporting (re- } \\
\text { porting bias) }\end{array}$ & Unclear risk & OS data are not reported. \\
\hline Other bias & High risk & $\begin{array}{l}\text { This study was terminated after interim analysis due to lack of efficacy in both } \\
\text { intervention groups. }\end{array}$ \\
\hline
\end{tabular}

Reardon 2015b

\section{Study characteristics}

Methods

Multicentre phase I/II trial. Phase II was 3-arm in ratio 1:1:1

Country: Canada and USA

Accrual dates: July 2008 to May 2011

Funding: Boehringer Ingelheim

Declaration of interests: David A. Reardon is a paid member of the advisory boards for Genentech/Roche, Novartis, Merck/Schering, and EMD/Serono. Agnieszka Cseh, Yali Fu, Julie Cong, Sven Wind are employees of Boehringer Ingelheim. David D. Eisenstat has received honoraria from Merck (formerly Schering Oncology Canada) and 1-time consultancy fees from Boehringer Ingelheim. Others have nothing to declare.

$\begin{array}{ll}\text { Participants } & \text { Randomised } 119 \\ & \text { Analysed } 119 \\ \text { Inclusion criteria }\end{array}$


Reardon 2015b (Continued)

- Histologically confirmed WHO grade 4 malignant glioma at first recurrence after temozolomide chemoradiotherapy

- Bidimensionally measurable disease (tumour $\geq 10 \mathrm{~mm}$ in 1 diameter)

- $\mathrm{KPS} \geq 70 \%$.

Exclusion criteria were

- 12 weeks from radiotherapy

- 2 weeks from surgery, chemotherapy, or investigational drugs

- progressive disease (PD) or toxicity with prior protracted temozolomide dosing

- previous EGFR-targeted therapy or bevacizumab

- $\geq 2$ disease recurrences

- or known interstitial lung disease

Age: mean 56.3 years \pm 10.3

Gender: $61.3 \%$ male

Performance status: KPS $\geq 70$

Resection: NR

Initial treatment: standard chemoradiotherapy

Time from diagnosis: NR

Interventions

Arm 1: afatinib $40 \mathrm{mg} /$ day $(\mathrm{n}=41)$

Arm 2: Afatinib $40 \mathrm{mg} /$ day plus TMZ $75 \mathrm{mg} / \mathrm{n}^{2}(\mathrm{n}=39)$

Arm 3: TMZ 75 mg/day

Outcomes PFS, SAEs, OS

Notes

Authors concluded that "Afatinib has a manageable safety profile but limited single-agent activity in unselected recurrent GBM patients."

\section{Risk of bias}

\begin{tabular}{lll}
\hline Bias & Authors' judgement & Support for judgement \\
\hline $\begin{array}{l}\text { Random sequence genera- } \\
\text { tion (selection bias) }\end{array}$ & Unclear risk & Insufficient detail to make a judgement. \\
\hline $\begin{array}{l}\text { Allocation concealment } \\
\text { (selection bias) }\end{array}$ & Unclear risk & Insufficient detail to make a judgement. \\
\hline $\begin{array}{l}\text { Blinding of participants } \\
\text { and personnel (perfor- } \\
\text { mance bias) }\end{array}$ & Unclear risk & Insufficient detail to make a judgement. \\
$\begin{array}{l}\text { All outcomes } \\
\text { Blinding of outcome as- } \\
\text { sessment (detection bias) } \\
\begin{array}{l}\text { All outcomes } \\
\text { Incomplete outcome data }\end{array}\end{array}$ & Low risk risk & "response assessment was evaluated before odd cycles by both the investiga- \\
$\begin{array}{l}\text { (attrition bias) } \\
\text { All outcomes }\end{array}$ & tor and an independent review committee (ICON Medical Imaging)" \\
\hline
\end{tabular}

Treatment options for progression or recurrence of glioblastoma: a network meta-analysis (Review) Copyright @ 2021 The Cochrane Collaboration. Published by John Wiley \& Sons, Ltd. 
Reardon 2015b (Continued)

Selective reporting (re- Low risk Expected outcomes were reported. porting bias)

Other bias

Unclear risk

Funding and author interests noted.

Reardon 2018a

\section{Study characteristics}

\begin{tabular}{|c|c|}
\hline Methods & $\begin{array}{l}\text { Design: Phase 2, multicenter, open-label, 2-cohort study } \\
\text { Country: USA } \\
\text { Accrual dates: November } 2012 \text { and January } 2015 \\
\text { Trial reg: NCT01609790 } \\
\text { Funding: Amgen, Inc. funded this study and provided trebananib to study participants. } \\
\text { Declaration of interests: David A. Reardon reports grants from Amgen; grants from Acerta Pharmaceuti- } \\
\text { cals, Agenus, Celldex, EMD Serono, Incyte, Inovio, Midatech, and Tragara outside the submitted work; } \\
\text { and personal fees from AbbVie, Amgen, Bristol- Myers Squibb, Cavion, Celldex, EMD Serono, Genen- } \\
\text { tech/Roche, Inovio, Merck, Momenta Pharmaceuticals, Novartis, Novocure, Oncurus, Oxigene, Regen- } \\
\text { eron, and Stemline outside the submitted work. Further declarations were made by the other authors. }\end{array}$ \\
\hline Participants & $\begin{array}{l}\text { No. analysed: } 48 \\
\text { Inclusion criteria } \\
\text { - Eligible patients were at least age } 18 \text { years, were in first or second relapse of histologically confirmed } \\
\text { glioblastoma after standard therapy (maximum feasible resection or biopsy, radiation, and temozolo- } \\
\text { mide), adequate haematologic, renal, and hepatic function. } \\
\text { Exclusion criteria } \\
\text { - Prior receipt of VEGF/VEGF receptor (VEGFR) or ANG-targeting agents } \\
\text { Age: } 18+ \\
\text { Gender: } 48 \text { Male (100\%) } \\
\text { Performance status: KPS of at least } 70 \\
\text { MGMT: } 5 \text { (10.4\%) methylated; } 20 \text { ( } 41.7 \%) \text { unmethylated, rest unknown } \\
\text { Resection/biopsy: } 10 \text { gross total resections, } 2 \text { subtotal resections before study ( } 25 \%) ; 71 \% \text { had no addi- } \\
\text { tional surgery. } \\
\text { Initial treatment details: standard RT + TMZ } \\
\text { Details of treatment of first occurrence: } \\
\text { Time from initial diagnosis: NR }\end{array}$ \\
\hline Interventions & $\begin{array}{l}\text { Arm 1: trebananib }(\mathrm{N}=11) \\
\text { Arm 2: trebananib + bevacizumab } 10 \mathrm{mg} / \mathrm{kg} \text { biweekly }(\mathrm{N}=37)\end{array}$ \\
\hline Outcomes & OS, PFS, SAEs, objective response \\
\hline
\end{tabular}


Reardon 2018a (Continued)

Notes

Authors reported that "Trebananib had no single-agent activity, and all treated patients exhibited progressive disease within 2 months."

\section{Risk of bias}

\begin{tabular}{|c|c|c|}
\hline Bias & Authors' judgement & Support for judgement \\
\hline $\begin{array}{l}\text { Random sequence genera- } \\
\text { tion (selection bias) }\end{array}$ & High risk & Non-randomised cohort study \\
\hline $\begin{array}{l}\text { Allocation concealment } \\
\text { (selection bias) }\end{array}$ & Unclear risk & Not applicable \\
\hline $\begin{array}{l}\text { Blinding of participants } \\
\text { and personnel (perfor- } \\
\text { mance bias) } \\
\text { All outcomes }\end{array}$ & High risk & No blinding. \\
\hline $\begin{array}{l}\text { Blinding of outcome as- } \\
\text { sessment (detection bias) } \\
\text { All outcomes }\end{array}$ & High risk & Not described. \\
\hline $\begin{array}{l}\text { Incomplete outcome data } \\
\text { (attrition bias) } \\
\text { All outcomes }\end{array}$ & Low risk & All patients accounted for. \\
\hline $\begin{array}{l}\text { Selective reporting (re- } \\
\text { porting bias) }\end{array}$ & Low risk & None suspected. \\
\hline Other bias & Unclear risk & Funding and author interests noted. \\
\hline
\end{tabular}

\section{Reardon 2018b}

\section{Study characteristics}

\begin{tabular}{ll}
\hline Methods & Design: RCT, ratio: ? Conference abstract. \\
& Trial ID: NCT02337491 \\
& Funding: NR \\
& Declaration of interest: NR \\
\hline Participants & No. randomised: 80 \\
& $\begin{array}{l}\text { Inclusion criteria: BEV-naive patients with first or second recurrence of GBM requiring } \leq 4 \text { mg dexam- } \\
\text { ethasone/day. }\end{array}$ \\
\hline Interventions & Arm 1: pembrolizumab (P) ( $=50)$ \\
& Arm 2: pembrolizumab + BEV ( $n=30)$ \\
\hline Outcomes & PFS "assessed independently per cohort relative to historical benchmarks" \\
\hline Notes & $\begin{array}{l}\text { Conference abstract only so scant data. Authors concluded "P is well tolerated }+/- \text { Bev but has limited } \\
\text { monotherapy activity for rGBM." }\end{array}$
\end{tabular}


Reardon 2018b (Continued)

Risk of bias

\begin{tabular}{lll}
\hline Bias & Authors' judgement & Support for judgement \\
\hline $\begin{array}{l}\text { Random sequence genera- } \\
\text { tion (selection bias) }\end{array}$ & Unclear risk & Insufficient details to make a judgement \\
\hline $\begin{array}{l}\text { Allocation concealment } \\
\text { (selection bias) }\end{array}$ & Unclear risk & Insufficient details to make a judgement \\
\hline $\begin{array}{l}\text { Blinding of participants } \\
\text { and personnel (perfor- } \\
\text { mance bias) }\end{array}$ & Unclear risk & Insufficient details to make a judgement \\
All outcomes & \\
\hline
\end{tabular}

Blinding of outcome as- Unclear risk Insufficient details to make a judgement

sessment (detection bias)

All outcomes

Incomplete outcome data Unclear risk Insufficient details to make a judgement

(attrition bias)

All outcomes

\begin{tabular}{lll}
\hline $\begin{array}{l}\text { Selective reporting (re- } \\
\text { porting bias) }\end{array}$ & Unclear risk & PFS "assessed independently per cohort relative to historical benchmarks" \\
\hline Other bias & Unclear risk & Conference abstract only \\
\hline
\end{tabular}

\section{Reardon 2020}

\section{Study characteristics}

Mesign: Double-blind, randomized, phase II study conducted in 26 hospitals in the USA.
Country: USA
Accrual dates: May 2012 and 2014
Trial reg: NCT01498328
Funding: Celldex Therapeutics, Inc
Declaration of interests: "D.A. Reardon is a paid consultant for Abbvie, Advantagene, Agenus, Amgen,
Bayer, Bristol-Myers Squibb, Celldex, Delmar, EMD Serono, Genentech/Roche, Inovio, Merck, Merck
KGaA, Monteris, Novocure, Oncurus, Oxigene, Regeneron,Stemline, and Taiho Oncology. A. Desjardins
reports receiving other commercial research support from Genentech/Roche, Triphase Accelerator,
Symphogen A/S,Orbus Therapeutics; holds ownership interest (including patents) in Istari Oncolo-
gy;and is an unpaid consultant/advisory board member for Orbus Therapeutics and Istari Oncology.
D.M. O'Rourke reports...." among others.

Participants

No. randomised: 73

No. analysed: 72

Inclusion criteria

- At least 18 years of age 
Reardon 2020 (Continued)

- In first or second relapse of histologically confirmed glioblastoma following standard therapy (maximum feasible resection or biopsy, radiation, and temozolomide)

- With EGFRvIII expression in primary or recurrent tumour tissue by central analysis using PCR Patients who previously received radiation and temozolomide for lower-grade glioma were permitted upon diagnosis of transformed glioblastoma.

Exclusion criteria

- Prior receipt of bevacizumab or other VEGF- or VEGF receptor-targeting agents

- Corticosteroid requirement $>4 \mathrm{mg}$ of dexamethasone per day during the week prior to entry; Karnofsky performance status $<70 \%$

- gliomatosis cerebri, infratentorial, leptomeningeal or metastatic disease

- prior therapeutic intracerebral agents

- residual grade 2 chemotherapy or radiation-related toxicities (except alopecia and haematologic toxicity)

- salvage surgery within 4 weeks or radiation within 3 months of screening MRI.

Age: median and range in arm 1: 59 (44 to 79), in arm 2: 55 (30 to 75)

Gender: In arm 1: 53\% were male, in arm 2; 59\% were male.

Performance status: KPS $\geq 70$.

MGMT: NR

Resection/biopsy: surgery after last relapse arm 1 = 15 (42\%), arm 2 = 10 (27\%)

Initial treatment details: maximum feasible resection or biopsy, radiation, and temozolomide.

Time from initial diagnosis: NR

Interventions

Arm 1: $\mathrm{N}=36$ rindopepimut $+\mathrm{BEV}$

Arm 2: $N=37$ control (injection of keyhole limpet haemocyanin) + BEV

Outcomes PFS, OS, objective response, SAEs

Notes

Authors concluded that "Our randomized trial supports the potential for targeted immunotherapy among patients with GBM, but the therapeutic benefit requires validation due to the small sample size and potential heterogeneity of bevacizumab response among recurrent patients with GBM."

\section{Risk of bias}

\begin{tabular}{|c|c|c|}
\hline Bias & Authors' judgement & Support for judgement \\
\hline $\begin{array}{l}\text { Random sequence genera- } \\
\text { tion (selection bias) }\end{array}$ & Low risk & $\begin{array}{l}\text { "Eligible patients were randomized to the treatment groups in a } 1: 1 \text { ratio by } \\
\text { the study sponsor using a prespecified randomization list created by a biosta- } \\
\text { tistician." }\end{array}$ \\
\hline $\begin{array}{l}\text { Allocation concealment } \\
\text { (selection bias) }\end{array}$ & Unclear risk & Not clearly described. \\
\hline $\begin{array}{l}\text { Blinding of participants } \\
\text { and personnel (perfor- } \\
\text { mance bias) } \\
\text { All outcomes }\end{array}$ & Low risk & $\begin{array}{l}\text { "Patients and investigators remained blinded to treatment assignments. Un- } \\
\text { blinded pharmacists who were otherwise uninvolved in study conduct ob- } \\
\text { tained randomized treatment assignments and managed study treatment. } \\
\text { Study treatments were prepared in the pharmacy and delivered to study staff } \\
\text { in blinded, preloaded syringes. KLH was given as a control injection to produce } \\
\text { a local reaction similar to that expected with rindopepimut to maintain } \\
\text { the treatment blind." }\end{array}$ \\
\hline
\end{tabular}

Treatment options for progression or recurrence of glioblastoma: a network meta-analysis (Review) 
Reardon 2020 (Continued)

Blinding of outcome assessment (detection bias)

All outcomes
"Retrospective assessment of radiographic imaging was also performed by an independent expert review committee consisting of two neuroradiologists, with adjudication and assessment of steroid use and clinical status by a neuro-oncologist. Expert review committee members were otherwise independent of study conduct and were blinded to treatment allocation and investigator assessments."

Minimal attrition with 1 patient did not receive treatment was was not included in the safety analysis.
Incomplete outcome data Low risk (attrition bias)

All outcomes
Expected outcomes reported.

Selective reporting (re- Low risk porting bias)
Unclear risk
Funding and author interests noted.

Santos 2018

\section{Study characteristics}

\begin{tabular}{|c|c|}
\hline \multirow[t]{6}{*}{ Methods } & Design: non-RCT, 2-arm. Allocation methods unclear. \\
\hline & Country: Brazil \\
\hline & Accrual dates: NR \\
\hline & Trial reg: doi.org/10.3892/ol.2017.7362 \\
\hline & $\begin{array}{l}\text { Funding: No information on funding, however POH was formulated for delivery by inhalation and the } \\
\text { preparation was supplied by the Multidisciplinary Laboratory of Pharmaceutical Sciences at Rio de } \\
\text { Janeiro Federal University (Rio de Janeiro, Brazil). }\end{array}$ \\
\hline & Declaration of interests: not stated \\
\hline \multirow[t]{10}{*}{ Participants } & No. randomised: 32 enrolled \\
\hline & $\begin{array}{l}\text { No. analysed: } 17 \text { ( } 3 \text { excluded due to diet non-adherence, others excluded due to inability to finish } \\
\text { study/death) }\end{array}$ \\
\hline & $\begin{array}{l}\text { Inclusion/exclusion criteria: all patients presented with relapsed GBM, had no further standard ther- } \\
\text { apeutic options, were aged }>18 \text { years, had measurable contrast-enhancing tumour on magnetic res- } \\
\text { onance imaging (MRI), adequate bone marrow function, white blood cell count of } \geq 3000 / \mathrm{L} \text {, absolute } \\
\text { neutrophil count of } \geq 1500 / \mathrm{L} \text {, platelet count of } \geq 100,000 / \mathrm{L} \text {, haemoglobin of } \geq 8.0 \mathrm{~g} / \mathrm{dL} \text {, bilirubin of } \geq 0.3 \\
\text { mg. }\end{array}$ \\
\hline & Age: 27 to 61 years \\
\hline & Gender: 7 female (40\%), 10 male $(60 \%)$ \\
\hline & Performance status: Karnofsky performance scale of $\geq 70 \%$ or higher. \\
\hline & MGMT: mentioned in introduction; however, not discussed in the Methods/Results section. \\
\hline & Resection/biopsy: previous biopsy mentioned; however no specific information in tables or rest of text. \\
\hline & Initial treatment details: conventional therapy (including surgery, chemotherapy and radiotherapy). \\
\hline & Time from initial diagnosis: not reported \\
\hline
\end{tabular}


Santos 2018 (Continued)

Interventions Intranasal perillyl alcohol + ketogenic diet versus intranasal perillyl alcohol + standard diet.

\begin{tabular}{|c|c|}
\hline Outcomes & Objective response, progressive disease \\
\hline Notes & $\begin{array}{l}\text { Of the } 32 \text { patients enrolled only } 17 \text { were included in the analysis ( } 9 / 17 \text { in the KD/POH group and } 8 / 15 \text { in } \\
\text { the standard diet/POH group); } 3 \text { patients were excluded as they did not adhere to the diet and the rest } \\
\text { did not survive the study period. The authors reported a partial response (reduction in MRI tumour size) } \\
\text { in } 7 / 9 \text { in the KD/POH group and in } 2 / 8 \text { patients in the control group. The study had a small sample size, } \\
\text { high attrition and there was a lack of information on study methods. }\end{array}$ \\
\hline
\end{tabular}

\section{Risk of bias}

\begin{tabular}{|c|c|c|}
\hline Bias & Authors' judgement & Support for judgement \\
\hline $\begin{array}{l}\text { Random sequence genera- } \\
\text { tion (selection bias) }\end{array}$ & High risk & $\begin{array}{l}\text { Not randomised. The way patients were allocated to treatment groups was not } \\
\text { described. }\end{array}$ \\
\hline $\begin{array}{l}\text { Allocation concealment } \\
\text { (selection bias) }\end{array}$ & Unclear risk & The way patients were allocated to treatment groups was not described. \\
\hline $\begin{array}{l}\text { Blinding of participants } \\
\text { and personnel (perfor- } \\
\text { mance bias) } \\
\text { All outcomes }\end{array}$ & High risk & $\begin{array}{l}\text { Patients and staff would be aware of treatment arms (non-compliant patients } \\
\text { were excluded from the study). }\end{array}$ \\
\hline $\begin{array}{l}\text { Blinding of outcome as- } \\
\text { sessment (detection bias) } \\
\text { All outcomes }\end{array}$ & Unclear risk & $\begin{array}{l}\text { The observing radiologists were aware of the GBM diagnosis and follow-up da- } \\
\text { ta. }\end{array}$ \\
\hline $\begin{array}{l}\text { Incomplete outcome data } \\
\text { (attrition bias) } \\
\text { All outcomes }\end{array}$ & High risk & High attrition as only $17 / 32$ completed the study. \\
\hline $\begin{array}{l}\text { Selective reporting (re- } \\
\text { porting bias) }\end{array}$ & Unclear risk & PFS, OS and SAES were not reported. \\
\hline Other bias & Low risk & None noted. \\
\hline
\end{tabular}

\section{Scorsetti 2015}

\section{Study characteristics}

\begin{tabular}{ll}
\hline Methods & Retrospective study of a selected cohort of patients \\
\hline Participants & No. analysed: 43 patients recruited consecutively. \\
& $\begin{array}{l}\text { Inclusion/exclusion criteria: patients with MRI evidence of progressive or recurrent GMB at least } 3 \\
\text { months after the end of radiotherapy. All patients had had open surgery resection after initial diagno- } \\
\text { sis, radiotherapy and adjuvant temozolomide. All patients had KPS greater than } 70 \text { and interval from } \\
\text { previous treatment greater than } 6 \text { months with no multi-focal disease. }\end{array}$ \\
& Age: median 51 (range 27 to 80$)$ \\
Gender: Male $22 / 43$ (51\%) female 21 (49\%) & Performance status: KPS 100: 11 (26\%); $90: 19$ (44\%); $80: 2$ (4\%); $70: 11$ (26\%)
\end{tabular}


Initial treatment details: all had surgery, radiotherapy and chemotherapy (complete resection 24 (56\%; subtotal 5 (12\%); partial resection $12(28 \%)$

Sort of recurrence: e.g. 1st, 1st and 2nd, any

Time from initial diagnosis: time to relapse from first diagnosis: less than a year 21 (49\%); 12 to 24 months 13 (30\%); more than 2 years 9 (21\%). Median 13 months (6 to 78 months)

Patients in the 2 treatment arms were described as well matched although those undergoing re-resection and/or radiotherapy were more likely to have had later relapse (15/21 more than a year from diagnosis vs $7 / 22$ in the chemotherapy alone arm; and those in the re-resection and/or radiotherapy groups had higher performance status at relapse $11 / 21100 \%$ vs $0 / 22100 \%$ in the 'chemotherapy only' arm.

Arm 1: (21 patients) combined treatment: surgery and/or radiotherapy plus chemotherapy
Arm 2: (22 patients) chemotherapy alone
It was not clear how many patients in the combined treatment arm had both re-resection and radio-
therapy (or radiotherapy alone) with chemotherapy. Allocation to treatment modalities not clear al-
though the conclusion recommends that treatment choice should be based on multidisciplinary evalu-
ation.

Outcomes

PFS and OR (MRI and clinical examination). Haematological toxicity and radio-necrosis.

Notes

\section{Risk of bias}

\begin{tabular}{lll}
\hline Bias & Authors' judgement & Support for judgement \\
\hline $\begin{array}{l}\text { Random sequence genera- } \\
\text { tion (selection bias) }\end{array}$ & High risk & $\begin{array}{l}\text { A non-randomised study. This study is at high risk of selection bias. Treat- } \\
\text { ment modality appeared to relate to clinical characteristics. Method of allo- } \\
\text { cation not described. Patients in the } 2 \text { treatment arms were described as well } \\
\text { matched although those undergoing re-resection and/or radiotherapy were } \\
\text { more likely to have had later relapse }(15 / 21 \text { more than a year from diagnosis vs } \\
7 / 22 \text { in the chemotherapy alone arm; and those in the re-resection/ and or ra- } \\
\text { diotherapy had higher performance status at relapse } 11 / 21100 \% \text { vs } 0 / 22100 \% \\
\text { in the chemotherapy only arm. }\end{array}$ \\
\hline
\end{tabular}

Allocation concealment High risk Patients appeared to be selected for different arms based on clinical factors.
(selection bias)

Blinding of participants $\quad$ High risk blinding.
and personnel (perfor-
mance bias)
All outcomes

\begin{tabular}{lll}
\hline $\begin{array}{l}\text { Blinding of outcome as- } \\
\text { sessment (detection bias) } \\
\text { All outcomes }\end{array}$ & Unclear risk & No blinding but survival outcomes may be less susceptible to assessment bias. \\
\hline $\begin{array}{l}\text { Incomplete outcome data } \\
\begin{array}{l}\text { (attrition bias) } \\
\text { All outcomes }\end{array}\end{array}$ & Unclear risk & $\begin{array}{l}\text { All patients appeared to be followed up in the selected cohort. It is not clear } \\
\text { whether all patients treated during the recruitment period were included. }\end{array}$ \\
\hline $\begin{array}{l}\text { Selective reporting (re- } \\
\text { porting bias) }\end{array}$ & Unclear risk & Chemotherapy toxicity reported for all patients rather than by treatment arm. \\
\hline
\end{tabular}


Scorsetti 2015 (Continued)

Other bias Unclear risk It was unclear how many in the combined treatment arm had both surgery and radiotherapy or radiotherapy alone.

\section{Study characteristics}

Design: Phase 3, RCT, randomised at 1:1 ratio, multicentre (28 institutions from 7 different countries)
Country: Austria, Israel, Germany, France, Czech Republic, USA, Switzerland
Accrual dates: September 2006 until May 2009
Trial reg: NCT00379470
Funding: the trial was funded and sponsored by Novocure Ltd. Representatives of the study sponsor
were involved in the study design, data collection, data analysis, data interpretation and writing of the
report.
Declaration of interests: "Eilon Kirson and Uri Weinberg are employees of Novocure Ltd., and have
stock options in the company. Herwig Kostron has received honoraria from Novocure Ltd.
Yoram Palti is the inventor of the Novo-TTF principle. He received consulting honoraria and travel sup-
port by Novocure Ltd. Nina Paleologos has served on advisory boards and speakers bureau to Genen-
tech, Merck \& Co (previously Schering-Plough). Susan Panullo has received research grants from Novo-
cure, NTI Pharma, Eisai, Immunocellular and Parexel, and honoraria for lectures from Merck \& Co (pre-
viously Schering-Plough)..." among others.

\section{Participants}

No. randomised: 237

No. analysed: 217

Inclusion/exclusion criteria: adequate haematologic, renal and hepatic function. Prior therapy must have included radiotherapy (with and without concomitant and/or adjuvant temozolomide). Patients with infra-tentorial tumour location were excluded, as were patients with implanted electronic medical devices (e.g. pacemaker, programmable ventriculo peritoneal shunt).

Age: 24 to 80

Gender: Male 165 (70\%), Female $72(30 \%)$

Performance status: KPS $\geq 70 \%$

MGMT: NR

Resection/biopsy: just over $25 \%$ of patients had debulking before enrolment.

Details of treatment: more than $80 \%$ of participants received RT and TMZ for primary treatment. More than $80 \%$ of patients had failed 2 or more prior lines of chemotherapy (second recurrence) and $20 \%$ of the patients had failed bevacizumab prior to enrolment.

Arm 2: Active control chemotherapy $(n=117)$. Most of patients received single agent or a combination chemotherapy regimen containing bevacizumab (31\%), or irinotecan $(31 \%)$, followed by nitrosoureas $(25 \%)$, carboplatin $(13 \%)$, temozolomide $(11 \%)$ or various other agents $(5 \%)$.

\begin{tabular}{ll}
\hline Outcomes & PFS, OS, SAEs \\
\hline Notes & $\begin{array}{l}\text { Many different treatments were used in the control arm, which makes interpretation of the findings dif- } \\
\text { ficult, especially as it is not clear whether these treatments are effective in recurrent GBM. }\end{array}$
\end{tabular}


Stupp 2012 (Continued)

Author conclusions "No improvement in overall survival was demonstrated, however efficacy and activity with this chemotherapy-free treatment device appears comparable to chemotherapy regimens that are commonly used for recurrent glioblastoma. Toxicity and quality of life clearly favoured TTF."

\title{
Risk of bias
}

\begin{tabular}{lll}
\hline Bias & Authors' judgement & Support for judgement \\
\hline $\begin{array}{l}\text { Random sequence genera- } \\
\text { tion (selection bias) }\end{array}$ & Low risk & $\begin{array}{l}\text { "Randomisation was performed using random block sizes and was stratified } \\
\text { by centre and according to whether patients underwent surgery for their latest } \\
\text { recurrence prior to trial entry." }\end{array}$ \\
\hline
\end{tabular}

Allocation concealment Unclear risk Not described.

(selection bias)

Blinding of participants $\quad$ High risk $\quad$ Blinding not possible with this intervention.
and personnel (perfor-

mance bias)

All outcomes

\begin{tabular}{|c|c|c|}
\hline $\begin{array}{l}\text { Blinding of outcome as- } \\
\text { sessment (detection bias) } \\
\text { All outcomes }\end{array}$ & Unclear risk & Not reported. \\
\hline $\begin{array}{l}\text { Incomplete outcome data } \\
\text { (attrition bias) } \\
\text { All outcomes }\end{array}$ & Unclear risk & $\begin{array}{l}\text { High risk for safety and QoL data. } 22 \% \text { attrition in the control arm for safety. } \\
\text { QoL data were available for only } 62 \text { patients }(27 \%)\end{array}$ \\
\hline
\end{tabular}

\begin{tabular}{lll}
\hline $\begin{array}{l}\text { Selective reporting (re- } \\
\text { porting bias) }\end{array}$ & Low risk & Expected outcomes were reported. \\
\hline Other bias & Unclear risk & Funding and author interests noted. \\
\hline
\end{tabular}

Suchorska 2016

\section{Study characteristics}

Methods

\begin{abstract}
Design: Non-randomised study
Country: Germany

Accrual dates: NR

Trial reg: NCT00941460

Funding: The DIRECTOR trial (NCT 00941460) was supported by a grant from Merck Sharp and Dohme (MSD; formerly Schering-Plough) and matching-funds grant from University Hospital Zurich, Switzerland.

Declaration of interests:

"M.W. is an advisory board member for MSD, from which he reports receiving research grants. G.T. reports receiving a travel grant from MSD. U.H. reports receiving speakers bureau honoraria from Medac. U.S. is a consultant/advisory board member for Roche and reports receiving speakers bureau honoraria from GlaxoSmithKline and Medac. G.R. reports receiving commercial research grants from Roche and speakers bureau honoraria from Amgen and Roche. W.W. reports receiving speakers bureau honoraria from Roche, MSD, and Prime Oncology. J.C.T. is a consultant/advisory board member for Merck Serono and Roche and reports receiving speakers bureau honoraria."
\end{abstract}


Suchorska 2016 (Continued)

\begin{tabular}{|c|c|c|}
\hline \multirow[t]{6}{*}{ Participants } & \multicolumn{2}{|l|}{105 analysed. } \\
\hline & \multicolumn{2}{|c|}{$\begin{array}{l}\text { Study population: people with recurrent GBM taking part in the DIRECTOR trial in which they were ran- } \\
\text { domised to receive } 1 \text { of } 2 \text { dose-intense TMZ regimens. }\end{array}$} \\
\hline & \multicolumn{2}{|c|}{ Median age: 55 in surgery group and 59.6 in the no surgery group } \\
\hline & \multicolumn{2}{|c|}{ Gender: $67.6 \%$ male in the surgery group and $61.8 \%$ in the no surgery group } \\
\hline & \multicolumn{2}{|c|}{ Performance status: All > 70} \\
\hline & \multicolumn{2}{|c|}{ Time to first progression: 11.5 months in the surgery group and 10.7 months in the no surgery group } \\
\hline \multirow[t]{2}{*}{ Interventions } & \multicolumn{2}{|l|}{ Arm $1(n=71)$ : surgery } \\
\hline & \multicolumn{2}{|c|}{ Arm $2(n=34):$ no surgery } \\
\hline Outcomes & \multicolumn{2}{|c|}{ PFS, post-recurrence survival, QoL } \\
\hline Notes & \multicolumn{2}{|c|}{$\begin{array}{l}\text { Extent of resection was prognostic for outcome: complete resection was associated with improved } \\
\text { post-recurrence survival compared with incomplete resection ( } 9.8 \text { months vs } 6.5 \text { months). }\end{array}$} \\
\hline \multicolumn{3}{|l|}{ Risk of bias } \\
\hline Bias & Authors' judgement & Support for judgement \\
\hline $\begin{array}{l}\text { Random sequence genera- } \\
\text { tion (selection bias) }\end{array}$ & High risk & $\begin{array}{l}\text { A non-randomised study in which the allocated interventions may have been } \\
\text { subject to selection bias. "Indication for surgery was commonly based on rec- } \\
\text { ommendations from multidisciplinary tumour boards." }\end{array}$ \\
\hline $\begin{array}{l}\text { Blinding of outcome as- } \\
\text { sessment (detection bias) } \\
\text { All outcomes }\end{array}$ & Low risk & $\begin{array}{l}\text { "Volumetric analysis of pre and post surgical MR images were performed by an } \\
\text { experienced investigator blinded to patients' outcome" }\end{array}$ \\
\hline $\begin{array}{l}\text { Incomplete outcome data } \\
\text { (attrition bias) } \\
\text { All outcomes }\end{array}$ & Low risk & All patients included in the analysis. \\
\hline $\begin{array}{l}\text { Selective reporting (re- } \\
\text { porting bias) }\end{array}$ & Low risk & None suspected. \\
\hline
\end{tabular}

Taal 2014

\section{Study characteristics}

Mesign: RCT Phase 2
Country: the Netherlands
Accrual dates: 11 December 2009, and 10 November 2011
Trial reg: Nederlands Trial Register (NTR1929)
Funding: Roche Nederland and KWF Kankerbestrijding.
Declaration of interests:


Taal 2014 (Continued)

MJvdB has done paid consultancy for Roche, Abbvie, Celldex, Amgen, and Merck Ag; has received research grants from Roche and AbbVie; and has been on the speakers' bureau for MSD. HMO and MJT have received personal fees from Roche for consultancy. The other authors declare no competing interests.

Participants
No. randomised: 153

No. analysed: 148

Inclusion criteria

- Histologically proven glioblastoma with 1st progression after previous chemoradiotherapy with TMZ

- Documented by MRI with at least 1 bi-dimensionally measurable target lesion with 1 diameter of at least $10 \mathrm{~mm}$

- Visible on 2 or more axial slices $5 \mathrm{~mm}$ apart

- Had not received previous chemotherapy for recurrent disease

- Had not previously received treatment with an anti-VEGF agent or nitrosoureas

- Were on a stable or decreasing dose of steroids for 7 days before the baseline MRI scan

- Had not received radiotherapy within the 3 months before the diagnosis of progression

- Had not received chemotherapy in the past 4 weeks

- Were at least 18 years of age

- Had WHO performance status of 0 to 2

- Had adequate bone marrow, renal, and hepatic function

Exclusion criteria

- Uncontrolled hypertension (SBP >150 mm Hg or DBP >100 mm Hg),

- Any arterial or venous thrombosis up to 6 months before registration,

- Evidence of recent haemorrhage on brain MRI,

- Substantial cardiac disease (eg, history of myocardial infarction within 6 months before inclusion or unstable angina),

- Use of therapeutic doses of oral or parenteral anticoagulants or thrombolytic drug

Age: $\geq 18$ (range 24 to 77 )

Gender: Approx. 59\% Male 41\% Female

Performance status: WHO 0 to 2

MGMT: unmethylated BEV 24, LOM 20, BEV + LOM 26; methylated BEV 18, LOM 23, BEV + LOM 21; Not done/UNK 16

Re-operation at recurrence: approx. $11 \%$

Initial treatment details: TMZ + RT

Time from initial diagnosis: reported as since last RT. Medians were similar across groups and the range was 69 to 2087 days.

Interventions

\begin{abstract}
Arm $1(n=46)$ : lomustine (LOM) orally at a dose of $110 \mathrm{mg} / \mathrm{m}^{2}$ on day 1 every 6 weeks with prophylactic anti-emetic drugs, for a maximum of 6 treatment cycles

Arm $2(n=50)$ : bevacizumab intravenously at a dose of $10 \mathrm{mg} / \mathrm{kg}$ every 2 weeks

$\operatorname{Arm} 3(n=52): L O M+B E V$

Note: "In the combination group, lomustine was initially given at $110 \mathrm{mg} / \mathrm{m}^{2}$ every 6 weeks, with a maximum lomustine dose of $200 \mathrm{mg}$ per cycle of 6 weeks. After the pre-planned safety review, we reduced the lomustine dose for the rest of the patients in the combination group to $90 \mathrm{mg} / \mathrm{m}^{2}$, with a maximum lomustine dose of $160 \mathrm{mg}$ per cycle of 6 weeks."
\end{abstract}


Taal 2014 (Continued)
Outcomes
PFS, OS, SAES, QOL

Notes

The study was not powered to formally compare results between the 3 treatment groups.

Authors concluded that: "The combination of bevacizumab and lomustine met prespecifi ed criteria for assessment of this treatment in further phase 3 studies. However, the results in the bevacizumab alone group do not justify further studies of this treatment."

QoL data were reported in Dirven 2015.

\section{Risk of bias}

\begin{tabular}{lll}
\hline Bias & Authors' judgement & Support for judgement \\
\hline $\begin{array}{l}\text { Random sequence genera- } \\
\text { tion (selection bias) }\end{array}$ & Low risk & Eligible patients were randomised by a web-based program and stratified by a \\
\hline $\begin{array}{l}\text { Allocation concealment } \\
\text { (selection bias) }\end{array}$ & Unclear risk & Not reported. \\
\hline $\begin{array}{l}\text { Blinding of participants } \\
\begin{array}{l}\text { and personnel (perfor- } \\
\text { mance bias) }\end{array}\end{array}$ & High risk \\
All outcomes & & Open label \\
\hline
\end{tabular}

\begin{tabular}{|c|c|c|}
\hline $\begin{array}{l}\text { Blinding of outcome as- } \\
\text { sessment (detection bias) } \\
\text { All outcomes }\end{array}$ & High risk & Open label, although for OS this can be assumed to be low risk. \\
\hline $\begin{array}{l}\text { Incomplete outcome data } \\
\text { (attrition bias) } \\
\text { All outcomes }\end{array}$ & Low risk & $\begin{array}{l}\text { All patients were analysed for survival and toxicity outcomes. Attrition for the } \\
\text { QOL outcome was high because "detailed assessment of functional outcome } \\
\text { once radiological progression has occurred is difficult". }\end{array}$ \\
\hline
\end{tabular}

\begin{tabular}{lll}
\hline $\begin{array}{l}\text { Selective reporting (re- } \\
\text { porting bias) }\end{array}$ & Low risk & Expected outcomes were reported. \\
\hline Other bias & Unclear risk & Funding and author interests noted. \\
\hline
\end{tabular}

\section{Tsien 2019}

\section{Study characteristics}

Methods

Design: multi-institutional, prospective randomized phase II trial (1:1)

Country: USA

Accrual dates: November 2012 to April 2016

Trial reg: RTOG 1205

Funding: NR

Declaration of interests: C. Tsien: Honoraria; Merck. Speaker's Bureau; Varian. Travel Expenses; Merck; RSNA Oncologic Imaging Committee. S. Pugh: Research Grant; Millennium, Pfizer-Astellas. A.P. Dicker: Research Grant; Radiation Therapy Oncology Group. Travel Expenses; Prostate Cancer Foundation; Department of Defense. J.J. Raizer: Employee; Astellas, Celldex. Stock; Celldex and Agenus. Stock Options; Exicure. M.M. Matuszak: Employee; William Beaumont Hospital. E. Lallana: Research Grant; Orbus Therapeutics, Novocure. J. Huang: Research Grant; Cantex Pharmaceuticals. Speaker's Bureau; Viewray 
Tsien 2019 (Continued)

Inc. Travel Expenses; Viewray Inc. O. Algan: None. N. Taylor: None. L. Portelance: Committee Member; NRG. J. Villano: None. J. Hamm: None. K.S. Oh: Research Grant; Merck \& Co., Inc. Review and create questions for CME section of journal; IJROBP. A.N. Ali: Partner; Northwest Georgia Radia- tion Oncology. M.M. Kim: None. S. Lindhorst: None. M.P. Mehta: Consultant; Astra-Zeneca. Stock; Oncoceutics. Data/Clinical research; PTCOG. Protocol development; NRG Oncology.

\begin{tabular}{|c|c|}
\hline \multirow[t]{10}{*}{ Participants } & No. randomised: 182 \\
\hline & No. analysed: 170 \\
\hline & Inclusion/exclusion criteria: NR \\
\hline & Age: NR \\
\hline & Gender: NR \\
\hline & Performance status: NR \\
\hline & MGMT: NR \\
\hline & Resection/biopsy: NR \\
\hline & Initial treatment details: majority of patients (80\%) had previously received chemoRT. \\
\hline & Time from initial diagnosis: NR \\
\hline \multirow[t]{2}{*}{ Interventions } & $\begin{array}{l}\text { Arm 1: hypofractionated reirradiation (HFRT, } 35 \text { Gy in } 10 \text { fractions) with concurrent bevacizumab (BEV) } \\
\text { IV } 10 \mathrm{mg} / \mathrm{kg} \text { q2 wks }\end{array}$ \\
\hline & Arm 2: Bevacizumab (IV 10 mg/kg q2 wks ) \\
\hline Outcomes & Median survival time, PFS rate, SAEs \\
\hline Notes & $\begin{array}{l}\text { Conference abstract only. Authors concluded that "Role of BEV-HFRT should be limited to small volume } \\
\text { recurrences, especially in previously non-irradiated treatment areas at least } 6 \text { months following com- } \\
\text { pletion of previous RT." }\end{array}$ \\
\hline
\end{tabular}

\section{Risk of bias}

\begin{tabular}{lll}
\hline Bias & Authors' judgement & Support for judgement \\
\hline $\begin{array}{l}\text { Random sequence genera- } \\
\text { tion (selection bias) }\end{array}$ & Unclear risk & Insufficient details to make a judgement. \\
\hline $\begin{array}{l}\text { Allocation concealment } \\
\text { (selection bias) }\end{array}$ & Unclear risk & Insufficient details to make a judgement. \\
\hline $\begin{array}{l}\text { Blinding of participants } \\
\text { and personnel (perfor- } \\
\text { mance bias) }\end{array}$ & Unclear risk & Insufficient details to make a judgement. \\
All outcomes & \\
\hline $\begin{array}{l}\text { Blinding of outcome as- } \\
\text { sessment (detection bias) } \\
\text { All outcomes }\end{array}$ & Unclear risk & Insufficient details to make a judgement. \\
\hline $\begin{array}{l}\text { Incomplete outcome data } \\
\text { (attrition bias) } \\
\begin{array}{l}\text { All outcomes } \\
\hline\end{array}\end{array}$ & Unclear risk & Insufficient details to make a judgement. \\
\hline
\end{tabular}


Tsien 2019 (Continued)

Selective reporting (re- Unclear risk Insufficient details to make a judgement.
porting bias)

Other bias Unclear risk Insufficient details to make a judgement.

Twelves 2017

\section{Study characteristics}

\begin{tabular}{ll}
\hline Methods & Design: Randomized Phase II trial (1:1) \\
Country: NR \\
Accrual dates: NR \\
Trial reg: NCT01812603 \\
Funding: NR \\
Declaration of interests: NR
\end{tabular}

\begin{tabular}{|c|c|}
\hline \multirow[t]{10}{*}{ Participants } & No. randomised: 21 \\
\hline & No. analysed: 21 \\
\hline & Inclusion/exclusion criteria: NR \\
\hline & Age: mean age was 58 years \\
\hline & Gender: 5/12 in treatment arm, $8 / 9$ in the placebo arm \\
\hline & Performance status: median KPS was 90 \\
\hline & MGMT: NR \\
\hline & Resection/biopsy: NR \\
\hline & Initial treatment details: Stupp protocol \\
\hline & $\begin{array}{l}\text { Time from initial diagnosis of recurrence: } 3.6 \text { weeks and } 3.0 \text { weeks for CBD:THC and placebo groups, re- } \\
\text { spectively }\end{array}$ \\
\hline \multirow[t]{3}{*}{ Interventions } & Arm $1(n=12):$ CBD:THC \\
\hline & Arm $2(n=9):$ placebo \\
\hline & Participants in both arms received dose-intense TMZ \\
\hline Outcomes & Tolerability, toxicity, median survival \\
\hline Notes & $\begin{array}{l}\text { Authors concluded that this study provides preliminary evidence that CBD:THC offers some efficacy in } \\
\text { people with recurrent GBM when used as an adjunct to dose-intense TMZ and confirms its safety and } \\
\text { feasibility. }\end{array}$ \\
\hline
\end{tabular}

\section{Risk of bias}

\section{Bias}

Authors' judgement Support for judgement 
Twelves 2017 (Continued)
Random sequence genera-
Unclear risk
Insufficient detail to make a judgement tion (selection bias)

Allocation concealment Unclear risk $\quad$ Insufficient detail to make a judgement
(selection bias)

Blinding of participants Low risk
and personnel (perfor-
mance bias)
All outcomes

Blinding of outcome as- Unclear risk Insufficient detail to make a judgement
sessment (detection bias) All outcomes

\begin{tabular}{lll}
\hline $\begin{array}{l}\text { Incomplete outcome data } \\
\text { (attrition bias) } \\
\text { All outcomes }\end{array}$ & Unclear risk & Insufficient detail to make a judgement \\
\hline $\begin{array}{l}\text { Selective reporting (re- } \\
\text { porting bias) }\end{array}$ & Unclear risk & Insufficient detail to make a judgement \\
\hline Other bias & Unclear risk & Insufficient detail to make a judgement \\
\hline
\end{tabular}

\section{van den Bent 2018}

\section{Study characteristics}

\begin{tabular}{|c|c|}
\hline \multirow[t]{6}{*}{ Methods } & Design: multicenter 3-arm comparative, randomized open label phase II trial \\
\hline & Country: multicountry \\
\hline & Accrual dates: 16 February 2015 and 1 July 2016 \\
\hline & Trial reg: NCT02343406 / EudraCT\# 2014-004438-24 \\
\hline & Funding: this study was sponsored by AbbVie. \\
\hline & Declaration of interests: extensive list, page 9 of the publication \\
\hline \multirow[t]{11}{*}{ Participants } & No. randomised: 260 \\
\hline & No. analysed: 260 \\
\hline & Inclusion criteria \\
\hline & - 18 years or older \\
\hline & - Histologically confirmed glioblastoma, with centrally confirmed EGFR amplification, \\
\hline & - Relapsing more than 3 months after the end of RT. \\
\hline & - Chemotherapy had to be discontinued at least 4 weeks prior to randomization. \\
\hline & $\begin{array}{l}\text { - Surgery at the time of the recurrence was allowed, but required an MRI made within } 48 \text { hours following } \\
\text { surgery. }\end{array}$ \\
\hline & $\begin{array}{l}\text { - Patients who were re-operated for the recurrence needed to have a bi-dimensionally measurable en- } \\
\text { hancing lesion with minimal square diameters of } 10 \mathrm{~mm} \text { on MRI, with stable or decreasing dose of } \\
\text { steroids for } 7 \text { days prior to the baseline MR scan. }\end{array}$ \\
\hline & - Adequate haematological, renal, and hepatic function, \\
\hline & - For women of childbearing potential a negative pregnancy test. \\
\hline
\end{tabular}


- To call a tumour EGFR amplified, the sample needed to show $\geq 15 \%$ tumour cells with an EGFR/chromosome enumeration probe 7 ratio of $\geq 2$.

- The presence of an EGFRvIII mutation was determined by a custom triplex real-time reverse-transcription quantitative PCR on RNA extracted from formalin-fixed paraffin-embedded tissue.

Exclusion criteria

- Prior treatment with nitrosoureas, bevacizumab, or EGFR targeting agents.

- Use of enzyme inducing anti-epileptic drugs

Age: median 58.7 (range 34.9 to $82.3 \mathrm{yrs}$ )

Gender: Male 167 (64.2\%), Female 93 (35.8\%)

Performance status: WHO PS 0: 88 (33.8\%); WHO PS 1: 123 (47.3\%), WHO PS 2: 49 (18.8\%)

MGMT: unmethylated 113 (51.2\%), methylated 126 (48.5\%), missing 1 (0.4\%)

Resection/biopsy/re-operation: not reported

Initial treatment details: not reported

Time from initial diagnosis: NR

Arm 1: Depatux-M $1.25 \mathrm{mg} / \mathrm{kg}$ intravenously over 30 to 40 min once every 2 weeks in combination with TMZ 150 to $200 \mathrm{mg} / \mathrm{m}^{2}$ day 1 to 5 in 28 day cycles;

Arm 2: Depatux-M $1.25 \mathrm{mg} / \mathrm{kg}$ intravenously over 30 to 40 min once every 2 weeks

Shortly after the start of the trial, the Depatux-M start dose was decreased from $1.25 \mathrm{mg} / \mathrm{kg}$ to $1.0 \mathrm{mg} / \mathrm{kg}$ because of ocular toxicity reported in the ongoing phase I trial.

Arm 3: lomustine or TMZ depending on the timing of relapse; patients who relapsed during TMZ treatment or within the first 16 weeks after the first day of the last TMZ cycle received lomustine $110 \mathrm{mg} / \mathrm{m}^{2}$ (maximum dose $200 \mathrm{mg}$ ) on day 1 of 42-day treatment periods, whereas patients relapsing afterward were treated with TMZ 150 to $200 \mathrm{mg} / \mathrm{m}^{2}$ on day 1 to 5 in 28-day cycles.

Outcomes $\quad$ OS, PFS, HRQoL, toxicity

Notes

Authors concluded that "this trial suggests a role for the use of Depatux-M in combination with TMZ in EGFR amplified recurrent glioblastoma, but its findings are not supported by the companion phase III study in newly diagnosed glioblastoma. The efficacy in glioblastoma of other ADCs targeting the EGFR but with a better safety profile should be explored."

\section{Risk of bias}

\begin{tabular}{lll}
\hline Bias & Authors' judgement & Support for judgement \\
\hline $\begin{array}{l}\text { Random sequence genera- } \\
\text { tion (selection bias) }\end{array}$ & Low risk & "EORTC web-based registration and randomization system" \\
\hline $\begin{array}{l}\text { Allocation concealment } \\
\text { (selection bias) }\end{array}$ & Low risk & Patients were first registered and then randomised \\
\hline $\begin{array}{l}\text { Blinding of participants } \\
\text { and personnel (perfor- } \\
\text { mance bias) }\end{array}$ & High risk & \\
All outcomes & & Open label \\
\hline
\end{tabular}

$\begin{aligned} & \text { Blinding of outcome as- } \\ & \text { sessment (detection bias) }\end{aligned} \quad$ Low risk $\quad$ PFS assessed by independent review


van den Bent 2018 (Continued)

All outcomes

Incomplete outcome data Low risk Low attrition
(attrition bias)

(attrition bias)

All outcomes

Selective reporting (re- Low risk $\quad$ Primary and secondary outcomes were reported.
porting bias)

porting bias)

Other bias Unclear risk $\quad$ Funding and author interests noted.

\section{Weathers 2016}

\section{Study characteristics}

Methods Design: randomized, 2-arm, comparative, single-centre, phase II trial with patients randomized to either treatment using a 1:1 randomization scheme. (Stratified by 1st, 2nd, or 3rd recurrence, age $(\leq 50$ versus $>50$ years)).

Country: USA

Accrual dates: January 2010 and December 2014

Trial reg: NR

Funding: National Institutes of Health [1R21CA152024-01] to J.D. National Institutes of Health [CCSGP30 CA016672] to R.D.

Declaration of interests: S.W. serves on the advisory board for Actelion. X.H. has no disclosures. D.L. has no disclosures. C.C. has consultant relationships with Actelion, DNAtrix, Reata Pharma, Newlink Genetics and Cytrx Corp. M.G. has no disclosures. M.L. has no disclosures. B.O. has no disclosures. M. P-P. has no disclosures. V.P. is a consultant for Orbus Therapeutics, Foundation Medicine, Celgene, Genetech, and Merck. I. T-L. has no disclosures. R. C. has no disclosures. W. Y. is a consultant and serves on the advisory board for Actelion, DNATrix, Merck, and Novartis. J. D. serves on the advisory board for Genentech, Inc., Novartis, Celldex Therapeutics, and Foundation Medicine, Inc. J.D. serves on the DSMB for VBL Therapeutics and is a consultant for Celldex Therapeutics, OXiGENE, Omniox, Inc. and Deciphera Pharmaceuticals. J.D. receives research support from Sanofi-Aventis, AstraZeneca, EMD-Serono, Eli Lilly, Novartis, and Deciphera Pharmaceuticals.

Participants

No. randomised: 71

No. analysed: 69

Inclusion/exclusion criteria: age $\geq 18$ years, histologically confirmed glioblastoma in 1st, 2nd, or 3rd relapse, prior standard radiation for glioblastoma, prior treatment with temozolomide chemotherapy, and adequate haematologic, renal, and hepatic function. Exclusion criteria included prior treatment with an antiangiogenic agent or a nitrosurea.

Age: $18+$

Gender: 48 Female (68\%), 23 Male (32\%)

Performance status: Karnofsky performance status (KPS) $\geq 60$

MGMT: NR

Resection/biopsy: NR

Initial treatment details: NR 
Weathers 2016 (Continued)

Time from initial diagnosis: NR

Arm 2: $(\mathrm{N}=35)$ bevacizumab was given intravenously at a dose of $5 \mathrm{mg} / \mathrm{kg}$ every 3 weeks + lomustine was initially given at $90 \mathrm{mg} / \mathrm{m}^{2}$ every 6 weeks but was later reduced to $75 \mathrm{mg} / \mathrm{m}^{2}$

\begin{tabular}{|c|c|}
\hline Outcomes & OS, PFS (No HRs reported) \\
\hline \multirow[t]{3}{*}{ Notes } & $\begin{array}{l}\text { Lomustine was initially given at } 90 \mathrm{mg} / \mathrm{m}^{2} \text { every } 6 \text { weeks but was later reduced to } 75 \mathrm{mg} / \mathrm{m}^{2} \text { following } \\
\text { the occurrence of } 17 \text { grade } 3 \text { and } 7 \text { grade } 4 \text { haematologic adverse events observed in } 12 \text { patients and } 27 \\
\text { cycles of treatment. }\end{array}$ \\
\hline & $\begin{array}{l}\text { After every 6-week cycle, patients underwent clinical evaluation and radiographic tumour assessment } \\
\text { with MRI. }\end{array}$ \\
\hline & $\begin{array}{l}\text { Authors concluded that "The combination of low dose bevacizumab plus lomustine was not superior } \\
\text { to standard dose bevacizumab in patients with recurrent glioblastoma. Although the study was not de- } \\
\text { signed to exclusively evaluate patients at first recurrence, a strong trend towards improved PFS was } \\
\text { seen in that subgroup for the combination of low dose bevacizumab plus lomustine." }\end{array}$ \\
\hline
\end{tabular}

\title{
Risk of bias
}

\begin{tabular}{|c|c|c|}
\hline Bias & Authors' judgement & Support for judgement \\
\hline $\begin{array}{l}\text { Random sequence genera- } \\
\text { tion (selection bias) }\end{array}$ & Unclear risk & Not described in the report. \\
\hline $\begin{array}{l}\text { Allocation concealment } \\
\text { (selection bias) }\end{array}$ & Unclear risk & Not described in the report. \\
\hline $\begin{array}{l}\text { Blinding of participants } \\
\text { and personnel (perfor- } \\
\text { mance bias) } \\
\text { All outcomes }\end{array}$ & Unclear risk & Not described in the report. \\
\hline $\begin{array}{l}\text { Blinding of outcome as- } \\
\text { sessment (detection bias) } \\
\text { All outcomes }\end{array}$ & Low risk & $\begin{array}{l}\text { "scans assessed separately by treating physicians and by an independent, } \\
\text { treatment-arm blinded, radiographic review by a neuro-radiologist based on } \\
\text { published RANO criteria" }\end{array}$ \\
\hline $\begin{array}{l}\text { Incomplete outcome data } \\
\text { (attrition bias) } \\
\text { All outcomes }\end{array}$ & Low risk & Low attrition. 69 out of 71 participants were included in the analysis. \\
\hline $\begin{array}{l}\text { Selective reporting (re- } \\
\text { porting bias) }\end{array}$ & Unclear risk & Adverse events not clearly reported. \\
\hline Other bias & Unclear risk & Author declarations of interest noted. Trial was closed early due to futility. \\
\hline
\end{tabular}

Wick 2010

\section{Study characteristics}

Methods

\author{
Design: phase III open-label multicentre RCT, ratio 2:1
}

Countries: 14 countries including Australia, Canada, France, Germany, the Netherlands and USA.

Accrual dates: March 2006 to August 2007 
Wick 2010 (Continued)

\section{Funding: NR}

Declaration of interests: Employment or Leadership Position: Shengyan Hong, Eli Lilly (C); Luna Musib, Eli Lilly (C); Astra M. Liepa, Eli Lilly (C); Donald E. Thornton, Eli Lilly (C) Consultant or Advisory Role: Wolfgang Wick, Eli Lilly (C); Vinay K. Puduvalli, Merck (C); Marc C. Chamberlain, Enzon (U), Genentech (U); Martin J. van den Bent, Eli Lilly (C); Lawrence M. Cher, Schering-Plough (C); Warren Mason, Eli Lilly (C); Michael Weller, Eli Lilly (C) Stock Ownership: Shengyan Hong, Eli Lilly; Luna Musib, Eli Lilly; Astra M. Liepa, Eli Lilly; Donald E. Thornton, Eli Lilly Honoraria: Vinay K. Puduvalli, Merck; Marc C. Chamberlain, Enzon, Genentech Research Funding: Vinay K. Puduvalli, Merck, Celgene, Pfizer, Eli Lilly; Lawrence M. Cher, Schering-Plough, Eli Lilly, Merck, AstraZeneca Expert Testimony: None Other Remuneration: Lawrence M. Cher, Schering-Plough

Inclusion criteria included the following: 18 years of age; life expectancy 8 weeks; Karnofsky perfor-
mance status (KPS) 70; histologically confirmed WHO grade 4 glioblastoma (including gliosarcomas);
magnetic resonance imaging (MRI) evidence of tumour progression after radiation and chemotherapy
(12 weeks must have elapsed since completion of radiotherapy or 4 weeks for chemotherapy); 2 prior
chemotherapy regimens; recovery from initial surgery; and adequate organ function. Enzyme-inducing
antiepileptic drugs (EIAEDs) were to be discontinued 14 days before study enrolment.

Exclusion criteria included the following: prior enzastaurin therapy within 30 days of enrolment; treatment with any nitrosourea (including lomustine), bevacizumab, investigational drugs, or intratumoural chemotherapy; stereotactic radiosurgery; concurrent systemic anticancer therapy or anticoagulant therapy; second primary malignancy; serious concomitant systemic disorders; ECG or other clinically significant cardiac abnormalities; and pregnancy or breastfeeding.

Interventions $\quad \operatorname{Arm~} 1(\mathrm{n}=): 500 \mathrm{mg}$ of oral enzastaurin daily (1125-mg loading dose on day 1$)$

$\operatorname{Arm} 2(\mathrm{n}=): 100$ to $130 \mathrm{mg} / \mathrm{m}^{2}$ of lomustine (day 1 and 6-weekly).

\begin{tabular}{|c|c|}
\hline Outcomes & PFS, OS, objective response, adverse events \\
\hline \multirow[t]{4}{*}{ Notes } & $\begin{array}{l}\text { Enzastaurin is an oral serine/threonine kinase inhibitor that targets both the protein kinase } \mathrm{C} \text { and the } \\
\text { PI3K/AKT pathways } 23 \text { to induce apoptosis and suppress proliferation and tumour-induced angiogene } \\
\text { sis. }\end{array}$ \\
\hline & Tumour evaluations and neuro-radiologic exams using MRI were done after every cycle ( \pm 5 days). \\
\hline & This trial was stopped due to futility. \\
\hline & $\begin{array}{l}\text { Authors concluded that "Enzastaurin was well tolerated and had a better hematologic toxicity profile } \\
\text { but did not have superior efficacy compared with lomustine in patients with recurrent glioblastoma." }\end{array}$ \\
\hline
\end{tabular}

\section{Risk of bias}

\begin{tabular}{lll}
\hline Bias & Authors' judgement & Support for judgement \\
\hline $\begin{array}{l}\text { Random sequence genera- } \\
\text { tion (selection bias) }\end{array}$ & Unclear risk & Not detailed in the report. \\
\hline $\begin{array}{l}\text { Allocation concealment } \\
\text { (selection bias) }\end{array}$ & Unclear risk & Not detailed in the report. \\
\hline $\begin{array}{l}\text { Blinding of participants } \\
\text { and personnel (perfor- } \\
\text { mance bias) }\end{array}$ & High risk & Open label study \\
All outcomes & \\
\hline
\end{tabular}

\begin{tabular}{|c|c|c|}
\hline $\begin{array}{l}\text { Blinding of outcome as- } \\
\text { sessment (detection bias) }\end{array}$ & Low risk & $\begin{array}{l}\text { "Neuroradiologic data were independently reviewed (central review) to con- } \\
\text { firm response and progression." }\end{array}$ \\
\hline
\end{tabular}


Wick 2010 (Continued)

Incomplete outcome data Low risk $\quad$ All enrolled patients analysed.
(attrition bias)

All outcomes

Selective reporting (re- Low risk Expected outcomes were reported and study was stopped early for futility. porting bias)

Other bias Unclear risk Funding and author interests noted.

Wick 2014

\section{Study characteristics}

Design: Phase 2 RCT; ratio 1:2
Country: Austria, Germany, Russia
Accrual dates: December 2009 to September 2011
Trial ID. NCT01071837
Funding: Apogenix GmbH
Declaration of interests: W. Wick reports receiving a commercial research grant from Boehringer In-
gelheim and Roche; speaker's bureau honoraria from Prime Oncology; and is a consultant/advisory
board member for Eli Lilly and Co. and Roche. B. Wiestler is a co-inventor of a patent on Neutralization
of CD95 activity blocks invasion of glioblastoma cells in vivo, which is owned by the German Cancer
Research Center and licensed to Apogenix. J. Debus and C. Hartmann report receiving commercial re-
search grants from Apogenix. C. Kunz and Harald Fricke are employees of Apogenix.

Participants

No. randomised: 91

No. analysed: 84

Inclusion/exclusion criteria: adult patients with 1st or 2nd progression of a histologically confirmed glioblastoma either not being eligible for tumour resection or having macroscopic residual tumour after tumour resection, documented by contrast-enhanced magnetic resonance imaging (MRI) with the largest diameter measuring $1 \mathrm{~cm}$ to $4 \mathrm{~cm}$ and a Karnofsky performance score (KPS) 60 were eligible. No more than 2 prior therapy regimens including 1 or 2 resections, 1 or 2 chemotherapies of which one must have been temozolomide-containing, and 1 radiotherapy (completed 8 months before enrollment) were allowed.

Age: median age 59 ( 25 to 79 ) in RT arm and 57 (20 to 73 ) in RT+APG101 arm

Gender: Male $46 \%$ and $67 \%$ in arm 1 and arm 2, respectively.

Performance status: $\geq 60$

MGMT status: methylated $57.7 \%$ and $70.6 \%$ for arms 1 and 2, respectively.

Time from diagnosis: 20.3 mo and 23.9 mo, respectively.

Arm 2 ( $n=58):$ RT + APG101 (400 mg given weekly in an iv infusion)

Outcomes PFS, OS, adverse events, QoL


Wick 2014 (Continued)

Notes

Authors concluded that "CD95 pathway inhibition in combination with rRT is an innovative concept with clinical efficacy. It warrants further clinical development."

\section{Risk of bias}

\begin{tabular}{|c|c|c|}
\hline Bias & Authors' judgement & Support for judgement \\
\hline $\begin{array}{l}\text { Random sequence genera- } \\
\text { tion (selection bias) }\end{array}$ & Low risk & $\begin{array}{l}\text { "Participant allocation was done according to an electronically generated ran- } \\
\text { domization list" }\end{array}$ \\
\hline $\begin{array}{l}\text { Allocation concealment } \\
\text { (selection bias) }\end{array}$ & Unclear risk & "Allocation took place by fax transmission from the CRO to the study site" \\
\hline $\begin{array}{l}\text { Blinding of participants } \\
\text { and personnel (perfor- } \\
\text { mance bias) } \\
\text { All outcomes }\end{array}$ & High risk & "This was an unblinded trial" \\
\hline $\begin{array}{l}\text { Blinding of outcome as- } \\
\text { sessment (detection bias) } \\
\text { All outcomes }\end{array}$ & Unclear risk & $\begin{array}{l}\text { "Biases were prevented by strict adherence to an analysis plan that was writ- } \\
\text { ten by the statistician (K. Junge) before any analysis of the data." "Tumor re- } \\
\text { sponse or progression was defined according to modified MacDonald criteria } \\
\text { taking...by the local investigator and centrally." }\end{array}$ \\
\hline $\begin{array}{l}\text { Incomplete outcome data } \\
\text { (attrition bias) } \\
\text { All outcomes }\end{array}$ & Low risk & $84 / 91$ pts were evaluable for the primary endpoint \\
\hline $\begin{array}{l}\text { Selective reporting (re- } \\
\text { porting bias) }\end{array}$ & Low risk & Expected outcomes were reported. \\
\hline Other bias & Unclear risk & Funding and author interests noted. \\
\hline
\end{tabular}

Wick 2017

\section{Study characteristics}

Methods
Countries: 8 countries including Belgium, Germany, the Netherlands, France, Switzerland.
Accrual dates: November 2011 to December 2014
Funding: F. Hoffmann-La Roche and EORTC Cancer Research Fund;
Trial ID: EORTC 26101 ClinicalTrials.gov NCT01290939; Eudra-CT 2010-023218-30
Declarations of interest: Dr. Wick reports receiving consulting fees from Merck Sharp \& Dohme and
Celldex Therapeutics, consulting fees and lecture fees from Bristol-Myers Squibb, grant support and
drugs provided for the trial from Roche and Boehringer Ingelheim, and drugs provided for the trial from
Apogenix and Pfizer; Dr. Bendszus, receiving grant support from Siemens, Stryker, and Medtronic, con-
sulting fees from Vascular Dynamics, Boehringer Ingelheim, and B. Braun, lecture fees from Teva, grant
support and lecture fees from Novartis and Bayer, and grant support, consulting fees, and lecture fees
from Codman Neuro and Guerbet; Dr. Taphoorn, receiving consulting fees from F. Hoffmann-La Roche;
among others.

Participants

No. randomised: 437

No. analysed: 437 
Wick 2017 (Continued)

Included if: histologic confirmation of glioblastoma; first progression after chemoradiotherapy; at least 3 months after end of radiotherapy.

Excluded if: received prior antiangiogenic treatment or nitrosureas. Radiotherapy at a dose of no more than 65 Gy with stereotactic radiosurgery or brachytherapy was allowed if recurrence was histologically proven.

Age: median 57.7 years (21.2 to 82.3 )

Gender: $60.6 \%$ male, $39.4 \%$ female

Performance status: WHO 0 to 2

MGMT status: methylated $23.8 \%$, unmethylated $28.6 \%$ and unknown $48 \%$

Re-operation: NR

Details of initial treatment: RT + TMZ

Time from diagnosis: NR

\begin{tabular}{ll}
\hline Interventions & Arm 1: lomustine $\left(60 \mathrm{mg} / \mathrm{m}^{2}\right.$ orally 6 weekly) plus bevacizumab $(10 \mathrm{mg} / \mathrm{kg}$ every 2 weeks) \\
& Arm 2: lomustine $\left(110 \mathrm{mg} / \mathrm{m}^{2}\right.$ every 6 weeks) \\
\hline Outcomes & OS, PFS, adverse events, QOL, molecular studies \\
\hline Notes & $\begin{array}{l}\text { Authors concluded that "Despite somewhat prolonged progression-free survival, treatment with lo- } \\
\text { mustine plus bevacizumab did not confer a survival advantage over treatment with lomustine alone in } \\
\text { patients with progressive glioblastoma." }\end{array}$ \\
\hline
\end{tabular}

\section{Risk of bias}

Bias Authors' judgement Support for judgement

Random sequence genera- Low risk "The EORTC used four stratification criteria to centrally randomly assign pation (selection bias) tients who had entered the trial."

Allocation concealment Unclear risk Probably concealed but not described in the report.

(selection bias)

\begin{tabular}{|c|c|c|}
\hline $\begin{array}{l}\text { Blinding of participants } \\
\text { and personnel (perfor- } \\
\text { mance bias) } \\
\text { All outcomes }\end{array}$ & High risk & Open label \\
\hline
\end{tabular}

\begin{tabular}{lll}
\hline $\begin{array}{l}\text { Blinding of outcome as- } \\
\text { sessment (detection bias) } \\
\text { All outcomes }\end{array}$ & Low risk & $\begin{array}{l}\text { "All the assessments and interpretations of disease status were performed lo- } \\
\text { cally but with continuous central quality control and independent central as- } \\
\text { sessment" }\end{array}$ \\
\hline $\begin{array}{l}\text { Incomplete outcome data } \\
\begin{array}{l}\text { (attrition bias) } \\
\text { All outcomes }\end{array}\end{array}$ & Low risk & All participants were included in the primary analysis. \\
\hline $\begin{array}{l}\text { Selective reporting (re- } \\
\text { porting bias) }\end{array}$ & Low risk & All pre-specified outcomes are reported. \\
\hline Other bias & Unclear risk & Funding and author interests noted. \\
\hline
\end{tabular}

$\operatorname{adj}=$ adjuvant 
$\mathrm{AA}=$ anaplastic astrocytoma

$\mathrm{AE}=$ adverse events

$\mathrm{CED}=$ cediranib

CCNU = 1-(2-chloroethyl)-3-cyclohexyl-1- nitrosourea, also known as lomustine

$\mathrm{CPT}=$ irinotecan

$\mathrm{DC}=$ dendritic cell

ECOG = Eastern Cooperative Oncology Group

FOT $=$ fotemustine

$\mathrm{GBM}=$ glioblastoma

$\mathrm{GEF}=$ gefitinib

$\mathrm{HU}=$ hydroxyurea

MGMT = Methyl Guanine Methyl Transferase

MMSE $=$ mini mental state exam

$\mathrm{NR}=$ not reported

OS = overall survival

$\mathrm{PFS}=$ progression free survival

$\mathrm{PS}=$ performance status

QoL = quality of life

$\mathrm{RT}=$ radiotherapy

$\mathrm{SAE}=$ severe adverse event

$\mathrm{TMZ}=$ temozolomide

TTD = time to deterioration

VEGF = vascular epithelial growth factor

Characteristics of excluded studies [ordered by study ID]

\section{Study Reason for exclusion}

Abacioglu 2011

This is a study of dose dense temozolomide in people with recurrent glioblastoma. This study was excluded because it was a non-comparative study, which therefore did not meet the review criteria for study design.

This is a systematic review of irinotecan-based salvage regimens for patients with recurrent glioblastoma multiforme (GBM).

ACTRN12615001072505 2015 This is a study to treat raised intercranial pressure associated with brain tumours in people with oedemas/glioblastoma. We excluded it because it did not meet the reviews intervention and outcomes criteria.

Ahluwalia 2018

This is a study of nivolumab plus standard dose bevacizumab versus nivolumab plus low dose bevacizumab in recurrent glioblastoma. We excluded it because it did not meet the review's minimum number of participants criterion.

Aoki 2016

This is a study of temozolomide plus nimustine chemotherapy for recurrent glioblastoma. We excluded it because it was a single-arm phase I/II study.

\section{Bartsch 2005}

This is a retrospective study of re-irradiation in people with recurrent glioblastoma, which was noncomparative.

Bogdahn 2011

This study is a study of two different doses of trabedersen compared with standard chemotherapy for recurrent GBM or AA. We excluded it because a significant proportion of participants did not receive the standard of care (chemoradiotherapy) for the primary treatment.

Boiardi 2008

A retrospective study of mitoxantrone added to temozolomide and re-operation for recurrent GBM. This study did not meet the review population criteria as study subjects had not received the Stupp protocol as primary treatment. 


\begin{tabular}{ll}
\hline Study & Reason for exclusion \\
\hline Brada 2010 & $\begin{array}{l}\text { This study evaluates temozolomide versus PCV among people with recurrent GBM. Participants in } \\
\text { this study had not received the Stupp regimen for primary treatment of their GBM and therefore } \\
\text { this study was excluded. }\end{array}$ \\
\hline
\end{tabular}

Brandes $2009 \quad$ This is a study of fotemustine after concomitant and/or adjuvant temozolomide in people with recurrent glioblastoma. We excluded it because it was a single arm study.

Chen 2015

This retrospective study compares BEV treatment with a variety of BEV-combination treatments and non-BEV treatments. It is not clear whether patients received chemoradiotherapy as first-line treatment and the second-line treatments differed widely between groups; therefore, We excluded it due to ineligible population and diverse interventions.

\begin{tabular}{ll}
\hline Cher 2017 & $\begin{array}{l}\text { This is a study of tanibirumab in people with recurrent glioblastoma. We excluded it because it did } \\
\text { not meet the review's minimum number of participants. }\end{array}$ \\
\hline CTRI/2018/01/011542 & This is a study protocol of mebendazole in glioblastoma. \\
\hline Dixit 2015 & $\begin{array}{l}\text { This is a study presented in a letter which compares bevacizumab with PCV chemotherapy in a ret- } \\
\text { rospective cohort of people with recurrent glioblastoma. Outcomes were neurological status and } \\
\text { performance status. It was excluded because it included people with grade } 3 \text { and grade } 4 \text { tumours } \\
\text { and comparison groups were not concurrent. }\end{array}$
\end{tabular}

This is a study of TVB-2640 in combination with bevacizumab in patients with first relapse of highgrade astrocytoma. We excluded it because it did not meet the criteria due to ineligible population. vacizumab monotherapy in people with recurrent glioblastoma. We excluded it because it is a radiographic analysis.

\begin{tabular}{ll}
\hline Fogh 2010 & $\begin{array}{l}\text { This is a study of hypofractionated stereotactic therapy in people with recurrent glioblastoma. We } \\
\text { excluded it because it was a non-comparative study. }\end{array}$ \\
\hline Gan 2015 & $\begin{array}{l}\text { This is a study of an EGFR agent called ABT-414 with or without TMZ in glioblastoma. We excluded it } \\
\text { because it is a dose-finding study. }\end{array}$ \\
\hline Gatson 2015 & $\begin{array}{l}\text { This is a study of rindopepimut plus bevacizumab in recurrent glioblastoma. We excluded it be- } \\
\text { cause the article has been retracted. }\end{array}$ \\
\hline Haslund 2016 & $\begin{array}{l}\text { A prospective, open-label, phase II study was designed to include } 175 \text { patients with recurrent GBM } \\
\text { in three centres in Denmark comparing ALECSAT to Bevacizumab plus Irinotecan but only } 25 \text { pa- } \\
\text { tients were randomised and the study was stopped due to futility. }\end{array}$ \\
\hline Hong 2013 & $\begin{array}{l}\text { This is a retrospective study of repeated microsurgical resection versus a single re-resection in } 10 \\
\text { vs } 32 \text { patients, respectively with GBM. Choice of surgical treatment was dependent on the sur- } \\
\text { geon's choice, only } 29 \text { of the patients received radiotherapy and temozolomide, and salvage treat- } \\
\text { ments varied; we therefore considered this study to be at a high risk of bias. }\end{array}$ \\
\hline Idbaih 2016 & $\begin{array}{l}\text { This trials is among people with recurrent grade } 2 \text { and } 3 \text { glioma therefore does not meet the re- } \\
\text { view's population criteria. }\end{array}$ \\
\hline Immonen 2004 & $\begin{array}{l}\text { This study is study of AdvHSV-tk gene therapy with intravenous ganciclovir in people with recurrent } \\
\text { glioblastoma. We excluded it because it did not meet the review's '2005 onwards' criterion. }\end{array}$ \\
\hline Ji 2016 & $\begin{array}{l}\text { This is an RCT of adenovirus-mediated delivery of thymidine kinase (ADV-TK) compared with "con- } \\
\text { ventional treatments" in recurrent GBM patients. Only } 68 \% \text { of participants had chemoradiotherapy }\end{array}$ \\
\hline
\end{tabular}




\begin{tabular}{ll}
\hline Study & Reason for exclusion \\
\hline & $\begin{array}{l}\text { for the primary disease; we therefore excluded the study on patient population. Authors concluded } \\
\text { that there was a notable improvement in PFS and OS. }\end{array}$
\end{tabular}

\section{Kaloshi 2015}

This retrospective study of BEV+CBP vs CBP did not fulfil the population inclusion criteria of $>80 \%$ participants having had chemoradiotherapy before study treatments.

Kesari 2017

This is a post hoc analysis of the EF-14 trial among people with newly diagnosed GBM that evaluated TTF plus TMZ versus TMZ after radiotherapy. At first recurrence, 131 patients in the TTF + TMZ group chose to continue with TTF plus second-line chemotherapy therapy, 73 patients in the TMZ only group chose to receive additional second-line chemotherapy and 13 of these people crossed over to the TTF arm. The patient population in this study differs from the review population that received the Stupp protocol only prior to first recurrence.

\begin{tabular}{ll}
\hline Kinzel 2018 & A non-comparative study evaluating the safety data of TTFields + lomustine (CCNU). \\
\hline Komotar 2010 & Not a study but an editorial. \\
\hline Konkel 2018 & $\begin{array}{l}\text { This is a study of TVB-2640 in combination with avastin versus avastin alone in patients with first re- } \\
\text { lapsed AA. We excluded it because it did not meet the study criteria due to ineligible population. }\end{array}$
\end{tabular}

\begin{tabular}{ll}
\hline Lang 2018 & $\begin{array}{l}\text { This is a dose-escalation, dose-finding study of an oncolytic adenovirus DNX-2401 and, as such, we } \\
\text { excluded it on study design. }\end{array}$
\end{tabular}

\begin{tabular}{ll}
\hline Levin 2017 & This RCT compares eflornithine with lomustine versus lomustine in people with recurrent AA (grade \\
& 3 glioma); we therefore excluded it due to patient population.
\end{tabular}

\begin{tabular}{ll}
\hline Mau-Sorensen 2016 & A phase 2 dose-finding study of selinexor in recurrent GBM. \\
\hline Minniti 2015 & $\begin{array}{l}\text { This non-randomised study included patients with AA (22\%) and GBM and therefore did not meet } \\
\text { the inclusion criteria. }\end{array}$ \\
\hline
\end{tabular}

Muhic 2013

This is an uncontrolled study of nintedanib in people with recurrent glioblastoma.

$\begin{array}{ll}\text { NCT02529072 } 2015 & \begin{array}{l}\text { This was a study of nivolumab with DC vaccines in recurrent glioblastoma. This study only had } 6 \\ \text { participants. }\end{array}\end{array}$

\begin{tabular}{ll}
\hline NCT02852655 2016 & $\begin{array}{l}\text { A dose-finding study of pembrozolomide pre- and post surgery versus post-surgery only in patients } \\
\text { with surgically resectable GBM. }\end{array}$ \\
\hline NCT028667472016 & $\begin{array}{l}\text { This study is about hypofractionated stereotactic radiation therapy and durvalumab in recurrent } \\
\text { glioblastoma. We excluded it as it was suspended on interim analysis with no data reported. }\end{array}$ \\
\hline NCT03014804 2016 & $\begin{array}{l}\text { This study is about tumour lysate antigen vaccine and nivolumab in recurrent glioblastoma. This } \\
\text { study was excluded because it was withdrawn with no data reported. }\end{array}$ \\
\hline NCT03149575 2017 & $\begin{array}{l}\text { This study was about temozolomide-avastin and bevacizumab in recurrent glioblastoma. We ex- } \\
\text { cluded it because it was terminated due to "change in clinical development plan" and no data were } \\
\text { reported. }\end{array}$ \\
\hline Penas-Prado 2015 & $\begin{array}{l}\text { This is a phase } 1 \text { dose-escalation study. } \\
\text { Rahman } 2014\end{array}$ \\
$\begin{array}{l}\text { This is an uncontrolled retrospective study of } 42 \text { patients with recurrent GBM, 28 who received lo- } \\
\text { mustine or carmustine with BEV as second-line treatment and 14 who received this combination as } \\
\text { third-line treatment. }\end{array}$ \\
\hline
\end{tabular}

This phase 2 trial was a dose-finding study that was therefore excluded on study design. 


\begin{tabular}{ll}
\hline Study & Reason for exclusion \\
\hline Ruiz-Sanchez 2012 & This retrospective cohort study did not have a concurrent comparison group. \\
\hline Schmidt 2006 & $\begin{array}{l}\text { This is a study of PCV for recurrent GBM among patients who had received radiotherapy for primary } \\
\text { GBM. We excluded it because it is a single arm study. }\end{array}$ \\
\hline
\end{tabular}

Seystahl 2013

A retrospective study of BEV vs BEV + Irinotecan in grade 2 and 3 glioma; excluded on patient population.

Short 2017 This was a dose-finding study and therefore excluded on study design.

\begin{tabular}{ll}
\hline Socha 2016 & $\begin{array}{l}\text { This retrospective study was conducted among elderly and/or frail patients, therefore did not meet } \\
\text { the review's study population criteria. }\end{array}$ \\
\hline Sun 2013 & $\begin{array}{l}\text { This is a Chinese study of temozolomide versus semustine in people with recurrent glioblastoma } \\
\text { and anaplastic astrocytoma. Data were not reported according to tumour grade and less than } 80 \% \\
\text { of participants had recurrent GBM. }\end{array}$
\end{tabular}

Taylor 2018

This is a study of palbociclib with resection versus palbociclib without resection in people with recurrent glioblastoma. It was excluded because it was stopped early due to lack of efficacy.

\section{Van den Bent 2009}

van den Bent 2016

Vauleon 2012

This negative study of erlotinib vs TMZ or LOM was excluded because it did not meet the patient population criteria, i.e. less than $80 \%$ of participants received chemoradiotherapy.

This is a study of temozolomide with or without bevacizumab in 1st recurrence of grade II or III glioma. We excluded it on patient population.

This is a retrospective study of 24 people with recurrent GBM who were treated with nitrosoureas or irinotecan and bevacizumab. This study was at a high risk of bias due to baseline differences between study groups.

\begin{tabular}{ll}
\hline Weller 2015 & $\begin{array}{l}\text { This RCT was a dose-finding study comparing two TMZ schedules and therefore did not meet the } \\
\text { study design criteria of the review. }\end{array}$ \\
\hline Yasuda 2018 & $\begin{array}{l}\text { This retrospective study included a mixed grade } 3 / 4 \text { glioma population with < } 80 \% \text { of participants } \\
\text { having a diagnosis of glioblastoma; it therefore did not meet the review's population criteria. }\end{array}$ \\
\hline Yung 2000 & $\begin{array}{l}\text { This is a study of temozolemide vs. procarbazine in people with glioblastoma at first relapse. We } \\
\text { excluded it because it did not meet the study criteria due to ineligible population (had radiation } \\
\text { therapy only as initial treatment, not chemoradiation). }\end{array}$ \\
\hline Zadeh 2018 & $\begin{array}{l}\text { An RCT of Toca 511 and Toca FC versus standard of care in patients with recurrent high-grade } \\
\text { glioma. Excluded because this study was terminated due to "sponsor decision". }\end{array}$ \\
\hline Zakharia 2017 & $\begin{array}{l}\text { This is an interim analysis of an early phase I study of of indoximod with temozolomide for adult } \\
\text { patients with temozolomide-refractory primary malignant brain tumours. }\end{array}$ \\
\hline
\end{tabular}

$\mathrm{AA}=$ anaplastic astrocytoma

ALECSAT = autologous lymphoid effector cells specific against tumour cells

$\mathrm{BEV}=$ bevacizumab

$\mathrm{CBP}=\mathrm{CREB}$ binding proteins

$\mathrm{CCNU}=$ lomustine

$D C$ vaccines $=$ dendritic cell vaccines

EGFR = epidermal growth factor receptor

$\mathrm{GBM}=$ glioblastoma

LOM = lomustine

OS = overall survival

Treatment options for progression or recurrence of glioblastoma: a network meta-analysis (Review)

Copyright $\odot 2021$ The Cochrane Collaboration. Published by John Wiley \& Sons, Ltd. 
$\mathrm{PFS}=$ progression free survival

$\mathrm{PCV}=$ procarbazine, lomustine $(\mathrm{CCNU})$ and vincristine

$\mathrm{RCT}=$ randomised clinical trial

TTF = tumour treating fields

TMX = temozolomide

Characteristics of ongoing studies [ordered by study ID]

ACTRN12617000534381 2017

\begin{tabular}{ll}
\hline Study name & Philip 2017 \\
\hline Methods & $\begin{array}{l}\text { Phase 2, multicentre, open-label, parallel-arm, randomised controlled trial (RCT) of STEP Care plus } \\
\text { standard best practice cancer care versus standard best practice cancer care alone. }\end{array}$ \\
\hline Participants & $\begin{array}{l}\text { Participants are people with advanced cancer; high-grade glioma, breast cancer and prostate can- } \\
\text { cer. }\end{array}$ \\
\hline Interventions & Early palliative "STEP" care plus best practice cancer care versus best practice cancer care alone. \\
\hline Outcomes & $\begin{array}{l}\text { Document the impact of "STEP" on end-of-life care, determine whether it is worth exploring further } \\
\text { and evaluate the timing of palliative care according to carers, families and professionals. }\end{array}$ \\
\hline Starting date & 2017 \\
\hline Contact information & Jennifer.philip@svha.org.au
\end{tabular}

Notes

\section{ChiCTR1900020646 2019}

\begin{tabular}{ll}
\hline Study name & Xue 2019 \\
\hline Methods & $\begin{array}{l}\text { A phase 2 randomized controlled clinical trial of temozolomide plus apatinib in newly diagnosed } \\
\text { high-grade glioma. }\end{array}$ \\
\hline Participants & Adults with glioma \\
\hline Interventions & Temozolomide and apatinib versus temozolomide alone. \\
\hline Outcomes & Progression-free survival, rate of 2 year overall survival and adverse events. \\
\hline Starting date & 6 May 2019 \\
\hline Contact information & xxy0636@163.com \\
\hline Notes & NCT03741244 \\
\hline
\end{tabular}

\section{Combs 2010}

\begin{tabular}{ll}
\hline Study name & NCT01166308 \\
\hline Methods & Open label RCT of carbon ion radiotherapy vs fractionated stereotactic radiotherapy \\
\hline
\end{tabular}


Combs 2010 (Continued)

Participants 56 patients with recurrent GBM with indication for radiotherapy

Interventions Arm 1: carbon ion radiotherapy

Arm 2: fractionated stereotactic radiotherapy

\begin{tabular}{ll}
\hline Outcomes & OS, PFS \\
\hline Starting date & July 2010 \\
\hline Contact information & Prof. Juergen Debus \\
\hline Notes & Apparently completed in 2016. No results reported. \\
\hline
\end{tabular}

JCOG1308C 2019

\begin{tabular}{ll}
\hline Study name & Kobayashi 2019 \\
\hline Methods & $\begin{array}{l}\text { A multicenter randomized phase Ill study for recurrent glioblastoma comparing bevacizumab } \\
\text { alone with dose-dense temozolomide followed by bevacizumab. }\end{array}$ \\
\hline Participants & Adults with recurrent glioblastoma and gliosarcoma. \\
\hline Interventions & $\begin{array}{l}\text { Bevacizumab alone versus dose-dense temozolomide (ddTMZ) and bevacizumab (BEV) sequential } \\
\text { combination therapy. }\end{array}$ \\
\hline Outcomes & Overall survival, progression-free survival, response rate and adverse events. \\
\hline Starting date & 22 July 2016 \\
\hline Contact information & kekobayashi@kki.biglobe.ne.jp \\
\hline Notes & JCOG1308C \\
\hline
\end{tabular}

КСТ0002632 2018

\begin{tabular}{ll}
\hline Study name & Hong 2018 \\
\hline Methods & $\begin{array}{l}\text { Randomised, double-blinded study of efficacy and safety of low-dose temozolomide with met- } \\
\text { formin or placebo for the patients with recurrent or refractory glioblastoma. }\end{array}$ \\
\hline Participants & Adults from age 19+ with recurrent or refractory glioblastoma. \\
\hline Interventions & Temozolomide + metformin versus temozolomide + placebo \\
\hline Outcomes & Progression-free survival, overall survival, tumour response rate \\
\hline Starting date & 21 November 2016 \\
\hline Contact information & hongyk@catholic.ac.kr \\
\hline Notes & KCT0002632 \\
\hline
\end{tabular}


NCT01252459 2016

\begin{tabular}{ll}
\hline Study name & GLIAA 2016 \\
\hline Methods & $\begin{array}{l}\text { Prospective, open label, randomized (allocation 1:1), 2-arm, parallel group, phase II multi-centre } \\
\text { trial }\end{array}$ \\
\hline Participants & Adults with recurrent glioblastoma \\
\hline Interventions & AA-PET based target volume delineation versus T1Gd-MRI based target volume delineation \\
\hline Outcomes & Overall survival, progression-free survival, quality of life \\
\hline Starting date & gliaa@uniklinik-freiburg.de/anca.grosu@uniklinik-freiburg.de \\
\hline Contact information & NCT01252459 \\
\hline Notes &
\end{tabular}

\section{NCT01903330 2018}

\begin{tabular}{ll}
\hline Study name & NCT01903330 \\
\hline Methods & A double-blinded, randomized, Phase 2 study. \\
\hline Participants & Adult patients with recurrent glioblastoma \\
\hline Interventions & ERC1671 + bevacizumab versus bevacizumab + placebo \\
\hline Outcomes & Adverse events, toxicity, overall survival, progression-free survival \\
\hline Starting date & 2017 \\
\hline Contact information & Tel.: $+17144567032 ;$ Fax: $+17144566894 ;$ dbota@uci.edu \\
\hline Notes & NCT01903330 \\
\hline
\end{tabular}

\section{NCT02394626 2015}

\begin{tabular}{ll}
\hline Study name & RE-SURGE \\
\hline Methods & Randomized controlled comparative phase II trial on surgery for glioblastoma recurrence. \\
\hline Participants & Adults with first recurrence of glioblastoma. \\
\hline Interventions & Surgery followed by adjuvant second-line therapy versus second-line therapy alone \\
\hline Outcomes & Overall survival, progression-free survival, morbidity of surgery \\
\hline Starting date & May 2015 \\
\hline Contact information & Contact: Andrea Mathis+41316329564 andrea.mathis@insel.ch \\
\hline
\end{tabular}


NCT02394626 2015 (Continued)
Notes
NCT02394626

NCT02678975 2016

\begin{tabular}{ll}
\hline Study name & $\begin{array}{l}\text { DIRECT (DIsulfiram REsponse as add-on to ChemoTherapy) in recurrent glioblastoma: a random- } \\
\text { ized controlled trial }\end{array}$ \\
\hline Methods & $\begin{array}{l}\text { Multicenter, RCT with single masking, looking at disulfiram and copper-supplement as add-on } \\
\text { treatment in glioblastoma patients with recurrence receiving alkylating chemotherapy. }\end{array}$ \\
\hline Participants & Adults with recurrent glioblastoma \\
\hline Interventions & Alkylating chemotherapy + disulfiram + copper versus alkylating chemotherapy \\
\hline Outcomes & Survival at 6 months, overall survival, progression-free survival, health-related quality of life \\
\hline Starting date & January 2017 \\
\hline Contact information & asgeir.jakola@vgregion.se \\
\hline Notes & NCT02678975 \\
\hline
\end{tabular}

\section{NCT02715297 2018}

\begin{tabular}{ll}
\hline Study name & GlioCave \\
\hline Methods & Multicentre, 2-armed, randomized, phase II study \\
\hline Participants & 200 adults with recurrent glioblastoma \\
\hline Interventions & FET-PET-based treatment versus a T1Gd-MRI-based treatment \\
\hline Outcomes & Overall survival, progression-free survival \\
\hline Starting date & February 2016 \\
\hline Contact information & mailto: Christoph.Straube@mri.tum.de \\
\hline Notes & NCT02715297 \\
\hline
\end{tabular}

\section{NCT02761070 2016}

\begin{tabular}{ll}
\hline Study name & RE-GEND \\
\hline Methods & $\begin{array}{l}\text { A multicentre randomized Phase Ill study for recurrent glioblastoma comparing bevacizumab } \\
\text { alone with dose-dense temozolomide followed by bevacizumab }\end{array}$ \\
\hline Participants & Adults with recurrent glioblastoma \\
\hline Interventions & Bevacizumab monotherapy versus temozolomide plus bevacizumab \\
\hline
\end{tabular}


NCT027610702016 (Continued)

\begin{tabular}{ll} 
Outcomes & Overall survival, progression-free survival, adverse events, complete response rate. \\
\hline Starting date & 11 July 2016 \\
\hline Contact information & mnagane@ks.kyorin-u.ac.jp \\
\hline Notes & NCT02761070
\end{tabular}

\section{NCT02794883 2016}

\begin{tabular}{ll}
\hline Study name & Raizer 2016 \\
\hline Methods & $\begin{array}{l}\text { Randomised, open label trial of tremelimumab and durvalumab in combination or alone in treat- } \\
\text { ing patients with recurrent malignant glioma }\end{array}$ \\
\hline Participants & Adults with recurrent malignant glioblastoma \\
\hline Interventions & Durvalumab or durvalumab + tremelimumab or tremelimumab \\
\hline Outcomes & Determine T-cell safety, overall survival and progression-free survival. \\
\hline Starting date & September 2016 \\
\hline Contact information & Not found \\
\hline Notes & NCT02794883 \\
\hline
\end{tabular}

\section{NCT02942264 2016}

\begin{tabular}{ll}
\hline Study name & Wu 2016 \\
\hline Methods & $\begin{array}{l}\text { Phase I trial of zotiraciclib (TG02) + dose-dense or metronomic temozolomide followed by random- } \\
\text { ized phase II trial of zotiraciclib (TG02) + temozolomide versus temozolomide alone in adults with } \\
\text { recurrent anaplastic astrocytoma and glioblastoma. }\end{array}$ \\
\hline Participants & Adults with recurrent anaplastic astrocytoma/glioblastoma. \\
\hline Interventions & $\begin{array}{l}\text { Phase I metronomic TMZ versus zotiraciclib, phase II MTD of zotiraciclib plus "winner" from phase I } \\
\text { versus "winner" from phase I. }\end{array}$ \\
\hline Outcomes & Maximum tolerated dose and progression free survival. \\
\hline Starting date & 14 December 2016 \\
\hline Contact information & Contact: Matthew R Lindsley, R.N.(240) 760-6534 matthew.lindsley@nih.gov \\
\hline Notes & NCT02942264 \\
\hline
\end{tabular}


NCT02974621 2016

\begin{tabular}{ll}
\hline Study name & Arrillaga-Romany 2016 \\
\hline Methods & $\begin{array}{l}\text { A randomized Phase 2 trial of cediranib and olaparib compared to bevacizumab in patients with re- } \\
\text { current glioblastoma who have not received prior VEGF therapy }\end{array}$ \\
\hline Participants & Patients With recurrent glioblastoma \\
\hline Interventions & Cediranib maleate and olaparib compared to bevacizumab \\
\hline Outcomes & Progression-free survival, safety and overall survival \\
\hline Starting date & 15 September 2017 \\
\hline Contact information & \\
\hline Notes & \\
\hline
\end{tabular}

\section{NCT030258932019}

\begin{tabular}{ll}
\hline Study name & $\begin{array}{l}\text { A Phase II/III study of high-dose, intermittent sunitinib in patients with recurrent glioblastoma mul- } \\
\text { tiforme (STELLAR) }\end{array}$ \\
\hline Methods & Randomised, open-label \\
\hline Participants & Patients with first progression of GBM \\
\hline Interventions & Group 1 (experimental arm): sunitinib, 300 mg administered orally in a weekly schedule. \\
\hline Outcomes & Group 2 (control arm): lomustine $110 \mathrm{mg} / \mathrm{m}^{2}$, taken orally on day 1 every 6 weeks. \\
\hline Starting date & PFS, OS, AEs, HRQOL \\
\hline Contact information & January 2017 \\
\hline Notes & M.E. van Linde \\
\hline
\end{tabular}

NCT03149003 2018

\begin{tabular}{ll}
\hline Study name & WIZARD201G \\
\hline Methods & Phase 2, active-controlled, multicenter, open-label randomized study \\
\hline Participants & Adults with recurrent or progressive glioblastoma. \\
\hline Interventions & DSP-7888 dosing emulsion with bevacizumab (Bev) versus Bev alone \\
\hline Outcomes & Overall survival, progression free survival and safety \\
\hline Starting date & 8 December 2017 \\
\hline
\end{tabular}


NCT03149003 2018 (Continued)

\begin{tabular}{ll} 
Contact information & Not found \\
\hline Notes & NCT03149003
\end{tabular}

\section{NCT036321352018}

\begin{tabular}{ll}
\hline Study name & CSCRGBM \\
\hline Methods & $\begin{array}{l}\text { Standard chemotherapy vs. chemotherapy guided by cancer stem cell test in recurrent glioblas- } \\
\text { toma }\end{array}$ \\
\hline Participants & Adults with recurrent glioblastoma \\
\hline Interventions & Physician Choice treatment versus ChemolD-guided treatment \\
\hline Outcomes & Overall survival, progression-free survival, tumour response and quality of life. \\
\hline Starting date & 15 May 2018 \\
\hline Contact information & Tulika.RANJAN@ahn.org \\
\hline Notes & NCT03632135 \\
\hline
\end{tabular}

\section{NCT03746288 2018}

\begin{tabular}{ll}
\hline Study name & Li 2018 \\
\hline Methods & $\begin{array}{l}\text { A multicentre, randomized, open-label, controlled phase Il clinical trial to evaluate the efficacy and } \\
\text { safety of CAN008 combined with re-irradiation (rRT) for treating patients with recurrent glioblas- } \\
\text { toma }\end{array}$ \\
\hline Participants & Adults with recurrent glioblastoma \\
\hline Interventions & CAN008 + radiotherapy versus radiotherapy \\
\hline Outcomes & Overall survival, progression-free survival, objective response rate, duration of response \\
\hline Starting date & 20 November 2018 \\
\hline Contact information & neure55@126.com \\
\hline Notes & NCT03746288
\end{tabular}

\section{NCT03970447 2019b}

\begin{tabular}{ll}
\hline Study name & GBM AGILE \\
\hline Methods & $\begin{array}{l}\text { GBM AGILE: global adaptive trial master protocol: an international, seamless phase II/III response } \\
\text { adaptive randomization platform trial designed to evaluate multiple regimens in newly diagnosed } \\
\text { and recurrent GBM. }\end{array}$ \\
\hline
\end{tabular}


NCT03970447 2019b (Continued)

Participants Adults with recently diagnosed or recurrent GBM.

Interventions Arm 1 ND GBM: regorafenib + TMZ, recurrent GBM: regorafenib.

Arm 2 ND GBM: XRT, TMZ,maintenance therapy. Recurrent GBM: Lomustine

\begin{tabular}{ll}
\hline Outcomes & Overall survival, progression-free survival, tumour response. \\
\hline Starting date & 30 July 2019 \\
\hline Contact information & $\begin{array}{l}\text { Contact: Rachel Rosenstein-Sisson mailto:RRosenstein.Sisson\%40GCAResearch.org?subject=NC- } \\
\text { T03970447, GCAR-7213, A Trial to Evaluate Multiple Regimens in Newly Diagnosed and Recurrent } \\
\text { Glioblastoma }\end{array}$ \\
\hline Notes & NCT03970447 \\
\hline
\end{tabular}

\section{NCT04003649 2019}

\begin{tabular}{ll}
\hline Study name & Badie 2019 \\
\hline Methods & A phase 1, randomised, open-label clinical trial. \\
\hline Participants & Adult patients with resectable recurrent glioblastoma \\
\hline Interventions & Nivolumab, ipilimumab, IL13Ralpha2 CAR T cells versus nivolumab, IL13Ra2 CAR T cells \\
\hline Outcomes & Adverse events, toxicity, overall survival, progression free survival and feasibility \\
\hline Starting date & November 23, 2018 \\
\hline Contact information & GliomaCarT@coh.org \\
\hline Notes & NCT04003649 \\
\hline
\end{tabular}

AA-PET = Amino acid positive emission tomography

$\mathrm{AE}=$ adverse events

FET-PET = type of amino acid positive emission tomography

$\mathrm{GBM}=$ glioblastoma multiforme

$\mathrm{HRQOL}=$ health-related quality of live

OS = overall survival

$\mathrm{PFS}=$ progression free survival

$\mathrm{RCT}=$ randomised controlled trial

VEGF = vascular endothelial growth factor 


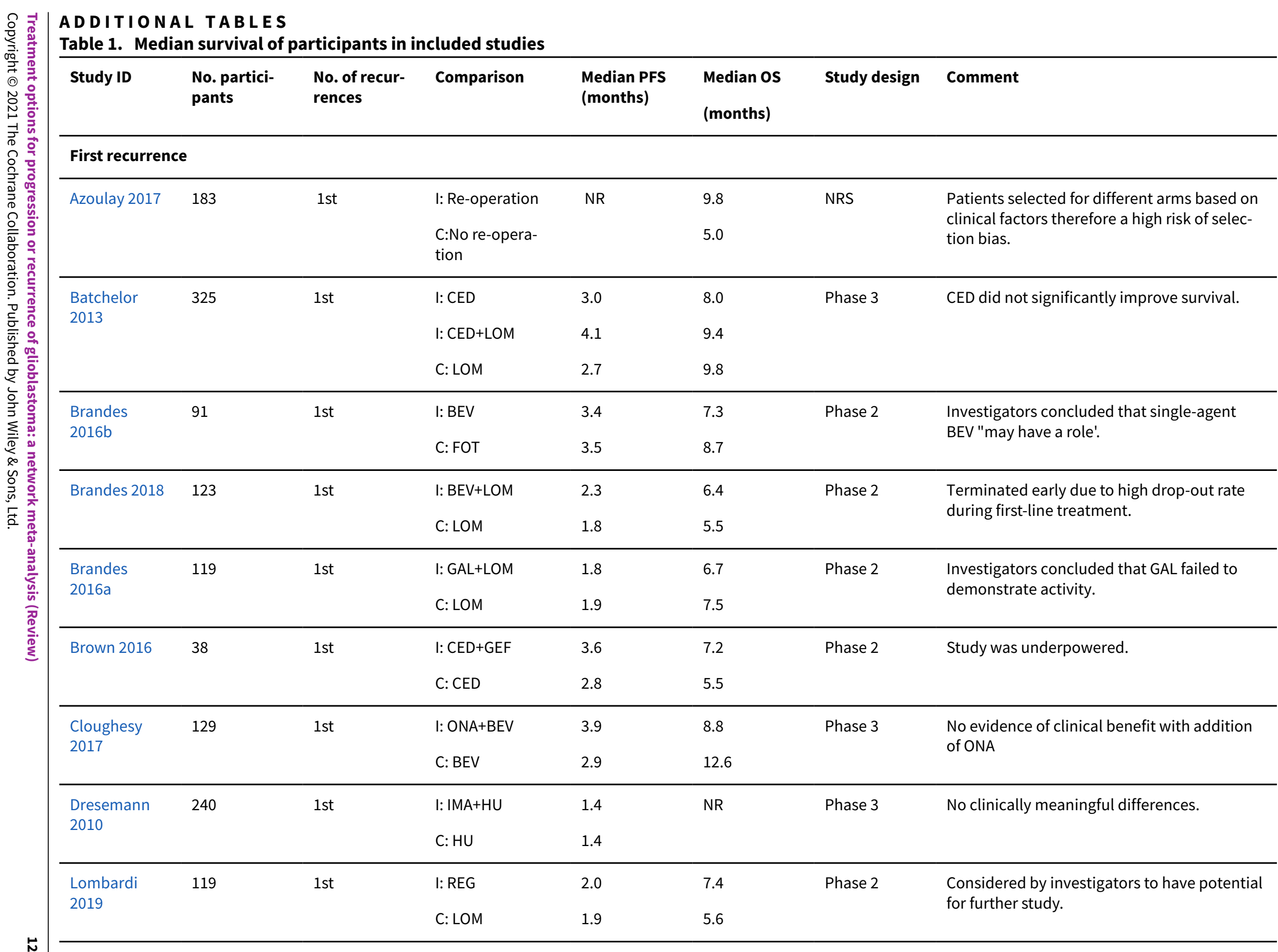




\begin{tabular}{|c|c|c|c|c|c|c|c|}
\hline Kunwar 2010 & 296 & 1 st & $\begin{array}{l}\text { I: cintredekin be- } \\
\text { sudotox } \\
\text { C: gliadel wafers }\end{array}$ & NR & $\begin{array}{l}9.1 \\
8.8\end{array}$ & Phase 3 & $\begin{array}{l}\text { No survival difference but higher risk of pul- } \\
\text { monary embolism with cintredekin besudo- } \\
\text { tox }(P=0.014) \text {. }\end{array}$ \\
\hline Narita 2019 & 88 & 1 st & $\begin{array}{l}\text { I: PPV } \\
\text { C: Placebo }\end{array}$ & NR & $\begin{array}{l}8.4 \\
8.0\end{array}$ & Phase 3 & $\begin{array}{l}\text { Did not meet primary endpoint and PPV } \\
\text { shortened the OS in certain patients. }\end{array}$ \\
\hline Omuro 2018 & 20 & 1 st & $\begin{array}{l}\text { I: NIV } \\
\text { C:NIV+IPI }\end{array}$ & $\begin{array}{l}1.9 \\
1.5\end{array}$ & $\begin{array}{l}10.4 \\
9.2\end{array}$ & Phase 2 & NIV was better tolerated than NIV+IPI \\
\hline $\begin{array}{l}\text { Puduvalli } \\
2018\end{array}$ & 74 & 1 st & $\begin{array}{l}\text { I: BEV+VOR } \\
\text { C: BEV }\end{array}$ & $\begin{array}{l}3.7 \\
3.9\end{array}$ & $\begin{array}{l}7.8 \\
9.3\end{array}$ & Phase 2 & $\begin{array}{l}\text { No clinical benefit with BEV+VOR. Does not } \\
\text { warrant further investigation. }\end{array}$ \\
\hline $\begin{array}{l}\text { Reardon } \\
2015 b\end{array}$ & 78 & 1 st & $\begin{array}{l}\text { I: AFA+TMZ } \\
\text { I: AFA } \\
\text { C: TMZ }\end{array}$ & $\begin{array}{l}1.5 \\
1.0 \\
1.9\end{array}$ & $\begin{array}{l}8.0 \\
9.8 \\
10.6\end{array}$ & Phase 2 & $\begin{array}{l}\text { Investigators concluded that afatinib had lim- } \\
\text { ited single agent activity. }\end{array}$ \\
\hline $\begin{array}{l}\text { Scorsetti } \\
2015\end{array}$ & 43 & 1 st & $\begin{array}{l}\text { I: Re-operation } \\
\text { C: No re-opera- } \\
\text { tion }\end{array}$ & $\begin{array}{l}15 \\
5\end{array}$ & $\begin{array}{l}17 \\
6\end{array}$ & NRS & $\begin{array}{l}\text { Patients selected for different arms based on } \\
\text { clinical factors therefore a high risk of selec- } \\
\text { tion bias. }\end{array}$ \\
\hline $\begin{array}{l}\text { Suchorska } \\
2016\end{array}$ & 93 & 1 st & $\begin{array}{l}\text { I: re-operation } \\
\text { C: no re-opera- } \\
\text { tion }\end{array}$ & $\begin{array}{l}2.0 \\
1.8\end{array}$ & $\begin{array}{l}11.4 \\
9.8\end{array}$ & NRS & $\begin{array}{l}\text { Patients selected for different arms based on } \\
\text { clinical factors therefore a high risk of selec- } \\
\text { tion bias. Complete resection was associat- } \\
\text { ed with improved survival compared with in- } \\
\text { complete resection. }\end{array}$ \\
\hline Taal 2014 & 153 & 1 st & $\begin{array}{l}\text { I: LOM } \\
\text { I: BEV+LOM } \\
\text { C: BEV }\end{array}$ & $\begin{array}{l}1.0 \\
4.0 \\
3.0\end{array}$ & $\begin{array}{l}8.0 \\
12.0 \\
8.0\end{array}$ & Phase 2 & $\begin{array}{l}\text { BEV+LOM met investigator criteria for further } \\
\text { evaluation in phase } 3 \text { studies. Single agent } \\
\text { BEV was found to have low activity. }\end{array}$ \\
\hline Twelves 2017 & 21 & $1 \mathrm{st}$ & $\begin{array}{l}\text { I: CBD:THC } \\
\text { C: placebo }\end{array}$ & - & $\begin{array}{l}18.3 \\
12.3\end{array}$ & & $\begin{array}{l}\text { All patients received dose intense TMZ. } 1 \text { year } \\
\text { survival was } 83 \% \text { and } 56 \% \text { in the CBD:THC } \\
\text { and placebo groups, respectively. }\end{array}$ \\
\hline $\begin{array}{l}\text { van den Bent } \\
2018\end{array}$ & 260 & $1 \mathrm{st}$ & I: ABT414+TMZ & 2.7 & 9.6 & Phase 2 & ABT414 had insufficient single-agent activity. \\
\hline
\end{tabular}




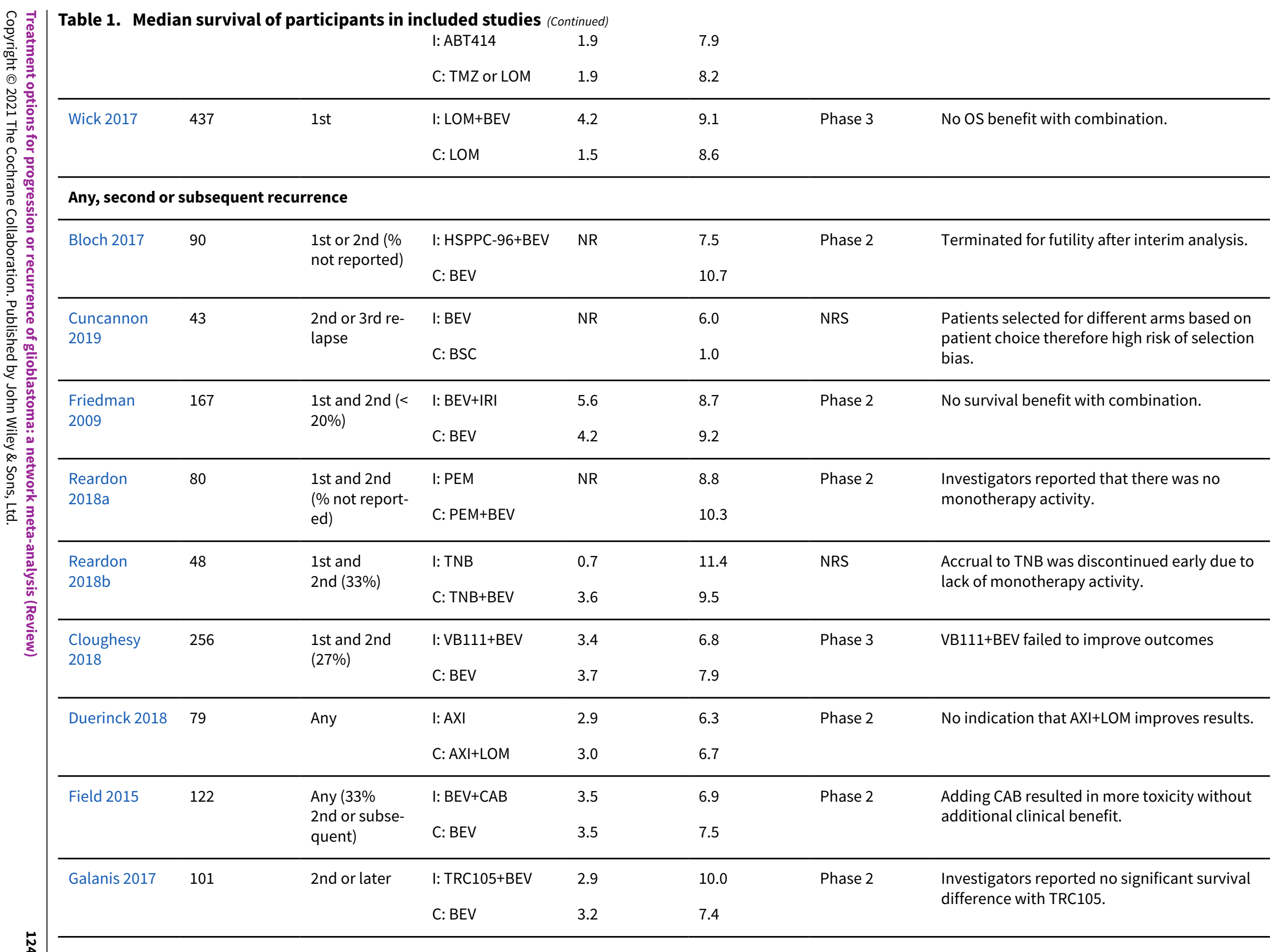




\begin{tabular}{|c|c|c|c|c|c|c|c|}
\hline Galanis 2019 & 121 & $\begin{array}{l}\text { Any }(\% \text { not re- } \\
\text { ported) }\end{array}$ & $\begin{array}{l}\text { I: DAS+BEV } \\
\text { C: BEV }\end{array}$ & $\begin{array}{l}3.2 \\
3.2\end{array}$ & $\begin{array}{l}7.3 \\
7.7\end{array}$ & Phase 2 & $\begin{array}{l}\text { DAS+BEV did not significantly improve clinical } \\
\text { outcomes. }\end{array}$ \\
\hline Gilbert 2017 & 117 & $\begin{array}{l}\text { Any }(\% \text { not re- } \\
\text { ported) }\end{array}$ & $\begin{array}{l}\text { I: BEV+TMZ } \\
\text { C: BEV+IRI }\end{array}$ & $\begin{array}{l}4.7 \\
4.1\end{array}$ & $\begin{array}{l}9.4 \\
7.7\end{array}$ & Phase 2 & $\begin{array}{l}\text { Both arms surpassed predetermined efficacy } \\
\text { thresholds. }\end{array}$ \\
\hline Heiland 2016 & 43 & $3 r d$ & $\begin{array}{l}\text { I: BEV } \\
\text { C: BEV+LOM }\end{array}$ & $\begin{array}{l}2.3 \\
6.1\end{array}$ & $\begin{array}{l}4.1 \\
6.6\end{array}$ & NRS & $\begin{array}{l}\text { Investigators concluded that last-line therapy } \\
\text { with BEV/LOM results in a longer PFS and OS } \\
\text { compared to BEV only. }\end{array}$ \\
\hline Modh 2018 & 34 & "median of 3" & $\begin{array}{l}\text { I: FSRS + BEV } \\
\text { C: Chemo+BEV }\end{array}$ & $\begin{array}{l}5.3 \\
1.8\end{array}$ & $\begin{array}{l}7.1 \\
4.8\end{array}$ & $\mathrm{RCT}$ & $\begin{array}{l}\text { Investigators concluded that FSRS in heavily } \\
\text { pretreated patients with recurrent malignant } \\
\text { glioma is feasible and improves local control } \\
\text { and PFS }\end{array}$ \\
\hline Reardon 2011 & 23 & $\begin{array}{l}\text { "heavily pre- } \\
\text { treated" }\end{array}$ & $\begin{array}{l}\text { I:ETO+BEV } \\
\text { C:TMZ+BEV }\end{array}$ & $\begin{array}{l}1.9 \\
0.9\end{array}$ & $\begin{array}{l}4.4 \\
2.9\end{array}$ & Phase 2 & $\begin{array}{l}\text { Investigators concluded that metronomic } \\
\text { ETO or TMZ is ineffective administered with } \\
\text { BEV in this context. }\end{array}$ \\
\hline Santos 2018 & 32 & Unclear & $\begin{array}{l}\text { I: IPA + ketogenic } \\
\text { diet } \\
\text { C: IPA + regular } \\
\text { diet }\end{array}$ & NR & NR & NRS & $\begin{array}{l}\text { Investigators concluded that results on keto- } \\
\text { genic diet were encouraging. }\end{array}$ \\
\hline Stupp 2012 & 237 & $\begin{array}{l}\text { Any } \\
\text { (88\% 2nd or } \\
\text { later) }\end{array}$ & $\begin{array}{l}\text { I: TTF } \\
\text { C: BPC }\end{array}$ & $\begin{array}{l}2.2 \\
2.1\end{array}$ & $\begin{array}{l}6.6 \\
6.0\end{array}$ & Phase 3 & $\begin{array}{l}\text { No improvement in survival but toxicity and } \\
\text { QOL favoured TTF. }\end{array}$ \\
\hline Tsien 2019 & 170 & NR & $\begin{array}{l}\text { I: BEV+RT } \\
\text { C: BEV }\end{array}$ & NR & $\begin{array}{l}10.1 \\
9.7\end{array}$ & Phase 2 & $\begin{array}{l}\text { BEV +RT was associated with improved 6- } \\
\text { month PFS ( } 54 \% \text { vs } 29 \%)\end{array}$ \\
\hline $\begin{array}{l}\text { Weathers } \\
2016\end{array}$ & 69 & $\begin{array}{l}\text { 1st (68\%), } \\
\text { 2nd, and 3rd }\end{array}$ & $\begin{array}{l}\text { I: LOM+BEV (low } \\
\text { dose) } \\
\text { C: BEV }\end{array}$ & 4.1 & $\begin{array}{l}9.6 \\
8.3\end{array}$ & Phase 2 & $\begin{array}{l}\text { Median PFS for } 1 \text { st recurrence ( } 47 \text { pts) was } \\
5.0 \text { mths vs } 3.2 \text { mths, respectively; median OS } \\
\text { was } 13.1 \text { mths vs } 8.8 \text { mths, respectively. }\end{array}$ \\
\hline Wick 2010 & 266 & $\begin{array}{l}1 \text { st and 2nd } \\
(25 \%)\end{array}$ & $\begin{array}{l}\text { I: ENZ } \\
\text { C: LOM }\end{array}$ & 1.5 & $\begin{array}{l}6.6 \\
7.1\end{array}$ & Phase 3 & Terminated early due to futility. \\
\hline
\end{tabular}




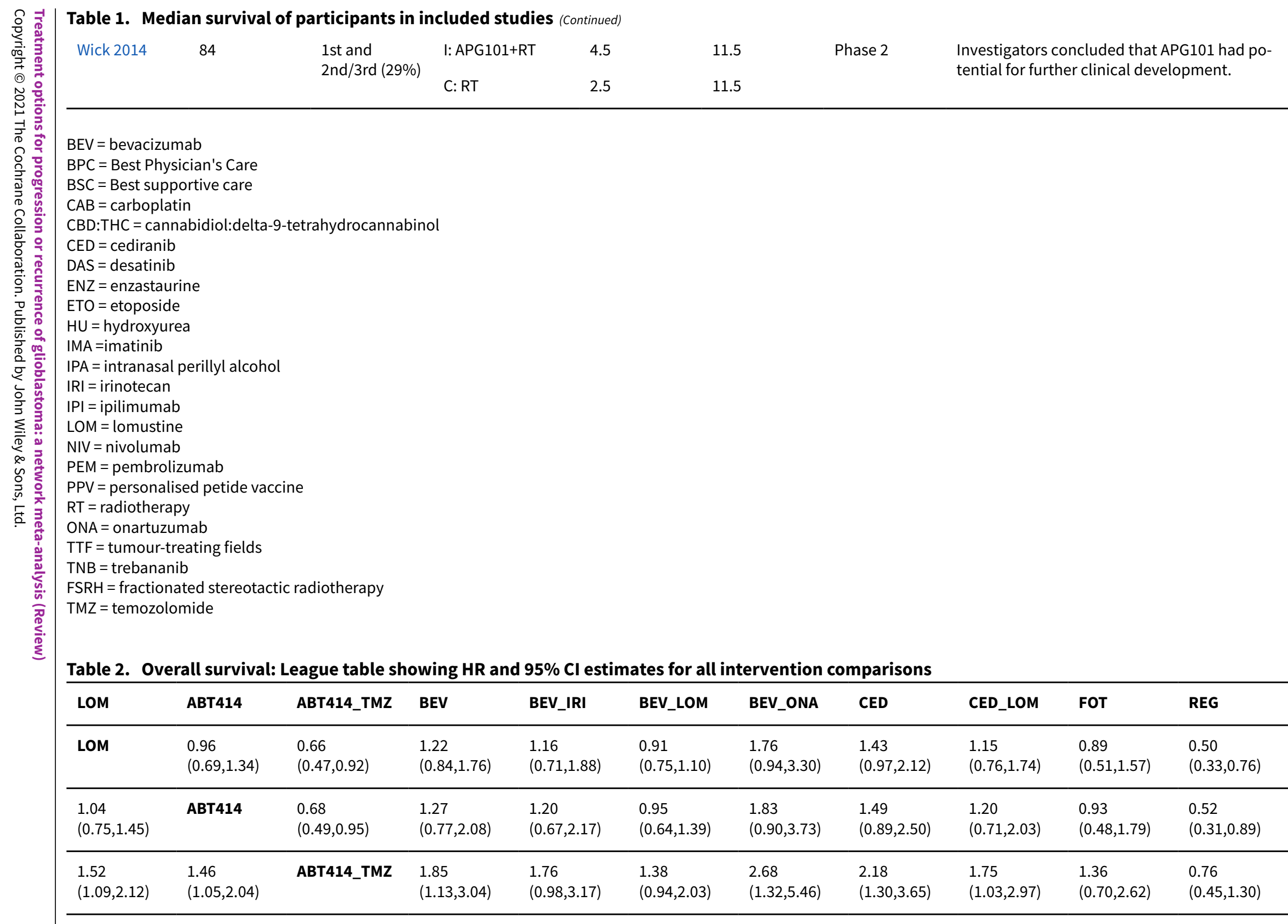




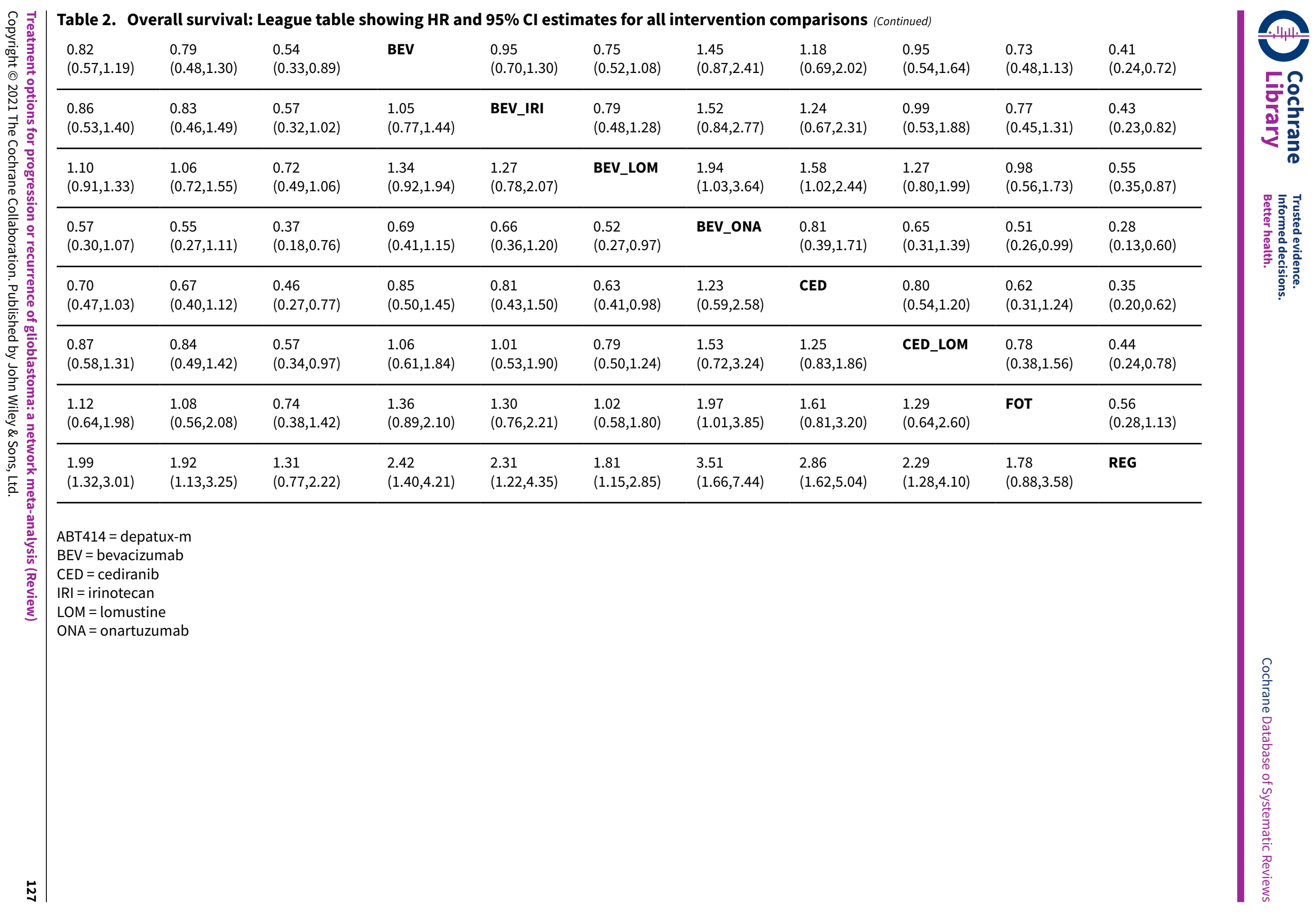


Table 3. Progression-free survival: League table showing $\mathrm{HR}$ and $95 \% \mathrm{Cl}$ estimates for all intervention comparisons

\begin{tabular}{llllll}
\hline LOM & BEV & BEV_IRI & BEV_LOM & BEV_ONA & REG \\
\hline LOM & $0.90(0.58,1.38)$ & $0.80(0.44,1.45)$ & $0.57(0.44,0.74)$ & $0.98(0.51,1.87)$ & $0.65(0.42,1.01)$ \\
\hline $1.12(0.72,1.72)$ & BEV & $0.90(0.60,1.34)$ & $0.64(0.41,0.99)$ & $1.09(0.67,1.77)$ & $0.73(0.39,1.35)$ \\
\hline $1.25(0.69,2.25)$ & $1.12(0.75,1.67)$ & BEV_IRI & $0.71(0.39,1.28)$ & $1.22(0.65,2.28)$ & $0.81(0.39,1.69)$ \\
\hline $1.75(1.36,2.26)$ & $1.57(1.02,2.43)$ & $1.41(0.78,2.55)$ & BEV_LOM & $1.71(0.89,3.29)$ & $1.14(0.68,1.90)$ \\
\hline $1.02(0.53,1.96)$ & $0.92(0.57,1.49)$ & $0.82(0.44,1.54)$ & $0.58(0.30,1.12)$ & BEV_ONA & $0.67(0.30,1.46)$ \\
\hline $1.54(0.99,2.40)$ & $1.38(0.74,2.57)$ & $1.24(0.59,2.59)$ & $0.88(0.53,1.46)$ & $1.50(0.68,3.30)$ & REG
\end{tabular}

$\mathrm{BEV}=$ bevacizumab

CED = cediranib

IRI = irinotecan

$\mathrm{LOM}=$ lomustine

ONA = onartuzumab

REG = regorafenib

Table 4. Severe adverse events for treatments compared with lomustine: League table with effect estimates and 95\% Cls

\begin{tabular}{llllll}
\hline LOM & BEVLOM & CED & CEDGET & CEDLOM & REG \\
\hline LOM & $2.51(1.72,3.66)$ & $1.00(0.54,1.85)$ & $2.46(0.46,13.26)$ & $2.51(1.29,4.90)$ & $1.90(0.92,3.95)$ \\
\hline $0.40(0.27,0.58)$ & BEVLOM & $0.40(0.19,0.82)$ & $0.98(0.17,5.50)$ & $1.00(0.46,2.15)$ & $0.76(0.33,1.72)$ \\
\hline $1.00(0.54,1.85)$ & $2.51(1.22,5.17)$ & CED & $2.46(0.51,11.80)$ & $2.51(1.43,4.42)$ & $1.90(0.73,4.94)$ \\
\hline $0.41(0.08,2.19)$ & $1.02(0.18,5.73)$ & $0.41(0.08,1.95)$ & CEDGET & $1.02(0.19,5.40)$ & $0.77(0.12,4.84)$ \\
\hline $0.40(0.20,0.78)$ & $1.00(0.46,2.15)$ & $0.40(0.23,0.70)$ & $0.98(0.19,5.18)$ & CEDLOM & $0.76(0.28,2.03)$ \\
\hline $0.53(0.25,1.09)$ & $1.32(0.58,3.00)$ & $0.53(0.20,1.36)$ & $1.29(0.21,8.10)$ & $1.32(0.49,3.54)$ & REG \\
\hline
\end{tabular}

$\mathrm{BEV}=$ bevacizumab

CED = cediranib

GET = getitinib

LOM = lomustine

REG = regorafenib 


\begin{tabular}{|c|c|c|c|c|c|c|c|c|}
\hline BEV & BEVCAB & BEVDAS & BEVIRI & BEVONA & BEVTRC105 & BEVVB111 & FOM & HSPPCBEV \\
\hline BEV & $1.27(0.61,2.66)$ & $1.52(0.69,3.34)$ & $2.22(1.18,4.18)$ & $1.17(0.57,2.39)$ & $6.86(2.55,18.41)$ & $3.77(2.25,6.33)$ & $0.44(0.11,1.72)$ & $1.01(0.33,3.10)$ \\
\hline $0.79(0.38,1.64)$ & BEVCAB & $1.19(0.41,3.51)$ & $1.75(0.66,4.61)$ & $0.92(0.33,2.57)$ & $5.39(1.57,18.47)$ & $2.97(1.21,7.29)$ & $0.35(0.07,1.63)$ & $0.79(0.21,3.03)$ \\
\hline $0.66(0.30,1.45)$ & $0.84(0.29,2.46)$ & BEVDAS & $1.46(0.53,4.02)$ & $0.77(0.27,2.23)$ & $4.51(1.28,15.96)$ & $2.48(0.97,6.37)$ & $0.29(0.06,1.40)$ & $0.66(0.17,2.62)$ \\
\hline $0.45(0.24,0.85)$ & $0.57(0.22,1.51)$ & $0.68(0.25,1.88)$ & BEVIRI & $0.53(0.20,1.37)$ & $3.09(0.95,9.97)$ & $1.70(0.75,3.84)$ & $0.20(0.04,0.89)$ & $0.45(0.13,1.65)$ \\
\hline $0.85(0.42,1.75)$ & $1.09(0.39,3.03)$ & $1.30(0.45,3.76)$ & $1.90(0.73,4.93)$ & BEVONA & $5.86(1.73,19.82)$ & $3.22(1.33,7.79)$ & $0.38(0.08,1.75)$ & $0.86(0.23,3.26)$ \\
\hline $0.15(0.05,0.39)$ & $0.19(0.05,0.64)$ & $0.22(0.06,0.78)$ & $0.32(0.10,1.05)$ & $0.17(0.05,0.58)$ & BEVTRC105 & $0.55(0.18,1.68)$ & $0.06(0.01,0.35)$ & $0.15(0.03,0.66)$ \\
\hline $0.26(0.16,0.44)$ & $0.34(0.14,0.83)$ & $0.40(0.16,1.03)$ & $0.59(0.26,1.33)$ & $0.31(0.13,0.75)$ & $1.82(0.60,5.54)$ & BEVVB111 & $0.12(0.03,0.50)$ & $0.27(0.08,0.92)$ \\
\hline $2.26(0.58,8.80)$ & $\begin{array}{l}2.88 \\
(0.61,13.49)\end{array}$ & $\begin{array}{l}3.44 \\
(0.72,16.52)\end{array}$ & $\begin{array}{l}5.03 \\
(1.12,22.49)\end{array}$ & $\begin{array}{l}2.65 \\
(0.57,12.28)\end{array}$ & $15.51(2.89,83.17)$ & $\begin{array}{l}8.54 \\
(2.00,36.51)\end{array}$ & FOM & $\begin{array}{l}2.28 \\
(0.39,13.29)\end{array}$ \\
\hline $0.99(0.32,3.04)$ & $1.26(0.33,4.82)$ & $1.51(0.38,5.93)$ & $2.20(0.61,7.98)$ & $1.16(0.31,4.39)$ & $6.80(1.52,30.30)$ & $\begin{array}{l}3.74 \\
(1.09,12.86)\end{array}$ & $0.44(0.08,2.55)$ & HSPPCBEV \\
\hline
\end{tabular}

$\mathrm{BEV}=$ bevacizumab

$\mathrm{CAB}=$ carboplatin

DAS = desatinib

IRI = irinotecan

$F O M=$ fotemustine

HSPCC = HSPCC-96 vaccine

ONA = onartuzumab

TRC105 = carotuximab 


\section{AP PEN DICES}

\section{Appendix 1. CENTRAL Search Strategy}

\#1 MeSH descriptor: [Astrocytoma] this term only \#2 MeSH descriptor: [Glioblastoma] this term only \#3 glioblastom* or GBM $^{\star}$ or astrocytom ${ }^{\star}$ or gliosarcom* \#4 \#1 or \#2 or \#3

\#5 MeSH descriptor: [Neoplasm Recurrence, Local] this term only $\# 6$ recurren* ${ }^{*}$ return* or relapse*

\#7 \#5 or \#6

\#9 \#4 and \#7

\section{Appendix 2. MEDLINE Search Strategy}

Intervention MEDLINE search:

1. astrocytoma/

2. glioblastoma/

3. (glioblastom* or $\mathrm{GBM}^{\star}$ or astrocytom ${ }^{\star}$ or gliosarcom ${ }^{\star}$ ).mp.

4. 1 or 2 or 3

5. neoplasm recurrence, local/

6. $\left(\right.$ recurren $^{\star}$ or return ${ }^{\star}$ or relapse $\left.{ }^{\star}\right) \cdot \mathrm{mp}$.

7.5 or 6

8.4 and 7

9. randomized controlled trial.pt.

10. controlled clinical trial.pt.

11. randomized.ab.

12. placebo.ab.

13. clinical trials as topic.sh.

14. randomly.ab.

15. trial.ti.

16. (before adj3 after adj3 (study or studies)).mp.

17. (CBA adj (study or studies)).mp.

18. interrupted time series.mp.

19. exp Cohort Studies/

20. ( cohort $^{\star}$ or prospective ${ }^{\star}$ or retrospective $\left.{ }^{\star}\right)$.mp.

21.9 or 10 or 11 or 12 or 13 or 14 or 15 or 16 or 17 or 18 or 19 or 20

22. (animals not (humans and animals)).sh.

23. 21 not 22

24. 8 and 23

Key:

$\mathrm{mp}=$ title, original title, abstract, name of substance word, subject heading word, unique identifier

pt $=$ publication type

$a b=$ abstract

$\mathrm{fs}=$ floating subheading

sh = subject heading

Economic MEDLINE search:

1. astrocytoma/

2. glioblastoma/

3. (glioblastom ${ }^{\star}$ or $\mathrm{GBM}^{\star}$ or astrocytom ${ }^{\star}$ or gliosarcom $\left.{ }^{\star}\right) . \mathrm{mp}$.

4. 1 or 2 or 3

5. neoplasm recurrence, local/

6. (recurren ${ }^{\star}$ or return ${ }^{\star}$ or relapse $\left.{ }^{\star}\right) . \mathrm{mp}$.

7.5 or 6

8.4 and 7

9. economics/

10. exp "costs and cost analysis"/

11. economics, dental/

12. exp "economics, hospital"/

Treatment options for progression or recurrence of glioblastoma: a network meta-analysis (Review) 
13. economics, medical/

14. economics, nursing/

15. economics, pharmaceutical/

16. (economic $\$$ or cost or costs or costly or costing or price or prices or pricing or pharmacoeconomic\$).ti,ab.

17. (expenditure\$ not energy).ti,ab.

18. (value adj1 money).ti,ab.

19. budget\$.ti,ab.

20.9 or 10 or 11 or 12 or 13 or 14 or 15 or 16 or 17 or 18 or 19

21. ((energy or oxygen) adj cost).ti,ab.

22. (metabolic adj cost).ti,ab.

23. ((energy or oxygen) adj expenditure).ti,ab.

24. 21 or 22 or 23

25. 20 not 24

26. letter.pt.

27. editorial.pt.

28. historical article.pt.

29. 26 or 27 or 28

30.25 not 29

31. Animals/

32. Humans/

33. 32 not ( 32 and 33)

34. 30 not 33

35.8 and 34

36. $\left(2015^{\star}\right.$ or $2016^{\star}$ or $2017^{\star}$ or $2018^{\star}$ or $\left.2019^{\star}\right)$.ed.

37.35 and 36

Key:

$\mathrm{mp}=$ title, original title, abstract, name of substance word, subject heading word, unique identifier

$\mathrm{pt}=$ publication type

$\mathrm{ab}=\mathrm{abstract}$

fs = floating subheading

sh = subject heading

\section{Appendix 3. Embase Search Strategy}

Intervention Embase search:

1. astrocytoma/

2. glioblastoma/

3. (glioblastom ${ }^{\star}$ or $\mathrm{GBM}^{\star}$ or astrocytom ${ }^{\star}$ or gliosarcom $\left.{ }^{\star}\right)$.mp.

4. 1 or 2 or 3

5. tumor recurrence/

6. (recurren ${ }^{\star}$ or return ${ }^{\star}$ or relapse $\left.{ }^{\star}\right) . \mathrm{mp}$.

7.5 or 6

8.4 and 7

9. crossover procedure/

10. double-blind procedure/

11. randomized controlled trial/

12. single-blind procedure/

13. random ${ }^{\star} . \mathrm{mp}$.

14. factorial ${ }^{\star} \cdot \mathrm{mp}$.

15. (crossover ${ }^{\star}$ or cross over ${ }^{\star}$ or cross-over $\left.^{\star}\right) \cdot \mathrm{mp}$.

16. placebo*.mp.

17. (double* adj blind*).mp.

18. $\left(\right.$ singl ${ }^{\star}$ adj blind $\left.{ }^{\star}\right) \cdot \mathrm{mp}$.

19. assign ${ }^{\star} . \mathrm{mp}$.

20. allocat*.mp.

21. volunteer ${ }^{\star} . \mathrm{mp}$.

22. (before adj3 after adj3 (study or studies)).mp.

23. (CBA adj (study or studies)).mp.

24. interrupted time series.mp.

25. exp Cohort Studies/

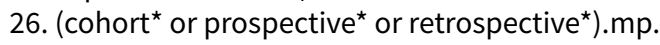

Treatment options for progression or recurrence of glioblastoma: a network meta-analysis (Review) 
27.9 or 10 or 11 or 12 or 13 or 14 or 15 or 16 or 17 or 18 or 19 or 20 or 21 or 22 or 23 or 24 or 25 or 26 28. 8 and 27

\section{Key:}

$\mathrm{mp}=$ title, original title, abstract, name of substance word, subject heading word, unique identifier

$\mathrm{pt}=$ publication type

$\mathrm{ab}=$ abstract

fs = floating subheading

sh $=$ subject heading

Economic Embase search:

1. astrocytoma/

2. glioblastoma/

3. (glioblastom ${ }^{\star}$ or $\mathrm{GBM}^{\star}$ or astrocytom ${ }^{\star}$ or gliosarcom $\left.{ }^{\star}\right)$.mp.

4. 1 or 2 or 3

5. tumor recurrence/

6. (recurren ${ }^{\star}$ or return* ${ }^{\star}$ or relapse $\left.{ }^{\star}\right) . m p$.

7.5 or 6

8. 4 and 7

9. Health Economics/

10. $\exp$ Economic Evaluation/

11. exp Health Care Cost/

12. pharmacoeconomics/

13. 9 or 10 or 11 or 12

14. (econom\$ or cost or costs or costly or costing or price or prices or pricing or pharmacoeconomic\$).ti,ab.

15. (expenditure\$ not energy).ti,ab.

16. (value adj2 money).ti,ab.

17. budget $\$$.ti,ab.

18. 14 or 15 or 16 or 17

19. 13 or 18

20. letter.pt.

21. editorial.pt.

22. note.pt.

23. 20 or 21 or 22

24. 19 not 23

25. (metabolic adj cost).ti,ab.

26. ((energy or oxygen) adj cost).ti,ab.

27. ((energy or oxygen) adj expenditure).ti,ab.

28.25 or 26 or 27

29. 24 not 28

30.8 and 29

31. $\left(2015^{\star}\right.$ or $2016^{\star}$ or $2017^{\star}$ or $2018^{\star}$ or $\left.2019^{\star}\right)$.dd.

32.30 and 31

\section{Key:}

$\mathrm{mp}=$ title, original title, abstract, name of substance word, subject heading word, unique identifier

$\mathrm{pt}=$ publication type

$a b=$ abstract

fs = floating subheading

sh $=$ subject heading

\section{H IST ORY}

Protocol first published: Issue 4, 2020

Review first published: Issue 12, 2020

\section{CONTRIBUTIONS OFAUTHORS}

TL performed study selection, data extraction and wrote the first draft of the review. ER performed study selection, data extraction and conducted the initial analyses. CM provided clinical guidance and contributed to the text of the review, AK and TR contributed the economic component of the review, SJ provided clinical guidance. All authors advised on and approved the final version of the review. 


\section{DECLARATIONS OF INTEREST}

Catherine McBain: none declared

Theresa Lawrie: none declared

Ewelina Rogozinska: none declared

Ashleigh Kernohan: none declared

Tomos Robinson: none declared

Sarah Jefferies: none declared

\section{SOURCES OF SUPPORT}

\section{Internal sources}

- No sources of support supplied

\section{External sources}

- NIHR 16/144 Cochrane Programme Grant Scheme, UK, UK

\section{DIFFERENCES BETWEEN PROTOCOLANDREVIEW}

The protocol included an additional secondary outcome 'seizures'. We obtained scant data for this outcome, did not attempt to synthesise these data, and decided to remove the outcome from the review. 